Illinois State University

ISU ReD: Research and eData

Theses and Dissertations

$11-18-2016$

\title{
Braving Shame: The Rhetoric of Bravery in Contemporary Women's Memoir
}

Debra Gayle Parker

Illinois State University, dgparke@ilstu.edu

Follow this and additional works at: https://ir.library.illinoisstate.edu/etd

Part of the Rhetoric Commons

\section{Recommended Citation}

Parker, Debra Gayle, "Braving Shame: The Rhetoric of Bravery in Contemporary Women's Memoir" (2016). Theses and Dissertations. 627.

https://ir.library.illinoisstate.edu/etd/627

This Dissertation is brought to you for free and open access by ISU ReD: Research and eData. It has been accepted for inclusion in Theses and Dissertations by an authorized administrator of ISU ReD: Research and eData. For more information, please contact ISUReD@ilstu.edu. 


\title{
BRAVING SHAME: THE RHETORIC OF BRAVERY IN \\ CONTEMPORARY WOMEN'S MEMOIR
}

\author{
Debra G. Parker
}

\section{Pages}

Braving Shame interrogates the rhetoric of bravery as a culturally infused way of hearing certain kinds of personal narratives and as rhetoric precariously at work in the memoir industry. As a cultural rhetoric, "bravery" has deep roots in masculine militaristic ideologies in which cowardice, courage, and shame are conceptually linked to a sense of duty. The memoir industry represents one environment that archives what is valued as brave writing. This dissertation investigates the cultural assumptions that drive literary bravery as it is used to assess contemporary memoirs, particularly memoirs written by women.

The introductory chapter explicates how founding texts in the fields of life writing and feminist rhetorical theory expose ethical concerns regarding memory and storytelling which intersect with the affective work of memoir bravery. Chapter two examines larger cultural discourses of bravery external to the memoir to argue that memoir bravery is rhetoric that is endorsed and sustained by these larger cultural discourses. In addition, chapter two examines the contemporary memoir as a genre that both represents and reinforces cultural assumptions about "bravery" as an ideology contingent on shame as the flip-side of bravery. The appraisal of bravery keeps at bay particular affects that threaten to undo bravery, namely cowardice, vulnerability, exposure, fear, and shame. This chapter surveys theories of cowardice and shame 
toward an effort to diagram bravery as a cultural value endowed by its cultural structure and links to specific affective associations with bravery. As a case study in memoir bravery, this chapter examines Cheryl Strayed's recent memoir, Wild, and her rise to popularity, and Lucy Grealy's childhood memoir, Autobiography of a Face.

The next two chapters continue to demonstrate the memoir industry's participation in the promotion of bravery as a cultural ideology. Chapter three presents a rhetorical analysis of Mary Karr's use of parenthetical constructions in her childhood memoir, The Liars' Club. This chapter converges theories of the autobiographical 'I' in life writing scholarship and interdisciplinary theories of authenticity to explore the potential constructed perception (of both the writer and readers) of an authentic narrator as a key ingredient for memoir bravery. Chapter four turns to the trauma narrative as a representation of memoir bravery and makes a case for the function of the rhetoric of bravery as a linguistic effect of readers' empathy. This chapter analyzes Laura Gray-Rosendale's memoir, College Girl, as an example of self-empathy. In contrast to Suzanne Keen's claims regarding empathy and the novel and the lack of evidence supporting reader response claims, this chapter conceives a feminist understanding of the rhetoric of bravery by centralizing self-empathy as a model of empathy potentially offered in the memoir. Written nearly two decades apart, both Karr and Gray-Rosendale have been appraised by readers and reviewers as brave writers who confront commonplace cultural scripts about privacy, duty, shame and what should or should not be spoken or silenced.

The final chapter addresses the pedagogical work of the contemporary memoir in a case study of a college classroom and as a further investigation of the authenticity, vulnerability, and empathy as active affective ingredients at work in the manufacturing of memoir bravery. In 
conclusion, Braving Shame invokes a new brand of bravery—one that de-emphasizes a masculine perception of bravery (as performance) and emphasizes a feminist ethic of care. KEYWORDS: rhetoric, life writing, memoir, bravery, empathy, trauma 
BRAVING SHAME: THE RHETORIC OF BRAVERY IN

CONTEMPORARY WOMEN'S MEMOIR

\author{
DEBRA G. PARKER
}

A Dissertation Submitted in Partial

Fulfillment of the Requirements

for the Degree of

DOCTOR OF PHILOSOPHY

Department of English

ILLINOIS STATE UNIVERSITY

2016 
(C) 2016 Debra G. Parker 


\title{
BRAVING SHAME: THE RHETORIC OF BRAVERY IN CONTEMPORARY WOMEN'S MEMOIR
}

\author{
DEBRA G. PARKER
}

COMMITTEE MEMBERS:

Amy E. Robillard, Chair

Karen Coats

Susan Kim 


\section{ACKNOWLEDGMENTS}

I would like to acknowledge the many, many people who have helped to make this dissertation possible. Firstly, thank you, Dr. Amy E. Robillard, my dissertation director, for your steadfast support, timely comments, and friendship. Your belief in revision has helped me understand my own writing processes in new ways. Thank you to my dissertation committee members. Thank you, Dr. Karen Coats, for pushing me to new theoretical understandings and for your willingness to work with me on this project, including your voluntary participation in my comprehensive exam process. Bless Bless! Thank you, Dr. Susan Kim, for your generous acceptance to join the committee at a late date. Your linguistic eye provided the necessary critique for chapter three as well as invaluable comments on the other chapters.

Secondly, thank you to other mentors and friends who have guided this dissertation project. Thank you, Dr. Rebecca Saunders, for the many hours of conversation about theory and life, and for helping to shape the beginning stages of this project. You are a remarkable interdisciplinarian. I am grateful for your friendship. Thank you, Stephanie Guedet, for the experience of going through "phd school" together, the many conversations, coffees, and "phd field trips," your friendship and steadfast motivation to go on.

To my amazing husband, Jim, and our sons Jacob and Benjamin. Thank you ten thousand times for your patience, unconditional love, and unending questions about when I will be finished. Mom's done boys!

To my parents for loving me always.

To my mom-friends, my book club, my neighbors, my colleagues who believed in me unconditionally even at times when I felt I had lost my way. Your laughter, friendship, and deep conversations were a true gift. 
Last but not least, thank you to my writing buddies, the cats in my life: Chico, Ozzie, Miss Edna, and Laura. Thank you for wallowing on my drafts, chewing on my pencils, and providing endless positive feedback.

D. G. P. 


\section{CONTENTS}

\section{Page}

ACKNOWLEDGMENTS

CONTENTS

iii

TABLES

vii

FIGURES

viii

CHAPTER I: THE CONTEMPORARY MEMOIR AS A CULTURAL PRODUCT OF

BRAVERY: AN INTERDISCIPLINARY APPROACH

Literature Review

Life Writing and the Memoir Boom: Negotiating Boundaries

Feminists Rhetorical Perspectives: Rethinking Ethics

Chapter Overview

CHAPTER II: BRAVING SHAME: CONTEXTUALIZING THE RHETORIC OF

BRAVERY

Memoir Bravery: A Wild New Brand?

Contextual Considerations of Bravery

Bravery: A Populated Concept

Bravery: It's What Defines Us

Cowardice: It's What We Loathe

A Mentality of Duty Revisited

Application to the Rhetoric of Memoir Bravery

Theoretical Considerations of Shame 
Effacing Shame: The Evolution of Shamelessness 58

Shame, Duty, and Bravery in Triangulation 64

$\begin{array}{ll}\text { Conclusion: Braving Shame } & 70\end{array}$

CHAPTER III: MEMOIR BRAVERY: A RHETORICAL ANALYSIS OF

PARENTHETICAL CONSTRUCTIONS IN MARY KARR'S THE LIARS' CLUB 73

Launching an Analysis of Authenticity in The Liars' Club 75

Authenticity: An Interdisciplinary Perspective $\quad 80$

$\begin{array}{lr}\text { Authenticity in Life Writing } & 80\end{array}$

Authenticity in Philosophy $\quad 82$

Authenticity as a Modern Commodity $\quad 84$

$\begin{array}{ll}\text { The Autobiographical 'I' and Authorial Ethos } & 87\end{array}$

A Rationale for a Rhetorical Approach to Memoir $\quad 90$

$\begin{array}{ll}\text { Precedence for Parentheticals } & 91\end{array}$

$\begin{array}{ll}\text { Method } & 95\end{array}$

$\begin{array}{ll}\text { Data Analysis } & 96\end{array}$

Frequency \& Distribution 99

$\begin{array}{ll}\text { Clusters \& Gaps } & 99\end{array}$

Domain Analysis \& Rhetorical Function 101

Conclusion: Authenticity as a Language of Loss and Longing 113 
CHAPTER IV: WRITING FROM THE WOUND: A FEMINIST PERSPECTIVE

OF THE RHETORIC OF BRAVERY IN LAURA GRAY-ROSENDALE'S

COLLEGE GIRL

A Critique of Empathy, Part 1: The Rhetoric of Bravery as an Empathetic

Readers' Response?

A Critique of Empathy, Part 2: Memoir Bravery and Self-Empathy

The Role of Vulnerability in Self-empathy

130

The Trope of Trauma and Recovery

Rhetorical Analysis of College Girl: A Model of Self-Empathy

The Vulnerable 'I'

The Detached ' $I$ '

The Testifying ' $I$ '

The Scholarly 'I'

Conclusion: The Interdependent ' $I$ '

CHAPTER V: THE PEDAGOGICAL POTENTIAL OF MEMOIR: THE RHETORIC OF BRAVERY IN THE CLASSROOM AND THE TEACHING 'I'

Bravery as a Class Act

The Teaching-Learning Context

The Memoir Project and the Personal Turn

The Weight of Disciplinary Assumptions

The Manufacturing of the Rhetoric of Memoir Bravery

The Trickiness of Person/Persona

Writing for One Another: Vulnerability, Bravery, and Empathy 
APPENDIX B: Parenthetical Constructions Content Data in The Liars' Club 


\section{TABLES}

Table

Page

1. Frequency of Parenthetical Constructions

2. Distribution of Parenthetical Constructions

3. Distribution of Clusters of Parenthetical Constructions

100

4. Distribution of Gaps of Parenthetical Constructions

5. Emerging Domains: Taxonomy of Rhetorical Functions of

Parenthetical Constructions and Data Sampling

6. Data of Self-implication

106

7. Sister-as-witness References

107

8. Embedded Anecdotes

109

9. The Silence of Charlie

117 


\section{FIGURES}

Figure $\quad$ Page

1. Brave, Shame, Duty: Triangular Model 65

2. Triangular Model: Loss at Center $\quad 69$

3. Triangular Model for Rhetorical Analysis: Bravery, Shame, Duty 70 


\title{
CHAPTER I
}

THE CONTEMPORARY MEMOIR AS A CULTURAL PRODUCT OF BRAVERY: AN INTERDISCIPLINARY APPROACH

\author{
You can, you should, and if you're brave enough to start, you will. \\ -Stephen King \\ Courage may be one of those virtues which is best realized not when pursued for its own sake \\ but when it arises as a by-product of some other virtue's natural expression. \\ -William Ian Miller
}

Why do we have so many brave memoirs? It has become common in contemporary Western society for readers and reviewers to praise memoirs, particularly those written by women, as brave or courageous. ${ }^{1}$ As a way of describing certain kinds of memoirs, "bravery" has a viral quality. Alison Bechdel's Fun Home is "brave and forthright and insightful" (Bechdel, fourth cover); Joan Didion's The Year of Magical Thinking is "an act of consummate literary bravery..." (Didion, fourth cover); Rahna Reiko Rizutto's Hiroshima in the Morning is "a brave, compassionate, and heart-wrenching memoir..." (Rizutto, fourth cover); Alice Sebold's Lucky is “a brave and modest work of demystification..." (Sebold, fourth cover); Jessica Stern's Denial is “brave, life-changing, and as gripping as a thriller..." (Stern, front cover); and the queen of memoir, Mary Karr says this about Kathryn Harrison's The Kiss: “The bravery in Harrison's raw, clear voice will stay with me a long time" (Harrison, fourth cover). What cultural assumptions drive a rhetoric that identifies memoirs as brave? How might literary bravery compare to other kinds of bravery?

In this dissertation, I explore the cultural factors and conditions that influence the rhetoric of memoir bravery. I identify the rhetoric of bravery as a cultural phenomenon-

\footnotetext{
${ }^{1}$ See Appendix A, "Memoir Blurbs of Bravery and Courage."
} 
particularly as rhetoric that appears to assess women who speak up, and as rhetoric precariously at work in the memoir industry. I approach "bravery" as a rhetoric associated with cultural ideologies regarding the heroic. The rhetoric of bravery that surrounds contemporary memoirs is a language that recognizes writers as "heroic" and, in turn, identifies certain kinds of stories as heroic. A "brave" book often is one in which the narrator has overcome adversities, confronts commonplace societal beliefs, or appears to readers to write in a way that is perceived as honest and authentic. Most people do not see themselves as heroic for overcoming adversity; nor do most people view themselves as brave. Generally, bravery is a status ascribed by others. Facing adversities is a common human condition. To write about them, however, is a feat that often falls under the category of bravery or courageous.

Bravery rhetoric is commonly located on the jacket blurbs of memoirs. In some cases, jacket blurbs refer to the story itself as brave; in other cases, it is the writer who is brave or courageous. Granted, book appraisals that appear on jacket covers are paratextual elements intended to help sell the story. Paratextual features, according to Gérard Genette, include elements that structure a text's "relation to the public" (15) such as the jacket blurbs, the title, forwards or other prefatory material, illustrations, and even the writer's own name (Genette 1). As the first literary scholar to conduct an extensive study on paratextual elements, Genette has seen his work critiqued and appropriated across disciplines, including autobiography. In a study of paratextual elements in autobiographies of musicians, Matthew Sutton draws heavily on Genette's work to conclude that paratextual elements "supplement the dialogue between the subjects and readers with a second discourse parallel to the text proper [and in effect] often interpellate readers directly, instructing them on how to 
contextualize and read the text that follows" (Sutton 208). In short, the job of paratextual elements may include a marketing angle, but their functions serve larger discursive purposes that, I argue, are rhetorically significant to autobiographical narratives and have yet to be theorized in life writing ${ }^{2}$ scholarship.

To a certain extent, the bravery of memoir appears to be about the telling of a difficult story. The difficulty may have to do with the measure of risk a writer may perceive, or the confrontational nature of a narrative that contests commonplace beliefs, or the resilience it takes for the writer to face uncomfortable memories or cruel situations. Repeatedly, a brave memoir is one in which the author tells a story of overcoming adversity. Beth DeVolder writes about the "wide reach" of the "overcoming narrative" in an essay in which she describes Western society as obsessed with "compulsory heroism" (746). By "compulsory," DeVolder is referring to the impossibility of refusing the status of hero because it is something "bestowed regardless of protests to the contrary" (748). The constitution of bravery rhetoric is multilayered in that it involves rhetors who bestow an attribute that is based on someone doing something that is perceived as brave — such as giving one's life for another in battle, facing cancer, raising a child alone, rescuing a neglected dog, or as it seems, writing a memoir. For instance, Karr and Bechdel write about the adversities and dysfunctions of their childhoods and the impact of family secrets on their growing up years; Didion and Rizutto write about grief and losses and the surprise of

\footnotetext{
${ }^{2}$ Life writing and autobiography are most often considered the "umbrella terms" with autobiography the more official term for the genre. Scholars across disciplines distinguish between the terms memoir and autobiography in divergent ways. For the purpose of this study, the distinctions are not within the scope of the argument. Life writing scholar G. Thomas Couser in his recent book, Memoir: An Introduction provides a comprehensive survey of the genre. Smith and Watson are influenced by Couser's approach to reading life writing texts (see Reading Autobiography page 19). Also, see Smith and Watson for a discussion on the linguistic and semantic distinctions of life writing terms. Terms that denote writing of self-representation are used interchangeably in this dissertation.
} 
finding oneself in the space of absence; Sebold and Harrison write about disturbing topics of incest and rape with narrative voices that appear vulnerable and authentic, which may feed into bravery rhetoric as a reader's response. That bravery rhetoric is frequently employed as a reader's response or as a paratextual feature warrants investigation into the rhetorical work it performs and the cultural ideologies it reflects and reinforces. This dissertation initiates that work.

Particularly insightful is Genette's metaphor of a "canal lock" to describe the negotiating function of paratext. From an engineering perspective, the purpose of a canal lock is to raise or lower the boat so that it can safely maneuver into deeper waters. Genette imagines the function of paratext as enabling the text to move from one space to another by acknowledging (and, therefore, relieving the pressure) of what he calls the "sociohistorical reality of the text's public" (Genette 407). For the contemporary memoir, the blurbs on jacket covers not only help market the memoir, but also mark the "sociohistorical reality" of the story's publication, circulation, and consumption. This is an important connection for understanding how the accumulation of brave stories governs the way stories are told, what kind of stories are told, and in turn, limits some stories as untellable or unable to be heard at this historical time. It is this recognizing and legitimizing work of the rhetoric of bravery as evidenced, in part, by paratextual features of the contemporary memoir that is central to this dissertation.

On one hand, bravery rhetoric in general may connote a viral-like fad or a fashionable way to describe certain actions or beliefs. I realize that the overgeneralization of its use waters down its significance as a meaningful category. The abundance of "brave memoirs" contributes to this cliché-effect, no doubt. On the other hand, the rhetorical 
pattern of naming difficult stories as brave reveals a preoccupation on the part of readers and reviewers with "bravery" as a category. While, in part, the rhetoric of bravery seems to spotlight the telling of a difficult story, the fact that it is commonly used to describe memoirs suggests it is rhetoric that is not only about the telling, but also about the ways in which certain kinds of stories are heard.

As a cultural rhetoric, "bravery" has deep roots in militaristic ideology. We tend to think of brave soldiers as ones who perform their duties, and in many cases, excel beyond the call of duty in times of danger. Military bravery is often contrasted with cowardice and the failure to perform one's duty, which is often a cause of shame and shaming in military contexts. William Ian Miller's The Mystery of Courage and Chris Walsh's Cowardice, A Brief History are texts that examine bravery and cowardice in relation to military references. Miller and Walsh acknowledge that bravery is a gendered concept contingent on a sense of duty. As a historian, Miller writes about the mystery of courage and states that "with courage comes embedded a theory of manhood" (13). Although military bravery and memoir bravery afford distinct cultural contexts, an ideology of duty, as I establish, rests in both. This association of bravery with militaristic notions of duty invokes ethics. The connotation of duty as doing the "right" thing raises questions about right and wrong, but it also suggests that interrelated in a sense of duty are the juxtapositions of four concepts: bravery, shame, courage, and cowardice.

In my second chapter, I analyze aspects of bravery and shame, courage and cowardice as they work together rhetorically. Examining the ethical aspects embedded in memoir bravery, I believe, opens new ways of analyzing ethics within the field of life writing studies. Ethical concerns in life writing scholarship commonly entail questions 
about truth, memory, and fact-checking, practices that center on negotiating boundaries of truth and lies. In contrast, a model that demonstrates the interrelations among bravery and shame and courage and cowardice invokes an ethics that centers on integration rather than the inclusive/exclusive work of monitoring potential fiction in a non-fiction genre.

Such a model, I argue, is reminiscent of the work that feminist scholars, particularly feminist rhetoricians, have done regarding care ethics. I do not think it is a far leap to then link caring to courage as philosopher and ethicists Alistair MacIntyre does: "If someone says that he cares for some individual, community, or cause, but is unwilling to risk harm or danger on his, her, or its own behalf, he puts in question the genuineness of his care and concern. Courage...has its role in human life because of this connection with care and concern" (After Virtue 192). ${ }^{3}$ I theorize that memoir bravery invokes a new brand of bravery that de-emphasizes a masculine perception of bravery (as performance) and emphasizes a feminist ethic of care.

The work of examining memoir bravery as rhetoric that reflects cultural ideologies requires several lines of inquiry. My analysis that the rhetoric of bravery connotes a militaristic sense of duty offers implications for analyzing ethics in life writing as depicted in the rhetoric of memoir bravery. To connect ethics to memoir bravery in ways that support a feminist perspective of bravery requires a theoretical understanding of the ethics of care in rhetorical studies. Toward these ends, I propose five claims that I explore throughout this dissertation.

\footnotetext{
${ }^{3}$ See also William Ian Miller's, The Mystery of Courage for elaboration on MacIntyre's linkage between care and courage. In particular, see Miller 287, footnote 6.
} 
(1) The rhetoric of bravery implicates a historical and cultural sense of duty which is significant in establishing patterns of meaning by which we orient ourselves in the social world and signify what we value.

(2) The rhetoric of bravery is contingent on an analysis of shame (and the complexities of cowardice) as the flip-side of bravery. Embedded in the rhetoric of bravery is an assessment that implicates shame as an affect associated with cowardice and the failure to perform one's duty. The rhetoric of bravery may perform the cultural function of potential shame erasure or redirection.

(3) The memoir industry represents one environment that archives what is valued as brave writing. On one hand, the accumulation of brave memoirs reflects and reveals a belief in the value of brave stories; on the other hand, this phenomenon renders what is left out, or stories that are left untold or unheard as potential losses. In this sense, the rhetoric of bravery connotes a sense of eulogy or loss embedded in its tribute to the heroic.

(4) The rhetoric of bravery that surrounds many contemporary memoirs depicts a feminist brand of bravery that contextualizes duty in relation to care ethics, and which inadvertently reveals a potential collective readers' response of empathy.

(5) Representations of brave memoirs may exhibit textual features that contribute to their uptake as brave stories. Such features may depict a vulnerable narrator who is then potentially perceived by readers as authentic and trustworthy. Memoirs that exhibit self-empathy in the text toward the vulnerable narrator may evoke a sense of empathy in readers. As such, the rhetoric of bravery that surrounds 
memoir may be interpreted as a collective linguistic reader's response of empathetic awareness.

\section{Literature Review}

Primarily, my work is situated within the emergent discourse in life writing scholarship that theorizes the memoir as having cultural significance. Julie Rak argues that the memoir does the work of citizenship; Megan Brown situates the memoir as a mode of self-care that includes care for others; G. Thomas Couser's final chapter in Memoir is titled "The Cultural Work of Memoir." Life writing scholars have examined the memoir's cultural work by primarily focusing on the effects on readers, on writers, or a combination of both. My work intersects with these and other life writing scholars, and extends the reach of analysis by invoking feminist works on rhetoric and care ethics. A rhetorical approach unearths a series of new questions, which as I argue, reveal cultural insights regarding the interdependence of the production and circulation of contemporary memoirs and deepseated cultural values. A critical approach to the rhetoric of bravery as it is employed in the memoir genre exposes cultural assumptions about the ideologies of bravery and the cultural weight of the militaristic connotations of bravery imposed on the genre. What is at stake for the memoir genre as a genre that may cultivate, traverse, reinforce, redefine, or redirect ideologies of bravery? This exploration enters conversations regarding the potential cultural work of memoir as debated in life writing scholarship, and contributes a rhetorical lens as a tool for further investigating ethics in life writing studies.

In what follows, I review the literature on ethics as conceptualized in two broad fields: life writing and rhetoric. Ethics in life writing scholarship has a history of framing ethical discussions in terms of the proxemics between truth and fraudulence. This approach 
to ethics, most likely, encroached into the field of life writing from a literary perspective of memoir as non-fiction and in contrast to the novel. (I survey the work of several life writing scholars, including Smith and Watson, Yagoda, Rak, Gilmore, and Brown, Eakin and Couser.) In the second part, I turn to the scholarship in rhetorical studies that traces the development of ethics as charted by feminist rhetoricians who have influentially intersected ethics with care. (Namely, I examine works of feminist care ethicists Gilligan, Noddings, Held, Manning, and Tronto, and the writings of rhetoricians Schell, Royster, Kirsch, Barton, Ranny, and Glenn). My overall aim is to begin the work of theorizing the rhetoric of bravery in relation to the contemporary memoir. ${ }^{4}$

\section{Life Writing and the Memoir Boom: Negotiating Boundaries}

Life writing scholars refer to the rapid increase of new memoirs published over the last thirty years as the 'memoir boom,' a phrase first used by Leigh Gilmore in her 2001 publication, Limits of Autobiography (2). As a term that was coined to characterize the explosive increase in memoir publications at the turn of the millennium, the term continued to show up in life writing scholarship and in popular writings to describe the unprecedented quantity of publications by both celebrities and common people that spiked in the 1990s.

Alongside the upsurge of memoir publications, predictably, came a trailing flow of scholarly analysis that ascertained the questions: Why memoir, why now?

\footnotetext{
${ }^{4}$ As noted, my approach to bravery is rhetorical, and an in-depth review of historical literature is outside the scope of this dissertation even though I draw on historical works in Chapter 2 as a way to examine bravery and shame and courage and cowardice. A few noteworthy areas that pertain to the rhetoric of bravery include literature on 'heroism' published in Disability Studies that address the issue of 'supercrip' wheelchair athletes (e.g, see Berger 2008); literature in Cultural Studies that pertain to 'hero worship' (e.g., see Hughes-Hallett 2004); and literature analyzing terrorism (e.g., see Hyde 2005).
} 
According to historian Ben Yagoda, between 2004 and 2008 memoir sales increased more than 400 percent. This staggering increase is enough for Yagoda to argue that the memoir is a desirable commodity. Thomas Couser contends, although not all agree, that "the term 'memoir' has eclipsed 'autobiography' as a term of choice for a certain kind of narrative" (3). Couser alleges that "memoir now rivals fiction in popularity... and exceeds it in cultural currency" (3). Nearly a decade after Gilmore coined the term, “memoir boom," Julie Rak recasts it in the 2013 title of her book, Boom! Manufacturing Memoir for the Popular Market, to not only emphasize the ongoing rise in the industry but to interrogate the existence of so many memoirs. Rak's attention to memoir manufacturing indicates a shift in life writing scholarship from a focus on analyzing the kinds of texts and sub-genres that comprise the memoir genre to examining the cultural effects of the publishing trend and the emerging status of the memoir genre as a desirable commodity.

Related to the memoir boom of the nineties and the commodification aspect of the memoir genre, it is also important to consider the temporal aspect of the phenomenon of memoir productions. Perhaps it is more than coincidental that a rapid increase in memoir publications manifests in the decades directly before and after the turn of a century, a common time, according to Andreas Huyssen, for an explosive interest in memory to occur (Twilight 3). Huyssen, a German scholar who writes about the cultural heritage industry, believes that the rise in modern museums reflects an obsession with the past. The archive, for instance according to Huyssen, is a way of articulating the past as memory in a public sphere that marks a time in history (Twilight 3). Huyssen characterizes the contemporary rise in archival productions in his book, Twilight Memories: Marking Time in a Culture of 
Amnesia, as an "end-of-the-century artistic collection" that comes on the heels of the "crisis of the structure of temporality that marked the age of modernity" (6).

Gilmore's memoir boom coincides with Huyssen's end-of-the-century fixation on memory and the drive to conserve the past. The metaphor of "twilight" is quite revealing. We think of twilight as a time of day when the sun is a few degrees below the horizon and the sky is filled with a soft glowing light. Twilight is a time of ambiguity and obscurity. Huyssen uses the term to describe the temporal flux of memory. For Huyseen twilight is "that moment of the day that foreshadows the night of forgetting, but that seems to slow time itself, an in-between state in which the last light of the day may still play out its ultimate marvels" (3). Twilight is an in-between time that at once looks back on the day that is over and foreshadows the time to come. Literally the word means two lights ("twi" - is from the Old English for two). For Huyseen, the "twilight status of memory" has the effects of both forgetfulness and the unstable construct of collective memory (6). Furthermore, the twilight zone of memory marks the emotional investment in the original or authentic artifacts that comprise the accumulative function of the archive. In light of Huyseen's metaphor, the questions of why memoir, why now might have a potentially valid interpretation in the temporal context of the turn of the century, but what about now—a decade and a half after "twilight?" What has become of the emotional investments deposited by anticipated losses? To what end has collective memory, even as an unstable entity, constructed the brave memoir and the commemorative rhetoric that surrounds it?

Narratives of overcoming adversity coincide with what many life writing scholars agree, is one of the most noticeable influences on the endurance of the memoir industry: 
the age of recovery that characterizes our era. Gilmore situates the 'memoir boom' of the 1990s as an offspring of the recovery movement of the 1980s (Gilmore 664), which carved a space "proximate to politics" but "more available for participation—and even civic engagement" because of the perceived separation between the elite political and the “ordinary people or life-worlds" (Gilmore 664). Going back prior to 9/11, we also live in the post-Oprah era - a season that energized the fusion, as Leigh Gilmore puts it, between “"public issues and private problems' without political analysis" (Gilmore, "American Neo-confessional” 663). Gilmore is partially quoting Janice Peck who in her book, The Age of Oprah, contextualizes talk show therapy in the 'recovery movement' of the 1980s, which she describes as "an amalgam of therapeutic practices, self-help groups, publications, mental health policies, and treatment programs” (Peck 7).

The so called 'recovery movement' that has served as a nurturing backdrop for the memoir boom also produced a wealth of criticism for the 'misery memoir,' a subgenre that rocketed in sales with its 1996 kick-starters Angela's Ashes by Frank McCourt and The Liars' Club by Mary Karr, and a few years later Dave Pelzer's memoir of his abusive childhood aptly titled, A Child Called It. The cultural force of this misery literature, or 'mis lit' as the phrase the popular media uses ${ }^{5}$ is its double-side: the prolific production of misery memoirs launched the memoir boom, and at the same time, enthused an army of backlash. In fact, in a recent article published in Auto/Biography Studies, "Boom|lash: Fact-Checking, Suicide, and the Lifespan of a Genre," Gilmore devises a spin on her previous term and offers the field a new term, 'boom|lash,' to reflect "the incorporation of the backlash against memoir as a genre into the boom itself" - a term

\footnotetext{
${ }^{5}$ For example, see http://www.telegraph.co.uk/news/features/3635834/Mis-lit-Is-this-the-end-for-the-miserymemoir.html.
} 
Gilmore employs to "interrogate the resulting relations among genre, evidence, and ethics" (3, abstract). Gilmore's term involves ethics, yes, but it calls for a convergence of criticism regarding ethics of the genre to become fully integrated and contextualized into the genre to the point where the genre of memoir invokes issues of ethics as a constituent part.

Distinctively, Gilmore describes the term this way: "Boom|lash captures the simultaneous attraction and aversion that attaches to particular memoirs and the energies animating the ritualistic celebration and denigration of the genre" (212). Gilmore's placement of the diacritical stroke is inspired by Lauren Berlant's recent book Love|Desire in which Berlant uses the stroke to indicate a composite subject and, as Gilmore explains, to compress "the distance between two terms to signal visually how approaching one means touching the other" (Gilmore 213-214). The talk of backlash against the memoir is primarily in regards to the ethical violations as represented by certain texts that receive media attention for their violations (e.g., James Frey's A Million Little Pieces and others). And yet writers keep writing memoirs and publishers keep producing them at a rapid pace, and even creating hybrid categories such as autofiction or memoir-novel when new in-between spaces are required. The proxy of the diacritic stroke allows a new way to conceptualize two terms by offering a slight variation to seeing the terms as entirely separate, or in opposition to one another, or as indicating a kind of competing dualism. Certainly, Gilmore's term has significant possibilities for theorizing life writing ethics beyond the dualistic tendencies that often underlie traditional discussions of ethics in life writing which, in effect, set up ethics in terms of the pursuit of judgment—what is right and wrong or good and harmful or true or untrue. I suggest that the symbiosis of boom|lash connotes a breaking away of the memoir genre as being conceptualized as primarily a literary genre, which in turn, permits the genre to be available to other realms of analyses such as the rhetorical and cultural. 
Megan Brown's work in a recent article, "Learning to Live Again: Contemporary US Memoir as Biopolitical Self-Care Guide,” demonstrates one way ethics in life writing scholarship intersects with rhetoric. Brown's article is partly in reaction to a New York Times Sunday Book Review in which Rebecca Tuhus-Dubrow argues for a new subgenre: "the self-help memoir" (Brown 359). A step-up, no less, from 'mis lit,' the label of 'self-help' is an utter demotion of the memoir from the status of literature. Interestingly, Brown does not approach the literature question, but rather, invokes Foucault's concept of the biopolitical to make a case for the citizenry work of the memoir as an exercise in self-care that also involves care for others. Brown explains that self-help and self-care differ in that "self-care is a biopolitical technology, serving the broader goal of governing at a distance as subjects learn and perpetuate norms for healthy, productive citizenship, for contributing to society" (Brown 361). Brown extends memoir as instances of self-care, invoking Foucault to specify the inherency of "care for others." This interpretation of the potential affective work of the memoir echoes Julie Rak's conclusion that the cultural work of the memoir involves acts of citizenship in her analysis of the memoir boom (Rak 213).

The theme of ethics runs common in life writing scholarship. Together with Gilmore's insight that the memoir genre is, in essence, negotiated by ethics and the backlash of the memoir boom, one may argue that the citizenry work of the memoir is, likewise, a matter of ethics. Rak's supposition offers an entrance for analyzing the cultural work of the memoir from the perspective of what memoir texts potentially may do for both readers and writers as members of society. Furthermore, Brown's contribution of situating the force of the memoir as an exertion in self-care opens yet another aspect of ethics to 
consider. Life writing, in general, raises compelling ethical questions that have led scholars such as Paul John Eakin to consider "ethics as the deep subject of autobiographical discourse" (Eakin 6), and Sidonie Smith and Julia Watson to acknowledge the shifty state of autobiographical truth (Smith and Watson 1). Life writing scholarship regarding ethics generally has asked questions of boundaries and discernment: e.g., what distinguishes truth from lie when memory is unreliable? When does one's narrative cross the line and invade the privacy of others? What distinguishes the memoir as nonfiction when it appropriates literary maneuvers shared with the novel? Although important, the problem with questions of boundaries is that we have no agreed upon ethical standard by which to draw the lines. Only when high profile cases of scandalous memoirs arise, notably James Frey's A Million Little Pieces and Binjamin Wilkomirski's Fragments, do we engage in the cartography work of ethics.

Following the memoir boom of the nineties, scholars began publishing criticism on life writing, including works focusing on ethics of representation, disclosure, consent, and rights to privacy—issues that involve boundary work as well as questions of what is good and what is harmful. Life writing ethics, therefore, emerged as a categorical response to the prolific publications of primary sources of life writing available for analysis and within already existing debates regarding the politics of the personal. Life writing studies entered an interdisciplinary crossroads at the turn of the century, a time when "going public as a private subject," as Nancy Miller expresses, "was equally in vogue [in academia] as a kind of fin de siècle gasp of selfexploration with roots, arguably, in an earlier feminist critique of universal values" (But Enough 1). 
One of the first texts to map the field as interdisciplinary is Paul John Eakin's edited volume of essays, The Ethics of Life Writing, published in 2004, the same year that G. Thomas Couser's text, Vulnerable Subjects: The Ethics of Life Writing came out. In a review essay in $J A C$ titled "Life Narratives and Ethics" Catherine Hobbs discusses the new interest in ethics from a rhetorical perspective. Hobbs keenly notes that Eakin's collective text, much broader in coverage than Couser's, includes selections that "represent diverse approaches and points on the spectrum of rigor... [and] place more emphasis on unpacking the 'potential for good' that autobiography offers" in contrast to "an ethics of life writing that is properly concerned with checking its potential for harm" (Hobbs 413; quoting Eakins 4). An emphasis on a positive spin on ethics, as Hobbs notes, is in part, embedded in "feminist theory in the era of poststructuralism... [which] rejected binary oppositions such as subject and object as well as mingling the personal and scholarly following the dictum 'personal is political"' (Hobbs 415). Questions of ethics in life writing, as Smith and Watson assert, are "at the heart of autobiographical studies today" (221). Life writing scholarship from the memoir boom of the nineties to now situates ethics as a central theme, and as Smith and Watson portray, as intersecting explicitly with "those working on the conjunction of the personal narrative and human rights, indigenous testimony, and global citizenship and the nation state" (221). As my review illustrates, the literature often portrays ethics as boundary work (e.g., what is inclusive or exclusive or what is considered truth or lies). As Gilmore alludes, now that we have three decades-worth of memoir production, the industry as a whole may be ready for a make-over of the category of ethics. And as history attests, we've come to expect the defensive and offensive plays within the industry, further supporting Gilmore's suggestion of the new term boom|lash. The archive of contemporary memoirs has been probed and prodded, diagnosed and dissected, 
prescribed and abused - to borrow medical metaphors-without, until recently, a critical concern for the ethics of care.

The field of rhetoric, and in particular feminist rhetorical studies, has problematized care ethics in ways that may afford new perspectives on the boundary work of ethics in life writing. Historically, the work in rhetoric and composition that has advanced the relational and contextual aspects of the private/public debates and other ethical dimensions of the personal is beginning to intersect with life writing scholarship as depicted in Brown's treatment of the care work of memoir. This crossroads of ethics is theoretically significant and warrants an understanding of the contributions feminist rhetoricians have made toward the revision of ethics in terms of care work.

\section{Feminists Rhetorical Perspectives: Rethinking Ethics}

Scholars in rhetoric have analyzed the concept of care largely in relation to the ways in which feminist ethics have engaged Carol Gilligan's 1976 publication, In a Different Voice. As a student of Lawrence Kohlberg, Gilligan questioned the assumptions, methodologies, and research conclusions of her mentor. Kohlberg concluded that patterns of mature moral reasoning were more typically found in men than women. Upon investigation, Gilligan discovered that Kohlberg's research was limited to male subjects and his overgeneralization of a standard put women at the disadvantage of being unable to reach the highest level of moral maturity. Gilligan found Kohlberg's conclusions unacceptable. Conducting her own studies using female subjects, Gilligan concluded that the "different voice" of women revealed an alternative orientation from Kohlberg's moral reasoning and other patriarchal notions that centered on an "ethics of justice." In reaction, and quite boldly for the time, Gilligan dubbed her alternative approach, an "ethics of 
care" (Gilligan 1976, 1988), which set in motion the binary discourse of care and justice and their contested alignments with female and male, respectively.

Gilligan's conceptualization of care is foundational for the work that follows in feminist ethics ${ }^{6}$ and in turn, the uptake of care in feminist rhetorical practices (Ranny 122). For early feminist ethicists, “"care' was meant to counter the covert masculinist bias of mainstreaming notions of "justice"” which in effect, "became shorthand for recognizing and valuing the specific, particular and affective bases of moral decision making" (Beasley and Bacchi 50). Gilligan has been widely criticized for promoting an essentialist view of women. Even so, according to Chris Beasley and Carol Bacchi who contest the limits of care ethics, the bigger problem with care, they argue, is that it remains "wedded to the individualist orientation" in its emphasis on morality due to its alignment of care with "women's maternal practices” (Beasley and Bacchi 50).

Eileen E. Schell's work in rhetoric and composition challenges a discourse of care ethics that aligns care practices with traditional gender roles in her 1998 text, Gypsy Academics and Mother-Teachers. Schell contends that an ethic of care is socially constructed and sanctioned rather than natural and ascribed to women. This leads Schell and others to argue for the distinction between 'feminine' and 'feminist' ethics of care, asserting that a "feminist ethic of care challenges us to think about the moral question embedded in caring, and it challenges us to remake social and political institutions so that care-work becomes a part of everyone's lives" (Gypsy 81; quoting Tronto 184). Gypsy revises care ethics (within the specific context of the politics of composition instruction in higher education) and provides a foundation for scholars of rhetoric to analyze care ethics in broader contexts and capacities. For example, Jacqueline Jones Royster and Gesa Kirsch's, Feminist Rhetorical Practices, a comprehensive survey of the

${ }^{6}$ See the following: Noddings 1984; Ruddick 1990; Manning 1992; Kirsch 1999; Held 2006; Tronto 2013. 
practice and research of feminist rhetorics over thirty years, analyzes the expansion of care ethics as a feminist model. As one might expect, care ethics is not defined by one perspective, nor is it confined by questions of morality alone, but rather it is a field that comprises a multiplex of evolving and productive dimensions.

In rhetoric, as in life writing, the study of ethics has turned attention to the fields of bioethics as an extension of care ethics. Ellen Barton best describes the contribution of rhetoric to the literature on bioethics with this fundamental insight: "decision-making with ethical dimensions is most often interactional and therefore rhetorical" (599). Kirsch, who claims that the "ethical turn" (Barton 597) in rhetoric occurred around the end of the 1990s, embraces the interactional aspect of ethics and advocates for a more reflexive approach. Furthermore, Mortensen and Kirsch propose that those who practice a reflexive ethics of care avoid “reinscribing a single ethical code, such as the traditional 'ethics of rights,' for they recognize the folly of developing universal principles that turn out, time and time again not to be universal at all, but to privilege only those held by a dominant group" (Ethics xxi; Barton 598). This nuanced revision of care as something rhetorical and interactional enhances clarity and supplements the deficiencies of the early feminists' theories developed by Gilligan and others around her time. Francis Ranney makes a significant contribution to discussions of care ethics in rhetoric in an essay titled "Mining the Collective Unconscious" published in Rhetorica in Motion, a collection of essays edited by Eileen Schell and K.J. Rawson. Ranney finds the literature on feminist ethics of care inadequate arguing that what is missing is the concept of self-care (121, italics mine). Intriguingly for my analysis, Ranney theorizes the role of self-care in care theory in a similar way as Megan Brown's conceptualization of self-care in life writing. In effect, Ranney suggests an "ethics of self-care from a perspective of rhetoric that involves clearing out an inner 
space where one feels free to act creatively and with purpose and effect" (132). Part of this freedom includes decisions to live with unresolved questions and the fluidity of moving across boundaries. Ranney employs rhetoric as a path to feminist ethics and calls for a shift in the way ethics is perceived, advocating that ethics is neither a "structure, nor a formula, nor a target, but a process that, whatever outcomes it may produce, is in itself ethical" (128). Essentially, care as relational and interdependent processes is the emergent common ground from an interdisciplinary reading of rhetoric and ethics, and I argue, has significant implications for the contemporary memoir.

As I have discussed in the review sections above, ethics has a history of being concerned with scrutiny—or the work of policing narratives, a history that both life writing scholarship and rhetoric has inherited. At least two significant aspects for life writing ethics are important to note from my review of literature. First, the shift from an ethics based on the potential for harm to the potential for good makes way for new questions in life writing ethics; and second, the ways in which feminist theories have influenced the personal in academic writing offers precedence for feminist theories to also influence life writing in similar ways as it has in rhetoric and composition. Life writing criticism on ethics, via the influence of feminist theories and rhetoric is beginning to shift away from binary and boundary concerns in lieu of broader and more integrative perspectives on ethics. My work enters at this crossroad.

Within the field of life writing, my work offers a way to centralize ethics in rhetorical parameters beyond the narrow scope of fraudulence or theories of representation. Life writing scholars, including Rak, Brown, and Gilmore have begun to problematize ethics more broadly, but the work of theorizing ethics in rhetorical terms primarily has not been done. My dissertation does that interdisciplinary work through a theoretically grounded analysis of the rhetoric of 
bravery and the contemporary memoir - an aspect of life writing scholarship that has not been theorized.

\section{Chapter Overview}

Using an English Studies model, I develop an interdisciplinary framework for analyzing the rhetoric of bravery as it surrounds the contemporary memoir, focusing primarily on memoirs written by women. This framework requires examining junctures among academic and disciplinary insights in fields of life writing, rhetoric, and care ethics as described in the literature review sections above. An interdisciplinary framework is necessary, first, because the field of life writing within which the brave memoir operates is itself an interdisciplinary-rich field. As such, concepts important to life writing, including ethics, authenticity, and vulnerability tend to move fluidly across disciplinary boundaries, but not without acquiring nuances, connotations, and even new meanings depending on the disciplinary contexts in which they are used. Sorting through disciplinary build-up is an important first step in interdisciplinary work. Secondly, my research claims as listed in the introduction require viewpoints from life writing, rhetoric, care ethics, theories of shame, and some historical works on bravery, and would not be aptly satisfied using a singular disciplinary framework.

\section{Chapter 2 -Braving Shame: Contextualizing the Rhetoric of Bravery}

In Chapter 2, I examine larger cultural discourses of bravery external to the memoir. I argue that memoir bravery is rhetoric that is endorsed and sustained by larger cultural discourses of bravery within which the popularity of the memoir and its proliferation emerges and endures. As a case study in memoir bravery, I examine Cheryl Strayed's recent memoir, Wild, and her rise to popularity. Through several publications since Wild, 
interviews with Oprah, and a film production of her memoir, Strayed has become a sort of posterchild of bravery in the memoir industry. I analyze Strayed's sustaining popularity as an effect of the rhetorical interdependence of the memoir on larger discourse domains, including the discourse of empathy that Oprah promotes. Chapter 2 is divided into two overarching sections: contextual considerations of bravery and theoretical considerations of shame. In the first section, I approach bravery as a rhetorical concept. I analyze instances in the media and news in which bravery is used as a central linguistic feature. My analysis demonstrates that memoir bravery fits within larger discourses of bravery that engage duty and shame: in short, duty performed well constructs bravery, and failure bears the potential consequence of shame. In the second section of Chapter 2, I provide a synthesis of relevant theories of shame useful for rhetorical analysis of memoir bravery. Chapter 2 concludes with a model that proposes the triangulation of bravery, shame, and duty as a heuristic for theorizing memoir bravery.

Chapter 3-Memoir Bravery: A Rhetorical Analysis of Parenthetical Constructions in Mary Karr's The Liars' Club

Mary Karr's The Liars' Club is the text that I examine in Chapter 3 as a representative of the brave memoir. Karr has earned a place of honor as the author of three memoirs, the first of which, The Liars' Club, was published at the onset of the 'memoir boom.' In this childhood memoir, Karr writes about her childhood memories of a dysfunctional upbringing. Karr, as a poetic storyteller, weaves a narrative tapestry that is at once original to her own family and relatable to others. Karr employs facets of the autobiographical 'I' seamlessly, moving from the experiential voice of the child to the reflective voice of the adult narrator, inserting playful parenthetical constructions. Through 
a rhetorical analysis of Karr's parenthetical constructions as textual instances of the autobiographical 'I,' I explore the potential perception of an authentic narrator as a key ingredient for memoir bravery. Furthermore, Karr's writing demonstrates textual moves that head off readers who may consider contesting her early childhood memory. I analyze textual and linguistic samples to theorize that a cultural belief in the value of bravery potentially infiltrates into memoir writing in ways that influence storytelling.

Chapter 4 - Writing from the Wound: A Feminist Perspective of the Rhetoric of Bravery in Laura Gray-Rosendale’s College Girl

In juxtaposition to Karr, Laura Gray-Rosendale employs a different strategy for critiquing the fallibility of memory. Karr tells her childhood stories in ways that wards off backlash whereas Gray-Rosendale directly participates in the critique of storytelling. In College Girl, Laura GrayRosendale attempts to reconstruct her fragmented traumatic memory of being raped as a college student. Her story unveils a journey of coming-to-terms with the absence and the unknowing of memory that trauma affords through an analytical approach that directly engages and interrogates the reconstructive processes of memory. I analyze College Girl as an exercise in self-care and a model of self-empathy. Written nearly two decades apart, I situate Gray-Rosendale and Karr's memoirs as representations of memoir bravery. Both authors have been appraised by readers and reviewers as brave writers who confront commonplace cultural scripts about privacy, duty, shame and what should or should not be spoken or silenced.

Chapter 5 - The Pedagogical Potential of Memoir: The Rhetoric of Bravery in the Classroom and the Teaching ' $I$ '

In Chapter 5, I turn to the pedagogical work of the contemporary memoir. I apply the theoretical discussions of memoir bravery to a college class that I taught as part of my internship 
requirement. Feminist theories have pioneered the "turn to the personal," and in so doing, emphasized contextual and relational aspects of writing, which I argue in this chapter, facilitate the juncture of memoir and bravery. 


\section{CHAPTER II}

\section{BRAVING SHAME: CONTEXTUALIZING THE RHETORIC OF BRAVERY}

What shames us, what we most fear to tell, does not set us apart from others; it binds us together if only we can take the risk to speak it.

- Starhawk

We tell ourselves stories in order to live. - Joan Didion

Memoirist Cheryl Strayed asserts that what is most important for aspiring writers is for them to grant themselves "permission to be brave on the page, to write in the presence of fear...to go deep sea diving into their own lives" (Tardif). This sentiment is not unlike the message that social researcher Brené Brown portrays in her popular books. Brown is best known for her books on courage and shame, and a 2012 TED talk on "The Power of Vulnerability."7 Recently, Brown launched an online learning community, COURAGEworks, a site that offers online courses and workshops to "anyone who is ready for braver living and loving" ("About" COURAGEworks). A quick Google search unveils numerous venues for purchasing "brave" items, including jewelry, handbags, and mugs — items that can be worn, seen, displayed. The recent collaboration of Elton John and Lady Gaga to form a new and limited line of clothing for Macy's called "Love Bravery" further exemplifies consumer practices related to what seems to be a bravery movement in contemporary U.S. culture. The very act of "putting on bravery" as one would put on clothes is a metaphor of self-fashioning, strength of identity, and resistance to the shaming eyes of others. What rhetorical work does the marketing of bravery do? Undeniably, bravery sells. It also conveys an interest consumers have in self-improvement and developing positive traits, such as love, kindness, compassion, mental wellness, self-assertiveness, and

\footnotetext{
${ }^{7}$ According to the website Brave Leaders Inc., an organization of which Brown is the Founder and CEO, the 2012 TED talk was "one of the top five most viewed TED talks in the world with over 25 million views." (See https://www.braveleadersinc.com/)
} 
empathy_which are common affects and attributes associated with the marketing of bravery. Within this larger "bravery culture" the contemporary memoir is one more product of "bravery" available to consumers. At the same time, the memoir is a literary genre that continues to be prolific in publication at a time when "bravery" is rampant in the culture. Strayed's advice to writers seems to be in line with our consumer culture's obsession with bravery.

In this chapter, I examine cultural conditions and discourses within which the rhetoric of bravery operates, and argue that the memoir is a literary form that both represents and reinforces cultural assumptions about "bravery" as an ideology. I identify several larger cultural and contextual features within which the memoir endures and which sets apart "bravery" as a prominent value for the stories we tell. To some degree, memoir bravery refers to the reader's perception of the narrator's voice of authenticity — one that takes risks reflectively, one who faces the fears that may accompany painful memories, or one who exposes vulnerabilities to a public audience. It is important to remember that the authentic is conventionally perceptible. Bravery is a travelling concept that moves across contexts and discourses, and therefore, carries with it culturally-constructed perceptions about what counts as brave (and what doesn't). While it is important to analyze the representational meanings of bravery within contextual parameters, for example in the context of the military, it is also noteworthy to consider the aspects of bravery that can traverse discourses, such as the heroic.

In general, bravery is characterized as a positive virtue, is often marked in gendered terms, varies in kind and degree, and serves ideological purposes. As a pliable concept bravery bears linguistic flexibility and can mean very different things, including confronting physical dangers, speaking up about taboo topics, taking risks, performing acts of kindness, keeping silent, being resilient, stepping up in leadership, and perhaps one of the most common 
associations, serving in the military. That said, bravery is also a spectacular rhetorical concept in that it functions as an assessment or a judgment of something or someone. Bravery is something others see. On occasion bravery is a word of longing - a term of eulogy used in remembrance (e.g., the brave dead soldier; the brave cancer victim; the brave survivor of a loss; the brave heart). Bravery is a populated concept with wide-spread appeal.

To examine what the rhetoric may exclude is as significant as analyzing what the ideology of bravery includes. A rhetorical approach to bravery postulates that rhetors (those who call out what is "brave") shine the spotlight on some, but not all, which may inevitably leave in the shadows those who are not brave, namely cowards. The talk of bravery as it is ever present in memoir discourse both reveals and conceals a cultural aversion to cowardice and its vice of shame. On one level, the appraisal of bravery keeps at bay particular affects that threaten to undo bravery, namely, cowardice, vulnerability, exposure, fear, and shame. These affects alongside the subjective meanings of "duty" populate a kind of bravery that stems from masculine roots as depicted in militaristic contexts. Although unacknowledged, the cultural legacy of bravery in its forms of inclusion and exclusion bears on the rhetoric of memoir bravery. As this chapter continues, it is important to consider in what ways memoir bravery reflects and reinforces a larger belief system which, in turn, governs - endorses, legitimizes, limits — the kinds of stories we (can) tell, the ways of telling, and the ways of hearing.

Life writing scholar G. Thomas Couser asserts that memoir should be read for what it does (as opposed to what it is) because of its location as a text "uniquely embedded in widely shared human practices and fundamental cultural assumptions" (26). Many scholars approach the memoir as having significance beyond the literary, and as I discussed in Chapter One, often involving ethical and contemporary expectations of autobiographical narrative: authenticity, 
vulnerability, and exposure, in particular. What are the cultural beliefs about bravery and what is at stake for the memoir as a genre partially contextualized by the rhetoric of bravery? Moreover, what might cultural beliefs about bravery tell us about ourselves as a society and the values we place on accumulating brave stories? These questions point to at least three significant areas for exploration: the cultural beliefs and assumptions about bravery, the connotations of "brave" in relation to memoirs and the cultural conditions that may affect their circulation, and the effects on memoir as a genre that is contextualized in bravery ideology. The rhetoric of bravery fosters cultural assumptions about bravery and conserves the values that operate within that rhetoric as it circulates within the culture. In fact, the paratextual appraisals and external reviews of certain kinds of memoirs seem to feature "bravery" as a go-to descriptor for marketing many memoirs. ${ }^{8}$

A closer look at Cheryl Strayed's work and the ways in which the memoir market and film industry has taken up her work as a model of bravery, showcases the convergence of the three areas I mentioned above. Beginning with a brief description of Strayed's memoir, Wild, I trace her rise in popularity to demonstrate the ways in which her memoir has been contextualized within the larger discourse of bravery. In effect, I argue that Strayed's memoir functions as a counternarrative that exposes and disrupts cultural assumptions about bravery as a gendered ideology — and that that interruption is what gets christened as "brave" by the media. Using Strayed as a case study, I propose that memoir bravery bears the potential to offer a cultural shift

\footnotetext{
${ }^{8}$ In this chapter, I lay the theoretical groundwork for the rhetoric of bravery as a culturally rich assessment of memoir. I am careful to avoid overgeneralizing the entire memoir genre as operating within this rhetoric. In the following chapters, I offer a close examination of two specific memoirs as representations of "brave memoirs" and as texts that illustrate my argument that memoir bravery is an important lens for approaching the contemporary memoir. The work that is not part of this dissertation, but that this dissertation points toward, is the identification and analysis of categories of certain kinds of memoirs that fall under representations of memoir bravery. Mary Karr's memoir about her dysfunctional childhood and Laura Gray-Rosendale's memoir about rape are two examples of possible categories of memoir bravery. Analyzing additional texts that may fall into these categories and naming other categories of memoir bravery is work that is outside the scope of this dissertation.
} 
away from a traditional masculine and militaristic perceptions of bravery and toward a new feminist brand of bravery.

\section{Memoir Bravery: A Wild New Brand?}

Wild: From Lost to Found on the Pacific Crest Trail is the story of Strayed's three month, 1,100-mile hike of the Pacific Crest Trail (PCT), which she did alone. The memoir's subtitle, From Lost to Found, depicts the inner struggle and navigation of personal loss, which in the memoir Strayed explains is about the loss of her mother and Strayed's consequential and enduring grief. In fact, in Strayed's own words Wild is about "how we bear what we cannot bear," a comment that she made during an interview with Oprah Winfrey. ${ }^{9}$ The remark has both literal and metaphoric value as it refers to her literal backpack, dubbed "Monster," the source of the metaphor that is symbolized in the memoir. For Strayed, her grief was her monster as the sudden death of her mother when Strayed was in her early twenties left her with a loss so painful that she could not bear it. Author Pam Houston endorses the book in a fourth cover blurb which acclaims: "this is a big brave, break-your-heart-and-put-it-back-together-again kind of book. Strayed is a courageous, gritty, and deceptively elegant writer" (Strayed, Wild, fourth cover).

What makes Strayed's book a brave one? Is the person Cheryl Strayed brave for hiking the PCT alone, a journey that many would not have the courage to do? Is the story brave because it is a narrative of redemption, a type of hero's journey, as the subtitle might indicate? In a review essay in Fourth Genre Leigh Gilmore acknowledges that memoir is "colonized as a form by redemptive narratives," but claims the autobiographical "'I' in Wild contributes a new figure

\footnotetext{
${ }^{9}$ For a transcript of the interview, see http://www.oprah.com/omagazine/Cheryl-Strayed-Interview-with-OprahWild.
} 
to the literary canon of walking, wilderness, and nature writing, and also to memoir itself' (189). Furthermore, Gilmore praises Strayed as one who

swerves from the gendered conventions of grief memoirs amply represented today... and with her conscious nod to feminist selffashioning, and her sheer will to walk as long as it takes...Strayed expands the territory of memoir to include women in the company of adventurers, daughters in the company of warriors, mothers in the company of the gods, and memoir in the pantheon of imaginative literature. (189) The cultural and gender work of Strayed's memoir, I argue, both represents and reinforces cultural assumptions about "bravery" as an ideology. As a representation of cultural assumptions about bravery, Wild offers a counternarrative in that it "depends on the possibility of critique of the master narrative... and to some extent, on empathy with the counternarrative" (Shuman 19). Amy Shuman in her book, Other People's Stories: Entitlement Claims and the Critique of Empathy, argues that "redemptive, subversive, or other liberatory claims made for narrative are based on the possibility of counternarratives" (17). Houston's endorsement of Wild as a brave book and Gilmore's description of the "I" in Wild as a "new figure" relies on an already existing ideology of bravery, but also destabilizes that ideology by swerving away from a more conventional approach to grief and a "nod" toward "feminist self-fashioning" as Gilmore puts it. One narrative that Wild challenges is the "gendered conditions of grief memoirs" as Gilmore attests, and the cultural judgments that pin a time-frame on grief as something that should end in a reasonable amount of time, whatever that means. On one hand, as a representation of a counternarrative "the territory of memoir" is expanded through inclusion of women in already existing masculine models of bravery such as depicted in Gilmore's terms: "adventurers," 
"warriors," and "gods." (189). While this cultural and gender work may upset the stability of a masculine ${ }^{10}$ model of bravery, at the same time, it nevertheless reinforces it as the prevailing ideology.

The popularity of Strayed's memoir was kick started by its inaugural position in Oprah's revived book club; plus, the 2014 movie release starring Reese Witherspoon as Cheryl Strayed and Laura Dern as Strayed's mother further commercialized the book. The ripple effect of Wild and the almost instant popularity of memoirist, Cheryl Strayed, branded her public persona as a posterchild of bravery. In fact, the publishing and media industries were well aware of this phenomenon as demonstrated by the follow-up publication of a small book of essays drawn from The Rumpus production of Dear Sugar and the public reveal that Cheryl Strayed is Dear Sugar! In this short text titled Tiny Beautiful Things: Advice on Love and Life from Dear Sugar (a bestselling 2012 book), Strayed offers her responses to letters she has received as Dear Sugar, which are part memoir, self-help, and advice rolled into one that for some readers may have a "biblical" appeal. To monopolize further, $H B O$ is currently developing another screen adaptation of Wild which they will call Tiny Beautiful Things, a drama "set to explore love, loss, lust and life through the eyes of a Portland family who live by the mantra that the truth will never kill you" (Andreeva). The TV adaptation will star Witherspoon and Dern as well as the work of Strayed's husband and filmmaker, Brian Lindstrom.

Strayed's heightened popularity has continued to give footing to the rhetoric of bravery as illustrated most directly in the recent publication of a book of her own quotations from various

\footnotetext{
${ }^{10}$ Questions of bravery's constituency compel us to ask other complex questions about whether gender matters. In what ways might grief memoirs, for instance, mark bravery in gendered terms? Would a male memoirist be able to tell a similar story of extended grief over the loss of his mother? Or would readers categorize a Wild story by a man as brave in the same way they figure the bravery and courage of Strayed, a female writer? These are hypothetical questions that are more relevant to ask than they are possible to answer.
} 
sources titled Brave Enough. Strayed's original publisher of Wild, Knopf, published a collection of quotes from Strayed's books, essays, interviews, and talks. Strayed writes in the introduction, "For every quote in this book imploring you to accept and forgive and be brave (enough), to be kind and grateful and honest, to be generous and bold, I'm imploring myself to do the same. In other words, I'm not trying to be the boss of you. I'm attempting to be a better boss of me" (xixii). Admitting that she "falls short on a regular basis" humanizes the memoirist that the industry has upheld as a model of bravery, making her still our relatable and beloved author and each one of us her "sweet pea" -a term of endearment that she often called those who wrote Dear Sugar letters.

Given the central theme of bravery in the example of Cheryl Strayed's publications and popularity, it may seem that the memoirist is following the cultural craze. That "bravery" has such an appeal to consumers at this time paves the way for memoirists, like Strayed, to cut in with a form that represents and services this cultural pulse. In the case of Strayed, bravery was already situated as a virtue and the cultural timing of when she published her recent work may have functioned as cultural condition for her success. On a rhetorical level, we must keep in sight not only the story itself but the storytelling as something seasoned with rhetorical moves that are culturally influenced, which hand in hand — the story, the telling, and the ways of telling and hearing - interdependently enact and govern a rhetoric of bravery. On an ideological level, the fast-paced success of Cheryl Strayed and the popularity of her memoir and her subsequent media achievements are due largely to an impelling culture of bravery that, I believe, endorses (and often confuses) vulnerability and exposure as "authenticity." In contrast to delivering what might be expected in a traditional hero's story, of one who successfully performs duties beyond the call, Strayed breaks the rules and challenges the traditional confines of the heroic as strong and 
brave by owning up to her own weaknesses and inabilities. What is gained from the Strayed case study that benefits a critique of the rhetoric of bravery is not necessarily the limitations of the cultural conditions and timing, but the unforeseen opportunity to enter an existing rhetorical phenomenon, upset it, and in the end, offer a redirection or a revision to the rhetoric of bravery.

The bravery of Cheryl Strayed as a memoirist is multifaceted, starting with the obvious nerve that it took for her to make the hike in her early twenties and the courage she mustered to write a memoir about it twenty years later. Strayed, like many writers who employ the memoir as a form, saddles into a genre that supports through convention the raw, unflinchingly poignant details of the self which are often displayed on the page alongside a voice of self-reflection. Although Strayed is more unrestricted in her essay writing than her memoir writing, describing poignantly her multiple sexual encounters, heroin abuse, and a failed marriage (as a short list), Strayed's "badass" writing has earned her a "cult of followers" as freelance writer, Elizabeth Greenwood, writing for the Atlantic claims: "'Write like a motherfucker' is one of [Strayed's] catchphrases, and she espouses 'motherfuck-itude' as a way of life, which boils down to quitting your whining, getting over yourself, and getting to work" (Greenwood). Strayed's seemingly unrefined media persona is often (mis)taken as bravery because it plays into what is conventionally perceived as authentic. Life writing scholars maintain that autobiographical narratives "must promote an identity whose authenticity is sufficiently persuasive, compelling and transformative to make its truth manifest and credible to readers" (Smith \& Watson, "Witness" 503). Writers may approach the design of an authentic persona in different ways, but writers who can successfully get readers to perceive them as authentic tend to come across to readers as brave. Strayed has demonstrated in essays prior to Wild that she is indeed a writer who does not cower in the face of truth-telling. For instance, the opening line of Strayed's award- 
winning essay, "The Love of My Life" reads: "The first time I cheated on my husband, my mom had been dead for exactly one week" (291). This is a jarring attention-getter that immediately may compel one to keep reading to discover the unfolding of the tale. The seemingly "shameless" opening line marks a voice that may be recognized by memoir readers as a "brave writer." Whether the writer feels shame for cheating is not in question. Rather, the writing sends to readers a message: this narrator is the real deal. The rhetoric of bravery, in this case, may reinforce a belief in the value of authenticity in memoir writing, and it may even have the potential to redefine the ways in which the authentic is perceived.

The uptake of Wild as a "brave" memoir and Strayed as a "courageous" writer is not unlike the praise allotted many contemporary memoirs and writers. In rhetorical studies, the term uptake is borrowed from J.L Austin ${ }^{11}$ and adapted by Anne Freadman as an illocutionary response elicited by particular situations (Barwashi and Reif 85). Freadman illustrates the concept of uptake using the game of tennis. She explains that in tennis the shots that are exchanged during the game are meaningful because they occur in a game as opposed to a different context (Barwashi and Reif 85). Arguably, in light of the way Freadman explains uptake as having illocutionary function, we might appropriate this and say that the uptake of memoirs as brave stories elicits a response reflective of a particular time and context - one that, as I explore in the remainder of this chapter, comprises tacit cultural beliefs about a sense of duty, the ideology of bravery, the affect of shame, and one that the memoir industry foresees is profitable. Curiously, there is something about bravery that causes it to endure and adhere to discourse spheres that engage vulnerability, authenticity, exposure, privacy, experience, and

\footnotetext{
${ }^{11}$ The term "uptake" was originally formatted by J.L. Austin in his instantiation of speech act theory in How to Do Things with Words.
} 
shame-concepts important in memoir scholarship, indeed, as well as concepts at work in larger cultural discourses.

\section{Contextual Considerations of Bravery}

\section{Bravery: A Populated Concept}

The words courage and bravery are often used interchangeably in memoir reviews, but linguistically, they have different etymologies. Bakhtin argues that language in this and any other moment in history is a "heteroglot representing the co-existence of socio-ideological contradictions of both present and past..." (Dialogic 291). Embedded in the word bravery or courage, for instance, is both a history of the words and their common present-day use. Both words warrant rhetorical understanding as both are at once other-centered and self-focused. In Bahktinian fashion, it is important to consider their separate etymologies as well as the ways in which the words have converged in everyday reviewers' discourse. Brave stems from Italian bravo, which literally means "bold," and is a common term used to express approval of a performance. In the late $15^{\text {th }}$ century brave had the meaning of "splendid" or "valiant." The Oxford English Dictionary traces the root as originally meaning "untamed" or "savage," stemming possibly from Medieval Latin bravus. Courage is an earlier word than bravery and is recorded as stemming from the $13^{\text {th }}$ century Old French corage (which is Modern French courage) and has the meaning "heart, innermost feelings; temper." Courage as "heart" spread to other languages, including Latin and Spanish. (Online Etymology Dictionary). The notion of bravery as bold, valiant, wild, and savage might conjure the fierce image of the face of Mel Gibson playing William Wallace in the 1995 film, Braveheart. If a "braveheart" is having the courage-as-in-heart to stand up and yell "FREEEEEEEDOM" after being nearly tortured to death, one might think this mode of bravery includes an element of courage. 
The frequent interchangeability of bravery and courage further reveals the convergence of the two terms in everyday usage. Rather than insisting on the separation of bravery and courage by noting their etymological differences, perceiving the two concepts as one may offer a productive understanding of memoir bravery. A possible representation might be to appropriate Lauren Berlant and Leigh Gilmore's use of the diacritic stroke to singularize two concepts, indicating that touching one means bumping into the other. Berlant does this in the title of her recent text, Love|Desire, and Gilmore appropriates Berlant's punctuation to theorize the incorporation of backlash into the memoir boom singularizing Boom|Lash, as I discussed in Chapter One. Similarly, Brave|Courage as a concept that comprises the meanings of both terms (bold and heart) in one would be useful as a way to theorize memoir bravery. I realize that, in some cases, calling a memoir brave may be merely unreflective appraisal of a memoir. Certainly, reviewing a memoir as "brave" or "courageous" is, in part, a marketing ploy as I have indicated. Whether these words have been overused and sound cliché or whether they are intentionally used as a marketing gimmick should not dismiss scholarly attention. That memoir bravery—as rhetoric — is influenced by consumerism and the formulation of products that market bravery is a significant cultural observation. Furthermore, as a language of choice for describing certain kinds of memoirs that narrate themes such as loss, grief, trauma, dysfunctional childhood, or any personal difficulty through which the writer has lived (and survived), provides important information about the cultural inscription of bravery as a value at this time. Some may argue that "bravery" is what defines us. Who is us and who makes this argument? The following example of a Super Bowl commercial will clarify. 


\section{Bravery. It's What Defines Us}

The prestigious automobile company, Audi, aired a commercial during the 2013 Super Bowl in which a (white, handsome) teen was getting ready to go to the prom, an event for which he apparently did not have a date. The commercial opens with the boy's mother pinning a boutonniere on his shoulder and encouraging her son that going alone is not weird (which made him feel worse). The boy's gloomy face is immediately turned upward, though, when his dad tosses him the car keys to the luxurious Audi. As the boy drives off viewers are led to believe that the car empowered the boy with confidence as he arrives at the dance, parks in the principal's spot, marches inside, and boldly walks up and plants a kiss on the lips of the prom queen - who was obviously on a date with another guy. The final scene shows the boy driving off in the Audi. The camera zeroes in on the boy's silly grin and gradually backs away to reveal a shining black eye. A caption appears on the screen that reads: "Bravery. It's what defines us."

Notwithstanding the ideology of privilege, the message of entitlement, the kiss without consent, and the act of violence — all problematic issues that instigated social media and internet backlash for Audi's commercial which was criticized as "rapey" 12 soon after it aired—-the rhetoric is ever clear and present: bravery is a hot cultural appeal. Yet, as the backlash to the airing of the commercial indicates, what constitutes bravery may indeed be undergoing a cultural revision. On one hand, as the Audi commercial depicts, bravery is (still) masculine, involves power or aggression, and a stance of fearlessness and self-confidence in the face of danger. The black eye and the grin reveal the self-satisfaction of the boy and a projection of that which the

\footnotetext{
${ }^{12}$ As a representation, here are several internet links that address the backlash of the Audi commercial: http://tigerbeatdown.com/2013/02/04/notbuyingit-the-problem-is-far-bigger-than-audis-braverywins/; http://www.chicagonow.com/high-gloss-and-sauce/2013/02/audi-super-bowl-ad-not-sexual-assault-offended-72/; http://www.phillymag.com/news/2013/02/03/conservatives-defending-audis-rapey-super-bowl-ad/; http://jalopnik.com/5981302/twitter-thinks-audis-super-bowl-ad-is-sexual-assault.
} 
commercial makers must believe resonates with the general public who watches the Super Bowl. The Audi commercial, I believe, points to a present-day culture of bravery—one in which bravery is conceptualized in gendered terms as a worldview which, as the caption depicts, "defines us." This example of "bravery" as depicted in the Audi commercial capitalizes on rhetoric highly charged with a legacy of bravery that is masculine, combative and aggressivethe effect of which is a new-found sense of self-maintenance, composure, and confidence that extends beyond the Audi boy and resonates with those viewers who only wish they could be so "brave." That said, on the other hand, the backlash following the airing of the commercial is indicative of changing times. A traditional masculine sense of bravery is challenged as the culturally accepted posture of bravery.

The cultural nerve struck by the gendering of bravery as depicted in the commercial reveals one instance for how shame enters into the cultural ideologies of bravery. The Audi kid was brave for overcoming his adversity and gaining a sense of self-confidence (that viewers are supposed to believe was a result of driving the car) which he demonstrated by marching into the dance and kissing the prom queen. In the Audi example, it is clear that the boy feels a degree of shame for not having a prom date but because he musters the courage to go to the prom anyway, viewers become endeared to his brave heart. This endearment foregrounds the kiss as the climax of the narrative and the hopeful "way to go dude" response that the commercial producers anticipate from their viewers. On one level, the bravery as depicted in the commercial is a gesture towards eradicating any potential of shame - which obviously is supposed to happen when one drives the car. On another level, viewers may be enticed to revisit comparable experiences of shame from their own youth and, for a moment, revise them vicariously through the brave Audi kid. The commercial 
demonstrates one way that bravery engages shame, which in fact, may border more or less on shamelessness. Historian Virginia Burrus explains this ambiguity of shame by situating shamelessness as not something "outside shame but is at once resistant to and continuous with it" and linked to "cultivating courage" (3). The producers of the commercial not only tap into what we value, but also expose what we hold in contempt: cowardice and its sidekick shame. In the next example, I turn to this flip-side of bravery to further explore the ways in which bravery rhetoric engages shame.

Cowardice. It's What We Loathe.

The November 2015 terrorists attack on Paris that killed 129 people ignited a rhetoric of cowardice with wide reach, spanning presidential statements to layman name-calling to French Muslim students who published a video slamming the terrorists as "anti-Islamic cowards" (Mirror). It does not take long to identify through a Google search a diverse and inclusive list of headlines or statements that refer to terrorists as cowards. For instance, U.S. Senator Bernie Sanders in a statement echoed the sentiments spoken a decade earlier in which President George W. Bush called the attacks of 9/11 cowardly. Sanders states, "We are all horrified by the cowardly attacks against innocent civilians in Paris. I offer my sympathy to the victims and their families. We stand in solidarity with the people of France, the first friend of the United States" (Politicusa.com). In a strikingly similar response, $A B C$ news reported shortly following the attacks of 9/11, that President Bush used the "c-word" twice in a statement at a Louisiana Air Force base. "Bush declared, 'Freedom itself was attacked this morning by a faceless coward ... Make no mistake: the U.S. will hunt down and punish those responsible for these cowardly acts." $(\text { Gerstein })^{13}$.

\footnotetext{
${ }^{13}$ Source: http://abcnews.go.com/Politics/story?id=121312
} 
The cowardly rhetoric of 9/11 sparked a debate over the use of the term. Bill Maher, a provocative host of an ABC late-night talk show Politically Incorrect had this to say: "We have been the cowards, lobbing cruise missiles from 2,000 miles away. That's cowardly...Staying in the airplane when it hits the building, say what you want to say about it, it's not cowardly" (Gerstein). Maher's comments, as one can imagine, came across to the public as irreverent and untimely, resulting in calls to boycott the program. Similarly, in an opinion piece in the New Yorker Magazine Susan Sontag stirred debate further. Sontag wrote, "If the word 'cowardly' is to be used, it might be more aptly applied to those who kill from beyond the range of retaliation, high in the sky, than to those willing to die themselves in order to kill others. In the matter of courage: whatever may be said of the perpetrators of Sept. 11's slaughter, they are not cowards" (Gerstein). Curiously, the editors of American Spectator, a conservative publication, agreed that "we should stop using the word "cowards"" and rather, think of the terrorists of 9/11 as "brave and evil" (Gerstein). The rhetoric of evil or "perverted" bravery did not catch on; however, the linguistic debate over whether terrorists are brave or cowardly points to the high stakes relegated to the insult and infringes on steadfast beliefs about the meaning of bravery as it is used in these instances.

Calling terrorists cowards may ward off the temptation of some to call them brave regardless of debates over whether suicide bombers are indeed brave or cowards. Chris Walsh, author of Cowardice: A Brief History argues that "calling [terrorists] cowards exploits the contempt we feel about cowardice" (12). Walsh observes, for example, one reason for the public's naming of the $9 / 11$ attacks and the Boston Marathon bombing as "cowardly" is that it functions rhetorically as a grave insult that, in essence, leaves the rhetor feeling good to have lashed it out - regardless of its accuracy (Walsh 1,4). Such epideictic rhetoric attempts to spoil 
the well and detach the rhetor from a sense of loss and pain (Walsh 4). Walsh recognizes the difficulty of defining cowardice without an appeal to courage or visa-versa as they often slide alongside one another, at times merging together and becoming muddled. As virtue or vice, (or neutral as Sontag maintains) both are seductive social concepts that lure by default the judgments of others-which in turn, reflect the rhetors' investment in their own identity maintenance, and which may have little to do with the accuracy of the name calling.

The rhetoric of cowardice implies that bravery should only be bestowed on the honorable. Inevitably, it is also rhetoric motivated by fear. A reporter for the $\mathrm{BBC}^{14}$ has predicted 2016 to be a "year of fear" for the United States. Writing about the presidential elections, the reporter assesses the state of the union as "perturbed and anxious... beset by a climate of uncertainty and fear" (Bryant). Alluding to economic insecurity and its overlap with fears about national security due to the numerous mass shootings and the aftermath of 2015 terrorists' attacks in Paris and San Bernardino, California, the reporter exploits fear in the rhetoric of hope. Fear is not the cause of hope, but politicians piggyback on fear as a springboard toward such rhetoric: Hillary Clinton in a tweet offers to be the everyday champion that she thinks America needs; Barack Obama, in the state of the union address says "we should not fear the future but shape it." The President situates America as the exceptional country: "no country on Earth is better poised to seize the future than the United States" (Obama). ${ }^{15}$ Ironically, fear gives momentum to both the expressions of hope and the defensiveness of name-calling.

On an intellectual level, courage or bravery may be ethically neutral terms in that they can be applied in contexts both good or bad. ${ }^{16}$ I would argue, however, that the layman's uptake

\footnotetext{
${ }^{14}$ Source: http://www.bbc.com/news/world-us-canada-

${ }^{15}$ Source: https://www.whitehouse.gov/sotu

${ }^{16}$ It is interesting to note the similarities between the jacket covers of Miller's book, Courage and Walsh's book, Cowardice. Similarly, the cover art on both books depicts a black and white photograph of a lone target lined against
} 
of bravery as a virtue, not a vice, is the public's intended use of memoir bravery. Yet, as Walsh indicates, bravery as a virtue or an act is difficult to define without considering the concept of cowardice. In fact, Miller, who has written books on humiliation and disgust, set out to write a book on cowardice as a way to complete a trilogy of a "misanthropic series" (Miller ix). Instead, Miller opted for a book on courage, for which he admits "cowardice, however, must still play a major role" (ix). Burrowed in Miller's meditation of "the mystery of courage" (which is the title of his book) is one simple claim: "Courage is the stuff of good stories" (7). Miller specifies this essentialism with what he describes as a "hazard" claim: that courage (which he often uses interchangeably with bravery) "is the most frequent theme of all of world literature" (8). Why? Miller explains, "The true miracle is that courage makes for better stories than its corresponding vice" and even as a "gray virtue, equally serviceable for both good and bad causes...courage has a special cachet; people care about it desperately" (8-9). If Walsh is right-that calling someone a coward is the gravest insult-in contrast, is naming one brave the most honorable attribute? Miller claims that we care desperately about courage, that it "still ranks people morally," and furthermore, "the courageous are not only objects of admiration and awe; they are also objects of gratitude" (9). Arguably, the Audi slogan: "Bravery. It's what defines us." may indeed be the epitome of our collective self-image as a nation.

\section{A Mentality of Duty Revisited}

Essential to understanding cowardice and courage, as I have discussed so far, is a sense of duty. Walsh draws examples from the military in his explication of cowardice to argue that

a stone wall facing a firing squad. Miller's image is a jacket design by Tim Jones that incorporates a 1927 photograph of General Reuda Quijano, a Mexican general who took an active part in the revolution as a representation of courage. Ironically, Walsh's publishers use a similar image to depict cowardice-a still photo from Paths of Glory, a 1957 anti-war film. Also noteworthy is the pale, yellow color of Walsh's book - obviously, a choice that alludes a sense of cowardly (e.g., yellow-bellied coward). 
without duty cowardice has no specific context, and therefore is impossible to identify. Duty prescribes the necessary and sufficient contexts which makes possible the construction and meaning of cowardice and courage. Walsh poses this definition: "a coward is someone who, because of excessive fear, fails to do what he is supposed to do" (7-8). In contrast, courage for Walsh is going beyond the call of duty. It is the term "duty" that, as Walsh puts it, "specifies a standard against which we can judge alleged cowardice. The coward fails to do something he is supposed to do" (6). As a point of discussion, Walsh draws on the etymology of cowardly—as derived from cauda which is Latin for tail— to note that the "cowardly creature 'turns tail' to escape danger, or 'puts its tail between its legs' in fear and submission" (think of the cowardly lion from the Wizard of Oz) (5). Walsh eventually connects the idea of "turning tail" with "abandoning duty" and argues that duty plays a key role in detaching cowardice from courage. (6). Walsh's assertion that "cowardice must be understood within the context of a corresponding duty" (6) makes sense as a way to contextualize cowardice, but it also seems to point to duty as something fixed or spatially stationed. This line of argument sidesteps a view of duty as a constructed, contextually-dependent, and gendered concept, arguably, not unlike the very concepts of cowardice and courage.

Walsh reiterates Aristotle's ancient schemata: "the coward is both excessively fearful and deficient in confidence; the reckless person has the opposite problem (not enough fear, too much confidence); the courageous person observes the mean in situations that inspire fear or confidence" (5). As further evidence, Walsh points to the Medal of Honor and its stipulation: "This award should be given only to someone who has 'distinguished himself conspicuously by gallantry and intrepidity at the risk of his life above and beyond the call of duty" (7; see note 14). This sentiment is reminiscent of William Ian Miller's claim that "with courage comes embedded 
a theory of manhood" (13), which I discussed earlier, as intricate to the meaning of bravery.

Walsh's recipe for a coward is a lack of courage and an excess of fear. For Walsh, being a coward is being a failure; and yet, Walsh recognizes the rhetorical force of being called a coward as a motivator for performing one's duty.

Application to the Rhetoric of Memoir Bravery

Walsh's examination of cowardice suggests at least two new ways to interrogate the rhetoric of bravery: namely, bravery as viewed through the lens of cowardice, and bravery as evidenced by duty performed beyond expectation. The two are linked. First, complicating bravery with its counterpart, cowardice, leaves room to infer that the failure of duty not only represents cowardice, but also opens a space for potential shame and shaming. Second, situating duty as an attribute of bravery demands the interrogation of the meaning of duty. From a close reading of Walsh, we are left asking several questions germane to memoir analysis: Does the rhetoric of memoir bravery reinforce the cultural contempt we may feel about cowardice? To what extent might our contempt toward cowardice fuel a rhetoric of bravery, and in so doing, avert the potential of shame and shaming? Lastly, what might be at stake for the memoir as a genre implicated in the military and gendered legacy of the interconnected concepts, bravery and cowardice? Walsh's presentation of courage and cowardice as nearly interdependent concepts and the reading this offers to sister-concepts of bravery and shame ultimately point to a mentality of duty as a pending element. External from Walsh's militaristic context what forms might duty take? Is duty seen as fulfilling one's responsibility, obligation, civil obedience, citizenship, giving of oneself for the common good of others? Is duty something self-imposed such as confession or living an examined life? Might the brave memoir, on some level, engage these 
common duties? A more foundational question is where does the brave solder and the brave writer converge and diverge.

Perhaps most problematic in the alignment of the brave memoirist with the brave soldier is where cowardice might land. Situating the brave memoir as a response to a call-to-duty implies the potential of failure. This line of inquiry does not make sense nor does it add to the analysis of memoir bravery unless we consider the "memoir boom" of the nineties as an era which gained stamina because of the possible ways it may have subverted cowardice. Such a hypothetical claim does not serve as evidence for why the memoir boom endures. If some believe in the duty to tell our stories, and others believe in the duty of silence, what in the end counts as failure? Perceiving duty as telling or not telling may not benefit an analysis of memoir bravery; however, those memoirists who do tell their stories enter into a realm where certain expectations exist about how one should perform certain "duties" of the genre. In this light, duty as a site where potential bravery or shame is negotiated may offer an intriguing area of analysis in terms of memoir ethics. All things considered, bravery as a concept stands in stark contrast to cowardice which is a grave insult with wide-reaching rhetorical force. As one source of greatest shame (Walsh 51), cowardice echoes defeat as something close to annihilation (Walsh 50). As Walsh's analysis of courage and cowardice implies, a theory of shame is necessary when duty is in the room.

The most significant takeaway from Walsh useful for memoir analysis is the legacy of "bravery" as a gendered concept. Walsh's emphasis that courage stands in stark contrast to cowardice reveals the significance of the rhetorical force of bravery in spite of whether the claim can stand in all contexts. Walsh's defense of the role of duty as a contextual marker for cowardice and courage depicts a cultural backdrop that is important to acknowledge as it informs 
the rhetoric of memoir bravery. To what end does it inform is the question. Inherent in the "brave memoir" may indeed be a sense of gallant duty to speak up, to talk back to commonplace beliefs, or as Strayed urges, to "dive into the depths of ones' life," (Tardiff) and dare to share the discoveries as a dutifully mindful person. To add to this analysis of duty, theoretical considerations of shame offer a way to further explicate contextual influences on memoir bravery.

\section{Theoretical Considerations of Shame}

Facing Shame: an (Un)cover Story

In Autobiography of a Face memoirist Lucy Grealy chronicles her childhood experiences with jaw bone cancer, a disease that led to several bone grafts throughout her childhood beginning at the age of nine. Grealy describes the disfiguration of her face as grafts would give way, and the strategies she employed to cover her face because "she did not look like what other people felt a face should look like" (Gilmore, "Covering Pain" 104). Grealy's memoir details her experiences of social stigma and shame in a narrative that describes an autobiography of a face and its perceived "ugliness" in the world. The force of the narrative is not in the patronizing script of overcoming adversity nor is it just another cancer story. Grealy writes plainly: "It was the pain from that, from feeling ugly, that I always viewed as the great tragedy of my life. The fact that I had cancer seemed minor in comparison" (246). The narrative is at once the story of Grealy's face cancer, and a narrative with an 'about face' force as it turns the mirror away from Grealy's face and toward the faces of the crowd who collectively have participated in constructing a society of norms. The narrative both exposes and conceals an individual's story as part of a larger system of practices, values and cultural beliefs. 
Walter Benjamin acknowledges the "two faces" of shame in his analysis that shame is "an intimate human reaction, but at the same time it has social pretensions... Shame, then, is no more personal than the life and thought which govern it" (Benjamin 125; qtd. in Probyn 77). Benjamin's metaphor distinguishes the ambiguities of shame, and seemingly reconciles that shame can be two things at once. On one hand, shame is a self-conscious emotion that is deeply entrenched in how we think about ourselves (Probyn 45). On the other hand, shame originates as many theorists contend, as a "process not in the individual, but in the being-with-others" (Westermann 227; qtd. in Seidler 233). As Benjamin alludes, shame is an ornery creature at times showing up on the face and posture of an individual and other times emerging as a social reprimand.

Carl Schneider makes the point that "human beings are creatures who need some sort of covering" (Karen 16), gesturing to the etymology of shame as a protective shield with the potential to both expose and cover. The tension of this duality is portrayed in Grealy's memoir. Autobiography of a Face is a narrative that entices readers to want to see the face that is never revealed in visual form. In fact, because Grealy resisted being photographed, finding any images of Grealy is difficult. Readers are teased by a cover image on the memoir that depicts a black and white photograph of a young blond girl who is covering her face with a wind-blown cloth. The irony of a title that promises to reveal the life of a face and an image that conceals it is intentional — a marketing gesture that life writing scholar, Leigh Gilmore, suggests both depicts pain and profoundly distorts it. For Gilmore, the ethical tensions in the message portrayed by the camouflaged face on the cover and the resistance to hide through autobiographical revelations in the narrative serves mixed messages and may obstruct an ethical response. Gilmore suggests that "an ethical response 
requires readers to recognize the impact of pain on individual lives, the historical and social contexts that condition the author's experience, and our own position in relation to these contingencies" (106). Otherwise, the danger is the potential effect of further disciplining readers to associate hiding with shame and to make assumptions about why the face of the little girl is covered.

Gilmore's attention to ethical issues that emerge when memoirs are read in sequence with paratextual ${ }^{17}$ elements on the cover is an insight that compels further analysis of the meaning of the word "cover" and its link to shame. A useful definition is one suggested by Peter Mendelsund who conducted an autobiographical study of book cover designs. Mendelsund observes: "to cover can mean to travel a certain distance, to pay for, to camouflage, to describe or comment on, but it can also mean to comprehensively include" (Gilmore 105). The versatility of cover offers a lens for understanding shame as an affect more complex than expressed in its etymological roots, "to cover oneself" ("shame," OED). While many experiences of shame may make us want to disappear, shame is also "born of the desire to fit in" (Probyn 38). Shame is oriented both inwardly and outwardly, the “ultimate refraction between 'familiar' and 'alien' and as such it is a "token of human mortality" (Seidler 235). The cover image on Grealy's memoir, for example, is both congruent and incongruent with the narrative. At the risk of reading too much into the concept of coverage, its double-edge at once both contains and exposes. The photographic

\footnotetext{
${ }^{17}$ For Gilmore, the potential revision work of memoir is sometimes compromised by the paratextual elements. Noting bravery rhetoric as paratextual similar to the way Gilmore treats cover images is one way to approach the conceivable incongruences or congruencies of cover blurbs with the work of the narrative. Gilmore's argument provides a check point for my interrogation of the rhetoric of bravery that surrounds the contemporary memoir, starting with the blurbs often found on the covers of memoirs written by women.
} 
image on the cover of Grealy's memoir functions as a counternarrative in the form of a visual paratext in that it disrupts the cultural ideology of childhood innocence. ${ }^{18}$ This appeal to pathos may help sell the book, but it also makes noticeable that there is a dominant ideology at work regarding beliefs about childhood as a time of carefree innocence and play. The image of the child on the cover of Grealy's memoir potentially interpellates readers to assume that the story in the book is that of the child on the cover-which from one perspective positions the image, and by extension the girl, as the subject while at the same time objectifying the subject. ${ }^{19}$ Memoirists often situate their experiences in broader cultural discourses that attempt to silence, marginalize, and define them. In effect, what is subjective and objective is often ambiguous. In fact, as Gilmore notes, "The cover photograph, dated 1994 - the same year the memoir was published —is neither a childhood photo of Grealy nor a contemporary photo of the author" ("Covering Pain" 104). This is an ethical problem as Gilmore sees it because the cover image is inconsistent with the work of the narrative in that it "participates in re-covering a face that Grealy's narrative teaches us to look at full on" ("Covering Pain" 104). When readers read the painful childhood experiences of Grealy (e.g., her desire to hide her face with her hair; the way other children

\footnotetext{
${ }^{18}$ Perry Nodelman, author of The Hidden Adult, addresses the trope of the innocent child in his text on defining children's literature. Nodelman addresses the contradictions in children's literature regarding innocence in that many texts written for children (by adults) teach children how to be adults by becoming less egocentric, more rational, and less childlike while concurrently teaching "children how to be more childlike by providing them with images of childhood and secretly or not so secretly recommending that the child readers maintain or adopt them" (167). Nodelman explains that the ambivalence in children's literature works to "both make children more like adults and to keep them opposite to adults - both to move children past innocence and encourage them to keep on being innocent" (167). The same contradiction may be central to childhood memoirs written by adults. The cover image on Grealy's memoir, for instance, conveys a child as vulnerable and needing rescued by the more capable adult. The assumption at work is because children's literature and memoirs of childhood are both genres written by adults, the ambivalence Nodelman's identifies in children's literature is present in memoirs about childhood. By extension as Nodelman proclaims, "the conscious or unconscious wish to keep children innocent clearly suggests how central adult needs are" in both genres.

${ }^{19}$ See Contesting Childhood: Autobiography, Trauma, and Memory by Kate Douglas for in-depth analysis of cover images on autobiographies of childhood.
} 
would stare at her), shame becomes both subject and object. On one hand, the provocative image of a shamed child is the perfect preview for Grealy's story of feeling shamed as a child and for inviting potential readers to step into her story and see themselves as part of the problem. On the other hand, as Gilmore points out, the image may indeed reinforce the problematic ability of shame to keep hidden what writers aim to expose. Extending from a subjective state as the intimate and personal experiences of the memoirist, shame as it is packaged in the narrative has the ability to break out and assume agency: being in the presence of shame may potentially implicate others (at least the readers of Grealy's memoir) as participants in constructing a social system within which a girl with face cancer is shamed or feels ashamed. But to what end? This is where the rhetoric of bravery enters as almost another layer of counternarrative imposed on the already disturbing image of the child - a rhetorical move that shifts the focus away from the shamed child and those who shame to a brighter, more endearing assessment of the child. Grealy must be a brave little girl.

Is this rhetoric a cop-out? Does it function to avert shame by redirecting the focus to something positive? Does naming a writer or a story brave do a disservice to the potential cultural work of the memoir? In one sense, it is an "outward" rhetoric that acknowledges the heroism of another, the one who stands out from the crowd, who steps up and performs a duty for the sake of others or for self-improvement. It is also rhetoric that flattens as it leverages the heroic with a worldview that imposes certain expectations about bravery. If left unexamined, it is hollow rhetoric that potentially diminishes the vital cultural work that critiques of narratives of shame may provide. As representations of human experience, the 
memoir has the potential to seize shame, hold it up for analysis, and release it back into the world, revised.

Locating shame within the rhetoric of bravery is not an easy task. In theorizing shame, one potential trouble I face in this dissertation is the problem of locating shame at all, which is like a slippery octopus with moving tentacles. Shame has the ability to slither across lines and between cracks in all its linguistic forms and cultural meanings. If I speak of shame in memoir, am I suggesting that the literary text of the memoir is a story about shame, a story that is shameful, a story that overcomes shame, a story that shames? Am I locating shame as the subject or object of the writing, or both? To what end does shame as gendered or (re)contextualized matter for the writing? How might the versatility of shame, its ability to sidle up with gender or to shift across contexts, often as an undetected chameleon hidden away from danger awaiting vulnerable prey, obstruct or facilitate sound rhetorical analysis? What might shame render in conjunction with bravery and duty? These questions are complicated to answer without uncovering further theoretical aspects of shame.

(Un)masking Shame: Shame, Compared to What?

Psychologist Gershen Kaufman, who analyzes the development and internalization of shame, writes in Shame: The Power of Caring that "shame is an affect of inferiority" (17). This suggests that what counts as shame is measured by comparison-but compared to what? The Swiss psychoanalyst Leon Wurmser in The Mask of Shame, one of the first monographs devoted to the study of shame, treats shame bleakly as a judgment of the self in which "weakness, defectiveness and dirtiness appear to form a kind of fundamental triad that recurs" (42). This sentiment is echoed in many standard readings on shame in social 
science disciplines and in the field of affect psychology. Although shame has been primarily regarded as a negative human emotion historically in psychoanalytic theory, named by some as "the ugly emotion," giving it a reputation as something that should be overcome, shame was nearly nonexistent as a subject of psychological study before the last three decades.

Until the recent proliferation of literature on shame across disciplines, shame had been mostly left alone to anthropology in the academic sphere. Anthropologists ${ }^{20}$ problematized Ruth Benedict's theories of shame and guilt cultures as posited in the 1947 groundbreaking text, The Chrysanthemum and the Sword: Patterns of Japanese Culture, in which Benedict "emphasized the public dimension of shame, its dependence on external rather than internal (or internalized) sanctions, and the absence of confession and atonement in shame cultures" (Benedict 223; qtd. in Leys 123). In part, Benedict's contribution was revolutionary because of the distinction she made between shame and guilt, a contrastive linguistic notion that has yet to be put to rest. Historian Ruth Leys, in From Guilt to Shame traces the genealogy of guilt and shame to demonstrate shame's rise to prominence in the United States. Leys maintains that before the 1960s shame and guilt were rarely differentiated and she attributes the divergence to the onset of psychoanalytical theory and "the significance Freud attached to guilt (or anxiety) as the decisive psychic affect" (123), which according to Leys, reflected the subordination of shame to guilt in Benedict's work (123).

Shame theorists tend to rely on guilt as a contrastive clarification for shame, arguing that "feelings of shame involve a painful focus on the self-'I am a bad person'—whereas

\footnotetext{
${ }^{20}$ An anthropological text that applied Benedict's theories to the Greeks was E.R Dodds, The Greeks and the Irrational (1951). See also Ruth Levy's mentioning of Dodds' text as a brilliant work in her chapter on shame in From Guilt to Shame: Auschwitz and After (2009).
} 
feelings of guilt involve a focus on a specific behavior-'I did a bad thing."' (Tangney, Stuewig, \& Martinez, "Two Faces of Shame" 799). This is a significant distinction because of the suggestion of a hierarchy - that guilt is the better of the two because it has the potential to be alleviated or forgiven or charged or disciplined, primarily because of its association with a specific act. Shame, on the other hand, as Dan Zahavi writes in Self \& Other: Exploring Subjectivity, Empathy, and Shame "is an emotion that targets and involves the self in its totality. In shame, the self is affected by a global devaluation: it feels defective, objectionable, condemned" (208).

Much is owed to the influence of the women's movement and feminism as sources that fueled a revision of the psychoanalytical approach to guilt and shame as well as muddled the polarized thinking that plagued the field (Aron \& Star 51, 30). In their comprehensive text, A Psychotherapy for the People, Lewis Aron and Karen Star note that shame studies emerged as early as the 1970s and gained traction in the 1990s on the heels of Derrida's strategy of deconstruction (52). In fact, Aron and Star maintain that the "hierarchical split between guilt and shame was structured along gender lines" (52). The authors explain further:

Guilt was associated with masculinity and men, agents and subjects, while shame was attributed to femininity and women, who objectified themselves and were objectified by others. Those at the top of the hierarchy, whether gender, class, race, or intellectual ability, might feel guilty about being on top at the expense of others, but those below them on the hierarchy were ashamed. (52) 
The shame-guilt pendulum continues to swing and of particular significance is the influence of the renewed work on trauma linking disassociation to shame. Ruth Leys, writing about the influence of trauma studies on shame in the context of survivor's guilt, argues that the cultural meaning of shame has shifted and that there is a postwar "reevaluation [of shame] that casts shame as at least potentially positive, not a destructive emotion" (124). The title of Leys's book From Guilt to Shame announces this potential recasting. Leys offers two reasons for the reevaluation of shame as a potentially positive and productive emotion - causes that depend on shame's comparison to guilt, demonstrating the symbiosis of the terms that is sustained in shame theory. The following sentence illustrates the theoretical traction of modern shame as a "privileged operator:"

First, shame is now considered more productive than guilt because it is thought that, whereas the actual or fantasmatic acts that produce guilty feelings are in principle irreversible, or at least inexpungeable, feelings of shame concern aspects of selfhood that are imagined to be amenable to correction or change. (Leys 124)

Note that his perspective differs from a view that arguably situates shame as more difficult to remedy because of its elusive and often inaccessible point of entry that may indeed reach into past experiences with trauma or with being shamed. Guilt, on the other hand, as associated with an act or behavior or having done (or not done) something is locatable. Guilt takes eyes off the person and places them onto the deed, whereas shame involves a gaze of judgment on the person. For Leys to argue that shame is more productive reflects not only a cultural shift of guilt to shame, but also invokes theories of identity politics. Leys offers a second principal reason for shame coming out on top in modern theory: 
Second and more broadly, many theorists find shame a better affect than guilt to think with. Donald Nathanson believes you can do better self theory with shame than guilt; Bernard Williams believes you can do better moral theory with shame than with guilt; Eve Sedgwick believes that, using Tomkins' theories, you can do better queer theory with shame than with guilt; Giorgio Agamben believes you can do better survivor testimony theory with shame than with guilt; Elspeth Probyn thinks you can do better gender and culture studies with shame rather than guilt; psychiatrists and therapists think you can do better trauma theory with shame than with guilt; and so on. (124) Although not all agree with Leys's assessment of modern shame as experiencing something of a revival,${ }^{21}$ Leys's contribution adds to the initial observations of shame theorist Silvan Tomkins. Tomkins recognized the comparative forces of shame decades earlier as an affect that "at once suppresses and intensifies other affects with which it binds" (123).

Largely ignored at the time, American psychologist Silvan Tomkins in the 1960s diverged from analyzing shame in terms of negativity and its binary limits, and argued that shame is dependent on interest, which marks shame as neither positive nor negative in and of itself. Tomkins asserts that shame "operates only after interest or enjoyment has been activated" (Probyn xi, italics mine), suggesting that it is impossible to feel shame without first having an interest in or caring about something. The origin of shame is a source of contention among theorists. Many affect psychologists, including Tomkins, contend that shame emerges in the early stages of infancy, manifesting in response to a failure or break in the circuit of mirroring gazing that joins a child to

\footnotetext{
${ }^{21}$ See Vincent 631; also see Wurmser; Cohen.
} 
another. Tomkins associates the inhibition of the connective gaze with an encounter with the strange or unexpected-finding oneself looking at a stranger or being looked at by a stranger, for example, or experiencing one who is familiar as suddenly strange. (Burrus 1)

Tomkins's theories did not gain wide popularity in affect psychology until the publication of the 1995 text by Eve Sedgwick, Irving Alexander, and Adam Frank titled Shame and Its Sisters: A Silvan Tomkins Reader. The term 'interest' has since become a significant concept in shame theory: without 'interest' there is no shame.

Adhering to questions of origin, one of the most common debates that is raised in literature across disciplines is whether shame is a self-conscious emotion or a social emotion, a distinction elaborated by Michael Lewis in his book, Shame: The Exposed Self. Lewis presents, as a somewhat unproblematized notion, the idea that shame is an everyday phenomenon that also has danger zones bordering on the pathological. Lewis writes: "Shame is universal. To feel shame is normal...But too little or too much shame may produce unique difficulties... [such as] narcissistic disorders and violent behavior" (12). Lewis's text was considered groundbreaking at the time - which was at the height of postmodernism in the early nineties. Lewis, as a psychologist, was influenced by the tides of social constructionism that washed across academia, and particularly influenced social science-based theories of the self. Lewis writes a strong conclusion that speaks boldly of the influence of the culture of his times:

It is impossible to understand human nature without accepting the fact that a person is easiest to define within a context or a group of contexts. The only aspect of personhood independent of context is our biological rumbles, the 
noise of our bodies going about their functions of self-regulation and adaptation. There is little meaning to be found there. Humankind is social and our definitions reside in a social nexus. Alone we have nothing to understand nor any way to do so. (233-234)

Note the emphatic and overly general rhetoric (e.g., "impossible," "only," "nothing") that Lewis employs. Writing at the height of the narrative turn that transformed social constructionism in the postmodern Foucaultian era, Lewis's uptake of the subjective self and the objective self that is mirrored in particular socially experiential contexts dates back to earlier theorists who wrote about self-awareness. ${ }^{22}$ The self as subject and object are important lenses for shame theorists who discuss shame as a self-conscious and/or social emotion. That shame has to do with the self and/or others, exposure and/or covering, connection and/or separation are themes that "shamenicks"- a term coined by Helen Block Lewis in 1971 to refer to scholars who studied shame, herself included — continue to explore and debate.

Is shame on the rise in modernity? The answer varies. From its initial emergence in fields of anthropology and psychology as a concept associated with and differentiated from guilt, interest in shame has spread across disciplinary fields and into the popular realm. In the early nineties Robert Karen wrote an extensive piece for The Atlantic Monthly, a publication that suggested a larger public interest in theories of shame. Karen opens the lengthy overview acknowledging the prior neglect of shame in the field of psychology that in comparison to the boom of scholarly literature at that time, interest in shame had peaked for some as '“'the master emotion,' the unseen regulator of our entire affective life" (40).

\footnotetext{
${ }^{22}$ See Duval, Shelley, and Robert A. Wicklund. 1972. A Theory of Objective Self Awareness. New York: Academic Press.
} 
Donald Nathanson, who worked closely with Tomkins, has observed that the work of scholars such as Silvan Tomkins, Helen Block Lewis, and Leon Wurmser and others in various disciplines have "outed shame and declared it the issue of our era" (Burrus 1). Following shame's coming out of the closet is a long line of theorists, scholars, and a slew of writers, including memoirists who engage and interrogate the meaning and force of its presence in their lives.

In fact, physician and author Curt Thompson personifies shame in anthropomorphic terms in his book The Soul of Shame: Retelling the Stories We Believe About Ourselves. Thompson's attempt to humanize shame exacerbates the power of shame to reproduce itself contending that "we feel shame, and then we feel shame for feeling shame. It begets itself" (31). Burrus agrees that "shame is an emotion of which we frequently seem deeply ashamed"23 (1). Perhaps it is the shame of shame that has kept the subject of shame at bay for scholars - an idea that insinuates the opposite may also be true: that the current of shamelessness in flux in various popular and scholarly discourses may potentially mainstream or redirect shame, or as I am calling it in the context of the memoir "brave shame"- a phrase I explain in detail later on.

\section{Effacing Shame: The Evolution of Shamelessness}

The recent academic history of shame as described above surveys its evolution as an affect compared and paired with other affects. Shame has reached a place where theories of comparison are no longer sufficient. Scholars have acknowledged that shame permeates most every aspect of human life. It is not an affect that can be caged as the "ugly emotion"

\footnotetext{
${ }^{23}$ Burrus explores the "distinctive cultural legacy of shame conveyed by ancient Christian literatures of martyrdom and asceticism, christology and confession "(5). She analyzes the "emergence of the characteristic emphasis of the modern West on guilt as opposed to shame" (5), and explores the possibility that "Christianity innovates less by replacing shame with guilt than by embracing shame shamelessly" (7).
} 
nor it is a viable other side to guilt, interest, or pride, terms that have chauffeured shame to its current place in theory. Shame in today's modern/postmodern era is questioned with new lines of inquiry that pinpoint the complexities that exist within shame itself, its origins, its necessary and sufficient causes, and most importantly for my work, its potential rhetorical destabilization as exhibited in the ambiguities between shame and shamelessness.

To demonstrate the postmodern bent in shame theory, Burrus provides an insightful description of the ambivalence between shame and shamelessness as part and parcel of the same entity. She writes:

Analysis of shame blurs at many points with what might be framed as shamelessness. Shamelessness is always at least as ambivalent as shame itself, balanced between a refusal and a willful embracing of shame.

Whatever it is, it is not simply outside shame but is at once resistant to and continuous with it. (Burrus 3)

From one perspective, shamelessness distorts shame. If the meaning of shame points to inadequacy or to hiding a deficiency, what does the meaning of shamelessness point to? Not the opposite-shameless does not entirely mean to be without shame. More interesting is to think of shame and shamelessness, not in opposition, but in association with the idea of “cover" as I analyzed earlier in this chapter. Martha Nussbaum writes in Upheavals of Thought: The Intelligence of Emotions that "shame involves the realization that one is weak and inadequate in some way in which one expects oneself to be adequate. Its reflex is to hide from the eyes of those who will see one's deficiency, to cover it" (196). In contrast, Burrus argues for the positive and productive function of shame in society in a reversal spin that proposes shame's role in fostering courage. Burrus writes, "Cultivating courage, 
shamelessness engages the fear of being shamed and thus also exposes the coercive force of shaming: as eye meets eye, defying shame's inhibition, shame is itself shamed" (3). The shaming of shame is new postmodern space for analyzing shame.

Theorists have come to accept that at the heart of shame is a "desire for connection [and at] a basic level, it has to do with our longing for communication, touch, lines of entanglement, and reciprocity" (Probyn x). This notion of shame, I believe, also describes a cultural phenomenon in that it represents a collective desire for belonging - a feature central to a feminist model of care ethics that aligns the relational, proximal, and contextual as interdependent. As we have seen, shame arises in relation to the self as an awareness that includes being seen. The "in-relationness" of shame has driven the study of shame from its initial start in anthropological analysis of shame in relation to guilt. But without a point of locus, what is shame? Burrus attempts to get at the essence of shame with this image: "shame, as precarious hyper-reflexivity of the surface of the body [that] can turn one inside out - or outside in"24 (12). This metaphor of shame as something bendable or elastic offers a way of seeing shame as an entity in and of itself. Differing from an approach that situates shame on one side of other affects (e.g., shame/guilt, shame/pride, shame/interest, and so on), this interiority approach offers a way of seeing shame as comprising a taxonomy of itself - one that does not rely on a comparison to other affects. One consequence of approaching shame as an entity in comparison with its own parts is what then can become the points for analysis. The comparison of shame and shamelessness sheds light on the ambiguity of shame and the dependence on context for making any reasonable claims about the values or personal benefits of shame.

\footnotetext{
${ }^{24}$ Burrus association of shame and the body is a reference to an observation by Sedgwick and Frank-that "common parlance associates shame with the face, etymology links it with skin" (Burrus 2).
} 
Another problematic feature of a taxonomic approach to shame is the ways in which shame is gendered, not in relation to guilt or a hierarchy of affects, but within itself. In her text, Embodied Shame: Uncovering Female Shame in Contemporary Women's Writings, J. Brooks Bouson distinguishes "female" shame, which she designates as deriving from a culture of male norms. Bouson explains, "Conceived as defective or deficient from male norms and as potentially diseased, women have long been embodiments of shame in our culture, and, indeed the female socialization process can be viewed as a prolonged immersion in shame" (2). As a point of origin, Bouson references Susan Bordo's ${ }^{25}$ work and the "analysis of the gendered story of mind/body dualism that has long pervaded Western culture" as a source for the "cultural embeddedness of embodied shame - shame about the body and self - that persists in the experiences of many women" (Bouson 3). ${ }^{26}$

The idea of female shame as something that exists in connection with the body is historically linked to the overall inferiority of shame as an affect, and therefore, by default, is cast in a negative light. Recent theorists, such as Burrus, however, situate shame in a positive light to argue that without it the social world would be chaos. Complementary to Burrus's work in Saving Shame, Carl Schneider in his text Shame, Exposure, Privacy integrates ideas from anthropology, biology, philosophy, psychoanalysis, and theology to argue that a sense of shame is an important resource in terms of the preservation of privacy. For Schneider, a passage from the Talmud illustrates the constructive work of shame as an

\footnotetext{
${ }^{25}$ Bouson's objective is to examine what she calls "embodied shame" as represented in works of fiction and nonfiction and to analyze the cultural practices that "objectify and sexualize...the female body" (3). In so doing, Bouson incorporates Bordo's observation that "female bodies are disciplined by the culture, becoming what [Michel] Foucault calls the 'docile body,' regulated by the norms of cultural life" (Unbearable Weight 165; Bouson 3). I revisit the distinction of "female shame" as a cultural construct in Chapter 4 as part of my analysis of Laura Gray-Rosendale's memoir about rape, College Girl.

${ }^{26}$ Feminist philosopher Sandra Bartky describes shame as women's "pervasive affective attunement to the social environment" (qtd. in Bouson 2).
} 
organizing principle guarding integrity: “A sense of shame is a lovely sign in a man.

Whoever has a sense of shame will not sin so quickly; but whoever has no sense of shame in his visage, his father surely never stood on Mount Sinai” (199). According to Schneider's conception, shame has work to do that is not to pile shame on shame, but to enable men to separate out shameful behavior from righteous behavior. Interestingly, Schneider's positive spin on shame points to the function of shame as a constituent of self-control and rationality, aspects of shame that may indeed form the basis for the "male norm" as Bouson describes.

The socialization process includes the gendering of shame which is an important aspect to explore particularly in relation to a masculine-normed sense of duty. Bouson recognizes that stories that confront 'female shame' as associated with the body, such as Grealy's memoir, open new spaces for redirecting shame. As illustrated earlier in this chapter, Grealy's Autobiography of a Face is a narrative that confronts shame about the body and taps into what Bouson calls "the cultural shaming of women" (2). Grealy's memoir serves as an illustration of one way in which personal shame interacts with larger cultural narratives of shame. Shame theorist Gershen Kaufman observes that shame is "first of all an individual phenomenon experienced in some form and to some degree by every person" (191), but at the same time, shame is "equally a family phenomenon and a cultural phenomenon [that is] reproduced within families, and each culture has its own distinct sources as well as targets of shame" (191). Bouson argues that texts that recognize and resist shame, or for her interests, "the body politics that pressure women to conform: to become socialized, and thereby shamed, bodies," do "vital cultural work by providing a powerful critique of the cultural narratives that shame women" (15). In other words, women's stories 
about shame may function as counternarratives in as much as they disrupt cultural narratives that shame women. Bouson sums up what many shame theorists agree:

[that] the way out of the shame impasse...is the recognition of shame and the narration of the shame story. But because there is shame about shame and because we tend to look away from the other's shame, attempting to avoid shame contagion, the telling of such stories is risky business. But it is also necessary business. (14)

Bouson's perspective on the work of authors, including Grealy, who examine shame is that they are "clearly bent on discomforting us [as] these authors ${ }^{27}$ expose—uncover-the shame that persists in the lives of many women in our postmodern, appearance-driven age" (14).

Surveying literature that theorizes shame in relation to shamelessness and gendered aspects is a trail that leads me back to arguing for the necessity of approaching shame with check points in place, and in ways that differ from situating shame as part of binary constructs or as an affect in and of itself. Shame carries too many linguistic variants for it to be useful as a singular concept. Shame as an entity with two faces, one intimately inscribed and one social prescribed, presents limitations for analysis in the context of memoir because of the annexation of shame to an individual or an individual within a social situation or experience. It is nearly impossible to know whether shame is something a writer or a reader feels. I offer, instead, an investigative approach to shame that lifts the burden of identifying specific location in terms of an individual (e.g., who is shamed or who is shaming who or who feels (a)shamed). I propose that by triangulating shame with bravery and duty provides

\footnotetext{
${ }^{27}$ Some of the authors whose work Bouson analyzes include the following: Alice Munro's Lives of Girls and Women, Dorothy Allison's Bastard Out of Carolina, Toni Morrison's The Bluest Eyes, Naomi Wolf's Promiscuities, Judith Moore's Fat Girl: A True Story, Jenefer Shute's Life-Size, Doris Lessing's The Summer Before the Dark, Nancy Mairs's Plaintext, Carnal Acts, and Waist-High in the World, among others.
} 
a heuristic for logically including shame as a key element in theorizing memoir bravery, and unburdens shame from the impositions of singular or comparative theories. Repeatedly, what emerges from an interdisciplinary synthesis of shame is that shame is not one thing. To emphasize further the elasticity of shame, in the following section, I propose a triangular model that stretches shame into a realm that benefits cultural and rhetorical analysis of memoir bravery.

Shame, Duty, and Bravery in Triangulation

My rationale for a triangular model is due largely to the slippery problem of locating shame. Examining shame in relation to bravery and duty enables a technique for surveying shame as part of a network rather than as a singular affect attached to a particular person or situation. This approach also loosens shame from its habitual binary attachments as well. The navigation of shame in a triangular model is based on its proximity to other fixed points. The advantage of this model is its ability to harness shame and at the same time, allow concepts to shift across contexts, affording multiple perspectives on the affiliations between concepts.

In imagining bravery, shame, and duty in triangulation, I position all three as nodes on an inverted triangle (see fig. 1). Bravery is located in the upper right corner across from and level with shame to represent the necessary linkage between the two as conjoined through the duality of courage and cowardice as I examined previously. As Walsh indicates, bravery as a virtue or an act of duty is difficult to theorize without considering the concept of cowardice and its consequential potential of shame. 


\section{Figure 1: Brave, Shame, Duty: Triangular Model}

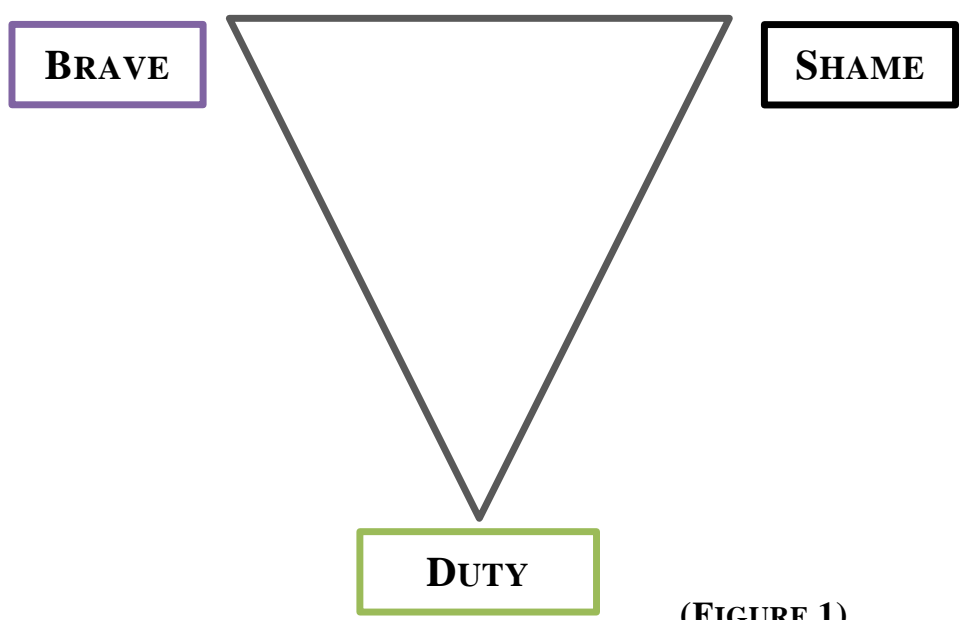

(FIGURE 1)

Duty is located at the bottom of the inversion. Positioning duty at this angle represents the potential for duty to be enacted in either direction: as duty performed, and therefore, potentially depicting bravery, or as duty failed, and subsequently, surfacing potential shame or the fear of shame. In this model, shame has the potential to deter the coupling of bravery and duty.

This model invokes questions of essence and consequence. For instance, are narratives that bear the potential to (re)examine shame compromised by the rhetoric of bravery? Bravery and shame cannot easily co-exist without explanation. Recall the earlier debate over whether terrorists can be called brave. Indeed, insulting terrorists as cowards may do little to evoke shame in the terrorists. Rather, the work of this language is rhetorical and perhaps has more to do with those casting the insult and those they might influence than with those for whom it is intended. Aside from calling terrorists cowards, in other contexts, such as in the military, the insult bears tremendous potential pain and anguish for the target of the insult. 
Moving around the triangle, does the rhetoric of bravery work the same way but in reverse? Might Walsh's assertion that cowardice is the gravest insult leave room for arguing that courage is the most honorable virtue? That mystery of courage William Ian Miller explores demonstrates that we care deeply about courage and it "still ranks people morally" as Miller argues: "the courageous are not only objects of admiration and awe; they are also objects of gratitude" (9). It is premature and perhaps impulsive, I would argue, to claim that bravery rhetoric affects only the rhetors, or those who employ the virtue. Bravery is language that represents deeper and ethical values than its surface effects of self and cultural identity maintenance.

The label of bravery is reserved for the one who stands out from the crowd-and, in my view, this is where duty enters. As I have discussed, what gets recognized as brave has to do with engaging an act that is beyond expectation, answering a call of duty, or performing beyond the call of duty. For women memoirists who are named brave writers, I claim that their bravery is infested with a historical and masculine sense of duty that has been appropriated and gendered and converted to a duty-to-tell. To what end, though? On one hand, a historically constructed masculine, militaristic sense of duty-to-serve assumes also that a fight for rights, freedom, and justice is the goal. Against this "male norm" for duty, where might a feminine caring posture of the duty-to-nurture fit? Are women writers brave because they can (and do) do both within the contexts and genres of the contemporary memoir?

The triangulation of bravery, shame, and duty reveals a fluidity among concepts which offers a viable model for theorizing the work of integrating the concepts and of contextualizing a rhetoric of bravery applicable to women memoirists. This model stands in 
contrast to theories that employ only binary structures as ways to examine concepts (e.g., shame in contrast to other singular concepts, such as shame/guilt, shame/pride, shame/interest, and so on; and, bravery as aligned with courage and in contrast to cowardice; and duty as either duty performed or duty failed.) While built on prior theories that employ binary constructs, a triangular model provides a constant paradigm that is relevant and accessible to diverse contexts.

Embedded in this model are sister-words associated with heroic discourse. Metaphorically speaking, the memoir is decorated with a medal of linguistic honor for bravery because of the perceived traits of authenticity, vulnerability, risk-taking for the sake of self and others, and at times, shamelessness. Perhaps one reason for so many brave memoirs as well discourses of bravery in general today is because as a nation we are still in post-9/11 recovery mode - a time when our wounded nation is determined to counter loss with a rhetoric of bravery that names everyone from firefighters on as heroes whether they performed a brave act or survived a feat that inducts them into victimhood or constrains them by circumstance. To what end might the rhetoric of bravery as enacted across discourses redirect attention away from the losses and toward the heroic feats of those who gave their best? Or, we might say that it reinvents what has been lost in heroic terms. Something significant is brewing in today's U.S. culture as evident in the practices of accumulation and consumption of bravery.

Through a triangular model, we can theorize further reasons for the production, circulation, and consumption of brave memoirs. In the model, bravery intersects with shame in ways that evoke notions of loss. In short, shame is denounced through the accumulation of brave stories. The model allows a fresh approach to a central question that many life 
writing theorists ask: what narratives can we tell and hear and what narratives can we not tell or hear? The memoir as a genre is inclusive in that it conserves memory; it is also by default exclusive, and therefore, marks loss. As an element in the model, shame's ambiguous presence sheds light on loss. As an affect, shame can function as both a desire to hide and a desire to fit, to conceal and to expose. We can theorize that loss and the potential of loss emerge as central operating concerns in this model. This model offers a new way to evaluate the rhetorical force of the memoir genre as comprised of stories that are both inclusive and exclusive, and thus, that exemplify a strategy for keeping shame at bay via the reinforcing work of bravery. Bravery rhetoric thus takes on a eulogizing function which at once acknowledges a virtue (bravery) that also marks loss.

The entrance of loss into the model (see fig. 2) leads us back to the criteria that William Ian Miller and Chris Walsh both employ for bravery: cowardice. Without a comparison to cowardice we would not understand bravery. Yet, Miller insightfully observes that on the battlefield, both the brave and the cowards die. Miller challenges the "tradition of eulogizing fallen soldiers" (75), exposing that "we expand the fund of courage to its widest extent...in eulogies of the dead" (75), and reminding us that the "cowardly are wounded as readily as the brave" (76). Miller nudges, "we tolerate a sincere belief in...courage after the fact." (76). On one hand, bravery rhetoric may be a language of lament purposed to archive what we want to remember as brave; on the other hand, it is rhetoric that "governs when and where there is still courageous work to be done" (Miller 76). Either way, as a memory marker or as a governing hand, loss serves as a constituent of bravery and functions as a productive force: it harvests memory and it yields a space for imitating and reproducing what is considered brave. Thus, brave memoirs beget brave memoirs. 
Figure 2: Triangular Model: Loss at Center

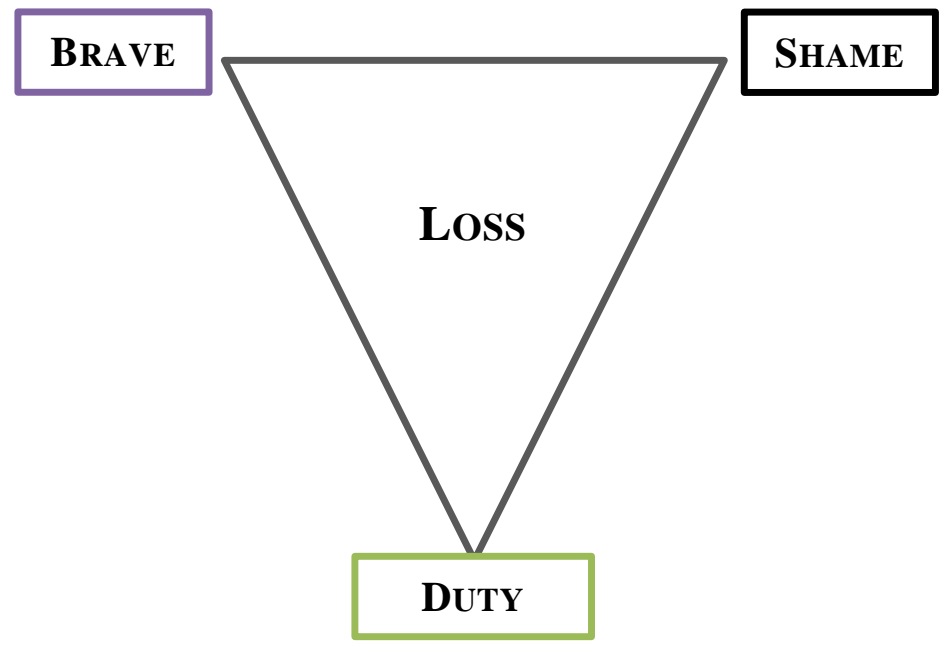

(FIGURE 2)

I revisit Miller's work in the closing of this chapter to offer a slight revision of the triangulation of bravery, shame, and duty as concepts tied together by a cultural longing to harvest losses. Miller probes deeper the potential effects of this blind eye toward loss. In writing about the homage we pay our soldiers who died in battle, Miller admits that a double-sided puzzle exists in the military context: because the honor of bravery and courageous dispositions are allotted after the fact, they are done so, partly, because there are no further demands for courage (76). Consequently, Miller seems to acknowledge the problematic belief in universal honor for all dead soldiers (the brave and the cowardly), and theorizes that we may compensate for this tolerance and seemingly infinite fund of courage by unleashing on those who remain alive and in battle - those who are left potentially imitating the bravery that has come before. Miller puts it this way: "we exhort the courageous...but we are also equally likely to exhort them by provisionally cursing them as wimps and weenies, cowards and chickens, as by calling them heroes" (76). Miller's theory of limited courage may offer insight into why the rhetoric of 
memoir bravery even exists, and by extension, why we have so many brave memoirs: loss is on some level tied to bravery and its intensity may affect the force of rhetoric as a means for constructing any archive of memory — whether that of a dead soldier or that of a memoirist.

\section{Conclusion: Braving Shame}

In this chapter I have theorized the concepts of bravery, shame, and duty separately and argued for their convergence in a triangular model. This model accounts for the interdependence of bravery, shame, and duty and theorizes "loss" as an intersection or as a potential space for analysis of memoir bravery. As a constitutive element in discourses that name the brave and the coward, loss manifests as an anticipation or motivating force which operates in a liminal space hovering between the three nodes on the triangle (see fig. 3).

Figure 3: Triangular Model for Rhetorical Analysis: Bravery, Shame, Duty

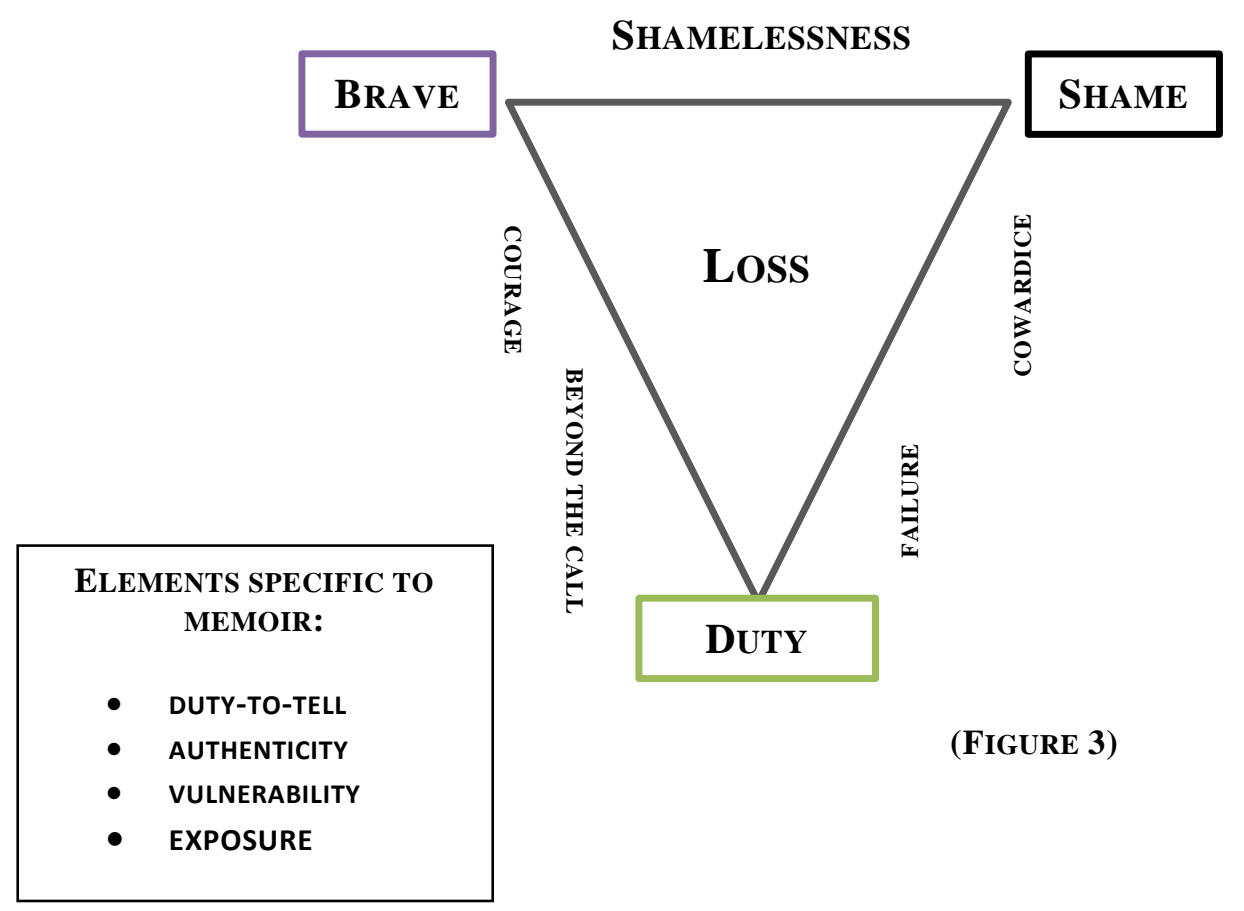


As theorized in the model, the presence of loss takes an encrypted form in the rhetoric of bravery; in other words, because loss implies incompleteness or imperfection and thus invokes shame as a desire for concealment, and because that which we consider shameful is something we wish to hide, or hide from, the writer who confronts shame qualifies as brave, almost by default.

As I have previously discussed, the cultural belief in the value and virtue of bravery is a baseline for understanding why it is generously employed for assessing autobiographical narratives. In general, bravery marks a virtue that is perceived by others as it identifies actions of some kind of self-sacrifice that a person has made. Yet, the very naming of the brave automatically includes what counts as bravery, and by default, excludes what may be perceived as cowardice. In effect, bravery rhetoric legitimizes and governs its replication. In the model, shame as a nodal component leverages bravery as a productive force in that shame functions to further reinforce what Probyn argues is the desire for connection and recognition (Probyn x). Duty enters the picture as both a prerequisite for bravery and a deterrent from potential shame. In relation to the memoir, the significance of acknowledging loss as constituting bravery provides a way of perceiving the brave memoir as a cultural product that in its bravery conceals and exposes the potential of shame. For example, Grealy is a "brave writer" because she outed the cultural narrative that shames the disfigured child, rerouting shame so that it boomerangs around to those who participate in a society that constructs and permits this narrative, Grealy included. The rhetoric of bravery is tailored with duty and shame at odds.

Braving Shame as my dissertation title and in the title of this chapter intentionally suggests a double meaning regarding the potential cultural work of the memoir. Does the memoir brave shame: does it offer a space where stories with a history of shame may be recast into acts 
of bravery through the telling of them? As a second nuance of the phrase, does the memoir offer a space where stories that may be shamed or silenced can be told and endure? The second idea bears the image of "braving the storm," so to speak. The accumulation of brave stories, in effect, characterizes a cultural practice for keeping shame at bay by reinforcing a collective and cultural longing for a certain kind of story: the brave one. It also bleaches shame of its content, so that potential shame is cast as an opportunity. 


\title{
CHAPTER III
}

\section{MEMOIR BRAVERY: A RHETORICAL ANALYSIS OF PARENTHETICAL}

\author{
CONSTRUCTIONS IN MARY KARR'S THE LIARS' CLUB
}

\begin{abstract}
C.S. Lewis was the first person to make me want to be a writer. He made me aware of the writer, that there was someone standing behind the words, that there was someone telling the story. I fell in love with the way he used parentheses-the auctorial asides that were both wise and chatty. -Neil Gaiman

Memoir is not an act of history but an act of memory, which is innately corrupt. -Mary Karr
\end{abstract}

In this chapter, I rhetorically analyze Mary Karr's childhood memoir, The Liars' Club, as a representation of a brave memoir. Specifically, my aim is to extend the theory work of the previous chapters toward a rhetorical analysis of Karr's memoir as a way to examine whether cultural concepts associated with bravery appear as textual representations, and if so, in what forms. Karr's childhood memoir works well as a textual subject for close analysis because of the observable and repeated pattern of parenthetical constructions. ${ }^{28}$ In my analysis, I argue that Karr's parenthetical constructions perform rhetorically in the text as a specific location of the autobiographical 'I' - a representation of authorial ethos in which readers may perceive an authentic narrator. As a form of the autobiographical 'I,' Karr's parenthetical constructions offer asides to the reader about the truth of the story. Sidonie Smith and Julia Watson theorize the autobiographical 'I' as consisting of multiple voices manifested as the self-narrator. The narrator's voice in Karr's memoir that is separated from the main text set off by parenthetical constructions suggests a textual location of the autobiographical 'I' that, I argue, performs

\footnotetext{
${ }^{28}$ In the scope of this study I limit "parentheticals" or "parenthetical constructions" to literal lines of text barred by parenthesis. It is beyond the scope of this project to identify or consider the function of other linguistic units that are commonly included in taxonomies of parentheticals, such as adverbials, appositives, or parenthetical matter marked by comas or dashes.
} 
rhetorical work differently from other voices of the autobiographical 'I' represented in the main text. Through the use of parenthetical constructions, Karr employs a rhetorical strategy that may strengthen her readers' perception of the narrator as an authentic and truthful storyteller, even at times when she admits her childhood memories are vague or invented.

Building on the theoretical work of the previous chapter, specifically, in this chapter, I make a case that the contemporary phenomenon of bravery rhetoric is also a discourse that embodies a belief in the value of authenticity as constructed in modernity. ${ }^{29}$ As one cultural element of memoir bravery, I elaborate the concept of authenticity as a central value of the contemporary era in which the memoir boom of the nineties occurs. The data from my analysis work in this chapter is significant for my dissertation as it suggests that embedded in Karr's writing is evidence of a culturally shared belief between readers and writer about the value and perception of the authentic. Although the scope of the analysis work in this chapter is limited to Karr's use of parentheses as an observable textual feature, the strategic deployment of this feature bears both rhetorical significance within the memoir and theoretical significance in identifying cultural elements of memoir bravery. Through rhetorical analysis of Karr's memoir, I theorize that the contemporary memoir reflects, endures, and further secures cultural beliefs about the authentic, and I further deliberate what is at stake for the memoir genre at a time when authenticity is valued and marketed as a modern commodity.

\footnotetext{
${ }^{29}$ Modernity is a term that Rebecca Saunders analyzes as "vexed as the traumatic loss commonly associated with it" - a term that "designates neither a homogenous or clearly defined time period nor a stable object of knowledge" (1). In the first chapter of her book, Lamentation and Modernity in Literature, Philosophy, and Culture, Saunders explicates the "culture of modernity" (1). In so doing, she examines modernity characteristically as it has been theorized across disciplines as a way to demonstrate that modernity is an unstable construct. Plenty of time prior to the onset of the memoir boom of the nineties the modern era was kneaded with a sense of longing that loss and the fear of loss yields. A thorough treatment of loss in modernity is outside the scope of this dissertation, but I would like to note that Saunders' portrayal of loss and lamentation influences the way I theorize the eulogizing aspect of bravery and the inscription of loss and longing as manifested in perceived authenticity as a cultural value and the hallmark of the contemporary memoir.
} 


\section{Launching an Analysis of Authenticity in The Liars' Club}

Mary Karr wrote in an essay for a 2007 edition of Slate, an issue dedicated to memoir, that part of the process of writing a memoir is making the rhetorical decisions about what to leave in and what to leave out. Karr admits, "As soon as you start to leave things out—-to shape a tale-you're maneuvering the actual." Karr concludes the short piece in Slate with a reference to her childhood memoir, aptly titled The Liars' Club, acknowledging that she is certain she has "forgotten, blurred, or misremembered a zillion events, characters, and details large and small." Karr recognizes the inclusive and exclusive aspects of memoir authorship and owns up to the fallibility of her own memory. In fact, Karr admits that the Liars' Club stories (the stories told among her father's drinking buddies, and thus, the inspiration for the pun of the title of the book) are "sheer fiction." Karr explains that "since they deal with frozen farts and the like, I figured their historical accuracy would never be under dispute" (Slate). The title of the memoir renders the possibility that the memoir contains other inaccuracies as she relies on her memories of childhood, which she acknowledges, easily become embellished, twisted, or appropriated by the demands of various rhetorical situations. How does Karr establish the kind of authorial ethos and credibility as a writer of a nonfictional memoir, which by default of the genre promises to deliver a factual narrative, claims to be referential and truthful, and is duty-bound by a genre dependent on authors telling the truth?

In The Liars' Club Karr writes about her childhood memories of a dysfunctional upbringing in the fictional east Texas town of Leechfield and later in a town in Colorado. The narrator seamlessly moves from the observant voice of the child to the reflective voice of the adult, at times, within the same breath. It would be nearly impossible to identify, let alone analyze, the shifting 'I' in Karr's writing with any precision because of the poetic style in which 
she writes. Identifying parentheses as a textual feature that marks one kind of autobiographical 'I' provides a way of analyzing the effect of one specific linguistic feature and its capacity to offer a reading experience in which the narrator's voice may have a feel of closeness and stability.

In my analysis, I identify Karr's parenthetical constructions as textual markers of the presence of the autobiographical 'I' which mark instances in the text where Mary Karr the real historical author seems to step into the narrative and offer clarification. The double-voicedness of Karr's self-talk may convey a feeling to readers that she is telling them the story instead of writing it in a memoir. The very presence of parenthetical constructions can undermine the authenticity and straightforwardness of the main text, but a rhetorical analysis of Karr's usages reveals a paratextual quality of the language within the parentheses. As linguistic units, parenthesis functions to distinguish one kind of text from another, emitting a kind of paratextual feel to the language within.

As I introduced in Chapter 1, according to the French literary critic Gérard Genette, ${ }^{30}$ paratextual features structure a text's "relation to the public" (15) such as portrayed in the jacket blurbs, the title, forwards or other prefatory material, illustrations, and even the writer's own name (Genette 1). In his 1997 book, titled Seuils in French (meaning "thresholds") and translated in English as Paratexts, Genette emphasizes the "liminal or threshold qualities of the conventions that mediate among author, reader, book, and publisher" (qtd. in Keen, Narrative 129). Genette's commentary focuses on "the elaborate set of conventions publishers employ" (qtd. in Keen, Narrative 129). Specifically, Genette does not distinguish parentheses as a form

\footnotetext{
${ }^{30}$ In chapter one, I introduced Genette's work as a way to categorize the references to bravery and courage that are often written on the jackets or in the front matter of memoirs to be examples of paratexts, which was my purpose for initially referencing Genette. In this chapter, I appropriate Genette's conceptualization of paratext to the parenthetical constructions in Karr's memoir.
} 
of paratext; nevertheless, his distinctive observation regarding the in-between status of certain kinds of paratextual features provides a useful category for classifying the pair of signs () used to indicate a separate grouping of text.

In her text, Narrative Form, Susanne Keen summarizes Genette's observations of paratexts:

Paratexts are of two kinds, the peritexts, which appear within or on the book itself, and the epitexts, which exist entirely outside the physical book... The publisher's peritexts include the cover, the title page, the publisher's information, the blurb, and the typesetting. The author's peritexts include the author's name (including anonymous and pseudonymous names); the title and intertitles of sub-units such as volumes, chapters, or running titles; the printed dedications and written inscriptions; the epigraphs, prefaces, notes. (129)

Keen's summary of the author's peritexts suggests a strong rhetorical intention on the part of the author to shape the text. According to Keen, each of Genette's categories, the peritexts and the epitexts, "plays a role in announcing the intentions of the text, the status of the author or publisher, and the generic expectations that the reader should activate to be prepared for the reading experience" (Narrative 129). Situating the recurring pattern of parentheses as a kind of peritext suggests an intentional function on the part of the author to lead the reader toward a certain reading experience. In this sense, the parenthetical constructions in Karr's memoir, I argue, function rhetorically similar to the role of peritexts as Genette critiques.

In a study of paratextual elements in autobiographies of musicians, Matthew Sutton draws heavily on Genette's work to conclude that paratextual elements "supplement the dialogue 
between the subjects and readers with a second discourse parallel to the text proper [and in effect] often interpellate readers directly, instructing them on how to contextualize and read the text that follows" (Sutton 208). The self-referencing that occurs within Karr's parentheses positions the narrator in a seemingly liminal space between the name on the cover and the main text of the narrative. The seeming presence of the author in the form of an autobiographical 'I' as positioned in this in-between space allows the narrator to control, to some degree, the delivery of the story, which in turn, may affect the way the story is received and believed. In short, the main rhetorical function, I assert, of the parenthetical constructions is to advance ethos - the credibility of the author as trustworthy — and to remind the reader to focus on her stance as an authentic and trustworthy narrator who will not dupe them even when she herself struggles with remembering particular details. In fact, as the memoir's title indicates, she often will tell readers when she thinks her memories are insufficient or inadequate for the job.

For memoir writers to find textual ways to establish themselves as a narrator who is potentially perceived by readers as authentic, honest, and believable is tricky not only because of the problem of memory but also the widespread suspicion of readers that has been spawned by cases of fraudulent memoirists which undermine the memoir as a non-fiction genre. I realize that Karr's use of parenthetical constructions could as well undermine her perceived authenticity in cases where readers feel she is not including all the parts of the story in the main text. The presence of a parenthetical aside indicates a felt need for further explanation of something that is implied but perhaps hidden in the nonparenthetical — an underlayer of meaning that accords with the double-voicedness of all of our self-talk. We have a self we express, and a self that we experience as more or different even while we are openly expressing ourselves. The use of parentheses in writing exposes this double discourse, seeming at the same time defensive (please 
understand me: I am more than what this utterance expresses. In other words, they are attempts to control the reader's uptake of my meaning), revelatory (in my parentheses, I am trying to make sure you understand that there is always something missing in the main text), hiding (the very use of parenthetical statements rather than putting it all out there in the main text suggests that I want what's in them to stay hidden; otherwise I would have put it in the main text), and superfluous (from the perspective of grammar, you should be able to remove the parenthetical aside and still have a sense-making document). ${ }^{31}$

Whether Karr's uses of parenthetical constructions help establish and maintain authenticity may depend on an analysis of what is happening with the autobiographical 'I' within those constructions. However, the enclosed language is not significantly different from the rest of the text in any way that I can identify. In some cases, as I analyze later in this chapter, Karr sets apart full anecdotes that could be part of the main text but she has set them apart as sidestories. We cannot know the author's intentions, but as I demonstrate in my analysis, the pattern of ongoing use of parentheses suggests an intentional rhetorical move even though as an exhibition of self-talk the language within the parentheses may convey diverse utterances. In my interpretation, I make an argument about the rhetorical meaning of the parentheses themselves and elaborate their function within the text as separate linguistic entities from the main text, and contend that they function to establish a perception of an authentic narrator offered to readers.

This elaboration first requires a survey of disciplinary perspectives on authenticity that theorize it as a concept with cultural authority and meaning, and an explication of the autobiographical 'I' as theorized in life writing scholarship before delving into the rhetorical analysis of Karr's memoir. In the following section, I examine the discourse of authenticity as (a)

\footnotetext{
${ }^{31}$ I would like to give credit for this list of clarifications to Dr. Karen Coats.
} 
central to conversations regarding life writing and ethics, (b) as a concept with philosophical underpinnings, and (c) as a desired modern commodity. Most concepts, authenticity included, can be approached through what they are cast as binarily opposed to. An interdisciplinary and integrative approach to authenticity reveals that concepts other than the binary of inauthenticity are often employed when theorizing authenticity. This finding, as I elaborate in the following section, bears implications for understanding the ways in which loss is conceptualized in authenticity which, in turn, provide insights into the rhetoric of memoir bravery.

\section{Authenticity: An Interdisciplinary Perspective}

\section{Authenticity in Life Writing}

The autobiographer writes with a handshake - an agreement to tell the truth, or what Philip Lejeune calls the autobiographical $\operatorname{pact}^{32}$ - a tacit negotiated relationship of author, reader and publisher that positions readers to expect the narrator and the author to be one and the same. Lejeune explains that the autobiographical pact is established in the "initial section of the text where the narrator enters into a contract vis-à-vis the reader by acting as if he were the author, in such a way that the reader has no doubt that the 'I' refers to the name shown on the cover, even though the name is not repeated in the text" (17). In this sense, the autobiographical narrative as a contractual genre upholds an implicit custody of truth-telling. A fundamental question that life writing scholars Sidonie Smith and Julia Watson acknowledge exposes the gray area between autobiography and biography or non-fiction and fiction. They ask: "what is the truth status of autobiographical disclosure? How do we know whether the narrator is telling the truth or lying?" (15). Smith and Watson suggest that because "autobiographical truth resides in the

\footnotetext{
${ }^{32}$ Lejeune's concept has become a contested concept in some life writing scholarship. Smith and Watson, for example, depict the concept as "fractured" (Reading Autobiography 15); Lauren Berlant argues that a contractual relationship between reader and writer is an impossible feat. Even so, such contestation does not disqualify the use of the autobiographical pact as a framing concept in this chapter.
} 
intersubjective exchange between narrator and reader, we might best approach life narrative, then, as a moving target, a set of shifting self-referential practices that, in engaging the past, reflect on identity in the present" (Autobiography 1). Consequently, the effective memoirist often writes with one eye on the accuracy of the storytelling, and the other on the potential of the story being contested.

The reason for caution is largely due to the media's coverage of fraudulent memoirists who are spun as inauthentic and untrustworthy. This has ethical consequences in that it marks what is perceived as authentic as a valued and expected trait of memoir writers. Thus, the perceived authentic narrator becomes understood as trustworthy. This practice is not unique to life writing. As a regulating function the perception of authenticity operates in multiple fields, including music, art, education, tourism, and history to name a few. In the field of life writing as in other fields, the value placed on authenticity is intensified by its reversal, the inauthentic - or the deceitful, the copycat, the counterfeit, the fraud, the hoax. The very concept, in its duality, is populated with the real, the original, or the genuine, terms that have become associated with the complexities of what is true. Consequently, what is true inherently connotes the possibility of what is false as the two terms have been conditioned by their juxtaposition to one another. Smith and Watson's metaphor of the moving target of memory may accentuate the obscurity of distinguishing what is true and what is not, but one aspect is clear: when the invisible line between truth and lies is crossed, it often becomes a consequential media frenzy for the memoirist who crossed that line (regardless of how or where it may have been drawn). Perceived authenticity as a value has ethical ramifications in life writing which may be influenced by a history of philosophical approaches to the meaning of authenticity as a concept. 


\section{Authenticity in Philosophy}

As a concept, authenticity has been shaped and reshaped since its emergence as a philosophical interest beginning with the early Romantics (Ferrara 24) ${ }^{33}$. In Modernity and Authenticity Alessandro Ferrera maps the evolution of authenticity as a philosophical concept initiated by the early Romantics and the Enlightenment ideal of autonomy, which "set the groundwork for the emergence of a subject-centered discourse of authenticity" (Pierce 437). Similar to Ferrar, Charles Taylor connects authenticity’s history to morality and describes its development as the "eighteenth-century notion that human beings are endowed with a moral sense, an intuitive feeling for what is right and wrong" (27). Taylor argues that because authenticity has come "to be something we have to attain to be true and full human beings," this "new form of inwardness" is part of the "massive subjective turn of modern culture" (27). The rise of the individual and the coinciding "inward turn" of modern philosophy fostered a link between authenticity, subjectivity, and the individual which gave rise to ethical questions regarding the objectivity and subjectivity of truth (Pierce 438). The search for meaning through theories of authenticity takes various philosophical paths, but many theorists concur that at its crux the authentic person is also considered a moral one. Ferrar observes that "in philosophy the theme of authenticity has unfolded within a tradition of thought which has as its origin [the] precisely moral idea of the authenticity of the person" (24).

Taylor and others readily place authenticity as a "facet of modern individualism" (Taylor $29,44)$. Philosophical approaches to the meaning of the individual in relation to society ushered theories of authenticity right alongside. Scholars point to Martin Heidegger as one of the first to systematically examine the idea of authenticity (Pierce 438). For Heidegger, authenticity is not

\footnotetext{
${ }^{33}$ See also Charles Guignon, On Being Authentic, 2004; Charles Taylor, The Ethics of Authenticity, 1992.
} 
an inward only process, but it involves a sense of self-resolve, or an "attitude of openness and resolve" that comes about via the being present in a field of others ${ }^{34}$ (Being and Time 234-35; qtd. in Taylor 13). Existential philosophers influenced the force of authenticity, as cultural theorist David Shumway describes, as a "defining feature of modernism" (527). It is no surprise that Shumway identifies the concept as one full of paradoxes (527). Shumway summarizes the tensions between authenticity as an early modern ideal, and therefore names it an "illusory myth" (527). Shumway notes that on one hand, the term "conveys the illusory myth of a totalizing, harmonious, unitary self' (527) while pointing out that cultural theorists such as Michel Foucault or Jacques Derrida, "seek to replace [the image of the ideal] with the image of a fragmented, plural, centerless and irreconcilably split subjectivity" (527).

Modern authenticity as conceived as a "child of the Romantic period" (Taylor 26) grew up being bounced around from home to home and most always became recognized as attached to a sense of true, even if ideal. Over time, a philosophical shift occurred in which authenticity moved away from being recognized through inward self-perception. Authenticity as a concept has undergone a social turn that now embraces collective forms of identity. As such, the constructed and perceived authenticity of another, including persons, objects, places, experiences, art, music, and texts and their authors, comprises a legitimizing cultural force. The perception of authenticity as true now, because of the social turn, also includes a perception of authenticity as a matter of trust, legitimacy, and sincerity. This modification invokes ethics as it offsets a space for the contemporary uptake of the authentic as real, which by default, repositions the perception of the inauthentic as unreal, or fake. One consequence is the constructed

\footnotetext{
${ }^{34}$ Heidegger questions the meaning of "being" through the conceptualization of Dasein —a German word that means "being there." Heidegger uses this concept as a way to recognize the paradox of "being present" in a field of other persons.
} 
convergence of truth, real, and the authentic. To illustrate this conceptualization of authenticity, I turn to the field of business and marketing to examine the commodification of authenticity.

\section{Authenticity as a Modern Commodity}

The authentic perceived as a modern construct leads to its application as a marketing imperative. The suggestive title of the 2007 text by James Gilmore and Joseph Pine states their thesis: Authenticity: What Consumers Really Want. Written from a business perspective the authors situate authenticity as the "new business imperative" (3) and argue that the "the appeal of the real [is the] new strain of consumer desire (3). Intended for an audience of business leaders who want to improve their organizations, Gilmore and Pine counsel their readers, "Organizations today must learn to understand, manage, and excel at rendering authenticity" (3, italics mine). This rendering or commodification of authenticity, however, is not without a mess of ethical complexities - the first of which is the blame that Gilmore and Pine place on: "the toxic levels of inauthenticity [that] we're forced to breathe" (43). The authors elaborate:

...in a world increasingly filled with deliberately and sensationally staged experiences—an increasingly unreal world — consumers choose to buy or not to buy based on how real they perceive an offering to be. Business today, therefore, is all about being real. Original. Genuine. Sincere. Authentic. (1)

By "staged experiences" the authors refer to a range of "experience-based commerce," including simple daily events such as going out to dinner to the fanfare of Disney and Starbucks as leading examples of the "shift to commercialized experiences" (11) and that such "contrived experiences force us to consider [...] what is real and what is not" (13). From a marketing perspective, the relevant question may not be 'what is the meaning of authenticity?' as the philosophers have 
asked, but 'how is it represented and rendered, and what does authenticity $d o$ ?' The catch,

however, is that "marketable authenticity" does not have to be "real" as long as it is perceived; in fact, being "real" may interfere with the perception of authenticity. These are rhetorical concerns that scholars in production-and-service centered fields such as amusement and tourism studies, ${ }^{35}$ the museum and heritage industries, and fields of marketing and consumerism must undertake.

Different disciplines ask different questions about authenticity, and despite Gilmore and Pine's large claim about what consumers really want, commodifying authenticity generates ethical questions. Some cultural theorists describe the force of authenticity as a "defining feature of modernism" (Shumway 527). Writing about modernity, Shumway characterizes the era as an age in which the reveling in the disappearance of the old gives way to the birth of cultural practices of collecting and reproducing (528). In short, Shumway attributes modernity's “acute problem of authenticity" to the "many features of traditional social life [that] seemed endangered" (527). Authenticity as a perceived cultural value of modernity, therefore, exposes a fear of potential loss. The notion of "staged experiences" that Gilmore and Pine mention may, in fact, be attempts to conceal the threat of loss.

What is at stake for authenticity in an era of multiple and reproductive practices of consumerism? This is not a novel question as it has been theorized in various forms, including most notably Walter Benjamin’s essay “The Work of Art in the Age of Mechanical

\footnotetext{
${ }^{35}$ In tourism studies, authenticity is largely approached in terms of producing or staging an "authentic experience." Benjamin's theories of mechanical reproduction have been essential in several works of scholarship, for example Dean MacCannell in The Ethics of Sightseeing and The Tourist connects the staging of the authentic experience in tourism with Benjamin's notion of aura, but contests that authenticity of aura is something bound by the original. MacCannell writes: 'the work becomes 'authentic' only after the first copy of it is produced" (The Tourist 48). Furthermore, MacCannell revises Benjamin's notion of aura (who situates aura as inspiring the reproduction of an object), to argue that in regards to a tourism site's socially constructed importance "the reproductions are the aura" (The Tourist 48). MacCannell qualifies this claim by explaining that "this is the structure of the attraction in modern society, including artistic attractions, and the reasons the Grand Canyon has a touristic 'aura' about it even though it did not originate in ritual" or reproduction (The Tourist 48).
} 
Reproduction" which addresses the question of what happens to authenticity when art is reproduced. Benjamin connects authenticity to theories of originality (218), a structural notion that Jacque Derrida troubles in his theories of the archive, ${ }^{36}$ and Michel Foucault in his contrastive approach to origin as embedded in the acquisition of "historicity" ${ }^{37}$ (The Order of Things 358). For Foucault, “modernity's new ways of producing and classifying knowledge are also techniques of power" (Saunders 4). The early philosophical debates about the meaning and constituency of authenticity have developed into deliberations about its rendering and consequential effects. Whatever authenticity is or is not pales against new questions that ask what it ensures, achieves, completes, or resolves.

What then bears on the memoir as a product that underwrites the commodification of authenticity, rendering it via storytelling? At the juncture of memoir as a commodity of authenticity, and authenticity as a language of loss, and storytelling as a practice of preservation, the productivity and reproducibility of the brave memoir, I argue, exposes a cultural grievance with loss - a silent protest enacted in the rhetoric of bravery and the myths it conjures. What we gain from an interdisciplinary approach to authenticity is a textured concept that is problematized

\footnotetext{
${ }^{36}$ See Jacques Derrida's work in Archive Fever. Derrida deconstructs the archival processes by troubling the notion of origin and authority. Derrida assumes a regulating force is at work in archival practices which functions to concurrently mark the archive as a place of conservation and exclusion - activities that feature both accumulation and loss as central to the process, challenging the neutrality of the archive. Through the act of reconfiguration (consignment) that occurs in the new environment, the making of the archive itself creates an authoritative systemone deviating from a system whose authority resides in its connection to the origin. By the mere act of inclusion, the elements consigned to the archive become representative, resembled, or reproduced, and therefore, authoritative and remembered. The reproductive feature of the archive, thus, is one of authority. For Derrida, the inclusive function of the archive produces memory and the exclusive function yields forgetting and silencing. The title of the text denotes a dramatized compulsion to repeat — which is translated loosely from a French idiom as 'archive fever.' Where Derrida's theory is relevant for my mentioning is that the compulsion to repeat discloses a restless desire for what is absent and unattainable, and in effect, points to an inconsolable state of longing incited by the presence of loss and the fear of potential loss.

${ }^{37}$ In Foucault's post-constructionist view, originality in modern man is elevated to an entity constructed without a beginning or an end but with an ongoing existence within the archeology of historicity. Foucault writes in The Order of Things that "the original in man is that which articulates him from the very outset upon something other than himself" (361).
} 
in relation to its reversal, inauthenticity, but open to being scrutinized by different concepts, such as loss. We also learn that the once asked philosophical questions of meaning have shifted to questions of effect, compelling an emphasis on trust over true. This shift discloses authenticity as a product, which is inevitable in our consumeristic world that attempts to commodify and market anything of value. It is my argument that the memoir is one form in which the perceived authentic is rendered. Building on this premise, in the following section, I turn to the ways in which self-representation in memoir is theorized in the figure of the "autobiographical 'I"' to argue that the narrative work of the ' $\mathrm{I}$ ' in Karr's memoir is a rhetorical manifestation of the authentic as potentially perceived by readers. This signifies that in addition to being inscribed in the rhetoric of bravery, loss may also be inscribed within the textuality of the brave memoir as a quality disguised in the collaborative work of the reader and writer in constructing the authentic persona.

\section{The Autobiographical 'I' and Authorial Ethos}

In Reading Autobiography, Smith and Watson distinguish four categories ${ }^{38}$ of the autobiographical 'I.' ${ }^{39}$ First, "the historical 'I'," which refers to the real authorial 'I' or the person producing the autobiographical narrative; next, the "narrating 'I'," or the "agent of discourse" (73); third, the "narrated 'I'," or "the subject of history" (73); and fourth, the “ideological ' $I$ '," which is similar to the socially constructed ' $\mathrm{I}$ ' that Louis Althusser insists is "steeped in ideology, in all the institutional discourses through which people come to understand

\footnotetext{
${ }^{38}$ A fifth category, referred to as the "implied author" by James Phelan (Living 69) is a source of debate among life writing scholars. Smith and Watson disagree with Phelan and others who argue that the implied author is a viable category because of issues of mobility (Smith \& Watson, Reading 76). The term "implied author" was first introduced in the 1961 work of Wayne C. Booth, The Rhetoric of Fiction. See also Isabell Klaiber's article "Multiple Implied Author" and Phelan's article "The Implied Author").

39 The narrating 'I' and the narrated 'I' are categories suggested by Francoise Lionnet. See Lionett's Autobiographical Voices 193.
} 
themselves and to place themselves in the world, or [. . .] through which people are interpellated as certain kinds of subjects" (Smith \& Watson 76). According to Smith and Watson, the narrating ' $\mathrm{I}$ ' - the one who is the "remembering agent who is telling the story" is the only 'I' available to readers (73). The "narrating 'I' is an effect composed of multiple voices, a heteroglossia attached to multiple and mobile subject positions" (74). For example, the multiplicity of the narrating 'I' as evident in Karr's childhood memoir embodies the voice of a child, a sibling, a parent, a grandparent, a rapist, or a reader. The mobility of the autobiographical 'I' foregrounds Smith and Watson's discussion and reveals their attempt to disqualify any simplistic or binary groupings.

The autobiographical 'I' in its multiplicity as Smith and Watson theorize bears the burden of truth-telling. In its articulations, the narrating ' $I$ ' and the narrated ' $I$ ' must be trustworthy figures and the ideological 'I' must bear the weight. As an ideological 'I' this form draws attention to the subjectivity that is inherent to experience. The language choices of the narrator negotiate the subjectivity of experience and the agency of the author as played out in the various forms of the autobiographical 'I.' In essence, the very experience that creates a subject, paradoxically, also fosters a sense of agency. Smith and Watson explain that "because every autobiographical narrator is historically and culturally situated, each is a product of his or her particular time and place. A narrator, then, needs to be situated in the historical notion of personhood and the meaning of lives at the time of writing" (76-77). For Smith and Watson, experience is mediated through memory and language — a claim that positions experience as discursive and socially produced (31). Smith and Watson further reason that "we are always fragmented in time, taking a particular or provisional perspective on the moving target of our pasts, addressing multiple and disparate audiences" (75). 
As I stated earlier in this chapter, in terms of effectiveness, the autobiographical narrative depends largely on the author's ability to establish and maintain ethos. The paratextual features that identify the nonfiction text indeed paves the way of expectation for readers, but after that, the author's formation of the autobiographical ' $I$ ' is what establishes and maintains authorial ethos for the reader. Vivian Gornick characterizes the responsibility of the narrator in terms of fashioning persona:

Out of the raw material of a writer's own undisguised being a narrator is fashioned whose existence on the page is integral to the tale being told. This narrator becomes a persona. Its tone of voice, its angle of vision, the rhythm of its sentences, what it selects to observe and what to ignore are chosen to serve the subject; yet at the same time the way the narrator-or the persona-sees things is, to the largest degree, the thing being seen. (7, italics mine)

Gornick's description of a seemingly symbiotic connection between the person and the persona correlates with Smith and Watson's emphasis on the interrelation of facets of the autobiographical 'I.' Given the multiple levels of subjectivity of the autobiographical narrator, bound by discourses and all of their sociocultural traces, Gornick's persona and Smith and Watson's autobiographical 'I' exist as they do in and through language.

The convergence of interdisciplinary theories of authenticity with theories of the autobiographical 'I' is an under-examined approach to life writing theory in general. It is an approach that diverges from an emphasis on authenticity as a matter of ethics and the consequential failures of memoirists who write fake books. To examine these two theoretical lines of inquiry together provides a way to conceive of the modern imperative to be authentic as 
enacted in memoir. In "Authentic Identities," Pierce argues that modern authenticity has become a collective duty (441). In other words, modern authenticity takes on a collective form that "involves trusting and being trusted" (446). This is a sentiment that Jacob Golomb takes a step further in his text In Search of Authenticity, in which he claims: "if authenticity has an inherently public character, it becomes one's duty to strive to attain it" (137; qtd. in Pierce 446, italics mine). Because trust is often "unavoidably tentative and uncertain, involving risk of misplacement and betrayal" (Pierce 445), the stakes of trusting another are high. This is something clearly evident in memoir discourse when writers are busted for trying to dupe their literary world and must bear the consequences of failing to perform the expected duty, per se, of presenting a narrator than can be perceived as authentic given the cultural demands of entitlement some readers may feel.

\section{A Rationale for a Rhetorical Approach to Memoir}

The value of a rhetorical analysis approach to memoir offers insight into what may be missed in a literary approach when interpretation is focused mainly on the content or broad structural elements of a text (Sutherland 1). The narrator's reliance on the micro-details of language in the construction of stories suggests the critical role of language in composition and delivery. In my analysis, I imagine Karr's parenthetical constructions as a kind of discourse that sets up an imagined interactive orientation between writer and reader, which, in turn, sanctions certain discourse rules. Paul John Eakin, who writes about the consequences of autobiographers who break certain rules of the discourse — such as not telling the truth—alleges that the rules of autobiographical narrative "function as identity rules [which] shift from text to person" (115). Eakin recognizes the tacit social force that often compels readers to an author-figure in the convergence of text and identity. I say author-figure because the reader (most likely) does not 
know the historical and real person writing the text, yet reading autobiography often produces the effect of believing that we know the real (historical and inaccessible) author. Eakin further explains that "when the public responds to rule-breaking autobiographers, it is the identity function of autobiographical discourse and not the literary function that comes into play" (115). The merging of discourse and identity enacts self-referencing forms of the autobiographical 'I' that carry rhetorical force in the text in ways that may persuade readers to identify an authentic persona.

Within the conventions of autobiographical narrative, the parenthetical instances in The Liars' Club function as linguistic units that, I argue, work rhetorically to establish and maintain a perceived authentic persona of the narrator. This approach of examining a single linguistic feature in memoir may seem like a novel way to explore authenticity. Indeed, I do not believe I am making a mountain out of a molehill, but rather I am offering an innovative way to approach memoir analysis using rhetorical methodologies that directly engage textual features. For my purposes, this approach to Karr's memoir complements my approach to the brave memoir as represented within the memoir genre through paratextual elements and as a mode of storytelling that reflects and reinforces larger cultural ideologies.

\section{Precedence for Parentheticals}

Analysis of the rhetorical function of punctuation is no stranger in research. In fact, Benjamin Franklin's dashes are often considered to have rhetorical significance. ${ }^{40}$ Danielle Bobker, in an article titled, "Intimate Points: The Dash in The Autobiography of Benjamin Franklin," notes the "crucial rhetorical role" that dashes play in his life narrative. Bobker interprets the dashes to represent Franklin's “ideas about memoir as an essentially incomplete

\footnotetext{
${ }^{40}$ See Bobker's study, "Intimate Points: The Dash in The Autobiography of Benjamin Franklin."
} 
and intermedial form... whose unstable status reflected the general instability of the eighteenth century culture of writing" (418). Accordingly, Bobker argues that the dashes ${ }^{41}$ are textual features with rhetorical significance - a function that is performed, as I see it, similar to paratextual elements. Bobker writes:

The dashes affect our experience of the Autobiography: they are fundamental to the text, not despite but because of their historical associations with the processes rather than the products of communication (both written and oral) and, more specifically, because of the rapport with readers they help to cultivate - a mode of thoughtful intimacy on which Franklin believed the success of his life narrative, and America itself, depended. (418)

Bobker's interpretation of the use of dashes in Franklin's memoir lends credibility to my work of analyzing punctuation in Karr's memoir as a textual form with persuasive rhetorical effects.

Malcolm Parkes traces the history of punctuation in the West in his cleverly titled text, Pause and Effect, demonstrating the "long history of changes, shifts, and adaptation [that] affirms an affinity between marks of punctuation and spoken or performed language" (Tartakovsky 215). Punctuation marks are, in essence, visual rhetoric devices that embody a "semantic in-between-ness [that is] part of the linguistic code" (Tartakovsky 215). The use of parentheses, in particular, has been taken up as a poetic device. Roi Tartakosvsky notes E.E.

\footnotetext{
${ }^{41}$ Dashes in Franklin's memoir have been a source of contention among editors. Bobker insists that "By my count, there are a total of 408 dashes in the 1997 Library of America edition of the Autobiography" (427). Bobker is interested in what the dashes do and makes a case that Franklin's dashes, "play up the incomplete and intermedial nature of his life narrative on every page. They generate the sense of intimacy typically associated with letters, manuscripts, and prose representations of speech in the period and, in so doing, challenge us to read between the lines, as it were - to take in the nuances of the narrative" (431).
} 
Cummings's use of parentheses as a poetic device ${ }^{42}(216)$ and lauds Cummings as "the unparalleled poet of parentheses"43 (218). John Lennard concurs that poets over the years have exploited parenthetical constructions. Lennard's text, But I Digress: The Exploitation of Parentheses in English Printed Verse provides an in-depth study of major poets and their use of parentheses. Lennard shows the development of parentheses as a poetic device, tracing from the earliest known usage in a scribal manuscript from 1399 to the present.

Within poetic contexts, Lennard distinguishes between "parenthesis the mark of punctuation and parenthesis the grammatical category by referring to the punctuation marks as lunulae ('little moons')" (Tartakovsky 218). Interestingly, even though scribes in the late $14^{\text {th }}$ century inserted parentheses for a variety of purposes, we learn from Richard Mulcaster's 1582 Elementaire, a pedagogical guide attempting to make the English language and culture more respected and accessible. Mulcaster, who was invested in "the right writing of our Englifh tung," offers this explanation for parentheses:

Parenthesis is expressed by two half circles, which in writing enclose some perfit branch, as not mere impertinent, so not fullie concident to the

\footnotetext{
${ }^{42}$ Tartakovsky argues that the questioning of linguistics is usually associated with Modernism (the general context within which E.E. Cummings is often placed) and credits David Perkins, in his History of Modern Poets for characterizing Cummings as "modern poets of Romantic sensibility" (217, 219; qtd.in Perkins). Tartakovsky explains that Cummings is "considered part of the Modernist avant-garde in the 1920s [and that] Perkins maintains that Cummings derived his style from the earlier phases of Modernism of the 1910s with a particular emphasis on the Imagist movement, early Pound, Dada, modern painting, and its theorizations" (217). Against this background, Tartakovsky makes the significant point that Cummings "objectified language and even committed what we might call organized acts of violence against it. But this is violence with a cause, as Cumming's linguistic innovations and typography serve poetic means within his philosophy" (217).

${ }^{43}$ Tartakovsky notes the "overwhelmingly vast majority of Cumming's hundreds of poems include parentheses in any number of forms" (218) and qualifies these usages in a footnote which limits references to parentheses to the actual punctuation mark and "not to parenthetical expressions in general which can be enclosed by parentheses, dashes, or commas (242). Tartakovsky aims to prove that Cummings' use of parenthesis as a devise is not always conventional as other theorists have noted. Tartakovsky's study is significant as a footnote in this chapter in that it lends credibility to an analysis of parentheses as punctuation marks and the potential they have toward analysis and interpretation.
} 
sentence, which it breaketh, and in reading warneth us, that the words inclosed by them ar to be pronounced with a lower \& quikker voice, then the words either before them or after them. (Richard Mulcaster, Elementarie, 1582)

This early emphasis on the performance of parenthetical constructions demonstrates two important aspects: first, that parentheses note the presence of a "voice;" and second, they inherently embody a rhetorical function in that visual rhetoric assumes embodied performancevoice, breath, pause, and intonation, for instance.

Recent studies in legal writing scholarship assert that parentheticals serve a prominent rhetorical function. In "The Promise of Parentheticals" Michael Murray, law professor at Valparaiso University School of Law, details an empirical study of the use of parentheticals in federal appellate briefs. The results of the study indicate that parentheticals are "regularly and frequently employed as a rhetorical device" (230). A similar study, published in the McGeorge Law Review, asserts that "the parenthetical is a powerful tool of persuasion in a litigator's arsenal" (Voigt 270). Complementary to the findings of legal writing research, linguistic studies of parentheticals demonstrate their importance in the organization of linguistic discourse.

In an article titled "On Thetical Grammar" linguists present a broad definition of parentheticals (as including more than the punctuation marks of parenthesis) to make a case for not only their syntactic function but also their important semantic function (Kaltenbock, Heine, \& Kuteva 852). The researchers of "thetical" grammar counter previous linguistic approaches to the study of parentheticals which have primarily treated the function of thetical linguistic units as periphery in that they are "interpolated in or require an anchor utterance." Parenthetical constructions commonly provide background information, contextual knowledge, or other less 
important details that warrant being set aside in parentheses. Likewise, resources such as grammar handbooks commonly refer to material within parentheses as secondary. ${ }^{44}$ Deviating from a strict syntactic interpretation, thetical grammar researchers make a case that "rather than being determined by the morphosyntactic structure of a sentence, the meaning of theticals is shaped by a network of conceptual components [and that] their meaning is determined essentially by the situation of discourse rather than by syntactic relations within a sentence" (Kaltenbock, Heine, \& Kuteva 852). It is not surprising that studies of the rhetorical function of parentheticals are present in legal rhetorics or computational linguistics. ${ }^{45}$ Such linguistic-based explorations are not prominent in life writing scholarship, however. What follows demonstrates the potential contributions of a rhetorical approach to analyzing patterns of this linguistic phenomenon in Karr's memoir.

\section{Method}

My aim was to identify patterns of usage of parenthetical constructions to discover their rhetorical function in establishing and maintaining authorial ethos, and to investigate the extent to which this offers to readers the perception of an authentic, trustworthy narrator. As a first step, I identified each occurrence of parentheses in Karr's text. As a second step, I identified patterns that emerged in terms of frequency and distribution (how often and in what places of the text they occur), and the places in the text where parentheticals are located with "gaps" in between or in "clusters" together. After noting the significance in patterns of usage, I analyzed categorically the content of the language within the parentheses. In my analysis of data, I concluded that

\footnotetext{
${ }^{44}$ See Summey, American Punctuation, a source that refers to parenthetical information as "incidental explanatory matter (107). Tartakovsky points to Robert Grant Williams' forceful point: "For many handbooks...the parenthesis signifies dead text, an appendage to the work which is neither vital nor functional, an appendix which instead of contributing to organic unity only stores toxic waste... the intrusive adjunct which readers quickly skim over to return to live text" (57; qtd. in Tartokovsky 219).

${ }^{45}$ See Banik, 2009; Dehe and Kavalova, 2007; Burton-Roberts, 2005.
} 
parentheticals mark specific instances in the text that function as reminders to readers that the author is real. Even though the narrator could plausibly be lying, the rhetorical work of the parentheticals function in ways that help sustain authorial ethos. In other words, readers may

assume Karr is trustworthy on the basis of their perception, created by this rhetorical device, that she is real, and therefore, trustworthy. In what follows, I detail the significant patterns of parenthetical data in table form and provide a brief analysis for each. I conclude the chapter with a discussion that argues for connections between my analysis of parentheticals in Karr's memoir with the culturally-conceived concept of authenticity and the vital role it plays in the rhetoric of bravery.

\section{Data Analysis}

\section{Frequency \& Distribution}

One of the most noticeable structural characteristics of Karr's text is the sheer frequency and regularity of parentheses as textual markers. On my count, Karr employs 208 sets of parenthesis across 317 pages of text. This averages to 9.5 per chapter. Below are two tables (see table 1 and table 2) that identify the distribution and frequency of each occurrence of parentheses in The Liars' Club across the fifteen chapters of the book. This evidence of consistent and frequent usage supports the notion that the parenthetical constructions provide a pattern of rhetorical consistency throughout the text which is maintained by the repetition of the style. 
Table 1: Frequency of Parenthetical Constructions

\begin{tabular}{|c|c|c|}
\hline Chapter & Frequency of Occurrences & Total \\
\hline \multicolumn{3}{|c|}{ Part I } \\
\hline Ch. 1 & $4,6,6,8,10,11,11,13,19,20,21,21$ & 12 \\
\hline Ch. 2 & $25,26,28,29,32,32,38,42,42,42,42,42,42,43,43,45$ & 16 \\
\hline Ch. 3 & $47,47,48,52,53,56,58,58,61,62,63,63,63,64,66$ & 15 \\
\hline Ch. 4 & $71,71,71,74,75,76,76,79,79,80,81,82,84,85,87,88,90,91,92,92,93,94,95$ & 23 \\
\hline Ch. 5 & $99,100,100,101,105,107,108,111,111,111,113$ & 12 \\
\hline Ch. 6 & $126,127,127,128,128,129,130,131,131,131,132,132,134,134$ & 14 \\
\hline Ch. 7 & $142,143,143,143,145,146,148,152,153,154$ & 10 \\
\hline Ch. 8 & $159,159,160,169$ & 4 \\
\hline \multicolumn{3}{|c|}{ Part 2} \\
\hline Ch. 9 & $179,182,183,184,187,190,194,196,197$ & 9 \\
\hline Ch. 10 & $198,200.206 .207$ & 4 \\
\hline Ch. 11 & $213,213,214,215,224,225,227$ & 7 \\
\hline Ch. 12 & 236,241 & 2 \\
\hline Ch. 13 & 260,261 & 2 \\
\hline \multicolumn{3}{|c|}{ Part 3} \\
\hline Ch. 14 & $277,278,283,284,285,288,289,293$ & 8 \\
\hline Ch. 15 & $299,299,310,311$ & 4 \\
\hline
\end{tabular}

(TABLE 1)

In addition to the frequency, also significant is the range of repetition or the distribution across the parts of the memoir. The text is divided into three parts with Part 1 having the longest number of pages and including the most number of chapters. At first glance, it may seem a moot point to note that the 171 pages of Part 1 contain the most occurrences of parentheticals. Because it is the longest section, it may seem obvious that it would contain the highest frequency level. However, when the average usage is calculated, what becomes significant is that parentheses are employed in Part 1 at more than double the rate of Parts 2 and 3 (see table 2).

My interpretation of this distribution is that a higher frequency early on denotes the initial presence of the autobiographical 'I' and its rhetorical function in establishing ethos. If the parentheses indicate the presence of the autobiographical 'I,' as I am arguing, inserting more parentheses earlier in the text reveals an (authorial) attempt to establish a rapport with the reader. Once the reader-writer relationship is established the frequency is reduced, even though the sustaining work of coherency continues throughout Parts 2 and 3. Fewer occurrences later on in the text may indicate that the relationship is more secure. 


\section{Table 2: Distribution of Parenthetical Constructions}

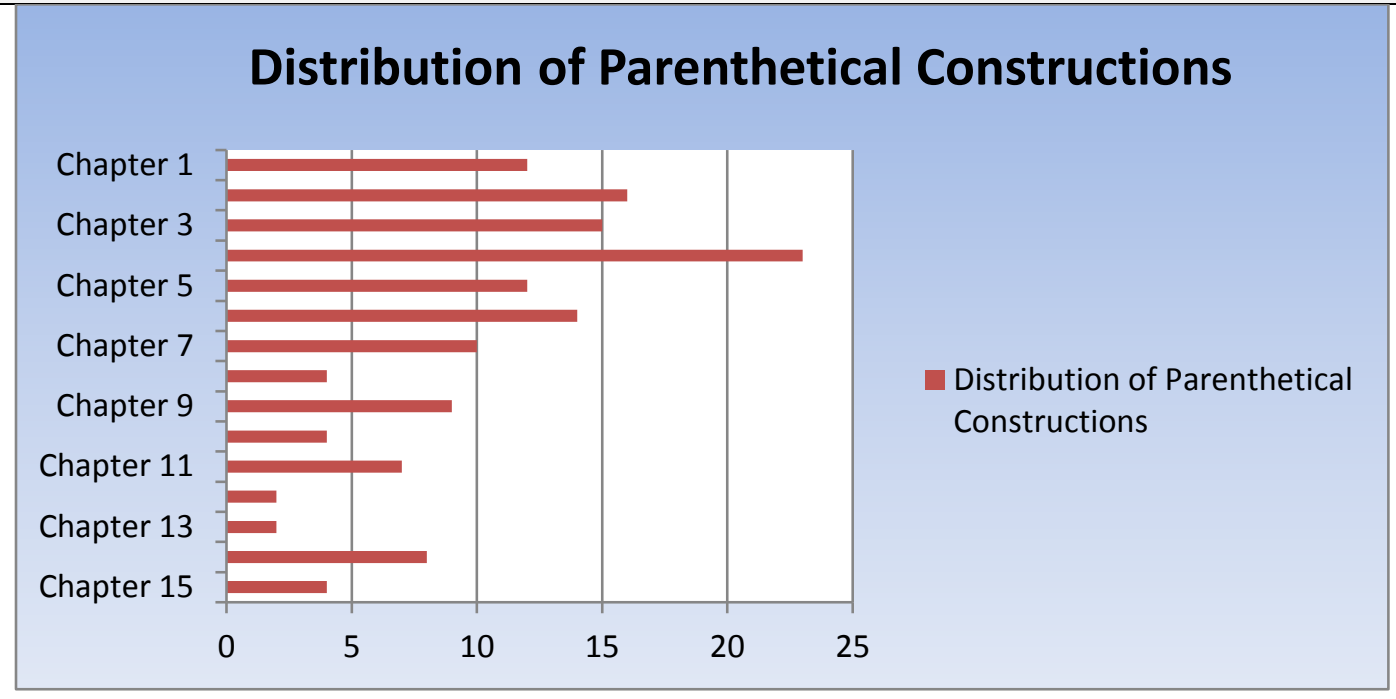

(TABLE 2)

The data in tables 1 and 2 supports the idea that establishing the credibility of the author is necessary early in autobiographical narrative as depicted in Karr's memoir. The stability that is enacted through the frequency of parentheses establishes not only an authorial presence in the text, but also encourages a perception of an authentic author- one that readers can trust to not only tell them the truth (and the truth about the fallibility of memory, as I demonstrate in the following section), but also permit them to know the "inside" story. The perception of trust on the part of readers is foundational to the author's success in establishing an authentic persona.

Another way to interpret the distribution of parentheses in Karr's memoir is to claim that they function as interruptions in the text in order to establish rhetorical coherency in ways that manage the interchange of autobiographical 'I's at work in the narrative. In essence, the parenthetical insertions are discourse markers that provide traction for the author to gain rhetorical footing, an effect that not only helps establish authorial agency, but constructs as well a feel of presence that compels a particular way of reading the text—one in which the reader may come to recognize that voice of the autobiographical 'I' on the page. 
To summarize the findings so far, a major significance of the frequency and distribution of data is that a higher frequency of parentheses occurs earlier than later in the text. In an interpretation that assumes that parentheses represent the presence or "voice" of the autobiographical ' $\mathrm{I}$ ' in the text, that the 'I' is more present early on signifies the important rhetorical work of establishing ethos and launching, however imagined, a reader-writer relationship. It also assumes that, because the 'I' is less obvious later in the text, the rhetorical work is less necessary because the author has established ethos, developed a persona that is trustworthy, and therefore, textual proof of authenticity is not as necessary as early on.

\section{Clusters \& Gaps}

To further investigate patterns of distribution, tables 3 and 4 locate the occurrences of parentheses in terms of clusters and gaps. table 3 identifies occasions in the text where instances of parentheses appear close together; and, table 4 locates space in the text between the occurrences of parentheses. The data indicates that a higher number of clustering occurs earlier than later in the text and more gapping occurs later than earlier in the text. The pattern that emerges from this data set complements the data in tables 1 and 2 and further supports this claim: the distribution of a higher number of clusters of parentheticals in the earlier part of the text sets up an argument that the rhetorical function of the autobiographical 'I,' in all of its manifestations, is to increase the readers' trust. Likewise, the higher the gaps between parentheticals that occur more often later in the text support an argument for an already established relationship than no longer needs as much wooing because a trust has formed. 


\begin{tabular}{|c|c|c|c|}
\hline \multicolumn{4}{|c|}{ Table 3: Distribution of Clusters of Parenthetical Constructions } \\
\hline Chapter & Pages & Occurrences & Total \\
\hline Ch. 1 & $3-22$ & $4,6,6,8,10,11,11,13,19,20,21,21$ & 12 \\
\hline Ch. 2 & $23-46$ & $25,26,28,29,32,32,38,42,42,42,42,42,42,43,43,45$ & 16 \\
\hline Ch. 3 & $47-68$ & $47,47,48,52,53,56,58,58,61,62,63,63,63,64,66$ & 15 \\
\hline Ch. 4 & $69-96$ & $71,71,71,74,75,76,76,79,79,80,81,82,84,85,87,88,90,91,92,92,93,94,95$ & 23 \\
\hline Ch. 5 & $97-118$ & $99,100,100,101,105,107,108,111,111,111,113$ & 12 \\
\hline Ch. 6 & $119-139$ & $126,127,127,128,128,129,130,131,131,131,132,132,134,134$ & 14 \\
\hline Ch. 7 & $140-157$ & $142,143,143,143,145,146,148,152,153,154$ & 10 \\
\hline Ch. 8 & $158-174$ & $159,159,160,169$ & 4 \\
\hline Ch. 9 & $178-197$ & $179,182,183,184,187,190,194,196,197$ & 9 \\
\hline Ch. 10 & $198-211$ & $198,200,206,207$ & 4 \\
\hline Ch. 11 & $212-228$ & $213,213,214,215,224,225,227$ & 7 \\
\hline Ch. 12 & $229-247$ & 236,241 & 2 \\
\hline Ch. 13 & $248-271$ & 260,261 & 2 \\
\hline Ch. 14 & $275-294$ & $277,278,283,284,285,288,289,293$ & 8 \\
\hline Ch. 15 & $295-320$ & $299,299,310,311$ & 4 \\
\hline
\end{tabular}

Table 4: Distribution of Gaps of Parenthetical Constructions

\begin{tabular}{|l|l|l|l|}
\hline Chapter & \multicolumn{1}{|c|}{ Pages } & \multicolumn{1}{|c|}{ Occurrences } & $\begin{array}{c}\text { Gaps of } \\
\text { 5+ Pages }\end{array}$ \\
\hline Ch. 1 & $3-22$ & $4,6,6,8,10,11,11,13,19,20,21,21$ & 5 \\
\hline Ch. 2 & $23-46$ & $25,26,28,29,32,32,38,42,42,42,42,42,42,43,43,45$ & 5 \\
\hline Ch. 3 & $47-68$ & $47,47,48,52,53,56,58,58,61,62,63,63,63,64,66$ & \\
\hline Ch. 4 & $69-96$ & $71,71,71,74,75,76,76,79,79,80,81,82,84,85,87,88,90,91,92,92,93,94,95$ & \\
\hline Ch. 5 & $97-118$ & $99,100,100,101,105,107,108,111,111,111,113$ (to end) & 5 \\
\hline Ch. 6 & $119-139$ & (from start) $126,127,127,128,128,129,130,131,131,131,132,132,134,134$ (to end) & 5 \\
\hline Ch. 7 & $140-157$ & $142,143,143,143,145,146,148,152,153,154$ & 5 \\
\hline Ch. 8 & $158-174$ & $159,159,160,169$ (to end) & 8 \\
\hline Ch. 9 & $178-197$ & $179,182,183,184,187,190,194,196,197$ & 5 \\
\hline Ch. 10 & $198-211$ & $198,200,206,207$ & 5 \\
\hline Ch. 11 & $212-228$ & $213,213,214,215,224,225,227$ & 5 \\
\hline Ch. 12 & $229-247$ & (from start) 236,241 (to end) & 9 \\
\hline Ch. 13 & $248-271$ & (from start) 260,261(to end) & 6 \\
\hline Ch. 14 & $275-294$ & $277,278,283,284,285,288,289,293$ & 5 \\
\hline Ch. 15 & $295-320$ & $299,299,310,311$ (to end) & 119 \\
\hline
\end{tabular}

(TABLE 4)

The data and analysis above support an argument for the significance of Karr's use of

parenthetical constructions as linguistic forms that textually establish the notion of a trustworthy

narrator as theorized in a discourse of authenticity. The frequency and distribution of

parenthetical constructions further insures a rhetorical coherency that lends structural support to

the authentic persona. However, further data is necessary for supporting the claim that

parentheticals indeed are representational of the autobiographical 'I' and that, in this form, 
function as authoritative representations of authenticity. Data in terms of frequency and distribution are significant in revealing the formation of discourse patterns but questions of what kind of content Karr includes in parentheticals reveal further their rhetorical function as markers of the autobiographical 'I.'

\section{Domain Analysis \& Rhetorical Function}

After determining the distribution pattern of Karr's numerous parenthetical constructions, the next step is to examine what kind of information is included within the parentheses. I use a descriptive approach that allows domains to emerge based on the grouping of similar content and/or rhetorical function. As a way to manage the task of this analysis, I have identified the following lead questions toward an analysis of the two-hundred plus examples of parenthetical constructions.

1. What domains emerge in the grouping of parenthetical constructions based on content and/or rhetorical function? Of those domains, what repetitive details serve a rhetorical purpose?

2. What rhetorical patterns surface in terms of the narrative when the clusters occur?

3. What rhetorical patterns arise in the parenthetical constructions that stretch more than 4 lines in length? (This question is important because lengthy parentheticals further support the notion that the language within parentheses is important enough to be set apart from the surrounding text of the memoir. It also supports an argument for the importance of parenthetical content as being central to the narrative and not periphery.)

Using these lead questions to segment the data and identify patterns, I approach the data with a general question: what does the language within the parentheses do rhetorically? At least four 
overarching rhetorical functions emerge from the data. These include the following: (a)

elaboration of detail, (b) expansion of knowledge, (c) running commentary, and (d) the insertion of a story.

For my next question after identifying the domains of rhetorical function, I ask how the function is performed. For example, how does Karr elaborate detail or expand knowledge or provide a running commentary or insert a story? The patterns that emerge in this process-based line of inquiry include at least five specific methods, or as I label them, rhetorical acts. I distinguish rhetorical acts as the following: (a) evidence, (b) quips, (c) self-implication, (d) writing from the present, and (e) foreshadowing. I determine that any of the four categories of rhetorical functions may or may not include one or more specific rhetorical acts (see table 5). As a visual, I show in table 5 the emerging domains and the taxonomy of rhetorical functions. Following the table, I provide an explanation and examples of rhetorical acts as identified in the bottom tier of table 5 The examples are directly from Karr's text.

Table 5: Emerging Domains Taxonomy of Rhetorical Functions of Parenthetical Constructions and Data Sampling

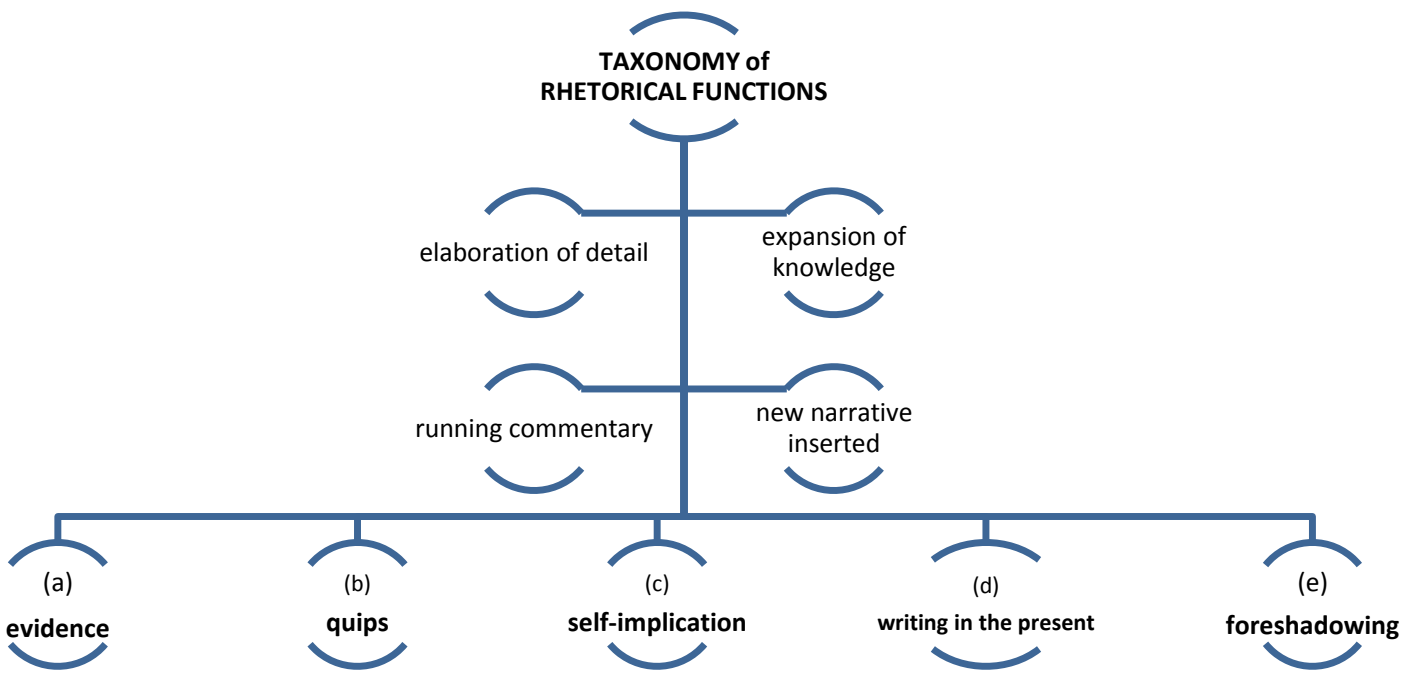

(TABLE 5) 
The examples in each of the following are from The Liars' Club. ${ }^{46}$

(a) evidence to support the narrative, such as background information, contextual detail, a disclaimer, or a qualification (e.g., "pronounced, she would have me tell you, 'Lisa' (4); “Our house was perceived as Dangerous, a consequence of Mother's being Nervous" (8); "she had on a beige silk suit" (11); "which is now the Houston Medical Center" (48).)

(b) quips or wisecracks that may or may not also be humorous (e.g., "Never" (42); "his term” (21); “which I don’t remember his answering” (81).)

(c) self-implication of the narrator in some way (e.g., "even then, my sister had a sense of propriety I lacked: if I wet my underpants playing, back then, I just stepped out of them and kept running" (25); "I had been a difficult birth, feet first, like Caesar, Mother liked to say" (28); "I called her Helmet-head" (45).)

(d) writing in the present or lines that show a shift in autobiographical voice that feels like an interruption of the story for some rhetorical reason (e.g., "Hence, our tendency to say, it ain't the heat, it's the stupidity" (42); "Here time telescopes and gets slow, for some reason. I almost have to nod my head very still to keep from backing away" (52); "children can be a lot like cats or dogs, sometimes, in how physical comfort soothes them" (56).)

(e) lines that provide foreshadowing of what is to come either in the narrative or a reference to something to come in the adult life of the child in the narrative (e.g., "even at seven I had a taste for liquor" (58); "I knew a drug dealer once..." (76); "I once made the trip dead drunk..." (88).)

\footnotetext{
${ }^{46}$ See Appendix B for a more complete list of parenthetical language in Karr's text.
} 
As I have stated, in my analysis I interpret each of the above examples that illustrate the rhetorical acts as textual indications of the presence of the autobiographical 'I.' In making this claim, I imagine a narrator's voice that is snatched from the telling of the story and marked in parenthesis to signify that the storyteller is aware of the telling. Subsequently, one significant effect on readers of this enactment may be a feel of communication or interaction - that a real person is not only telling the story but is speaking directly to the reader.

Of the rhetorical acts described above, and for this analysis, most significant for supporting an argument that Karr's parentheses function authoritatively to establish an authentic persona and do so via rhetorical coherency are (c) self-implication, or lines that implicate the narrator, and (d) writing from the present, or lines that show a shift in autobiographical voice, often depicted from the stance of the present. My rationale for selecting these two categories and elaborating further their effect is that I believe they are more representative of rhetorical devices in autobiographical narrative than the other devices. For instance, what I am labelling evidence, quips or wisecracks, and foreshadowing are rhetorical features also commonly identified in fiction, whereas the two categories of self-implication and writing in the present offer more rhetorical depth for the autobiographical life writer.

In what follows, I provide an in-depth analysis of the autobiographical 'I' as revealed through Karr's rhetorical acts, giving special attention to specific language where Karr "implicates" the self — and by that I mean language that is self-referencing and in some way selfblaming or self-exposing. One prominent way Karr does this is through the voice of her sister. Karr fashions a sort of sub-persona using her sister, Lecia, as a witness to her recollections of their shared childhood. First, I chart examples of language in which Karr implicates the self (see table 6. Among these examples are references to her sister and the misgivings that Karr imagines 
her sister might have about the stories she tells. In a separate table, I provide "sister-as-witness" language samples (see table 7). Finally, I examine the assertion of authorial agency as represented in the use of present tense. To illustrate, I provide language samples that illustrate the rhetorical function of embedded anecdotes (see table 8).

The data in the following tables represent a sampling of instances in which the autobiographical voice is clearly located in parenthetical constructions and which falls into specific discourse patterns. The textual examples in table 6 portray an author who is aware of her narrative being heard. This inference is significantly different from a claim that the author is aware of telling of a narrative. As I indicate in the table, particular lines demonstrate that the autobiographical ' $I$ ' is engaged in discourse - a claim supported by such lines as the last one in table 6 where Karr speaks directly to the reader with a regional expression, "I shit you not..." (288). The effect of such direct folk language interrupting the narrative may fuel the rhetorical energy necessary for what cultural critic Lauren Berlant calls an intimate-public. This is a concept that signifies the "affective ties among strangers who consume common texts that form communities based on shared emotions" (Female viii). Karr also includes humorous parenthetical lines such as this one: "even then, my sister had a sense of propriety I lacked: if I wet my underpants playing, back then, I just stepped out of them and kept running" (25); or this one "My spankings were a kind of sporting event..." (71). In a Berlantian sense, Karr's readers may come to form an "affect world" within which they share a belief that they know the author, when in actuality they know only the invented autobiographical 'I' as represented in the text, the only 'I' to which they have access. 
Table 6: Data of Self-Implication

\begin{tabular}{|l|l|}
\hline \multicolumn{2}{|l|}{ DOMAIN: Self-Implication } \\
\hline Page & \multicolumn{1}{c|}{ Data } \\
\hline 25 & $\begin{array}{l}\text { ("even then, my sister had a sense of propriety I lacked: if I wet my underpants playing, back then, I } \\
\text { just stepped out of them and kept running") }\end{array}$ \\
\hline 28 & ("I had been a difficult birth, feet first, like Caesar, Mother liked to say") \\
\hline 45 & ("I called her Helmet-head") \\
\hline 71 & $\begin{array}{l}\text { "(My spankings were a kind of sporting evet complete with rounds and what my sister still claims was } \\
\text { a system of scoring more subtle and intricate than the mating signals of certain spiders)" }\end{array}$ \\
\hline 71 & $\begin{array}{l}\text { "(Being spanked is never near as bad as being laughed at during the spanking. Trust me. The presence } \\
\text { of another kid ups the humiliation quotient exponentially)" }\end{array}$ \\
\hline 79 & $\begin{array}{l}\text { "(I later learned that she'd been shown the same pictures by Grandma. She had also promptly } \\
\text { forgotten them. In this way, we entered amnesia together)" }\end{array}$ \\
\hline 99 & $\begin{array}{l}\text { "(I had the smug pleasure of using this term up north and having a puzzled young banker-to-be then } \\
\text { ask me if these worm farmers in Texas sold worms for fishing, or what)" }\end{array}$ \\
\hline 100 & "(which I had built up by being a smart mouth and getting my ass whipped a lot)" \\
\hline 105 & "(a phrase I'd picked up from one of Mother's less-than-Christian tirades)" \\
\hline 108 & $\begin{array}{l}\text { "(Silence can make somebody bigger, I've come to believe. Grief can, too. A big sad silence } \\
\text { emanating from someone can cause you to invest that person with all manner of gravitas)" }\end{array}$ \\
\hline 113 & "(The terrible thing about children-I'd like to mention here-is that they're so childish.)" \\
\hline 190 & "(Comfort makes fools of us that way, and a kid gets faith back quick)" \\
\hline 224 & "(Something about the small betrayal of moving away from her still gives me a stab of guilt)" \\
\hline 241 & $\begin{array}{l}\text { "(Later, I'll learn that's the structure of an elegy: lament, consolation; bad news, followed by good } \\
\text { news)" }\end{array}$ \\
\hline 261 & $\begin{array}{l}\text { "(Sure the world breeds monsters, but kindness grows just as wild, elsewise every raped baby would } \\
\text { grow up to rape)" }\end{array}$ \\
\hline 288 & "(I shit you not, the cat would only come in or out once these words were spoken)" \\
\hline
\end{tabular}

(TABLE 6)

In addition to self-implication, Karr orients readers to look to her sister as source of evidence for justifying her childhood recollections. By situating her sister Lecia's voice as an ongoing refrain throughout the narrative, and particularly locating that voice within parentheses in several instances, Karr calls attention to her sister as a witness to her childhood experiences, a move that situates Karr as an even more trustworthy narrator. Lecia, as a watcher of truth, keeps in check Karr's handling of memory, which in effect, verifies Karr as an authentic storyteller. Table 7 provides a sampling of parenthetical "sister-as-witness" references. 
Table 7: Sister-as-witness References

\begin{tabular}{|c|c|}
\hline & \\
\hline rage & Data \\
\hline 4 & (pronounced, she would have me tell you, "Lisa"). \\
\hline 25 & $\begin{array}{l}\text { (Even then, my sister had a sense of propriety I lacked: if I wet my underpants playing, back then, I } \\
\text { just stepped out of them and kept running.) }\end{array}$ \\
\hline 26 & (Lecia went on to make an adult fortune selling whole-life insurance in Houston.) \\
\hline 42 & $\begin{array}{l}\text { (Lecia had managed to come out blond like her people, but Grandma never got over my looking } \\
\text { vaguely Indian like Daddy.) }\end{array}$ \\
\hline 47 & $\begin{array}{l}\text { (If I gave my big sister a paragraph here, she would correct my memory. To this day, she claims that } \\
\text { she genuinely mourned for the old lady, who was a kindly soul and that I was too little and mean- } \\
\text { spirited then to remember things right. I contend that her happy memories are shaped more by } \\
\text { convenience than reality: she also recalls tatting as fun, and Ronald Reagan, for whom she voted } \\
\text { twice, as a good guy.) }\end{array}$ \\
\hline 58 & (Lecia says that I would eat them only in pairs, so none would feel lonely in my stomach.) \\
\hline 62 & $\begin{array}{l}\text { (Lecia and I had impressed Uncle Frank by both learning to read pretty much without instruction } \\
\text { before we were three. Mother took us each down to his office inturn, and we each dutifully read the } \\
\text { front page of the day's paper out loud to him, so he could be sure it wasn't just some story we'd } \\
\text { memorized.) }\end{array}$ \\
\hline 79 & $\begin{array}{l}\text { (I later learned that she'd been shown the same pictures by Grandma. She had also promptly forgotten } \\
\text { them. I this way, we entered amnesia together.) }\end{array}$ \\
\hline 87 & $\begin{array}{l}\text { (Lecia was nothing if not cool in a crisis. She learned to drive at twelve, at which age I once saw her } \\
\text { convince a state trooper that she'd just left her license at home because she was running out to get her } \\
\text { baby milk while he was still sleeping.) }\end{array}$ \\
\hline 90 & $\begin{array}{l}\text { (Were Lecia writing this memoir, I would appear in one of the only three guises: sobbing hysterically, } \\
\text { wetting my pants in a deliberately inconvenient way, or biting somebody, usually her, with no } \\
\text { provocation.) }\end{array}$ \\
\hline 107 & $\begin{array}{l}\text { (Lecia became an adult devotee of such heels. Once at a party in Boston, a loafer-wearing debutante } \\
\text { suggested jokingly to her that if God had wanted women to wear heals, He wouldn't have designed } \\
\text { our feet as He did. Lecia replied that if God hadn't intended us to wear heels, She wouldn't have made } \\
\text { our legs look so great in them.) }\end{array}$ \\
\hline 131 & $\begin{array}{l}\text { (In fights Lecia and I have as grown-ups, she'll scream at me, "You were always so fucking cute!" } \\
\text { And I'll scream back, "You were always so fucking competent! Which sums up our respective jobs in } \\
\text { the family.) }\end{array}$ \\
\hline 169 & $\begin{array}{l}\text { (Lecia was sleeping over at a friend's that morning, having outgrown Daddy somehow, having also } \\
\text { gotten agile at worming her way into families quieter than ours.) }\end{array}$ \\
\hline 184 & $\begin{array}{l}\text { (Lecia took sixth in the Washington pole bendings, though she would have me point out here that the } \\
\text { competition in her category was far stiffer than in mine, which was only little kids.) }\end{array}$ \\
\hline 187 & $\operatorname{can}$ \\
\hline
\end{tabular}

(TABLE 7)

The most significant effect of Karr's references to her sister is that Lecia as a witness offers subtle testimony that Karr's memories are true. Karr comes across as one who owns-up to the rocky status of her own memory, and her unstable narrative of childhood resonates against the sound voice of her sister's. In casting her sister as a shadow-like persona, Karr establishes an authorial identity as a trustworthy, authentic narrator because she has an eye-witness. 
Furthermore, Karr's acknowledgement of the frailty of memory enhances a potentially perceived genuineness that may insulate her trustworthiness that, in theory, could result in errors uncovered in fact checking if anyone cared to do the research. Revealing her sister's differing memory (see 47), for example, allows for the historical fact to be contested without contesting the authenticity of authorship. Even if Karr is mistaken in her version of the story, it is a genuine mistake and her intent is uncompromised. Said another way, just as the required mens rea of intent is what differentiates murder from tragic accident in the eyes of the law it is perhaps as well what separates an authentic but fallible memoir from hoax. What is revealed in this particular analysis bears on the contemporary memoir and the ethics of life writing in general: authenticity may have more to do with the truth of a memory than the truth of a fact. For all its frailty and imprecision, a memory can still be perceived as having an authentic quality if portrayed convincingly, and this is what many readers have come to expect.

In analyzing Karr's parenthetical constructions, one of the most noteworthy features is that some of them are quite lengthy. Several of the examples in table 8 are mini-narratives that occur within a larger story. Why Karr separates these instances may be a question that only she can answer - and her answers may vary. Artistic function aside, the story about Karr's encounter with the cottonmouth in the bayou (see 79) does little to advance the narrating of her Grandma's death, which she is in the midst of doing when this detail is inserted. However, the rhetorical effect is noteworthy for the reader who by this time in the story has most likely developed a felt relationship with the autobiographical 'I.' Inserting a story-within-a-story has an appeal that a friend might appreciate.

By inserting a childhood memory having little to do with the point of the narrative at hand, Karr feeds into this mythical interaction between writer and reader, nurturing a sense of 
intimacy. The pull and tug of distance and intimacy, I believe, is one rhetorical effect on readers

of these lengthy anecdotes. For example, Karr's anecdote about her sister's "insane physical

bravery" (see 63) ends with a sisterly jab thrust at her toughness. The reader may get a sense of

being in-the-know (more or less) of the kind of playful relationship Karr has with her sister-a

move that may infuse Berlant's notion of intimacy among strangers in ways that pervade the

reading experience. Because intimacy involves rights, also at work is a pervading sense of

entitlement. Readers may feel because of an affective investment in the story, a personal

attachment to the author that extends beyond the scope of the invented autobiographical ' $\mathrm{I}$ ' in all

its multiplicity. Besides the affective work of the longer anecdotes, these instances of a story-

within-a-story are anything but beside the point as they reveal a voice of the autobiographical 'I'

that in several cases contests what many may consider commonplace cultural beliefs. In some

instances, the language is so penetrative that it may elicit readers as silent participants.

\begin{tabular}{|c|l|}
\hline \multicolumn{2}{|l|}{ Table 8: Embedded Anecdotes } \\
\hline \multicolumn{2}{|l|}{ DOMAIN: Embedded Anecdotes } \\
\hline Page & \multicolumn{1}{|c|}{ Data } \\
\hline 63 & $\begin{array}{l}\text { (To this day, I don't know whether to measure this as courage or cowardice, but it stuck. After I grew } \\
\text { up, the only man ever to punch me found himself awakened two nights later from a dead sleep by a } \\
\text { solid right to the jaw, after which I informed him that, should he ever wish to sleep again, he shouldn't } \\
\text { hit me. My sister grew up with an almost insane physical bravery: once in a parking lot outside her } \\
\text { insurance office, she brushed aside the .22 pistol of a gunman demanding her jewelry. "Fuck you," she } \\
\text { said and opened her Mercedes while the guy ran off. The police investigator made a point of asking her } \\
\text { what her husband did, and when she said she didn't have one, the cop said, "I bet I know why.") }\end{array}$ \\
\hline 66 & $\begin{array}{l}\text { (I picture him now reading this, and long to reach out of the page and grab ahold of his shirt front that } \\
\text { we might together reminisce some. Hey, bucko. Probably you don't read, but you must have somebody } \\
\text { who reads for you--your pretty wife or some old neighbor boy you still go fishing with. Where will you } \\
\text { be when the news of this paragraph floats back to you? For some reason, I picture you changing your } \\
\text { wife's tire. She'll mention that in some book I wrote, somebody from the neighborhood is accused of } \\
\text { diddling me at seven. Maybe you'll see your face's image spread across the silver hubcap as though it's } \\
\text { been flattened by a ball-peen hammer. Probably you thought I forgot what you did, or you figured it } \\
\text { was no big deal. I say this now across decades and thousands of miles solely to remind you of the long } \\
\text { memory my daddy always said I had.) }\end{array}$ \\
\hline 76 & $\begin{array}{l}\text { (I knew a drug dealer once who collected them in glass tanks all over his trailer. He had a harelip that } \\
\text { somehow protected him from the stink, but the rest of us became, when dickering over pharmaceuticals } \\
\text { with him, the noisiest and most adenoidal mouth breathers. We all sounded like Elmer Fudd, so a coke } \\
\text { deal took on a cartoonlike quality: "You weally tink dis is uncut?" It was particularly hard to talk this } \\
\text { way when you were tripping your brains out on LSD and had gone there only as a last resort to buy } \\
\text { something to help you come down.) }\end{array}$ \\
\hline
\end{tabular}




\begin{tabular}{|c|c|}
\hline 79 & $\begin{array}{l}\text { (The closest I had ever come to that smell before Grandma's room was the closest I'd come to a } \\
\text { snakebite. One evening when Daddy had rowed our rented boat into a patch of morning glories, he all } \\
\text { of a sudden lifted the dripping oar from the bayou and took a swipe about three inches above my head, } \\
\text { so the water from the oar fanned down over my face and bare arms. There was a quick plop in the water } \\
\text { next to the boat. The cottonmouth had been draped off a branch right over me, he said. We watched it } \\
\text { drag its S-shaped body through the brown water. I started shaking, not from cold.) }\end{array}$ \\
\hline 127 & $\begin{array}{l}\text { (When she got older and studied calculus, she even worked out a formula that factored into account the } \\
\text { percentage of alcohol in various liquors - wine's only about fourteen percent alcohol, for example-as } \\
\text { well as how much time had elapsed from the first drink, whether Mother had eaten, and much she } \\
\text { weighed. She'd then compare the outcome to that from another drinking bout in a way that sounded like } \\
\text { this: "At Thanksgiving she was doing at least four ounces of eighty-six-proof alcohol per hour for four } \\
\text { hours, and she weighed ten pounds less but was nowhere near this wild. Of course she'd eaten a lot. . } \\
\text {.) }\end{array}$ \\
\hline 132 & $\begin{array}{l}\text { (The pictures themselves were being seared into my head with all the intensity of childhood. When I } \\
\text { stumbled on the actual paintings years later in museums, I often lapsed into that feeling you get when } \\
\text { stepping inside your old grade school, of being tiny again in a huge and uncontrollable world-and yet } \\
\text { the low-slung water fountains tell you that you're a giant now. Van Gogh's Bedroom at Arles, when I } \\
\text { stood before it at eighteen, seemed ridiculously small, yet intensely familiar.) }\end{array}$ \\
\hline 145 & $\begin{array}{l}\text { (The figure also varies with Mother's telling, from "only } \$ 100,000 " \text { to "over half a million" depending } \\
\text { on the point she's trying to make with the story. To this day, if pressed to give us the exact number, she } \\
\text { presents a kind of walleyed expression with a loose-shouldered shrug that suggests such sums of money } \\
\text { must be taken in stride, give or take a hundred thousand.) }\end{array}$ \\
\hline 153 & $\begin{array}{l}\text { (The thought that burdens me most today is that somebody did call Daddy to let him know, and } \\
\text { Daddy - gripped by the same grinding machine that gripped us - just stayed in the slot that fate had } \\
\text { carved for him and said he planned to come on home directly. Or he said kiss my rosy red ass, for } \\
\text { Daddy could turn the volume on any portion of the world up or down when he had a mind to. I can very } \\
\text { well picture his big hand setting the phone back in its black cradle. The men on his unit might have } \\
\text { been frying up some catfish they'd caught. From high in his tower, he could have looked out that } \\
\text { curved window across fields of industrial pipes and oil-storage talks, past the train yards to the grid of } \\
\text { identical houses - in the yard of one of which Mother was setting first to our lives-and maybe Daddy } \\
\text { just decided to change the channel away from that fire to the sizzle of cornbread-dipped catfish floating } \\
\text { in hot lard. Boy that fish smells good, I can imagine him saying.) }\end{array}$ \\
\hline
\end{tabular}

(TABLE 8)

Notice that the examples of embedded anecdotes often employ present tense. ${ }^{47}$ The rhetorical work of present tense transports the reader directly into the space of the writing where the autobiographical 'I' resides. Smith and Watson refer to the convention of using present tense as a "metric of authenticity" that "projects an aura of authenticity" ("Witness" 593). The "youare-there sense of immediacy" functions rhetorically to put readers at the scene as a witness. In

\footnotetext{
${ }^{47}$ I use Karr's use of present tense within the parentheticals as data for arguing for the effect that language may have on readers' perception of the narrator. Karr does employ present tense in language outside of parentheticals. It would be a useful study to analyze sample passages that employ present tense as a comparison to the work I have done on present tense usage within parentheticals. That work is outside the scope of this dissertation, but warrants mentioning so that my readers know I am not claiming that Karr only employs present tense within the parentheticals.
} 
effect, the reader's imagined proximity to the story in the text may evoke varying reader responses. Furthermore, the immediacy of memory is induced by the use of present tense which does more than construct a sense of urgency in the text. For some readers, it may present the illusion that Karr is doing the remembering at the time they are reading.

To end this section of analysis, I point to one particular anecdotal example through which several points of my rhetorical analysis converge, including the authority that a sense of authenticity bears, the structural consistency that the parentheticals maintain, the ideological identities that are both represented in Karr's autobiographical 'I' and the readers' sense of intimacy, and the powerful rhetorical force of The Liars' Club as a brave memoir. This example is the parenthetical construction on page 66 (see table 8) that reads as Karr's "letter to her rapist."

Across several pages before the parenthetical construction on page 66, Karr describes the traumatic event of being raped at age seven and keeping silent about it afterwards. In the narrative, the convention of present tense positions readers in the proximity of the rape. In effect, before the eight-page narrative account is over, readers may realize that they are implicated in the crime if only as bystanders. At a moment when many readers may be squirming from having "witnessed" the rape of a little girl by a big boy with braces, Karr makes one of the most unexpected and effective moves of rhetorical agency. Shifting to the adult voice (an instance where the autobiographical "I" who is narrating is clearly present and distinctly marked by parentheses as a voice different from the one narrating the childhood experience), and without naming the abuser, Karr directly confronts the adult boy in a lengthy paragraph-long parenthetical on page 66- one that is perhaps the strongest representation of authoritative authenticity in the entire book. The lengthy parenthetical anecdote reads as follows: 
(I picture him now reading this, and long to reach out of the page and grab ahold of his shirt front that we might together reminisce some. Hey, bucko. Probably you don't read, but you must have somebody who reads for you--your pretty wife or some old neighbor boy you still go fishing with. Where will you be when the news of this paragraph floats back to you? For some reason, I picture you changing your wife's tire. She'll mention that in some book I wrote, somebody from the neighborhood is accused of diddling me at seven. Maybe you'll see your face's image spread across the silver hubcap as though it's been flattened by a ball-peen hammer. Probably you thought I forgot what you did, or you figured it was no big deal. I say this now across decades and thousands of miles solely to remind you of the long memory my daddy always said I had.) (Karr 66)

As a rhetorical convention, the discursive positioning of first-person has a profound effect. Smith and Watson describe it this way: "as readers imaginatively share the vulnerable protagonist's struggle to survive, their empathetic identification is awakened [as readers] are transported 'there' by a narrator's rhetorical shifts into the simple present tense" ("Witness" 593). The shifts between past and present, juxtaposing the adult voice and the child's silence, in this example, lifts the burden of having to side with one at the expense of the other. The potential tug on emotion of both the writer and the reader in this scene sets up a conceivable shared moment of truth: a child being raped is tragic; a child raping a child is tragic; a society within which a child rapes a child is tragic. Karr's intricate narration of the rape scene renders an 
ambiguity about her own emotion as often dealt to victims - whether to show anger and confront or be quiet and complicit. The adult Karr speaks for the silenced child, and everyone hears. Karr confronts her abuser by talking back to the dominant paradigms that structure who can speak or who can be heard, a rhetorical move that profoundly represents a textual example of memoir bravery.

As demonstrated in this rhetorical analysis section, a study of parenthetical constructions in terms of linguistic form and textual content indicate the importance of their rhetorical functions: the frequency of occurrence, distribution patterns, and contextual domains together have implications pertinent to theorizing the autobiographical 'I' as an installment of authenticity. As the data implies, the rhetorical functions of parentheticals are to establish and manage authenticity through rhetorical consistency. One effect of Karr's parenthetical constructions may conjure for readers an ethereal sense as if Mary Karr is calling readers aside and whispering in their ears.

\section{Conclusion: Authenticity as a Language of Loss and Longing}

Based on the above rhetorical analysis, I provide evidence for an argument that authenticity as a quality of the brave memoir assumes textual form in Karr's memoir as represented in the linguistic unit of parenthetical constructions. I further infer that the language within the parentheses invokes theories of the autobiographical ' $I$ ' as a sustaining rhetorical force that establishes and maintains ethos. The most striking revelation of the analysis of Karr's parentheticals is the pattern of deployment - that more are present and appear closer together in the early parts of the memoir than later on. As I have stated, I interpret this pattern as supporting a process in which the narrator becomes more secure once initial ethos has been established. The 
rhetorical consistency that the parentheticals portray, encourages readers to perceive of a narrator who is trustworthy, even at times when the author's memory fails.

This analysis provides one example of the way in which Karr's memoir, as a case study of a brave memoir, renders authenticity. In light of this analysis and to forefront my concluding remarks, I reiterate the remaining parts of the structural questions that I posed at the beginning of this chapter: to what extent is loss figured in Karr's rendering of authenticity? And, to what end does an inscription of loss drive a desire for the authentic and how might this bear on the contemporary memoir? To engage these questions, I elaborate two rhetorical aspects of Karr's memoir that further support the relationship between authenticity and loss and why this theory work is important for understanding the cultural implications of the contemporary memoir as manifested in the rhetoric of bravery. First, I examine Karr's opening passage of the memoir to illustrate that the narrator enters proclaiming amnesia — a rhetorical move that already at the opening calls out memory as fickle; and second, I examine Karr's depiction of her mother's silence, a theme that is woven throughout the memoir, presented within and outside of parentheticals, and that, I propose, may be the textual rocket launcher for Karr's numerous parenthetical constructions.

In the opening passage of The Liars' Club Karr writes this:

My sharpest memory is of a single instant surrounded by dark. I was seven, and our family doctor knelt before me where I sat on a mattress on the bare floor. He wore a yellow golf shirt unbuttoned so that sprouts of hair showed in a $\mathrm{V}$ shape on his chest. I had never seen him in anything but a white starched shirt and a gray tie. The change unnerved me. He was pulling at the hem of my favorite nightgown — a pattern of Texas 
bluebonnets bunched into nosegays tied with ribbon against a field of nappy white cotton. I had tucked my knees under it to make a tent. He could easily have yanked the thing over my head with one motion, but something made him gentle...He held a piece of hem between thumb and forefinger...It took three decades for that instant to unfreeze. (Karr 3)

To contextualize the passage, Karr follows this seemingly pristine memory of her seven-year old self with an admission that this (sharpest) memory was not always part of her memory bank, leaving readers to assume the likelihood of childhood amnesia resulting from a traumatic experience. In fact, Karr describes the memory as something frozen which took "three decades to unfreeze" (3). She depicts this metaphoric unfreezing in stages of memory recall moving from the still panoramic shot of the memory on pause to an unpausing where gradually the scene moves, and following the animation, the volume begins to rise. Karr remembers specific sounds of boots stomping, a screen door opening and shutting, voices, and a dog growling (5). Persuasively, readers may feel led by the hand as witnesses, not to Karr's traumatic experience (because the details of what's happening are not revealed until much later in the memoir), but to her experience of recollection.

Between the opening passage that unveils a childhood memory that Karr admits was once blocked and the near admission of unreliability as depicted by title of the memoir itself "The Liars' Club," Karr frames a picture of memory and storytelling as unstable, fragmented, and unreliable. From the onset, the persuasive appeal of ethos situates Karr as a trustworthy narrator because she blatantly owns up to this fallibility of memory. Being upfront about her childhood amnesia conceivably encourages readers to then believe her when she claims this is my "sharpest memory." Karr insists on personifying a narrator that may charm the reader with the intimacy of 
inside knowledge. This approach to establishing an authentic persona, in part, protects the narrator from potentially losing readers' good faith in her ability to remember and reinforces the unspoken promise that she will be honest when her memory falters.

Secondly, loss figures into her mother's silences. Karr's mother, Charlie, is a character in the memoir who is introduced in the beginning from the child's perspective. The opening scene of the unfolding of childhood amnesia begins to foreshadow the later narrative of her mother's life-long grief from losing two children that she had before Karr and her sister. A son and a daughter were taken away by the children's father and his mother to an unknown location. Readers learn that Charlie's "capital-N Nervousness" is due, in part, to this loss. In the memoir, Karr develops the character of her mother from the perspective of her young, unknowing persona which experienced the overbearing weight of her mother's "spooky silence" that was at once unpredictable and controlled. Consequentially, Karr erects a multifaceted narrative voice to outdo and undo her mother's overbearing silence.

Grandma Moore, Charlie's mother, whom Karr despised so much that when she finally died, Karr secretly sang, "Ding, dong, the witch is dead" (99), brought even more silence into the Karr house when she came to live with them for a short while. Even though Grandma dies in the early middle part of the memoir, her damaging effect on Karr's mother lingers through to the end. Karr describes her mother's silence as an entrapment, referencing the projected emotions of a caged panther as depicted in a Rilke poem (55) and, equally, as a desire to be scrubbed out of existence (147). We learn that the unbearable grief that silences Charlie is pressed harder by her own never-forgiving mother (Grandma Moore) who blames her daughter for the tragic loss of the two children. Grandma Moore, who in her own twisted sense of grief and rage, could not find a way to let the Karr girls (Mary and Lecia) enter the sacred emptiness left by the absent 
grandchildren who came before. This loss, in part, constructed the wall of silence around Charlie

that Karr could not penetrate. (See table 9 for a sampling of passages that mention silences.)

Table 9: The Silence of Charlie

\begin{tabular}{|c|c|}
\hline \multicolumn{2}{|r|}{ Sample references to "silence" in Karr's memoir; in italics is my paraphrasing. } \\
\hline Page & Data \\
\hline 46 & $\begin{array}{l}\text { Grandma Moore dies: "The worse part wasn't all the change she brought, but the silence that came } \\
\text { with it. Nobody said anything about how we'd lived before. ... I somehow knew that suggesting a } \\
\text { dinner in the middle of the bed, or stripping down when I came in from playing, would have thrown } \\
\text { such a pall of shame over the household that I couldn't even consider it." }\end{array}$ \\
\hline 55 & $\begin{array}{l}\text { Follows poem by Rilke about a panther stuck in a zoo: "Looking back from this distance, I can also see } \\
\text { Mother trapped in some way, in her own silence. How small she seems in her silk dress, drinking stale } \\
\text { coffee. I can see the panther pace back and forth behind the bars on the surface of her sunglasses, as if } \\
\text { he were inside her peering out at us. Sometimes seeing her that way in memory, I want to offer her a } \\
\text { glass of water, or suggest she lie down in the shade of the willow behind her. Other times, I want to pull } \\
\text { the glasses from her face, put my large capable hands on her square shoulders, and shake her till she } \\
\text { begins to weep or scream or do whatever would break her loose from that island of quiet." }\end{array}$ \\
\hline $58-59$ & $\begin{array}{l}\text { Reference that compares her parents: "Dad is predictable... Mom you never know" (What Karr does } \\
\text { know about her mom is her ability to remain silent and be secretive.) }\end{array}$ \\
\hline 71 & $\begin{array}{l}\text { This line illustrates Charlie's bottled up hurt and the attempt to control it: "But some kind of serious } \\
\text { fury must have been roiling around inside her. Sometimes, instead of spanking us, she would stand in } \\
\text { the kitchen with her fists all white-knuckled and scream up at the light fixture that she wasn't whipping } \\
\text { up because she know if she got started she'd kill us. This worked better than a spanking could have. } \\
\text { Your mother's threats of homicide-however unlikely she tries to make it sound-will dampen down } \\
\text { your spirits... Anyway, her whippings, when they did come, were almost a relief given the spooky } \\
\text { alternative of her silence." }\end{array}$ \\
\hline 93 & "Mother's spooky silence" \\
\hline 96 & $\begin{array}{l}\text { Karr finds grandma dead but keeps quiet about it. A few pages later she sings: "ding, dong the witch is } \\
\text { dead" (99) }\end{array}$ \\
\hline 103 & "Mother had left us at home because she was hurt. For her, being hurt meant drawing into herself." \\
\hline 108 & $\begin{array}{l}\text { Mom came home after burying grandma; Lecia is rubbing her feet and Karr imagines Gulliver being } \\
\text { swarmed on by the little people. Karr says, "And, looking up from the floor, I thought she was way } \\
\text { taller than I remember. (Silence can make somebody bigger. I've come to believe. Grief can, too. A big } \\
\text { sad silence emanating from someone can cause you to invest that person with all kind of gravitas.) } \\
\text { There were pouches under her eyes that hadn't been there before..." }\end{array}$ \\
\hline 109 & "She turned into a shadow;" "I studied Mother" \\
\hline 122 & Reference to the "silence contest of the Liars" Club men" \\
\hline 141 & "just silence in the house" \\
\hline 145 & "The silence that came back was even heavier than the air outside" \\
\hline 147 & Reference to Mother shattering all the mirrors in the house; Mothers face scrubbed out \\
\hline $\begin{array}{l}155- \\
158\end{array}$ & $\begin{array}{l}\text { Karr begins the elaboration the story of the fire that she began in the opening passage of the memoir; } \\
\text { Mother has a knife, Mary wants to scream: "no sooner do I choke down that scream than a miracle } \\
\text { happens. A very large pool of quiet in my head starts to spread..." This is where her memory goes } \\
\text { silent; she makes her family into cartoon characters and stick people. }\end{array}$ \\
\hline 158 & $\begin{array}{l}\text { "After they took Mother Away, I sank into a fierce lonesomeness for her that I couldn't paddle out of } \\
\text { into other things... Daddy never mentioned the night of the fire... Maybe our own silence on the subject } \\
\text { was meant to protect him somehow" }\end{array}$ \\
\hline 171 & Mother is locked up and she comments that the kids are also locked up just in bigger room \\
\hline 253 & "Mother had shifted into her ghost self" \\
\hline 319 & $\begin{array}{l}\text { "Those were my mother's demons, then, two small children, whom she longed for and felt a } \\
\text { having lost." }\end{array}$ \\
\hline
\end{tabular}

(TABLE 9) 
Karr eventually breaks through her mother's silence by exposing it and by telling the story behind it. Even so, Karr lets readers know that she is not immune to the family tendency toward silence even at a young age which we learn from the example of her keeping silent after being raped. In another passage, when Grandma dies, it is Karr who walks into the bedroom and finds her but quickly exits, finds her sister sitting in a doorway and snuggles up back to back, sitting in silence until it is broken by her mother's scream as she finds Grandma Moore dropped dead on the bed.

Haunted by a childhood of silences, it is my interpretation that Karr's writerly choices in The Liars' Club serve the purpose of exposing the structures that support the stories that cannot be spoken. Karr gives voice to her mother, and in turn, grants a kind of self-care that nurtures a child longing to be spoken to. By inference, I suggest that Karr's meticulous parentheticals further serve this purpose as they function to launch Karr's voice into a liminal, but accessible space. In so doing, Karr confronts the inaccessible space that confined her mother's voice and the constructive power of silence that, as she puts it, "can make somebody bigger" (108). For Karr, the sense of loss inscribed by her mother's silence produced a childhood longing that, I believe, shows up textually in Karr's memoir. This longing that loss produces, I conclude, is of the same essence that fuels a perception of the authentic as desirable and a cultural belief in the value of authenticity. To this end, the inscription of loss drives a desire for the authentic that bears on the contemporary memoir and as a rhetorical force, reflects and reinforces larger cultural discourses of loss.

My analysis in this chapter demonstrates that memoir bravery, as I have theorized, operates on both a level of discourse surrounding the memoir genre and within the textuality of the memoir. In using Karr's childhood memoir as a case in point, I propose the benefits of a 
rhetorical analysis approach as a way to examine the cultural work of the memoir. In an era of blurred fake-reals, the contemporary brave memoir feeds a cultural hunger for perceived authentic experiences. Consequently, in our consumer-driven culture, this is a system that may cause an enduring sense of being-in-longing. This may indeed be why we have so many brave memoirs. 


\title{
CHAPTER IV
}

\section{WRITING FROM THE WOUND: A FEMINIST PERSPECTIVE OF THE RHETORIC OF BRAVERY IN LAURA GRAY-ROSENDALE'S COLLEGE GIRL}

\author{
Trauma ...is always the story of a wound that cries out, \\ that addresses us in the attempt to tell us of a reality \\ or a truth that is not otherwise available. \\ - Cathy Caruth
}

Laura Gray-Rosendale's memoir, College Girl, begins with the horrific description of a sleeping college girl being attacked in the middle of night in her Syracuse College apartment in 1988. The attacker, a man who Gray-Rosendale did not know, broke into the apartment, beat and raped her. One of Gray-Rosendale's roommates barricaded herself in a separate room during the attack and another called the police, who apprehended the attacker while he was still in the house. The memoir describes the immediate aftermath in typical trauma discourse- the fragmentation of self, the loss of time, the surges of fear, and the broken shards of memory. That's part one. The second half of the memoir turns toward analysis, as the author, now a graduate student in Wisconsin, attempts to reconstruct the memory of the attack as a way of dealing with a relapse of her Post Traumatic Stress Disorder. Gray-Rosendale might have ended the memoir with part one. Rather, the author employs an investigative style in which she not only follows clues from interviews and legal and medical sources to reconstruct the night of the attack and the immediate aftermath, but in doing so, she offers readers a commentary on the memoir genre, exposing the rhetorical methods and ethics of its construction.

Is Laura Gray-Rosendale a brave writer? She has been introduced as brave and courageous at speaking engagements, ${ }^{48}$ and her memoir has been appraised by reviewers as

\footnotetext{
${ }^{48}$ For example, in October of 2014 Gray-Rosendale returned to the Syracuse campus as a guest speaker for the Writing Program's Nonfiction Reading Series (NFRS), in which Eileen Schell, associate professor of rhetoric at Syracuse and founder of NFRS, introduced the speaker. A campus news source reports Schell's introductory comments in which she thanked Gray-Rosendale for coming and for addressing the difficult topic of sexual assault:
} 
brave and courageous writing. One editorial review reads: "[College Girl] is about the dividing line between bravery and cowardice. [...] Words like brave or honest usually used to describe a memoir of trauma and recovery don't even come close to capturing this searingly painful, unflinchingly self-reflective, and painstakingly subtle memoir" (SUNY Press). ${ }^{49}$ The explicit and individual account of rape and its aftermath may prompt readers to think of the author as "brave," but what does this mean? Several responses are possible, including but not limited to the following: She is brave because she survived. She is brave because she reveals a very personal story that some may feel should be kept private. She is brave because she faces her abuser through the form of memoir. She is brave because she writes a kind of memoir that others who have been raped cannot or would not write: she is the exception not the norm. She is brave because she writes about a topic that makes others feel uncomfortable. Through the writing Gray-Rosendale confronts the cultural conditions of speaking about rape and the culture of silence that has hushed many victims, but it is that last response that points to the crux of the rhetoric of bravery as being more about those who speak it than the one of whom they speak about. The rhetoric of bravery is heroic language, as I described in previous chapters; it is language that sanctifies, or sets apart one from the crowd as being special; it is language that eulogizes, or pays tribute to one who has experienced loss; it is language that commemorates, honors, legitimizes, authenticates, and memorializes. What else is it?

\footnotetext{
"We know it is a deep wound, and it cuts to the core of the being of the person and the soul of the person. And so to take on that topic is to take something on that few of us have the courage to" (Silvarole). Gray-Rosendale believes that "surviving sexual assault is not a private thing [as it] often [is] a very public crime and affects a lot of people" (Gadoua). The uptake of the memoir as a brave story of trauma and recovery is the public's common response to the book since its publication in 2013 .

49 The quote is a composite of two quotes found on the SUNY Press website. The original authors of the quotes are Evan Handler, actor and author of Time on Fire: My Comedy of Terrors and Michael Kimmel, author of Guyland: The Perilous World Where Boys Become Men.
} 
In this dissertation, I have approached the contemporary memoir as a genre that both represents and reinforces cultural assumptions about "bravery" as an ideology. Explicitly, I have explored as a cultural phenomenon the uptake of certain kinds of memoirs, particularly memoirs written by women, as “brave.” In this chapter, I analyze Laura Gray-Rosendale's memoir, College Girl, as a representation of a "brave" memoir. In my analysis, I continue to examine the rhetorical ways in which memoir bravery reflects and reinforces a cultural attraction to the heroic narrative, but with one extension: a feminist understanding of the rhetoric of bravery.

Building on the rhetorical and theoretical work in previous chapters, in this Chapter, I analyze College Girl as one story of rape and a specific instance of traumatic violence. I argue that the rhetoric of bravery both reveals and constructs not only a way of telling, but also $a$ way of hearing stories of violent rape. I propose that the rhetoric of bravery functions as a collective readers' response to stories of trauma. By "readers" I am grouping those readers, reviewers, and publishers who employ the rhetoric of bravery as a way for gauging the significance of many memoirs. As a response rhetoric, what is the criteria for bravery? Must narratives of rape include a hero, a brave one who steps up and performs "beyond the call of duty" by telling a difficult story or a counternarrative that, in the end, may or may not reap multiple (and maybe good) effects within the culture? This question is not as much about the act of heroism itself as it is a reflection of a preferred way of hearing rape stories. If this is the case, the rhetoric of bravery may soften the way stories of traumatic violence are received, and in turn, redirect attention to the wounded individual.

The rhetoric of bravery, I propose, is one way of retelling or recasting someone's story in a way that has meaning to someone else. It conveys the capacity to both promote the heroic and nurture the wounded in stories of trauma. We cannot know whether individual readers identify at 
the empathetic level with the narrator or whether they ask themselves: what would I do in that situation - and from there project empathy. What we can know is the evidence of self-empathy projected in specific stories of trauma. This claim requires, first, a critique of empathy, and second, an understanding of self-empathy.

\section{A Critique of Empathy, Part 1: The Rhetoric of Bravery as an Empathetic Readers'}

\section{Response?}

In Other People's Stories: Entitlement Claims and the Critique of Empathy Amy Shuman examines "the role of personal narratives in the public sphere" (6) and questions "how an individual life story acquires a more-than-personal meaning” (8). Shuman offers a critique of empathy in situations where stories are retold "without attention to the responsibilities between listeners and tellers," and interrogates the large claims and promises of storytelling ${ }^{50}(11)$. Shuman's focus is on the ethics of "conversational storytelling," which she argues "has developed culturally specific critiques of empathy," and which are relevant to discussions regarding "the ethics of narrative" (5). Shuman's work is contextualized in the sociolinguistic levels of discourse analysis and focuses on "the way stories travel beyond their original tellers and contexts" (3). Although different issues are at stake for conversational stories than published memoirs, there are important implications I would like to draw from Shuman's argument that may help articulate a critical view of the rhetoric of bravery as an empathetic way of hearing stories of trauma.

Shuman claims, "Storytelling is pushed to its limits both by the use of a particular story beyond the context of the experience it represents and by the use of a personal story to represent

\footnotetext{
${ }^{50}$ Shuman explains her writing purpose, in part, is to "trouble the divide between situated lives, personal stories, and contextualized productions of meaning, and the stories that are told as grand historical narratives with global or historical contexts, on the other" (11).
} 
a collective experience" (3). Shuman raises the issues of "entitlement and tellability" as problematic when stories are retold by examining how "stories taken out of context are used to create sympathy for the individual whose suffering is represented in the stories" (8). Shuman defines a "sympathetic response to another's situation" as "a willingness to share an interpretation of or feel compassion for another's plight," which is different from empathy, "an attempt to experience the suffering of others" (8). Shuman elaborates, Empathy puts in place the possibility that, through the luxury of storytelling, others can indirectly experience that person's suffering for their personal or collective enlightenment without enduring those tragedies, or if they have endured tragedies, they are offered transcendence through compassion toward others. (8)

Shuman views empathy as arising from a behavior of storytelling. In light of Shuman's description, can we say that the rhetoric of bravery — as an ideology comprised of collective experiences, beliefs, and assessments about bravery — functions as kind of retelling of a story? At best, is it rhetoric that recasts someone else's story by appealing to a culturally-loaded concept (bravery), and in so doing, shifts the focus away from the story and onto the person in the story who has now become a hero, albeit a wounded hero. The rhetoric of bravery also entitles the one using it, and in a sense, shifts the focus again from the story and the wounded hero to the evaluation that is being offered. In this way, bravery rhetoric opens and limits a way of hearing the story.

The narrative ethics raised by Shuman bears on the rhetoric of bravery on at least two fronts. First, we might consider the rhetoric of bravery as a problem of entitlement. What right do others (readers, reviewers, publishers) have to recast someone's personal story as a brave 
story, which presents it in the accompanying narratives and cultural meanings commonly associated with bravery. Shuman explains the problem of entitlement as an "[e]thical question of ownership which overlaps with cultural conventions for representing experience" (3). In short, it is reductive rhetoric that situates a story categorically. The recasting of a story as "brave" labels it and limits the way it is then heard, or in the case of memoir, the way it is read. Bravery as a cultural ideology may contribute to the way bravery rhetoric is used in relation to certain kinds of memoirs as representing, not necessarily experience, but beliefs about what experiences count as brave. Telling a rape story counts.

Second, the rhetoric of bravery does not adequately measure readers' response in terms of empathy. From Shuman's distinction between sympathy (feeling for another) and empathy (feeling with the other), one might ask whether identifying a trauma story as brave figures to what degree and range, if any, as a measure of sympathy or empathy. To call someone brave has as much potential of being a self-defense mechanism as it does an expression of a heartfelt understanding of another person's story. According to Suzanne Keen, author of Empathy and the Novel, "no text evokes the same responses in all of its readers" (Empathy 4). Keen acknowledges that empathy as "a vicarious, spontaneous sharing of affect, can be provoked by witnessing another's emotional state, by hearing about another's condition, or even by reading" (Empathy 4). My reading of Keen is not that she is against empathy or leaves no room for accepting evidence that would satisfy her curiosity about the empathetic work of the novel. ${ }^{51}$ Her critique is not of empathy, per se, but rather it is directed at the unwarranted claims made on behalf of the

\footnotetext{
${ }^{51}$ Keen "pursues the question of what a habit of novel reading does to the moral imagination of the immerse reader" (Empathy xxv), and makes it clear to her readers that she "does not assume from the outset that empathy for fictional characters necessarily translates into what Stephen Pinker calls 'nicer' human behavior” (Empathy xxv).
} 
novel's capacity to effect empathy in readers, for empathy depends on the readers' approaches and takeaways from the novel. Keen says it this way:

it would be gratifying to discover that reading Henry James makes us better world citizens, but I wonder whether the expenditure of shared feeling on fictional characters might not waste what little attention we have for others on nonexistent entities, or at best reveal that addicted readers are simply endowed with empathetic dispositions...I would be delighted to affirm the salutary effects of novel reading, but I am not prepared to take them on faith. (xxv)

For Keen, that reading novels can potentially lead to an empathetic response is not what she finds troubling. Her critique of empathy centers on, as she argues, what "little is known about the process that would transpose experiences of feeling with fictional beings to actions taken on behalf of real others" (Empathy 35).

To what extent does Keen's critique of empathy and the novel bear relevance for the memoir? Does it matter to readers whether the "character" is fictional or not? Keen admits that the "expenditure of shared feeling on fictional characters" might "waste what little attention we have" (xxv), but does this apply to nonfictional characters who are not usually depicted as characters at all but "real" people? Furthermore, what kind of "attention" is Keen referring to and is it the same level of attentiveness that is perhaps assigned by many readers to the wounded narrator in nonfiction? Granted, the nonfiction narrator is a constructed persona, a textual autobiographical 'I,' a character in a memoir, an author who has recovered enough to write a memoir — but does the genre context make a difference in the reader-empathy link? Or, does 
empathy primarily rest in the reader and stem from what the reader brings to the text, regardless of whether the text is fiction or nonfiction?

On one hand, locating evidence in many readers' response-based arguments is slippery, often prone to the subjectivity of the researcher and the biases that may affect the collecting and interpreting of data. For Keen, evidence for the scope of empathetic reading is lacking because of the inconsistencies and varying degrees of which readers may identify with a character, or participate in a situation in cases where the author appears to invite empathy (Keen, Empathy xii). On the other hand, the rhetoric of bravery offers evidence of one consistency in response to many trauma memoirs. To what extent might the wide-spread consistency of bravery rhetoric be considered a viable readers' response? If, then, the rhetoric of bravery meets Keen's consistency requirement, as a nonfiction genre, can the process of reading memoir transpose experiences of feeling with nonfictional narrators to actions? Again, this question: does it make any difference whether the character with whom the readers empathize is fictional or not? Finally, might the rhetoric of bravery as I have theorized it function as a linguistic effect of readers' empathy? Finding answers to these questions involves the same level of difficulty that Keen exposes in regard to empathy and the novel. What we do find evidence for in the memoir, particularly trauma memoirs, is the capacity of the narrator to extend empathy to the self, which, in the end, offers readers one model of empathy.

\section{A Critique of Empathy, Part 2: Memoir Bravery and Self-Empathy}

To elaborate the tie between memoir bravery and self-empathy it is important to continue examining Keen's line of inquiry in which she dismantles the linkage between literature, empathy, and caring by challenging the "other-centeredness" of empathy (Empathy 20). First, 
Keen challenges the large claims that empathy theorists ${ }^{52}$ make about the novel and its ability to cultivate readers' empathy (Empathy 20), arguing that a lack of evidence exists for claims that single out the novel as "a technology most adept at invoking empathy" (Empathy 35).

Furthermore, Keen notes that the "transformation of empathy into other moral affects [such as caring and altruism] does not necessarily lead to a single kind of feeling” (17). Keen argues against theorists, such as psychologist Martin $\operatorname{Hoffman}^{53}$ who studies the relationship between empathy and morality, debating the views of Hoffman and others that empathy is a people skill or the root of morality. Keen stresses the limits of empathy in that "people may feel others' distress but do nothing to alleviate it" (Empathy 19). To further illustrate, Keen points out that empathy that may arise from feelings of guilt, such as in cases where the "perceiver actually has caused the victim's distress...[or] if the observer does nothing to relieve the suffering individual...[or] if the perceiver belongs to a group believed to be responsible for causing suffering" (18). Guilt-based empathy as what may arise in bystanders or in those who directly or indirectly cause suffering, Keen argues, "may or may not impel a perceiver toward altruism or helping — guilty feelings may in fact incline a perceiver toward a feeling of helplessness in the face of others' suffering" ${ }^{54}$ (18).

Another key factor Keen asserts in disputing claims such as what Martha Nussbaum in her book Cultivating Humanity make about fiction's ability to foster a caring society is the problem with biases and the rendering of empathy by the market. Keen points out the bias of

\footnotetext{
52 The theorists whose work Keen challenges include Martha Nussbaum, Azar Nafisi, Steven Pinker, Lynn Hunt, (see Keen xviii-xx for an overview of these theorists' stances on empathy and reading), and Martin Hoffman (see Keen 16 ff) among others.

${ }^{53}$ Martin Hoffman suggests "five possibilities for the shaping of empathy into different moral affects, each related to the perceiver's evaluation of causes. (See Keen 16-23 for a refutation of Hoffman).

${ }^{54}$ This position on guilt-based empathy differs strikingly from Martin Hoffman's view. In contrast, "Hoffman believes, however that guilty feelings can be channeled into patterns of helping, but concedes that without teaching by parents or others, this outcome is less likely to develop" (Empathy and Moral Development 9; qtd. in Keen 18).
} 
"familiarity" in empathy, which she argues "impedes response to strangers" (20). Even Hoffman observes that "empathy may work best in homogeneous groups" (Empathy and Moral Development 216; qtd in Keen, Empathy 20). In addition to the limits of empathy in terms of the unfamiliar, Keen notes a second bias that impedes empathy, which she refers to as the "here-andnow" (20). Related to the impediment of the familiar, feeling empathy for what is directly within one's life as opposed to what is faraway "dilutes responsiveness" and "sometimes interfere[s] with justice" (Keen, Empathy 20). The biases and complexities of empathy prohibit its application as a blanket affect for covering the potential transformations of novel reading. Yet, as Keen worries, "The reputation of narrative empathy is tainted by association with popular technologies for sharing feelings" (39). To underscore this concern, Keen provides an extensive commentary on porn calling it "the market's most successful vehicle for rendering feelings;" porn invokes "a strong sense of 'feeling with' another" (40). The appeal to porn may be an extreme illustration, but it accentuates the notion that empathy comes in many varieties. Keen critiques the publicity of empathy as a "twenty-first century" notion that gets "good press as a concept and a desirable character trait" (39). Keen also critiques empathy as a concept associated with only positive virtues. She does this by noting the potential for empathy to surface in varying degrees and in diverse contexts, and by challenging those who situate empathy as a virtue primarily focused on others.

The etymology of empathy lends support to Keen's critique of theorists who position empathy as other-centered. Rooted in the Greek word pathos, and translated from the German word Einfühlung, "empathy" became the translated English word penned by psychologist E.B. Titchener in 1909. The term Einfühlung was used by aesthetician Theodor Lipp to mean "a process of 'feeling one's way into' an art object or another person" (Keen, Empathy 186, note 3). 
To further explain the etymological journey of empathy as it began in English, I quote the following footnote from Keen's text Empathy and the Novel, and her reproduction of Titchener's elaboration in his 1925 text, Beginner's Psychology:

We have a natural tendency to feel ourselves into what we perceive or imagine. As we read about the forest, we may, as it were, become the explorer; we feel for ourselves the gloom, the silence, the humidity, the oppression, the sense of lurking danger; everything is strange, but it is to us that strange experience has come. (Titchener 198; qtd in Keen, Empathy 186, note 3)

Titchener's explanation suggests that empathy maintains an inward posture or a stance of the self that faces the self. The questions posed for empathy and memoir differ slightly from Keen's interrogations of empathy and the novel because of the implication of the "real" (which I realize is problematic to some theorists who might assume that what we call "real" in memoir is yet another fiction). Shuman emphasizes empathy as an "act of understanding others across time, space, or any difference in experience" (4). In autobiographical narratives that depict the narrator across time and space and experience, in what ways might empathy travel towards the self? The etymology of empathy, as Titchener notes, points to caring for the self.

\section{The Role of Vulnerability in Self-empathy}

One foundational cultural condition for the judgment of the rape memoir as "brave" involves the role of the narrator's vulnerability and the inevitable shift toward agency as manifested in the memoir. Gray-Rosendale begins her memoir with a depiction of the narrator in a most vulnerable position - a college girl asleep in her own bed. She ends the memoir with a voice of reason, a scholarly voice of a professor who has come to understand and embrace the 
vulnerability of the college girl with a deep sense of self-empathy. Gray-Rosendale writes from the wound of rape, a space of exposed vulnerability that, in the end, enters into a space of agency, and even advocacy. Cultural critic Judith Butler suggests that there is a deliberate “exposure that mobilizes vulnerability" ("Vulnerability”) — a claim that disentangles vulnerability and agency as binaries, which is a deconstruction that reveals their mutual imbrication. Through the memoir, Gray-Rosendale seeks to integrate the broken college girl as an essential aspect of the strong woman. In so doing, Gray-Rosendale represents her experiences using trauma and recovery as a trope, emphasizing the fragmentations that often occur as a result of violent trauma. The college girl's vulnerability that Gray-Rosendale establishes at the beginning of the memoir enters into an agentive force later in the writing. Vulnerability does not guarantee an agentive response, nor is vulnerability a prerequisite for agency. However, as a componential cause of agency, the vulnerability of the college girl that Gray-Rosendale establishes early on in the memoir is, thus, a contingent and component cause of the agentive narrator that comes later in the memoir. This agentive force manifests, I argue, as a feminist form of self-care performed by the autobiographical 'I's' in the memoir.

To theorize vulnerability in terms of what it may provide as a category of care ethics is to claim that "there is something in the experience of one's own vulnerability that allows for an appreciation of the vulnerability of others" (Murphy 56). At the root the Latin vulnus meaning "wound" denotes a more direct connection to care, at least in a medical sense. In his text, The Ethics and Aesthetics of Vulnerability, Jean-Michel Ganteau traces vulnerability to its association with the ethics of care. Ganteau explains that "vulnerability is shared, that it is common property, and that it allows for a vision of the human as essentially interdependent and in no way 
autonomous" (Ganteau 5) ${ }^{55}$ An appreciative stance toward vulnerability as reimagined in contemporary feminists' theories may indicate a cultural turn toward perceiving vulnerability as something other than its commonplace opposition to agency. In her chapter in Theorizing Sexual Violence, Anne Murphy further explains this throwback to care ethics as echoing a "longstanding concern in feminist ethics, namely the idea that culturally feminine—and hence undervalued — traits such as interdependence, community mindedness and vulnerability should be given their due, and that traditionally masculine traits such as independence and autonomy have been overvalued in the domain of ethics" (56).

Murphy acknowledges that vulnerability has deep roots in feminist theory but she detects "something novel in the way in which feminists are presently approaching this motif" (55). Murphy observes that in past theories, "vulnerability has been figured as something that plagues women disproportionately" pointing to the portrayal of vulnerability as an embodied liability for women "in need of redress" (55). In the last ten years, however, Murphy claims that a shift in feminists' perspectives suggests a "motif of vulnerability may be productively mined" (55). The way Laura Gray-Rosendale cares for the wounded, vulnerable college girl beginning with the retelling of the night of the attack, illustrates the way "vulnerability may be productively mined" in a memoir of trauma. This idea of situating vulnerability as a necessary component of the narrator's agency shifts the field away from common binary constructs in which vulnerability and resistance are at odds, toward an appreciative, relational, and interdependent perspective of vulnerability. ${ }^{56}$ The potential for self-empathy requires establishing the narrator's vulnerability

\footnotetext{
${ }^{55}$ See also Held 36 and Nussbaum, The Fragility 352.

${ }^{56}$ Judith Butler describes the interdependence of vulnerability and agency in a paper presented at the 2014 MLA Convention titled "Vulnerability and Resistance." In this critical treatment, Butler interrogates the binary conditions of these terms and proposes a theory of vulnerability that does not pit vulnerability against resistance or agency. In fact, Butler questions what happens to vulnerability in this binary model: "is it negated when it converts to agency or is it still there assuming a different form?" ("Vulnerability"). Butler reasons through the location of vulnerability in relation to agency in these rhetorical questions: "When we oppose vulnerability $[\ldots]$ is it because we would like to
} 
and the demand for care. In a feminist interpretation of vulnerability, the narrator does not sweep in and rescue the wounded as a hero, but rather carefully nurtures her to a place where she can look at her wounds with courage, focusing the center of attention on the wounded and her recovery, and not on the heroism of the act of care.

In memoir, the capacity for self-empathy as it surmounts in the narrator's own progression toward agency, or even advocacy, elaborates a feminist brand of bravery, one in which interdependence, relationality, and self-care are vital stakes in the rhetoric. In College Girl, Gray-Rosendale employs various aspects of the autobiographical 'I' to prompt the narrator's shift in status, moving between victim and survivor, and finally, advocate. The question I am interested in theorizing through a rhetorical analysis of College Girl is whether the evident self-care that emits from the tensions and interplay in the text between the narrator's vulnerability and her sense of agency, which arise from having survived a horrific traumatic and violent experience, has the potential to affect readers with a sense of empathy as evident in the rhetoric of bravery. Can we see ourselves in her shoes caring for the wounded college girl? To what end, then, might a feminist reading of College Girl play into an interpretation of the rhetoric of bravery in which self-empathy — as a model of empathy that "feels with" and that acts on that feeling by caring for the self—is a viable element for affecting empathy as a reader's response? Another possible response to add to the list of reasons for Gray-Rosendale to be

see ourselves as agentic? If we oppose vulnerability in the name of agency, does that imply that we prefer to see ourselves as acting instead of being acted upon?" ("Vulnerability"). Butler confronts the underlying cultural motive for perceiving vulnerability as weakness: we prefer to act, to be in the agentive position - rather than be acted upon. I don't think Butler, in identifying this cultural bent toward a preference for agency over subjectivity intends to debunk that stance. Rather, Butler urges a rethinking of the ways in which vulnerability enacts resistance, and thus bears the potential of entering into agency. (The Conference theme, "Vulnerable Times," further reflects the wideranging application of vulnerability as a contemporary mode for thinking. In Marianne Hirsch's call for papers she evoked this interdisciplinary exchange: "studies of the environment, social ecology, political economy, medicine, and developmental psychology as terms that help address the predisposition of people and systems to injury" (Hirsch 1). Scholars across disciplines interrogated the meaning of vulnerability in the contemporary era.) 
considered a brave writer is this: She is brave because she takes care of her wounded self. In a Good Samaritan fashion, the adult narrator nurtures the suffering college girl, and through the writing provides a teaching parable for society.

In light of Keen's critique of empathy and my aim of working towards a feminist theory of the rhetoric of bravery, several broad questions come into play: first, what is the memoir's capacity for empathy, meaning, to what degree might the memoir invite readers into a space where readers experience empathy for the narrator? Second, how might empathy and the memoir converge or diverge from debates that occur in fiction regarding empathy and the novel $?^{57}$ Third, what is at stake for the memoir genre as a contemporary form of self-care $?^{58}$ Fourth, to what degree, if any, do larger cultural discourses of bravery - the recent rise in antibullying campaigns, mental health programs, and other public service and marketing endeavors that make appeals for self-improvement using bravery rhetoric — intersect with a new brand of bravery that identifies bravery as a form of self-care? I realize the crux of my argument still faces the question of knowability. How can we know whether readers' respond to a text with empathy unless there is action that follows? I am proposing that the rhetoric of bravery is one kind of linguistic "action" that may have embedded within the rhetoric a sense of empathetic awareness. As a significant line of inquiry, it is important to examine the cultural conditions for bravery within the text of the memoir.

The theory work important in this chapter is to weigh Keen's critique of empathy against an assertion that memoirs of trauma, like College Girl, model self-empathy. Keen's purpose is to

\footnotetext{
${ }^{57}$ Questions that require a comparison of memoir and the novel are outside the scope of this chapter to provide indepth analysis. But it is important to ask them as a way to enter the work of analyzing a trauma memoir as they suggest potential points of analysis for memoir and empathy in a culture that values bravery.

${ }^{58}$ See Megan Brown's argument that "self-care is a biopolitical technology, serving the broader goal of governing at a distance as subjects learn and perpetuate norms for healthy, productive citizenship, for contributing to society" (Brown 361). I discuss this perspective at length in Chapter 1.
} 
question "the contemporary truism that novel reading cultivates empathy that produces good citizens for the world" (xv). My question is similar but is about the potential of memoir as a work of nonfiction to cultivate empathy. In terms of their convergence, Keen recognizes that in fields of cognitive literary studies, "literary works - whether fictional or not - have an emotional and tangible effect on readers and on the real world in which we live with literature" (Keen, Empathy xi). Even so, Keen questions the "bold claims that have been made for the positive consequences of the novel" (Empathy xv) when, in fact, "[1]inking novel reading to a widely shared moral principle — caring — without demanding that fiction be about caring allows broad claims about the medium to exist without evaluating content" (Empathy 20). Memoirs of trauma are exceptional: they do often make demands about caring. To what extent, then, might such demands become part of the cultural work of the contemporary memoir as many life writing scholars have claimed $?^{59}$

\section{The Trope of Trauma and Recovery}

For Laura Gray-Rosendale, the memoir provides a potential literary space for her story as a victim of sexual assault to gain a hearing in a culture with a history of silence about rape. ${ }^{60}$ Furthermore, the memoir offers a literary forum for trauma, one in which trauma is recounted and through which, as trauma theorist Cathy Caruth declares, the "unspeakable" can be spoken. The memoir provides a means for victims to speak the "unspeakable." This is what gives momentum to the uptake of rape memoirs as brave stories and of those who write them as brave individuals. Feminist writers and activists over the years have taken up the struggle to break the

\footnotetext{
${ }^{59}$ See my literature review in chapter one of the claims about the cultural work of the memoir genre made by scholars such as G. Thomas Couser, Julie Rak, and Leigh Gilmore.

${ }^{60}$ In this statement, I am not making an exclusive claim for memoir. Fiction, film, drama, YA novels, and other genres are increasingly graphic with regard to the full saying of a violent rape. Pat Conroy or Toni Morrison are two such examples of writers who have found hospitality in fiction for stories of violent rape.
} 
silence and weight of shame that is often associated with rape. As narratives of trauma, rape stories often are portrayed along the trajectory of "trauma and recovery" - a storyline that begins with the traumatic violence and its aftermath and moves toward recovery. It is not uncommon to find contemporary memoirs written as stories of suffering victims of trauma and its aftermath. ${ }^{61}$ The official recognition of Post-traumatic stress disorder ${ }^{62}$ (PTSD) by the American Psychiatric Association in 1980 provided a narrative path for stories of trauma. PTSD was introduced as a diagnosis in the third edition of the Diagnostic and Statistical Manual of Mental Disorders (DSM). Before then it was used primarily to refer to soldiers' experiences to diagnose the psychological sufferings in the aftermath of war. PTSD provides explanation for the psychological effects and the common traits that occur in the healing processes of various kinds of traumatic experiences. The language of PTSD also provides a productive way of talking about rape.

The broad question of why women's memoirs of rape are often considered brave requires an analysis of "trauma and recovery" as a cultural-conventional trope for telling and hearing stories of violence. In rape memoirs, "trauma and recovery" is often emphasized as a singular concept, which in effect, tends to recast victims as survivors by the ways in which narratives of trauma often depend on recovery. I don't mean "recovery" as something achieved or arrived at, but as a complex ongoing process much like "being in recovery." On one level, the notion of recovery tends to reinforce a cultural expectation that one who has experienced violent trauma

\footnotetext{
${ }^{61}$ Using social inquiry and ethnographic methods, in their book Empire of Trauma: An Inquiry into the Condition of Victimhood, Fassin and Rechtman trace the "historical construction and the political uses of trauma" as it has become "a major signifier of our age" and a "normal means of relating present suffering to past violence" (xi). In telling the "story of how the traumatic victim became culturally and politically respectable, and how trauma itself became an unassailable moral category" the authors reveal that "trauma has come to authenticate the suffering of victims" (xi).

${ }^{62}$ For a detailed examination of posttraumatic stress disorder (PTSD) as a concept, see part one of Fassin and Rechtman's the Empire of Trauma as they trace the notion from its onset as a medical diagnosis introduced in the 1980 third revision of the U.S. Diagnostic and Statistical Manual of Mental Disorders (DSM-III) (15, note 1).
} 
can (and should and is entitled to) heal. All of those. Yet, there is a measure of cultural capital regarding one's prior status as a suffering victim that often complicates the trauma narrative-for without the suffering victim there is no interesting story (and therefore, no capacity for empathy, and certainly no bravery). The nuanced singularity of 'trauma and recovery' as a phrasal unit works both ways - as depicting the expectation of recovery, but also a recovery fixed on enduring care for the wound and the wounded. ${ }^{63}$

It is important to identify "trauma and recovery" as a trope precisely because of the inadequacies of language for narrating trauma. Susan Brison writes in reference to her own violent attack and sexual assault of the difficulty of "finding language that is true to traumatic experience"64 (Aftermath xi). Brison posits this question: "How can we speak about the unspeakable without attempting to render it intelligible and sayable" (xi, italics mine). Trauma theorist Judith Herman begins her landmark work, Trauma and Recovery, with this observation: "Certain violations of the social compact are too terrible to utter aloud: this is the meaning of the word unspeakable" (1, italics original). And yet violent rape — a traumatic experience that is rendered unspeakable — often finds a kind of literary hospitality in the memoir genre. One explanation for memoir's hospitality to traumatic violence may be Herman's next line: "Atrocities, however, refuse to be buried...[r]emembering and telling the truth about terrible events are prerequisites both for the restoration of the social order and for the healing of individual victims" (1). The healing and cathartic advantage to the writer of trauma is certainly one beneficial effect of memoir.

\footnotetext{
${ }^{63}$ In psychoanalytic language, this is the jouissance of the victim.

${ }^{64}$ Susan Brison writes in Aftermath: Violence and the Remaking of a Self about being attacked while on a morning walk in southern France on July 4, 1990. The attacker surprised her from behind and after severely beating and sexually assaulting her, left her for dead.
} 
In her book Writing Wounds, Kathryn Robson examines what is at stake in assimilating trauma into narrative. Robson argues that "to tell the story of trauma risks diluting the horror of traumatic experience and 'forgetting' what happened, thereby losing the possibility of remembering and bearing witness to the traumatic past" (Robson 12). Robson further suggests that how we interpret and judge such narratives derives from a balance "between an imperative to convey the horror of trauma and the equally urgent need to contain or minimize that horror," or put another way, "between the requirement to remember and the urge to forget" (12). Most influential to the speakability of traumatic violence is the diagnosis of PTSD and the language it provides for not only talking about the aftermath of trauma, but for also validating symptoms (including forms of amnesia) as a medical condition, which in effect, further fortifies the tie of trauma to recovery.

The very fact that the memoir has been written would suggest that the author has recovered to some degree- enough to write, anyway. When the rhetoric of bravery is used in reference to a rape memoir, another aspect of the problem of memory emerges. On the cultural level, memoir bravery expresses an existing cultural tension similar to the "imperative to convey" and the "need to contain" the horror of rape. In other words, assessing rape memoirs as "brave" may entail an attempt to do something with the horror of rape that makes society feel more at ease. As history has demonstrated, heroes bear our burdens adeptly, but often in their deaths.

Also problematically embedded in the discourse of trauma are the contested categories of "victim" verses "survivor." 65 In fact, the replacement of "survivor" for "victim," which is

\footnotetext{
65 The title of Gabe Mythen's entry in the 2007 Handbook of Victims and Victimology sums up the climate in a rhetorical question: "Are We All Victims Now?" The ambiguity of 'victim' in which anyone and everyone can potentially claim to be a victim and the extension of its reach gave way to a stronger, more resilient term: 'survivor.' Sociologist Ronnie Lippens argues that the victim discourse that mobilized in the twenty-first century represented a
} 
preferred in many circles for diverse reasons, attests to the notion of bravery rhetoric as potentially rewriting cultural scripts of victimhood in general-if one buys into the notion that a "survivor" is "brave" in ways that a "victim" is not. As I have said, the rhetoric of bravery itself becomes a way of hearing rape stories. As a society, we may be predisposed to hear stories of rape as being "brave" primarily because we have been conditioned to expect that the person who was raped has "recovered" from the traumatic event, or at least, enough time has passed that the one raped has "worked through" the psychological aftermath of violence. Whether to call a person who was raped a "victim" or a "survivor" raises similar problematic issues as does an emphasis on "trauma and recovery" as a singular concept: both suggest a preference for a strong and positive outcome (a hero's journey of sorts).

Offering another perspective, Joanna Bourke, author of Rape: A History from 1860 to the Present, writes in the Forward of Renee Heberle and Victoria Grace's edited collection, Theorizing Sexual Violence, this warning: "positioning women as either 'victim' or 'survivor' can be another way of insisting that they have to take responsibility for healing themselves" (Heberle and Grace iv). The lack of critical discourse for distinguishing the nuances of "victim" and "survivor" in the processes of "recovery" further complicates the language problems of narrating the trauma of rape. Marilyn Nissim-Sabat approaches the two terms as being rather symbiotic. In her book, Neither Victim nor Survivor: Thinking Toward a New Humanity, ${ }^{66}$

\footnotetext{
"sovereign hunt for victimhood" through the plethora of aspects that "one could fall victim to," such as "antisocial behavior" or "risky behaviors" that can cause "harm" (32). Out of this newfound status of victimhoods grew what Fassin and Rechtman refer to as an "empire of trauma."

${ }^{66} \mathrm{Nissim}$-Sabat argues for three categorizations of victims in American public life. These include (a) victims whose suffering is caused by events that is no fault of their own (such as natural disasters), (b) victims whose suffering is viewed as self-imposed (such as people living in poverty or women who are battered), and (c) victims whose suffering is caused by the actions of others (Schott 930). Nissim-Sabat's view of victims "posits a split between external circumstances of traumas and subjective volition or judgment" (Schott 931). This approach to conceptualizing the term victim is rooted in a "passive conception of the subject" (Schott 931), which seeped into ideologies of rape "victims" as passive.
} 
Nissim-Sabat addresses the ways in which "victim" and "survivor" are conceptualized in relation to public discourses about poverty, racism, slavery, capital punishment, and drug and alcohol abuse (Schott 930). Nissim-Sabat suggests a complex interplay exists between "victim" and "survivor" as concepts. In short, Nissim-Sabat insists on the convergence of the subjectivity of the person and the traumatizing events by questioning the interplay between "victim" and "survivor": embedded in survival discourse is victim discourse. The overlap of victim/survivor points back to the possible underlying assumption of perceiving "trauma and recovery" as a singular concept. Does 'recovery' entail being made (or remade) "whole?"67 Does "healing" then mean an automatic shift in status from "victim" to "survivor?" Responses to rape that position "survivor" as the preferred term over "victim," not because the person who was raped feels like a survivor, do so because the word "survivor" connotes an individual's resilience or the ability to act in the face of danger and to survive; whereas "victim" alludes to a kind of passivity and a narrative of weakness.

When talking about rape, issues of language problems prevail. Feminists have theorized the rhetorical force of the word "rape" using Michel Foucault's nexus of power and discourse in language ${ }^{68}$ Like "rape," the terms "victim" and "survivor" not only express strong emotional appeal, but in Foucault's power/knowledge bind, they are terms that bear the potential of constructing "truth" through their very existence as linguistic categories. Feminists have taken to task the meaning of "rape" and what happens to the perceived meaning when it is changed to

\footnotetext{
${ }^{67}$ Anne Murphy discusses the "rhetoric of 'wholeness' and integrity that informs feminist discourses on recovery from rape and sexual assault" (58) (also see Cahill's Rethinking Rape).

${ }^{68}$ Nicola Gavey refers to the "gendered grammar of violence," as constructing not only "women as the objects of (men's violence), but also as the subjects of fear-that is of critical importance in sustaining rape" (96). In her text, Just Sex? The Cultural Scaffolding of Rape, Gavey writes: "In the case of rape, the truths propagated within such knowledge can be said to play a constitutive role in shaping the possibilities for gendered action that create the cultural conditions of possibility of rape. (97).
} 
"sexual assault" or "date rape" or when we contemplate the meaning of "consent," for examples. "Rape survivor" is language that weighs down the one raped with a cultural expectation of survival - which in my view, directly invokes an important contradiction and possible rationale for why we might call rape survivors brave: naming a "rape survivor" brave reinstates the "survivor" as a hero - as one who has acted beyond the call of duty and for the sake of others. The rhetoric of bravery acknowledges the survival of the one with praise from the many; but in so doing, it potentially advances a perspective that rape is a shared societal problem. Embedded in this advancement is the nexus of power and discourse that is at work in a feminist rhetoric of memoir bravery.

In a feminist interpretation of memoir bravery, the figure of the wound demands attention, and yet, like trauma, often "remains impossible to grasp" (Robson 13). If trauma is "beyond language," as trauma theorists in particular tend to agree, and yet trauma is portrayed in the literary form of memoir, there must be something about memoir as a form or genre that fosters the telling and hearing of stories of trauma, and therefore, allows trauma to be represented and effective. Caruth further imagines trauma in the figure of a wound with a story to tell as she writes:

Trauma seems to be much more than a pathology, or the simple illness of a wounded psyche: it is always the story of a wound that cries out, that addresses us in the attempt to tell us of a reality or truth that is not otherwise available. This truth, in its delayed appearance and its belated address, cannot be linked only to what is known, but also to what remains unknown in our very actions and our language. (Caruth 4) 
Similarly, Robson suggests that the image of the wound leaves a gap or a "loss" of something that was intact before the traumatic blow. Paradoxically, the interruption that trauma marks and the loss that it produces allows for an understanding "that is not otherwise available" (Caruth 4). The absence as an effect of the wound makes loss itself something productive. This understanding is more clearly imaginable in conjunction to a specific wounded body. In essence, the figure of a bodily wound is a literary image with double meaning. Robson explains it this way:

the bodily wound acts as a figure for the psychic rupture, spilling out words and blood in an attempt to convey a message we could not otherwise hear. The 'wound' stands in for-in effect, speaks for-a 'reality or truth that is not otherwise available': it is a double image, signaling injury on one hand and the gap(s) in our own lack of knowledge of psychic trauma on the other. (Robson 14)

This "double imagery" of the figure of the wound offers the memoirist the starting blocks for the sprint ahead of conveying through language what has been deemed "unspeakable," and by extension, "unhearable."

\section{Rhetorical Analysis of College Girl: A Model of Self-Empathy}

Eventually, I was going to have to find a way to tell my story. Making narrative out of this chaos...
It would be a memoir that also exposed gaps and fissures in my traumatic memory,
somehow negotiating the divide between those gaps and my desire to have coherence.
It would be a memoir that acknowledged and exposed the limits of storytelling
and memoir-writing themselves in adequately relating traumatic experiences.
- Laura Gray-Rosendale 175-176

The rhetoric of bravery as it surrounds memoirs of rape becomes not only a rhetoric of assessment, but also a common way of hearing rape stories. Writers of rape stories must engage the discourse domains that structure the ways in which their stories will (and can) be formed and 
heard, which, I argue, pushes authors to begin with the individual and circumstantial details of the rape ${ }^{69}$ To this end, I have suggested that the trope of trauma and recovery provides a readable structure for rape memoirs. In College Girl, Laura Gray-Rosendale employs the trope of trauma and recovery as a way to convey a counternarrative that disrupts rape culture. In so doing, she introduces a journey of a wounded, vulnerable narrator who many readers may predict will walk a familiar path: from trauma to recovery. Never taking the focus away from the vulnerability of the college girl and the sharp cuts that rape marks on an individual, GrayRosendale confronts the belief that rape is an individual story that can be neatly and coherently packaged in memoir even within the available narrative trope of trauma and recovery.

\footnotetext{
${ }^{69}$ It is outside the scope of this dissertation to include comparative work on rape memoirs. For the sake of further research, I offer this extensive footnote. Since the 1980s an abundance of memoirs written by rape survivors detail the rape at the start of the memoir. Patricia Weaver Francisco's Telling: A Memoir of Rape and Recovery opens with the harrowing details of a rapist who entered her downtown Minneapolis apartment while her husband was away and brutally raped her and mentally tortured her for several hours. Francisco interweaves the details of the rape with a self-conscious search for language for narrating the elusiveness of trauma and the problem of transposing rape onto a culture of silence that has been constructed. Francisco admits to a feeling of responsibility that kept her silent and ashamed for the next ten years, afraid of even speaking of the rape. She writes, "For if I speak, I will remember" (11). She had to learn not to say "I was raped but a man raped me" (14) distinguishing between the active and passive voice and the connotations of responsibility associated with active voice. Francisco acknowledges that as a rape survivor she heard the request for silence in a culture that believes in this denial: "If we aren't talking about it, maybe it isn't happening" (20, italics original). Structuring the memoir with the rape at or near the opening is one way to confront the culture of silence by rhetorically "forcing" readers to not only "listen," but also imagine stepping in the shoes of the victim - and no doubt, this strategy plays an important role in the rhetoric of bravery. The way Francisco intersperses the symptoms of trauma with the details of the rape portrays a way of telling that embraces an awareness of available ways of listening. She describes the pillow over her face, the rapist's desire for a "body without a face," the knife on her neck, the entering of his body into hers, and the beginning of separation from her own body as she finds a spot on the ceiling to focus on (28-29). The juxtaposition of the details of violence against a voice of reflection functions to establish authorial ethos as based on not only the experience of rape, but also the credibility of her testimony. The structure of Nancy Venable Raine's memoir, After Silence: Rape \& My Journey Back is another example of a memoir that opens with rape. Raine writes this matter-offact opening line: "On an October afternoon in 1985 I was raped by a stranger who crept through the open back door of my apartment while I was taking out the trash" (1). Subtly, the "open back door" suggests that the narrator struggles with being responsible for the man entering her apartment. One available way of "hearing" rape is to question the responsibility of the one who was raped. When a memoirist plays along with the "blame-the-victim" narrative, the risk may be the reinforcement of it. If rhetorically effective, however, the move may elicit a counterresponse that invites an empathetic reader response. What's important to note is that the narrator "tells" the rape story by entering into the existing scripts for telling, and in so doing, attempts to woo readers to imagine a credible and reliable narrator.
} 
Gray-Rosendale sets up the memoir as if it would follow the evolution of a narrator who moves through the trajectory of trauma to recovery by opening the book with the traumatic violence of rape. However, in the process of working through the aftermath, the narrator struggles to find adequate expression, exposing "the limits of storytelling and memoir-writing themselves in adequately relating traumatic experiences" (Gray-Rosendale 176). What readers may discover is not a cohesive story of an individual's recovery. In contrast, by confronting the incapacity of storytelling, of trauma tropes, of medical language, and of the memoir genre, GrayRosendale delivers a multi-faceted model of self-care within populated contexts of others. GrayRosendale makes a case for the necessity of our interdependence on one another in a world where our "desire for coherence" may never be met with satisfaction. In so doing, the memoir dispels the "myth of recovery" as something full and comprehensive, and promotes an acceptance of living with the unknown in a precarious world of interdependence.

Beginning with the night of the rape, Gray-Rosendale places the narrating 'I' as a vulnerable victim at the center of violence. A sense of powerlessness and helplessness is further demonstrated in the textual and visual rhetoric of the memoir. The language itself portrays the narrator's detachment from self and fragmentation of memory as the rape happens. This portrayal mirrors on the page the detachment and fragmentation of the self that violent trauma affords. Moving then from a detached self, a victimized 'I' appears in the text as the narrative voice shifts from the one experiencing the violence to one who is observing the violence. In other words, the voice of the narrator — the one who is being raped — turns into a voice of someone watching the one being raped. This split is a method of survival. What happens next to the decentered narrating 'I' is the movement back to "reality" and an awakening to the fact that this 'I' has indeed survived the rape and now must face the aftermath of the violence. Eventually, 
readers meet a narrating 'I' who can narrate the story of the lost college girl, who can find the language for her story within limits, who can explain the college girl's post-traumatic symptoms, survival wounds, and the ongoing cycle of trauma and recovery that survivors often experience, and who can integrate the multiple voices of others who were also victims of the rape. Throughout the memoir, the echo of many voices ricochet in the college girl's story. The Vulnerable ' $I$ '

I am not a statistic. —Laura Gray-Rosendale 121

As I have alluded to, memoirs of rape often have one commonality: they begin with the rape. Gray-Rosendale opens her memoir with the details of the rape in the first chapter, a move that takes readers to the night of the attack, reinforcing the individuality of the person and the specific locality of the violence. The rapist breaks into the apartment, enters her bedroom in the middle of the night, awakens the sleeping college girl, and violates her in the most horrific nightmare imaginable. She writes:

A fistful of my hair jerks me back.

There's a slabby male figure leaning over me, pants bunched around his hips.

I screech into the blackness, my fingers hunting for my glasses. A hand shuts off my scream.

I thrash, strain my neck to see a face.

It's gigantic, vacant, blank. Like a blackboard. (3-4)

In these lines, the narrator sets up the rhetorical parameters for reading the memoir by establishing for readers an imagined close proximity to the attack. Readers may be chilled by the opening scene of the memoir and the horrific violation of personal space and body as the faceless 
attacker awakens the college girl. The narrator describes what she can see and hear: the slabby male figure, pants bunched around his hips, pages crackling on the floor. What she cannot see is the attacker's face. She uses the metaphor of a "blackboard" as a way to explain her struggle to impose a face. She writes:

Outlined chin and jaw loom over me. I try to scribble in eyes, nose, lips. But I can't call up chalk.

He moves his hand.

\section{I scream.}

Thick fingers jam up my throat. My tongue swells.

Leathery sweat fills my nostrils. (20)

The details of the violence itself are juxtaposed against a vagueness, a blankness that exposes the narrator's lack of memory. Immediately in the opening of the memoir, we see the narrator experiencing the trauma itself.

One potential effect of these vivid lines is that readers are invited to enter into the space of violence and to feel the paralysis alongside the college girl. That she "can't call up the chalk" exemplifies the narrator's powerlessness to inscribe her own story. From the beginning of the memoir, the language appeals to pathos inviting readers to emotionally invest in the welfare of the college girl. As Keen has theorized, the invitation to empathize with a character may be obvious in the text, but the evidence of whether readers' do indeed feel compelled to empathetic feelings is inconclusive. Keen's critique of empathy, however, may not apply as directly to readers of traumatic nonfiction as it may to readers of fiction because the knowledge that this really happened and the follow-up thought that this could happen to me may evoke a level of empathy more available to readers of memoir. What we can conclude in Gray-Rosendale's 
opening scenes are the clear and present demands for empathy for the vulnerable college girl. As a writing strategy, this sets up the parameters for self-care as it unfolds in the memoir.

This opening strategy also makes the private space of her bedroom a public spectacle. The strategy of detailing the rape may add shock value for readers, on one level, as a result of the imagined close proximity to the assault and the sheer violation of private space. Seemingly positioned as spectators of a gruesome violence, readers may become conflicted with affective tensions between the lure to watch and the reaction to turn away. The first-person account of the rape positions the narrator at the center of the story and singles out her specific rape, setting it apart from becoming yet another statistic. I refer to this rhetorical move as "re-centering" the 'I.' "Re-centering" is something that the memoirist does for the sake of the writing, and because most likely years have passed since the rape (25 for Gray-Rosendale), the author must appear to go back in time and remember what it was like to be in the moment of the violence.

Gray-Rosendale's trajectory of the autobiographical narrating 'I' connotes particular rhetorical effects on readers. For instance, some readers may feel uneasy by being positioned as spectators and "witnessing" a rape as revealed through the language in the text. We watched it happen but are incapable of intervening. According to Keen, this may be an instance in which the reader feels empathy but acts as a bystander. Fortunately, the narrating 'I' that comes later in the memoir, the adult narrator who takes on the job of caring for the college girl, demonstrates the kind of empathy that manifests as action or agency. The close proximity to the rape that readers may feel in the opening pages sets up the rape as a shared violation regardless of whether readers feel empathy or not. The adult narrator resists the subjective, potential invisibility of the college girl recorded as a "statistic" — a raped victim — and instead, insists that rape is a larger social 
issue. This gesture is illustrated in the stark realization of the narrator that what happened to the college girl did not happen to her alone (122) as depicted in these lines:

I am not a statistic.

A raped-girl like me.

A raped-girl turned professor.

A raped-girl professor who refuses to keep quiet about it.

These lines demonstrate the progression from victim to survivor to advocate; they summarize the movement of vulnerability as it enters into agency; and they portray a model of self-empathy that is not a fleeting feeling, but a deep understanding that results from feeling what the other felt. To what extent can a model of self-empathy evoke a reader's response of empathy?

The Detached 'I'

i am. sea cucumber. i eject my insides out. over and over. strings of pasta. chunks. of tomato.

- Laura Gray-Rosendale 26

Gray-Rosendale employs the visual rhetorics of the text in ways that communicate selffragmentation and detachment. For instance, Gray-Rosendale writes using incomplete sentences that end sharply. She also uses lower case letters across several lines to indicate the disappearance of her person and the separation of her mind from her body, which is conveyed as both a process of shrinking and of replacement. The writing signifies a kind of rule-breaking that is still comprehensible but feels foreign, as if the one writing is unfamiliar with the conventions for writing. Referring to herself in third person, the autobiographical narrator describes the violence as if she is watching from a distance, stepping into the shoes of a spectator of herself who is also herself. She writes: 
He pulls the college girl's head back by the bangs, jams his fingers down her throat. A side of fist pummels her lips. The college girl realizes. No one is going to hear me.

I watch from above as the college girl makes a decision. If I have to, she tells herself. I'll do it. I'll give in to save my life.

Peez. Peez. I won't fight. You any ore. (25)

Notice the representation of a speech impediment caused by the sock that is stuffed in her mouth, further emphasizing the strange sound of her own voice. Within the space of a few lines, the narrator shifts from distancing herself as the third person "college girl" to a position close enough for readers to hear her murmuring pleas for her life.

As the passage continues, Gray-Rosendale describes the concreteness of the disassociation as the "college girl" becomes fixated on the streetlight outside the window. She imagines "nothing more magnificent, more full of glorious-dazzling, fairy light magic" than the beauty of the streetlight (25). She moves in and out of her body through the language on the page until the college girl is gone and all that is left is the body-less narrator-until the next page when the college girl comes back to life- but in lower case:

me ripping. my lips apart with his. hand and pounding. into me. crying. against my socks. please no. he thrusts. and thrusts. over and over. seems like forever. then he goes soft again and. he cannot keep. himself inside me. and he shoves his fingers. around my hole and. i'm screaming against. my socks. (26) 
Without reluctance, the narrator continues to describe the act of rape in lower case, present tense fragments across the seven and a half pages of chapter four. At the end of the chapter she is a “sea cucumber" with no voice (26):

i am. over...

i cannot remember. how to count.

gasp and. screech. against socks. mouth sides grab. air.

i scream. make no sound. (27)

The metaphor of silence in this passage is a powerful foreshadowing of the rest of the memoir in which the narrator is faced with the realization that she is broken and unable to be put back together. She describes, "But not all of me is here. Some of me is still in the streetlight" $(30,34$, 36) - a line that she recites as if it were the refrain of a very dark poem. The rhetorical effect of proximity and distance enable the teller of the narrative to demonstrate her own sense of empathy — of feeling with - the poor college girl. The ties are severed and the search for the lost college girl begins.

At this point, the empathetic responses of Gray-Rosendale's readers may vary on a wide scale. Whether readers feel an empathetic sentiment for the college girl is not something we can determine. As Keen has explained, empathy is as a mind-driven phenomenon that draws on a reader's Theory of Mind and associative memories and mirror neurons (Empathy viii; 6). In short, empathy arcs from reader to text, not from text to reader. Gray-Rosendale's explicit account of the night of the rape may enable the conditions under which empathy can be deployed. However, as Keen argues, evidence for whether a text has the capacity for effecting empathy in readers is inconclusive. As an example of empathetic writing, however, the text may in fact enable the autobiographical writer to depict self-empathy through the writing. This 
proposal prompts me to ask again whether this step available in nonfiction bridges the gap between the reader's capacity for empathy, as the text may enable, in ways that fiction may not offer.

In addition to the visual rhetoric of the word forms in the text, College Girl is written in several short chapters which give a fast-paced feel to the reading of the memoir. The brevity of chapters, some of them only a page or two, also exemplify a feeling of disintegration —as if the chapter divisions in the memoir reflect the divisions of the self that Gray-Rosendale describes as occurring during the act of violence - a symptomatic gesture toward the language of PTSD. Gray-Rosendale exemplifies the "gaps and fissures" of post traumatic symptoms in the physical text of her memoir. In so doing, she provides a textual and visual reading experience of trauma. The narrative that Gray-Rosendale sets up with the initial violence of rape launches the trope of "trauma and recovery" and draws on the language it provides for her narrative. In Writing History, Writing Trauma Dominick LaCapra contends that trauma "survivors' narratives' are often necessarily 'nonlinear,' enabling trauma to register in language and its hesitations, indirections, pauses, and silences" (121)

Directly following the rape scene passages Gray-Rosendale keeps readers in the moment of the cloudy confusion of the immediate aftermath: the loss of time, the loss of details, the loss of the streetlight where she felt lifted away (40). The body-mind departure is emphasized as she refers to her body as her "parts" (48). The fears of returned trauma, of the rapist finding her again even though he has been caught, of being alone, of the dark, of men—all converge in the description of the aftermath — which Gray-Rosendale structures through the PTSD language of the loss of time and memory. Literally on the page, the narrator transforms into a diarist who 
chronicles any accessible detail of her life in fear of losing herself again. "Time stopped" (58) becomes the new refrain.

Trauma theorists describe the cycle of disruption of connection that occurs at the moment of traumatic violence as a culprit for the inaccessibility of any coherency in memory. In appearance, Gray-Rosendale relives the trauma through language providing readers with an asclose-as-possible view of the sharp moments of both the act of violence and the psychological disconnect that violence causes, showing readers the processes of the victim's detachment from that self. In effect, some readers may also "experience" along with the victim this detachment which provides both the teller and the hearer the necessary space for developing empathy with the victim. The writing shifts in places to portray Gray-Rosendale's "out-of-body" survival strategy. As I mentioned, she refers to herself in this state in the third person and as the "college girl." Such textual moves portray for readers the victim morphing into survivor as one who attempts to distance oneself from harm.

The vulnerable narrating 'I' who portrays a singular individual's experience of trauma in the opening pages shifts to a narrating 'I' who renders herself a reflective interpreter of that experience later in the memoir. The narrator, seemingly, gains a perspective as a witness of herself, enacting space for potential self-care and a self-empathetic awareness of the lost college girl. Maura Spiegel and Rita Charon write in the Editors' Preface of the Fall 2004 edition of Literature and Medicine about the role of proximity in narratives that foster empathy: "In one inflection, narrative is the medium we exist in; the air we breathe; it is how the mind makes sense of things, interprets stimuli. In this formulation, we must become conscious of the ways in which we are claimed by and make claims according to narratives" (vii). The interplay of proximity and distance as persistent themes in rape narratives that at once take readers into the 
vicinity of the rape and momentarily move them into the aftermath provides the proximal structure that empathy requires. Spiegal and Charon contend, "To feel our own feelings in our telling, or to feel with another's stories, the right distance or the right nearness must be achieved" (viii). The rhetorical moves and the flexibility of proximity and distance that Gray-Rosendale allows her narrating 'I' to experience produces an empathetic self-voice, so to speak. In this way, a capacity for feeling empathy towards the raped college girl is modelled by the narrator as an act of self-care.

The Testifying ' $I$ '

And I didn't just tell the police, that it happened.

It all happened.

It happened.

—Laura Gray-Rosendale 116

What happens to the narrating 'I' who becomes detached from the traumatized and victimized 'I' at the beginning of the memoir? The details of psychological detachment from self that Gray-Rosendale asserts in her memoir is at once a survival mechanism and a rhetorical move that permits the narrator to remove the 'I' from a position of being "acted upon" and instead, assume the role of actor. Trauma theorist Dori Laub writes about the Holocaust and the healing process of survivors. He explains that "there is in each survivor an imperative need to tell, and thus to come to know one's story" (Laub 78), but he also emphasizes the pressure to testify. Laub refers to this pressure as an "instinct" in which "there's an urgency to deal with the experience, to shape it, to make it happen, and it's like something is born" (Caruth 48, quoting Laub). Laub connects the healing process of trauma to the metaphor of the wound to clarify that "testimony is the healing of the wound by shaping and giving shape to an experience that's fragmented, a healing way of pulling fragments together" (Caruth 48, quoting Laub). 
Laub's analysis of Holocaust survivors has implications for rape memoirs in the insightful observation that "survivors did not only need to survive so that they could tell their story, they also needed to tell their story in order to survive" (Laub 78). In Laub's view, the shift to testifier is a shift to agency-one which Laub argues cannot be done alone. In Testimony, Laub writes: "The imperative to tell the story of the Holocaust is inhabited by the impossibility of telling, and therefore, silence about the truth commonly prevails" (79). Laub writes of the necessary role of an "internal companion" and of listening to the "internal dialogue" that purposes an "imperative to witness" trauma (Caruth 48-49, quoting Laub). In this respect, GrayRosendale's shift from victim to survivor in the language of the memoir denotes a shift in the voice of someone being acted upon to a voice of testimony.

Through the most unfortunate turn of events, Gray-Rosendale confronts the problem of the rape victim's testimony, which may seem to differ significantly from Laub's observation about the power of testimony in Holocaust stories. In fact, she writes in a chapter near the end of Part One, "A rape survivor is just a witness" (142). This deflated tone comes as a result of GrayRosendale learning that her rapist has agreed to a plea bargain in which he pled to first-degree burglary, not to rape (141). The District Attorney offers this explanation from a legal standpoint to Gray-Rosendale: "Burglary and rape are considered the same level of felony. It doesn't matter which one he pled to as the top count. It's the same level of offense. He'll serve the same jail time" (142). The DA fails in her attempt to persuade Gray-Rosendale that this is "good news" (142). In the circumstances of this case, the testimony of the survivor meant nothing. GrayRosendale writes, "His conviction does not speak to any reality I know. It negates what happened to me completely, makes it look as if it never was" (142). 
Readers find out that the rapist was a grandson of a prominent local businessman whose family had donated generously to the university. We learn that he was a "nice boy" who had an unfortunate drinking problem. We learn that his mother is sorry about what happened. As a result of the way the legal system works, we eventually learn that the account of rape became buried deep in his case file as he served time as a burglar. The rhetorical significance of "rape" as a violent crime loses effect when converged with "burglary." For Gray-Rosendale this "clever loophole in the law that allowed rapists to appear like burglars, to cloak and disguise their other, more violent offenses...was a public as well as a personal outrage" (193). In response to these unsatisfying legal consequences, Gray-Rosendale expresses feeling "erased from the picture" and left out of the story as if her story was never told (145). Later in the memoir, GrayRosendale suggests an alignment of the practice of having to present an "expert mediator...for survivors to make sense of our own experiences" with an effort "to co-opt survivor discourse" by undermining their stories (207). One incentive for writing the memoir may have been the conclusion that Gray-Rosendale eventually reaches: survivors have "little to no control over their own narratives" (208). The memoir is an attempt to gain control over her own narrative, even if it is a chaotic, fragmented, and collaborated story as she comes to realize.

Thus, her story is told now in memoir in a voice that is not the static chatter of testimony of a specific crime, but a resounding expression of a crime against humanity and at the same time a crime perpetuated by human systems as revealed in a flawed legal system that permits a rapist to be named a burglar. Perhaps Laub's level of understanding of testimony —as something that cannot be done alone is indeed a truth that Gray-Rosendale discovers. Her imperative to tell her own story of rape, to borrow Laub's words, "is inhabited by the impossibility of telling" (79), 
which is not only hindered by the unavailability of language to narrate trauma, but it is also blocked by systemic and legal circumstances.

The layer of understanding that Gray-Rosendale adds to Laub's view of testimony is that the impossibility of telling comprises not only the "silence about the truth that commonly prevails" (Laub 79) or the limits of the language of trauma for that matter. There is a bigger systemic problem with silence about the truth: it not only prevails, but it also reproduces silences. Gray-Rosendale's narrative is more than a rape story or a trauma memoir. If it were just that, there would be no need for the second part of the memoir in which Gray-Rosendale assumes the autobiographical role of scholar and teacher, introducing to memoir audiences a new style of brave writing.

The Scholarly ' $I$ '

I would have to research what happened to me as if I was studying someone else's life, writing someone else's biography. And, as paradoxical as it sounded, I would have to rely on things other than my own memories in order to remember what had happened to me. - Laura Gray-Rosendale 174

If College Girl had ended with Part One, we might consider it a rape memoir that, like many other rape memoirs, advocates social awareness and cultural change regarding rape by offering up a singular and personal violent trauma as a powerful means of persuasion. As Keen has noted, social awareness and cultural change are huge claims when evidence is lacking for adequately measuring the degrees, varieties, or consistencies of readers' responses. The evidence for an empathetic response to Gray-Rosendale's memoir lies in the text itself in the form of selfempathy. Gray-Rosendale masterfully uses the form of the memoir and the trope of trauma and recovery as a way to carefully deliver the disruptive blow that rape is a societal problem. Just as the one who was raped cannot produce a coherent individual or singular account of the trauma 
without invoking the broken narratives of others, society must realize its own broken systemic components, such as the neat medical explanation of recovery. As one who has deliberately exposed her own vulnerability, re-imagined her experience of traumatic violence as best she could by reenacting it in the language on the page, confronted a flawed legal system by writing about it in the memoir, Gray-Rosendale, at best, has earned the right to be heard. She has demonstrated memoir bravery as we tend to think of it. Through the writing, Gray-Rosendale demonstrates a measure of self-care that, I believe, can transpose as a model for the potential wider reach of empathy beyond literary empathy (i.e. identifying with the character or the rhetorical situation in the story).

College Girl is a unique memoir in that it intersects the personal and the scholarly. In fact, College Girl is a memoir that does not fit entirely into prevailing subgenres of life writing. The text is categorized as "memoir/women's studies" and includes end notes and works cited segments: it is part trauma narrative and survivor discourse, part confession, part critical life writing. In many ways, Gray-Rosendale's memoir may be considered a kind of academic or analytical memoir that performs what Gillian Whitlock describes as "understanding the self distinctly in and through a disciplinary construct" ("Disciplining the Child" 47). One of the most overtly scholarly sections of the memoir is the first few chapters in Part Two where GrayRosendale summarizes an academic article on survivor discourse that she co-authored with one of her professors from Syracuse. In these chapters, she also provides readers with an overview of PTSD and the central problem of memory loss. In addition, and what lays the groundwork for the final section of the memoir where Gray-Rosendale's investigation leads her back to Syracuse and to locating the friends who helped her that night, is her awareness of the reconstructive power of the recovery aspect of trauma. She writes, "Trauma survivors' stories are primarily works about 
the complex process of learning new things (discovery and investigation), acknowledging that it's what we create and build as a result of our experiences that is perhaps most important" (218). This, in part, is the disruptive force that challenges an understanding of trauma that emphasizes recovery as a kind of closure. The lesson Gray-Rosendale teaches is that recovery is an ongoing, collaborative, and reconstructive endeavor.

As I have analyzed earlier in this chapter, one of the most distinct paths for violence is through narrative that attaches the story of violence to an individual's life. This is how we tell and how we hear - through stories about individuals. If Gray-Rosendale had begun with the heady sections of Part Two, it would have been a very different kind of memoir. The evolution of the narrating 'I' that Gray-Rosendale advances in the second part of the memoir resembles the autobiographical voice of herself as scholar and teacher. From that standpoint, she performs the research necessary to reconstruct her story which she has come to realize is so fragmented that a coherent narrative may be an impossible feat. Her research processes include collecting data and documents, performing a site visit, and most revealing, conducting interviews with three other "college girls" who, as unrecognized victims of the rape, share their versions of that violent night. What Gray-Rosendale learns through talking with her former roommates and friend is the fiction of believing in a coherent singular narrative. Her story with all of its missing parts, she realizes, was not hers alone but was "a part of lots of other people's stories too" (253). Indeed, most readily her story belonged to, as she puts it "a wide circle of victims, in the end" (253).

At the heart of Part Two of Gray-Rosendale's memoir, the scholarly 'I' conducts a search to reconstruct memory and rediscover the lost college girl. Gray-Rosendale admits that "storytelling can be important therapeutically for survivors" but for her this simply was not enough (205). Specifically, she launches an investigation of the written forms available that 
represented the rape and that existed before the publication of the memoir. These included legal documents, court proceedings, police and medical reports, and the local media's portrayal of the criminal act — some of which Gray-Rosendale reproduces in the second half of the memoir. Gray-Rosendale combines the personal quest for answers with her academic work to foster a seriously agentive narrator who confronts, as she writes, "various social and cultural institutions [that] tend to want to 'handle' survivor discourse - to mediate and co-opt it for purposes that are not always in the best interests of the survivor" (205).

Before the memoir, Gray-Rosendale's rape was represented through cultural agents that constructed a piecemeal narrative, including news reports, medical records, police reports and court proceedings. In the curt act of reporting and recording, these texts aimed to uphold an ethical system infused with ideals of a fair, unbiased, and objective posture when, in fact, they simultaneously constructed flat, distorted representations of the trauma. These matter-of-fact documents do the job of recording, representing, and constructing, but they do that work without human relations or without an embodied voice. As such, there is no risk, no vulnerable subject, and no need for the rhetoric of bravery. The institutional spaces for recording rape (media, legal, medical) enact culturally-approved measures for "telling" and "hearing" criminal accounts of sexual assault under the most impersonal and un-relational of conditions.

In contrast, the memoir offers a space in which the personal and relational are necessary conditions for telling stories of rape. From a rhetorical perspective, Gray-Rosendale assumes an entitlement to re-tell her story using the cultural form of a memoir and, in so doing, confronts the representations of her story as recorded and reported by other cultural agents. As such, the memoir has the potential to step up and perform as its own kind of cultural agent, influencing the ways in which trauma resonates in the public sphere. The cultural agents aside from memoir tend 
to construct an impersonal account of rape, that first identifies the individual anonymously but with specific culturally-loaded labels, and then reduces her to a statistic using the most generic language as illustrated in the following example of the media's representation of the rape.

A locally owned news source, Syracuse Newtimes, ran a series of "seven short articles about the November 20, 1988 rape of a woman in an apartment near Syracuse University.” (Gadoua). The short articles (about 1,350 words each) mentioned the arrest of the "perpetrator" and sketched the legal procedures that followed (Gadoua). Another local Syracuse article, reported the day after the attack, actually named the perpetrator giving his full name and address as one "charged with first-degree rape and four counts of second-degree assault" (Gadoua) but left the "woman" unnamed and, consequently, abandoned to the culturally-constructed "victimabuser rape narrative." Withholding the name of the victim is a gesture of respect for the victim, of course, but it also has the potential repercussion of leaving the victim without identity other than the "girl who was raped." Most importantly, the voice of the victim is remitted to the realm of the private, and therefore, silenced. The issue of naming is significant for many reasons, but here, by choosing not to name her abuser in the memoir, Gray-Rosendale clearly reverses the power dynamic of naming, invoking the larger politics of identity ethics. The juxtaposition of the news report withholding the name of the 'victim' and the memoirist withholding the name of the 'abuser' reveals a kind of identity ethics at work in larger discourses and debates about the right to privacy.

For Gray-Rosendale, the decision of not naming the abuser in the memoir may seem like a generous move that benefits the abuser and not the victim. Whether this is a moment of grace - a generous gesture that befits the rapist - is unknowable without asking the author herself, and yet, I interpret it as a gift to herself to not have his name appear in her memoir. 
Vivian Gornick, in The Situation and the Story, advocates that "sympathy for the subject is necessary because an absence of sympathy shuts down the mind: engagement fails...and the work narrows" (34-35). Extending sympathy to a rapist, however, is a delicate rhetorical act as other memoirists have encountered. Mary Karr, for instance, in her childhood memoir The Liars' Club, does not tell the name of the "big boy with braces" who raped her when she was only a fifty pound seven-year-old (Karr 66). As I discussed in the previous chapter, Karr writes a paragraph that addresses her anonymous abuser directly, a move that sends chills up many readers' spines as one might imagine the boy-turned-man reading the words. The effects of withholding perpetrators' names in memoir may be rhetorically complex, but arguably, the selective self-silencing of both Karr and Gray-Rosendale involve ethical decisions of self-care.

Nancy Miller in an essay titled "The Ethics of Betrayal: Diary of a Memoirist" writes this: "Sometimes I have the uncomfortable feeling that the truest, ethical position is closely related to silence or self-silencing" ("The Ethics of Betrayal" 157). Self-silencing is indeed a complex ethical question and some may ask, as Catherine Hobbs does, whether self-silencing itself is unethical (Hobbs 414). To ask the question of whether Gray-Rosendale's choice (or Karr's for that matter) of withholding the rapist's name is meant as a gesture of sympathy is to miss the point. To name the abuser in one's memoir is to recognize his identity as a person, whereas, not naming the rapist keeps him forever a monster, "a faceless, vacant blank—like a blackboard" upon which others can sketch their own monsters. This rhetorical move is one example that demonstrates textual space that memoir offers where others can imagine stepping into the shoes of the narrating 'I,' and thus, potentially cultivate empathy.

As a scholar, Gray-Rosendale takes the liberty of weaving into her memoir the ways in which her scholarship intersects with her personal trauma. She recalls as a graduate student in 
Wisconsin an emergency appointment with a psychologist because of a relapse of PTSD (170).

During the session, Gray-Rosendale realizes that she actually knows very little about the details of that horrible night. She remembered her roommate, Sal, the one who "barricaded herself in the room next door," but she had no idea why Sal had done this. She remembered Cathy, the roommate who had gone downstairs to call the police, and she remembered her friend Lindsey who took care of her in the immediate aftermath and the days following (176-177). GrayRosendale ends up locating the three most significant people who were present the night of the rape, and who participated in different ways in her story. What she discovers is what William Zinsser writes in Inventing the Truth: The Art and Craft of Memoir: that for trauma survivors there is "multiple ownership of the same past" (Zinsser 6; qtd. in Gray-Rosendale 218). GrayRosendale elaborates:

At heart, our narratives are never really about just one person's story. Since traumas are experienced communally, our stories are always shared ones, impacting (and continually revising) every other life and story they touch... Survivors may need other people's angles on the events in order to piece our own stories together. (218-219)

This insight was the deciding factor that led Gray-Rosendale to look up her former roommates and to reconnect with her friend, Lindsey. The encounters with other versions of her story proved to be the road to the "reality or truth that is not otherwise available" as Caruth declares (4). 
Conclusion: The Interdependent 'I'

I will never know the whole story.

We writers of memoirs - but especially trauma memoirs—never can.

But I do know more of it now, and I know the extent to which it really was a part of lots of other people's stories, too.

It's a wide circle of victims, in the end.

-Laura Gray-Rosendale 252-253

As part of her investigation, Gray-Rosendale returns to the scene of the crime, so to speak. She conducts a close-reading of court documents and police reports, a walk around the college apartment where she was raped, and most compelling, conducts interviews with her two roommates and another best friend at the time whom she had lost touch with over the years. The quest for memory's reconstruction began as a search for missing pieces and this is what prompted Gray-Rosendale to make the phone calls to the other college girls. Upon discovering the years of post-traumatic symptoms which the other college girls experienced, Gray-Rosendale realizes that her story does not belong to herself alone. The violence of that night yielded more than one victim and survivor. Yet, who gets recognized as "victims" determine the kinds of cultural care that is available. Her roommates, for instance, had remained "altogether unrecognized victims" (Gray-Rosendale 234).

Lindsey is the friend who had been Gray-Rosendale's main caregiver. The intimate care of showering the raped girl, of dressing her, of sleeping with her in a room with the lights on because she was afraid, of seeing her bruised, battered, and vulnerable belonged to Lindsey. In fact, Gray-Rosendale's rape had "changed [Lindsey's] life irreparably" (227). What GrayRosendale realized during her conversation with Lindsey years later is this: "What happened to me in the weeks after the rape had happened to her too" (227). This awareness became further evident in interviews with Sal and Cathy. Sal reported having her own symptoms of PTSD of "huge lapses in memory" and "paralyzing fear and deep sadness" (231), "flashbacks and 
nightmares" (233). The difference between the one who was raped and Sal, as Gray-Rosendale came to realize, is that Sal "had not been recognized medically or legally as a victim of the crime" (234) in the ways that the raped girl had been recognized. It was the "victim of the crime" who "received both medical and legal help" (234). Sal could not recall why she had barricaded herself in her room while right next door her roommate was being brutally raped (235). This unknowable detail had to remain one of the gaps in both of their stories. Cathy, too, was another "unrecognized victim" (234) with her own version of the story, and who "with therapy and the passing of time...was able to integrate her experiences more fully into the rest of her life story" (241).

Upon hearing versions of that violent night from others and its lingering and profound effect on the lives of others, the quest for coherence shifted as did the search for the lost college girl. Gray-Rosendale writes: "I will never know the whole story. We writers of memoir-but especially trauma memoirs - never can. But I do know more of it now, and I know the extent to which it really was a part of lots of other people's stories, too" (252-253). For Gray-Rosendale "putting one's experiences into narrative forms (partial though they may be) is what makes the trauma survivor's future possible" (261). Brison elaborates: "It does this not by reestablishing the illusion of coherence of the past, control over the present, and predictability of the future, but in making it possible to carry on without these illusions" (Brison 104; qtd in Gray-Rosendale 261262). The notion of coherence or a unified self-narrative are "myths of identity," according to Smith and Watson, who argue that "we are always fragmented in time, taking a particular or provisional perspective on the moving target of our pasts, addressing multiple and disparate audiences" (61). Smith and Watson explain that "engaging in the past, reflect[s] on identity in the present" and invokes the cultural techniques we learn for remembering (1). In Aftermath, 
Brison echoes this sentiment as she lyrically offers the reverse of what might be expected from trauma stories: "I once was found and now I'm lost" (110). The effect of trauma on the individual is undeniable as Brison advocates, "Let survivors speak themselves" (30). Through the same feminist vein travels Gray-Rosendale's message of interdependence that our stories are not ours alone.

College Girl is a memoir that makes rape a public issue and resists cultural narratives that attempt to consign rape to the private sphere. In so doing, Gray-Rosendale works through the very present cultural narrative of the vulnerability of the victim of rape as a way toward this resistance. First and most noticeable, College Girl may speak directly to those who have had similar experiences with sexual assault or know someone who has. One's own traumatic memory loses shape over time and reading the narratives of others' losses can be cathartic and productive. Nancy Miller addresses this paradoxical aspect as she conceptualizes the resonating work of memoir. Miller writes, “Another's text can give you back your life. Memoir reading works like a kind of interactive remembering - where the screen prompts the construction of memory itself" (But Enough 7). In this sense, the memoir performs as a model of self-care that includes care for others who identify with the memoir on some level. Miller asks a second, more poignant question, "What happens when...there seem to be no commonalities between your life as a reader and the writer's?" (But Enough 11). Miller answers her own question by conceptualizing the memoir as memorandum:

I want to propose the notion of memoir as prosthesis—an aid to memory. [...] In this sense, what memoirs do is support you in the act of remembering. The memoir boom, then, should be understood not as a proliferation of self-serving representations of individualistic memory but as an aid or a spur to keep cultural 
memory alive...The six degrees of separation that mark the distance from your life to another's are really, as it turns out, degrees of connection. And my memoir is also about you. $(14 ; 26)$

College Girl refuses to conceal rape as a private story, and instead, through the form of memoir, offers a memorandum to the public that rape is a matter of public concern. Writing from the wound of rape, Gray-Rosendale models self-empathy. In response, the public notes her bravery in a rhetoric that acknowledges, they too, got the memo. 


\title{
CHAPTER V
}

\section{THE PEDAGOGICAL POTENTIAL OF MEMOIR: THE RHETORIC OF BRAVERY IN THE CLASSROOM AND THE TEACHING 'I'}

\author{
The way the narrator writes himself is the thing being written about. \\ One echoes the other. \\ -Vivian Gornick 47
}

When we tell our stories, we are playing a part in shaping the culture. - Judith Barrington 75

In this dissertation, I have approached memoirs as textual representations of bravery to examine the writers' rhetorical moves as they emulate larger discourses of bravery within the culture. To this end, I have explored memoir bravery as a cultural phenomenon, as a way of hearing certain kinds of personal narratives, and as a rhetoric with potential self-empathetic connotations. In the previous chapters, I have critiqued authenticity, vulnerability, and empathy as significant elements of memoir bravery. In Chapter Three I analyzed the rhetorical moves of the narrator in Mary Karr's The Liars Club. On close inspection, Karr's narrating 'I' assumes a multiplicity of roles that reinforces not authenticity per se, but the importance of establishing authorial ethos by presenting the perception of an authentic narrator even at times in the text when the narrator's memory is admittedly fuzzy. In Chapter Four, I examined the role of vulnerability in Laura Gray-Rosendale's memoir, College Girl, in which she narrates the night of a violent attack and rape and then reconstructs the aftermath via the trope of trauma and recovery, offering for readers a counternarrative and a model of self-empathy.

In this final chapter, I turn to the college classroom to explore the ways in which elements of memoir bravery are encountered and manufactured by students as they participate in the practice of memoir. I am using "manufactured" not in the sense of artificial or contrived but as a factory would produce and manufacture a product. Within the contextualized space of the 
classroom, I examine the role of authenticity and vulnerability in pedagogical practices and in students' production of memoir writing. By examining students' engagement with the craft of memoir and their interactions with one another, I argue that the college classroom is a plausible space for the production of memoir bravery as revealed through students' writing processes.

Part of my analysis in this chapter is of my own stance as a teacher and a researcher and the reflexivity of my own pedagogies. In her text, The Ethnographic I, Carolyn Ellis playfully challenges the role of the researcher as one who "not only looks but is looked back at, that not only acts but is acted back upon by those in her focus" (xix). Furthermore, Ellis asks, "Might the researcher also be a subject? Might the 'I' refer to the researcher who looks inward as well as outward?" (xix). The effect of my own presence in the classroom, and my ability as a teacher/researcher - to impose values or to alter space or to motivate interactions-factors into the "potential" part of memoir pedagogy as my chapter title depicts. Ellis invokes the term autoethnography as a category for self-analysis. She defines autoethnography as "research, writing, story, and method that connect the autobiographical and personal to the cultural, social, and political" (xix $)^{70}$. While I do not present an autoethnographic study in this chapter, I draw on Ellis's category as a way to examine my own reaction to certain inconsistent, sometimes incompatible, disciplinary beliefs about personal writing for academic purposes, and its value as an educational mode. What can be gained from making the 'I' of the teacher/researcher part of the focus is a more comprehensible analysis of potential disciplinary biases that may affect the way I perceive my student's work.

\footnotetext{
${ }^{70}$ While this chapter does not represent the "conventions of literary writing" (xix) that Ellis suggests autoethography claims, it does connect the personal and the cultural, and in this case, my personal pedagogy with the culture of academic disciplines.
} 


\section{Bravery as a Class Act}

My premise is that the culture of the classroom mirrors the larger cultural discourses within which the rhetoric of bravery operates: what counts as "bravery" in the classroom shares similar characteristics to the kind of acts commonly perceived as brave in the culture and in general. Conversely, the rhetoric of bravery as portrayed in the language and gestures of students may resemble similar features in larger cultural discourses of bravery. What form does bravery rhetoric take in the classroom? This question generates a series of additional questions, including the following: Is authenticity as big a deal in the classroom as it is in the larger discourses of the memoir genre? Is the student writer who presents a vulnerable persona or who takes on difficult or contested topics considered to be a brave writer in the same ways as published memoirists may be? What are the parallels or incongruences in the capacity for self-empathy in the classroom compared to the larger cultural discourses of bravery? For instance, is shame averted or redirected in the classroom? Do students bring to the practice of memoir the larger cultural ideologies of bravery?

The college classroom is a space in which students practice writing, and as aligned with modern best practices, it is commonly perceived as a collaborative space where students share their writing with one another. The collaborative environment inducts students into an academic ritual where they must learn the etiquette of peer feedback. It is here, in writing workshops, where bravery rhetoric often appears. The college classroom, and the writing workshop in particular, lends itself to the rhetoric of bravery for at least two reasons: students have to appear brave in the face of criticism, and students have to bravely offer criticism to their classmates. The requirement of responding to classmates' writing, in some cases, may be a cause of anxiety for some students, but in many cases, with guidance students can learn to offer feedback in 
constructive ways as well as learn to see the value in receiving feedback. Contributing factors to students' discomfort are first, a feeling of fear about sharing their personal writing with classmates, and second, the need to carefully monitor themselves when giving feedback. This is not a news flash. Student writers in courses across disciplines may share these anxieties. In classes that assign personal writing, however, I believe both of these factors reveal two specific problems: (a) student writers assume their personal stories reflect on themselves as persons; (b) student writers have trouble seeing themselves as separate persons from the personae in the text. This trickiness of distinguishing the persona from the person is what opens the door to the rhetoric of bravery in the classroom environment. The practice of memoir in the classroom manufactures bravery rhetoric among students largely as an affective and empathetic reaction to the shared experience. They feel for and with one another because of their shared experience of

memoir writing. The practice of life writing in the classroom may manufacture bravery because of the courage required of some students to share their writing with their peers. Some student writers may fear being judged by their classmates, which in turn, may require courage on the part of the writer to participate in writing workshops. Students, like all of us, often need validation from their peers that their personal experiences are meaningful. Affect theorist Elspeth Probyn explains that "the risk of writing is always that you will fail to interest or engage readers" (72). As such, the practice of personal writing may evoke an array of affects among students in the classroom, particularly those who feel their identity is at stake in their writing.

\section{The Teaching-Learning Context}

The general education committee at a small, liberal arts university in the Midwest where I used to teach launched a new general education curriculum, which I had the opportunity to help 
implement. ${ }^{71}$ One outcome of the new curriculum was the installation of undergraduate interdisciplinary seminars designed to meet general education requirements for graduation. ${ }^{72}$ The committee identified a gap in student learning regarding the ability to integrate knowledge and transfer skills from one learning context to another. Partly as a means of addressing this problem, the new curriculum included two seminars with a shared objective: to integrate multiple disciplinary perspectives on a topic and as a means toward integration of knowledge. One pedagogical assumption of the committee was that these seminars could potentially model processes of integration and further enhance the goals of liberal arts education. The committee approached interdisciplinary work as a process that "draws on disciplinary perspectives and integrates their insights to produce a more comprehensive understanding" of a complex topic or question (Repko 12). ${ }^{73}$ Faculty members were encouraged to submit course proposals for a pilot program.

Against this institutional backdrop, I piloted one of the first seminars titled Representations of Childhood, Truth, and Memory — a course designed to explore childhood in the twenty-first century and the role memory plays in our perceptions and beliefs about childhood via the stories we tell. Students read scholarly materials from the fields of memory studies, childhood studies, and life writing as well as the childhood memoirs of Mary Karr,

\footnotetext{
${ }^{71}$ General Education in many U.S. colleges and universities includes a range of requirements that covers the breadth of liberal arts and science. Requirements commonly include skill-based courses such as writing, speech, and mathematics, and courses in humanities, social sciences, and science. For a good resource, refer to the Association of American Colleges and Universities (AAC\&U), and specifically, see General Education Essentials by Paul Hanstedt.

72 The two seminars were designed with baccalaureate goals in mind. One seminar was a 200-level course and reflected the desired outcomes of the Catholic and Benedictine tradition; the second seminar was a 300-level course and reflected themes of either "human dignity" or "the common good." Both courses were to be inquiry-based that required no specialized knowledge of students, yet challenged and empowered students to integrate knowledge into their investigation of questions. My seminar was a 300-level and examined the theme of "human dignity" in relation to "representations of childhood," and which I incorporated childhood memoirs as course texts.

${ }^{73}$ See the website of the Association of Interdisciplinary Studies (AIS) which houses several resources on interdisciplinary theory, practice, and pedagogy (http://www.oakland.edu/ais/).
} 
Alison Bechdel, and Lucy Grealy. ${ }^{74}$ I was using literary memoirs as textual representations of childhoods and as a means for raising some of the seminar's foundational questions such as these: How is childhood remembered? What cultural scripts for remembering childhood are enacted in Western society and to what end? How does culture convey national, personal, and collective memory? What are the effects of private and public memory on our construction of childhood? I was using memoir outside of its common homes in literary studies and creative writing programs. ${ }^{75}$ Teaching this course fulfilled by internship requirement and my research aim was to explore the memoir's potential as an educational tool in an interdisciplinary context. Megan Brown argues that the memoir as an "educational tool" has the potential to uncover "which questions [we can] consider when we write about ourselves" ("The Memoir as Provocation" 123). In fact, Brown testifies that the memoir is a "provocation for thinking critically about cultural definitions of selfhood and authenticity" ("The Memoir as Provocation" 123). Like Brown, I imagined the memoir as a text with multiple purposes beyond its common function as a literary text. To this end, one of the major assignments in the seminar was for students to compose a memoir essay about their own childhood as a way to examine the

\footnotetext{
${ }^{74}$ To clarify, as designer of the seminar's curriculum I had full autonomy in deciding what texts and assignments to include. The course syllabus was prepared in advance of the course offering and approved by a sub-committee. To my knowledge, other seminars did not assign personal writing as a major part of the curriculum.

${ }^{75}$ It is common in U.S. universities for creative writing programs to be housed in English departments. Often first year writing programs are also located in English departments and are distinct from the creative writing programs. In describing the state of composition studies, Doug Hesse contends that the "field has turned away from the imaginative and toward argument, civic discourse, academic genres, and rhetorical moves" and that "creative nonfiction is the clearest canary in the historical coal mine" (37). Hesse explains the historical moves that led to developments in rhetoric, and the influential scholarship such as James Berlin's critique of the poetic which drove the field's attention away from the poetic, leaving creative nonfiction up for grabs. According to Hesse, the genres of creative nonfiction found a home in creative writing primarily because they were available to be claimed. (37). As the canary of creative nonfiction perched in creative writing programs, the songbirds of personal writing have no real genre to attach to in composition studies. First year composition courses are still widely viewed as basic skills courses which prepare students for writing in the university. That creative writing is not commonly part of the "academic writing" curriculum of composition courses reinforces the skills aspect of the course by default. Interestingly, creative writing courses have gained in popularity in both graduate and undergraduate programs. Yet, composition pedagogy remains conflicted when it comes to personal creative writing in any form or genre.
} 
reconstructive aspects of memory and to raise questions of autobiographical truth. I fully anticipated the stories that students produced would become themselves "course texts" and offer additional autobiographical representations of contemporary childhoods. As a rhetoric and composition instructor, I felt confident guiding students through the writing processes of composing their own memoir essays. I imagined the students' practice of memoir as a means to engage students in the academic rigor and demands of the seminar's content. What I had not anticipated was the students' personal investment in their memoir essays and the weight of my own disciplinary assumptions from rhetoric and composition studies that came to light in the interdisciplinary context.

The small seminar consisted of nine students from diverse backgrounds and various majors who had elected to take this particular seminar to meet a general education requirement. (The students could have met the requirement with a different seminar.) The students mostly came from surrounding local towns and shared similar regional backgrounds but were diverse in their socio-economic backgrounds, gender, level of academic standing, and interest in life writing (e.g., some students expressed enthusiasm about personal writing and others expressed anxiety). All of the students had completed their first year, which meant they had passed the first-year writing courses although they entered the seminar with different levels of writing skills.

\section{The Memoir Project and the Personal Turn}

The memoir project consisted of two parts: first, the students composed a six-to ten-page memoir essay and, second, the students composed a four-page reflective essay. ${ }^{76}$ In the reflective essay, the students evaluated their writing processes, noted observations of narrating

\footnotetext{
${ }^{76}$ For research purposes, I received approval from the Internal Revenue Board (IRB) to conduct research on human subjects. This ethics clearance included students' permission to use their writings anonymously in publications. See APPENDIX C for the "informed consent" presented to and signed by participating students.
} 
autobiographical memory, and reflected on beliefs about childhood. By the time students began the memoir essay they had already spent several weeks reading memoirs and analyzing them as representations of contemporary texts of childhoods.

In the assignment instructions, I included several concepts drawn from life-writing scholarship to help students rhetorically with the writing. Here is an excerpt from the instructions:

A memoir is not the story of a life, but rather a story from a life in which the author tells a story and mulls over it to unravel its meaning. Stories from childhood that are remembered by adults include the presence of two narrators interwoven in the text (the child's voice of experience and the adult's voice of insight). The first step, therefore, is to consider a question that memoirist Vivian Gornick asks, "Who am I when writing this and why am I writing this?" Your task is to "turn oneself into a character" as Philip Lopate suggests and consider your work as a valid contribution to understanding childhood, beliefs or contradictions about childhood.

The instructions also included tips for getting started and further resources for writing life narrative. My intention when introducing students to concepts important to the practice of memoir was to reinforce the significance of disciplinary (and genre) knowledge in an interdisciplinary context, and to provide students with disciplinary parameters for talking about their writing.

The memoir project dramatically altered the climate of the classroom as my students began composing and sharing their personal stories. My small class morphed into an outspoken roundtable of experts on autobiographical memory, in which many, without hesitation, 
contributed personal stories to class discussions. I don't mean that my students became wellversed in the scholarship of autobiographical memory; on the contrary, they became a chorus of self-representing voices, often uninhibited in sharing personal stories and beliefs in our class discussions. Stories of addiction and recovery, misdemeanors, dysfunctional relationships, living with Tourette's, rejections, jealousies, and other growing-up pains informed much of our classroom conversation. I knew the shift-to-the-personal was underway when a student one day commented that she tells her friends that this class is her "Tuesday-Thursday therapy." I became nervous about the turn the course had taken, worried that we had lost sight of the course objectives, or that we had become what Megan Brown refers to as a "Me Studies" class. In fact, the students would clown around that they had a "Vegas" agreement with one another: What is said in the room stays in the room. One thing was true for this group of students: telling reaped more telling. The affective climate of the classroom was high stakes at times. It was as if the practice of memoir had granted students the permission to speak the personal with authority. Pedagogically, my goal for students was to shift our emphasis from the analysis of published text to the production of their own texts, and in so doing, apply the techniques that we had been discussing. That proved to be a lofty goal. What occurred during the students' writing processes was an inability to see themselves and their classmates as separate from the narrator in their stories. After all the heady analysis of personal narrative texts, students were not able to generate texts with the kind of detachment that Gornick would say is necessary for fashioning a persona. This became obvious to me when I read the reflective essays that students wrote about their writing processes as I will explain later in this chapter. I became leery about whether the memoir was right for the job and wondered whether I had made a terrible mistake as I was 
reminded every time I would shut our classroom door in fear of the chatter of our class being overheard in the hallway.

\section{The Weight of Disciplinary Assumptions}

I began considering the disciplinary assumptions that I had inherited about personal writing with the reality of my students' affective work that was taking place right before my eyes. At times, my students carried on the conversation as if I were not in the room-which left me musing over what Brown suggests is a "fine line between personal writing classes and group therapy" ("The Memoir as Provocation" 126). On one hand, I struggled with certain disciplinary assumptions that aligned personal writing with the anti-intellectual. As Brown notes, Harris makes this observation within the context of undergraduate creative-writing courses, which she warns have been deemed anti-intellectual by some on the basis of insufficient theoretical understanding and "because personal writing leaves no room for consciousness-raising" (Brown, “The Memoir as Provocation” 126). The memoir project infiltrated our seminar, and the students became engaged with their writing and storytelling in ways that left other aspects of the seminar in their wake.

On the other hand, I considered various perspectives that upheld sociocultural aspects of personal writing in relation to autobiographical memory. Cognitive psychologists tell us that "autobiographical memory is specific, personal, significant and enduring," and yet the act of remembering is a "social process because it can be influenced and shaped by the social milieu" (Peterson et al. 267, 268). Joan Didion profoundly acclaims, "We tell ourselves stories in order to live" (11). Judith Barrington observes, "When we tell our stories, we are playing a part in shaping the culture" (75). As the students shared their autobiographical memories of childhood, their stories were often prompted and shaped by the stories of others. This teaching experience 
led me to acknowledge the weight of my own (sometimes conflicting) disciplinary assumptions from composition studies and the field of life-writing that emerged in an interdisciplinary context and the potential effects on how I presented the memoir project to students. I realized that a pedagogy of the memoir entails a self-conscious assessment of disciplinary assumptions.

Rhetoric and composition studies as a discipline (in the U.S.) is notorious for contesting the status of personal writing as an appropriate mode of academic discourse (Gere 204; Hesse 38). ${ }^{77}$ Patricia Sullivan argues that there is a "common thread ... that runs through our composition courses across differences in our curricular philosophy, and it serves to maintain the personal/academic binary: students are defined by their lack" (41). Sullivan invokes the Foucaultian notion of "subjugated knowledges" or that certain ways of knowing are seemingly disqualified or inadequate or naive. Underlying the assumption that personal writing is an inferior way of knowing is a larger cultural conflict that points to the role of composition instructors (in the U.S.), who have "long occupied a feminized role in the university, expected to shape student subjectivity so as to prepare them for subsequent 'real' disciplinary work [and that] for women teachers, this shaping of student subjectivity has historically involved fostering selfregulation by removing or controlling irrationality/emotion" (Stenberg 349-50). It is the alignment of the "personal" with the "emotional" that has historically infected debates about personal writing in academic discourse. ${ }^{78}$

\footnotetext{
${ }^{77}$ Discussions in the field of composition and rhetoric regarding the role of personal writing in the classroom gained momentum in the Peter Elbow and David Bartholomae debates in the 1990s. In the 2001 issue of College English, the uptake of the debate resulted in a symposium among scholars including Deborah Brandt, Ellen Cushman, Anne Ruggles Gere, Anne Herrington, Richard Miller, Victor Villanueva, Min-Zhan Lu, and Gesa Kirsch (see Symposium Collective). As Hindman writes in the introduction, this special issue of College English aims "not only to clarify the myriad denotations of 'the personal' in academic discourse but also to suggest viable criteria for evaluating the effectiveness of personal writing's contributions to knowledge-making in English studies" (35).

${ }^{78}$ Feminist scholars and affect theorists over the last two decades, at least, have theorized emotion away from its naturalistic conception as individual, private, and internally located, moving it toward a socially constructed and bodily lived state. Stenberg asserts that "we need to find useful pedagogical strategies to foreground emotion as a cultural discourse and to examine how social and cultural factors shape the ways we respond (emotionally) to
} 
Influenced also by disciplinary scholars who rose up against expressive writing in the 1990s, the anti-Peter Elbows who relegate the personal as anything but rigor, I had been schooled by social constructivists who argue in their best David Bartholomae voice that "students need to be taught the discourses of academic writing" (Bartholomae, Writing on the Margins 63). My knee-jerk reaction — that the personal does not fall under academic discourses, and therefore, is not rigorous - is a matter of habit, of being disciplined to understand academic discourse as bound to discursive productions. ${ }^{79}$ For twenty plus years I have taught first year composition, an environment famous for regarding personal writing as a contested mode of academic discourse as Anne Ruggles Gere admits (204) or a space where "the belletristic 'personal' essay [has] dwindled as an object of study or production except in the old guise of the narrative 'mode' or the new school genre of literacy narrative" (Hesse 38) as Doug Hesse states in "The Place of Creative Writing in Composition Studies."

As a life writing instructor, I assumed a slightly different stance toward personal writing and its potential for rigor. I was often compelled to move students toward in-depth rhetorical and genre analysis, to see how writers recognize the charm in the ordinary, invite the daring, talk back to commonplace beliefs as Philip Lopate encourages, or to grasp how writers depict the loneliness of the monster or the cunning of the innocent, as Vivian Gornick stresses. I encouraged students to make connections between the content and the rhetorical moves in the

others' words and views" (351). Relatedly, Micciche calls for a "framework for understanding emotion's legitimate role in the making of meaning and in the creation of value in our culture," and argues that, without this framework, "we impoverish our own and our students' understanding of how we come to orient ourselves to one another and to the world around us" (1). Both Micciche and Stenberg call for a new understanding of the rhetoric of emotion.

${ }^{79}$ By "discursive" productions I invoke Joddy Murray's description in Non-Discursive Rhetoric: Image and Affect in Multimodal Composition:

Discursive text is a form of symbolization that is ordered and sequential - that aims to convey one idea after another. Discursive genres include the expository essay, oral presentation, research and argument papers, and the common modes such as narrative and exposition-in short, most of the genres common to the college composition classroom. (4). 
texts and their own experiences in life. As an academic discipline, life writing invites (may even require) the personal as an essential lens for analysis of the texts.

This internal struggle between sister-disciplines led to a heightened awareness of my own influences in the classroom: Is there such a thing as too much personal in the classroom? Why did I believe on some level that too much personal might jeopardize "academic rigor" — whatever that meant? In effect, I desired for my narrative as a teacher of this seminar to have meaning as well. Admittedly, I was thinking about my audience and the assessment of my work as this was a course for my internship — a stance that may indeed have increased my awareness of pedagogical assumptions.

In the analysis of my own pedagogy, the voices of my practicing discipline (composition studies) echoed with disparity to the voices of my newfound discipline (life writing studies) as the memoir project progressed. As a composition instructor, I felt the responsibility to direct class discussions and personal writing toward the metacognitive so that students knew the academic reasons for the personal writing in our interdisciplinary seminar - as if tying personal writing to the learning outcomes justified the memoir project. For instance, in the first half of the seminar when students confronted the childhood of Mary Karr, the sexuality of Alison Bechdel, the cancer of Lucy Grealy, the grief of Cheryl Strayed with their own stories of trials and trauma, I steered them back to focus on the text. I had to sort through my disciplinary baggage to understand the pedagogical tensions I felt during the seminar when the discussions felt too personal to me. Subsequently, what became more obvious to me as the semester progressed was that through the memoir project I had invited the personal into the classroom-a move that, in part, may have influenced the manufacturing of the rhetoric of bravery. 


\section{The Manufacturing of the Rhetoric of Memoir Bravery}

The students in the seminar generally approached personal narrative writing as a space to write about their lives as "authentically" as possible, and this meant writing the truth about their story in a voice that reflected their "real" personality as they may have perceived themselves. Writing the truth about their story often meant exposing something personal that may cause the author to feel vulnerable to criticism during writing workshops. In turn, students may feel vulnerable to criticism because they do not have the necessary detachment from the writing to see the narrator as a persona, and instead, see themselves as the narrator. In effect, the trickiness of separating the person and the persona, I argue, is the root cause of memoir bravery as it sets up the condition in the classroom for a certain kind of rhetoric to emerge - one that suggests an empathetic awareness among students. The source of potential empathy in this classroom context was not necessarily the students' identification with one another's stories or caring about the welfare of the other as much as it was identifying with the experience of the act of writing the memoir project. Sharing in the experience of writing functioned to bond students together on a level where empathy seemed to be an affect projected toward others in relation to their own shared sense of vulnerability and self-empathy.

In what follows, I examine the interplay of person/persona, authenticity, and vulnerability as elements of bravery in my students' writing to understand the development of empathy as it emerges in relation to the practice of responding to the personal writing of others, and in relation to students' first-hand experiences writing personal narrative.

\section{The Trickiness of Person/Persona}

Vivian Gornick identifies the development of a persona as one of the most essential and vital rhetorical advances a memoir writer can make toward inviting readers to care deeply about 
the story. In her guide for aspiring writers, The Situation and the Story: The Art of Personal Narrative, Gornick insists that when writing personal narrative, it is important to keep an eye on the self and the world all the time. Gornick writes:

The subject of autobiography is always self-definition, but it cannot be self-definition in the void. The memoirist, like the poet and the novelist, must engage the world, because engagement makes experience, experience makes wisdom, and finally it's the wisdom—or rather the movement toward it— that counts. 'Good writing has two characteristics,' a gifted teacher of writing once said. 'It's alive on the page and the reader is persuaded that the writer is on a voyage of discovery.' (14)

Undergraduate students who are novice writers of the genres of autobiography seldom need to persuade their readers that they are on a "voyage of discovery" because it is often really what happens during the writing process. Balancing self-discovery and "fashioning a persona" (Gornick 7) generally collide with issues of authenticity in ways that cause students to perceive the narrator of personal writing as the actual person who authors the piece rather than as a narrator who has been "fashioned" for the purpose of telling this story. Contributing to this perceived convergence, I presume, is the workshop environment of the classroom within which the writer who is being critiqued is physically present in the room. Partly, it is this convergence of person/persona that, I believe, summons a way of offering criticism that is considerate of the person.

Within the rhetoric that emerges in the classroom is an enduring concern and fear of rejection that hovers in the atmosphere. As a crucial matter, I sincerely believe it is important for students to be able to search for meaning in their stories and in their lives. Exposing and 
disentangling a perception of "I am what I write" is a necessary part of the trickiness of developing a persona that can do the work of meaning-making. Borrowed from the Latin word for mask, persona is a common theatrical concept. This idea of "masking" themselves for the sake of the writing did not gel with my students' ideas about the truth of life writing, at least as far as the students in this interdisciplinary class were concerned. My students did not develop a thick skin for critique nor did they strive to separate themselves as writers from their own narrating voices on the page. It is this possible failure, as Gornick may envision, that motivated a turn to the personal which endured throughout the semester, and which permitted me to observe the effects of the convergence of person and persona for student writers.

One key effect of the merging of person and persona as revealed in students' reflective essays was the hope that their stories would matter to others. Repeatedly, students admitted to feeling nervous about whether their writing was interesting to others, a concern that projected their unspoken belief, "if my writing is not interesting, I must not be interesting." This thinking is a symptom of an inability to separate the real person who is writing the story from the "narrator" who is telling the story. One student writer describes her inability to detach herself from the writing and from her own fears about how others might react to her story. The piece this student authored, titled "Stereotypical" was about the perils of attending a small, private school that sheltered her from the diverse realities that she encountered in college. She frames her essay with an experience from a forensics class on the first day in college to give readers a glimpse into her level of discomfort:

Sitting in the Intro to Forensics class, I didn't understand. I couldn't relax. There was a black man. He was tall. He had dreads. He was close enough to me that I could tell he reeked of weed. When he walked into the classroom, he had on 
headphones with Bob Marley colors. I could hear the thumping of the music. All I could do was pray that he would not sit next to me. I quickly thought of what I would do if he did. I could leave the classroom but then I would leave a bad impression on the first professor I'd have in college. I could move to another seat but that would be rude. Suddenly, he took his seat. It was three seats away from mine. It was about 7 feet. I kept my eye on him. I watched his every move.

("Stereotypical”)

In the essay, the student writer tells two stories: one story-line follows the Bob Marley stereotype as described above where readers are privy to the self-implicating racist thoughts of the writer while in the second and more prominent story-line, readers get a glimpse into the sheltered rulegoverned education that as the writer describes, "prepared [her] academically for college but not emotionally or socially." The student is confronting the commonplace understanding that being "college ready" means (only) an ability to perform academically. A worthy memoir topic for a college student, this writer's greatest anxiety was guessing what effect that her story could have on her peers.

The anticipation of her peers' reactions to her writing was also her own projection of potential judgment on her character. This led the author of "Stereotypical" to make multiple and careful revisions which further reveal her awareness of audience and its impact on her story. She describes it this way:

word choice was the most challenging part of writing because I didn't want to offend anyone or sound like I want pity...When I started I had a whole different plan in mind. I got my first two pages done and it sounded like a pity party. So, I deleted all of it and started again. ("Stereotypical") 
The self-awareness and discernment that is required for a writer to delete one's own words mirrors acts of published writers. What's at stake emotionally for the writer of "Stereotypical" is complicated, but she sorts out the complexities using rhetorical means, which, in the end, pays off for her. In a section of her reflective essay she describes the following:

I was nervous to read in front of the class. I didn't want to offend anybody or have them to look at me differently. When I read, I did not expect the reaction I got. [One student] found it hysterical which I was glad. I was sort of offended at first. Then I realized that I am dealing with a difficult topic that many people look down upon so without humor throughout the memoir I would come off in a negative way. I am glad that everyone found it funny because it really took away from the harsh topic. ("Stereotypical”)

Clearly, the writer of "Stereotypical" expresses relief when her peers found humor in her story, offering her validation and acceptance.

Two initial insights are gained from this example. First, the intricate threads of vulnerability and authenticity woven in the student's writing processes reveal how both elements are at work in response to one another. The writer, in effect, allowed herself to be in a vulnerable position as she perceived it—exposed and open to rejection and potentially, shame—by taking a risk and sharing her story as genuinely as she could while being fearful that she may come across as offensive. Second, the student's inability to clearly separate the person from the persona, in effect, challenges whether the author even is aware of constructing a persona.

An additional third insight gained from this example has to do with the rhetorical function of humor. The reaction of humor was an affective response. It was a clear and direct rhetorical response that, in the end, performed the work of comforting and affirming the writer. 
The laughter of the one student affirmed the writer and her risk-taking effort to be humorous, and it also broke the tension for the rest of the class. The students saw the face of the writer break into a smile of relief. No one said the writer was "brave." But she was tacitly affirmed in a way that marks elements of bravery. I do not mean to mire the ideology of "bravery" with the rhetoric of bravery in this example. Both are clearly at work: the writer is "brave" for taking a risk; the class employs rhetoric (laughter) which averts any potential for shame on the part of the writer. In this case, the laughter of the students is the rhetorical act that, in the end, affirms the writer and extends a kind of ease to themselves that they have done something good. I interpret this classroom scenario as an example of students expressing empathetic awareness. They each know what it is like to be in the vulnerable position of sharing personal writing with the group. Likewise, they each can empathize with the writer's vulnerable feelings and the relief of feeling understood.

To what extent might the courage of a writer who is nurtured in the classroom environment extend beyond the classroom is a question for further research, but for the author of "Stereotypical," the classroom marks the end of her public appearances. She concludes her reflection,

The best part of this project is that I learned something about myself that I didn't know before. Writing was a learning experience. I didn't know that I felt this way until I put it on paper. I have a newfound respect for the authors of memoirs. It is difficult to write about something that has to do with your life and is very personal. I do not know how the authors publish their memoirs for the world to read. I am not at that point yet. I don't think I am going to show anybody outside of the classroom. I am not 
comfortable sharing it because it is such a new thing to me.

\section{("Stereotypical”)}

The insight that self-understanding is something that one selectively discloses to others shows that this student had developed a trust with her peers in the seminar, but she was not willing to widen to the public sphere. This, coupled with the insight that her discovery is "such a new thing" to her, suggests that she has gained awareness of the detachment that Gornick argues is necessary in memoir writing even though she may not be able to practice it.

Writing for One Another: Vulnerability, Bravery, and Empathy

Most noticeable to me as the memoir project progressed was the students' level of genuine interest in one another's stories and the rhetorical interdependence that arose in the classroom as students began sharing their drafts. Often student writers looked to one another to determine whether their stories were worthy to tell or had some kind of meaning that resonated beyond the individual experiences and memories of the writer. In general, the students gauged whether their stories have meaning by the actual responses of their peers.

In their reflective pieces, students commented on the significant role that an audience of peers and the writers' uneasiness regarding the potential responses of their peers have on their own rhetorical choices. The students struggled from the beginning of the project to write something interesting about their own lives and that could also matter to others. ${ }^{80}$ For some students, this led to them writing about a topic that induced various emotional stakes for themselves as writers. Sharing their memoir pieces with the class was a required part of the

\footnotetext{
${ }^{80}$ The following titles and descriptions of memoirs are used with written consent from the authors and IRB approval. I have agreed to keep their names confidential: "Melancholy Ever After" (Growing up in a small town, experimenting with drugs out of boredom); "The Monster that Lived Inside Me" (Alcoholism and recovery); "Stereotypical" (Attending a small, private high school that sheltered her from the realities of diversity); "The Castle" (Breaking and entering an abandoned building and an encounter with the police); "Tic Tac Twitch" (Growing up with Tourette's syndrome); "Not So Disgustingly Cliché" (The struggle of choosing boyfriend over best friend); "The Other Woman" (A story that complicates the meaning of cheating).
} 
project, which in hindsight I believe was the motivating factor for influencing which topics that students chose to write about. Students did not conscientiously select a topic motivated by a public reading, but as they began the writing process, students kept an eye on the end product and the delivery to their peers as they made many of their writing choices. In other words, students imagined writing for each other. ${ }^{81}$

As I mentioned, as evident throughout the duration of the memoir project, students gauge whether their stories have "meaning" by the responses of their peers. One student writer discloses the anguish of deciding what to write as a topic because she worried whether her story was important enough to write. After writing several drafts, the student realizes one of the most significant aspects of personal life writing: the act of the writing affects the story itself. She reflects on her writing processes in this way:

Somehow, as I was digging up emotions and telling truths on paper I came to realize that what I had thought to be my story in the beginning was altered as I ventured further into this process. I now look at the situation described in my writing differently than when I first wrote this piece because I think I was forced to really evaluate it from many different angles. I still struggle with the reality that now that my words are written and they have met various eyes, people are able to judge what I have said. They are able to make assumptions about my character and my weaknesses based on what I wrote. ("Challenged”)

\footnotetext{
${ }^{81}$ For my students, sharing their writing with peers in the class was not unlike the best practices we find in first year composition courses or creative writing workshops. But the level of investment or interest many students displayed while listening to writers read their work and then offering feedback appeared to me to be different from what I have experienced in first-year composition courses. By different, I mean more "real" or "genuine." I interpret this observation as having to do with the symbiotic connection that students made between the writer of the text and the text itself. Not only did student writers show concern and anxiety about their identity being wrapped up in their stories, but because the students shared this uncomfortableness, they approached on another's writing with care.
} 
The author of "Challenged" identifies the potential of aha! moments in her writing process, but instead of feeling confident and courageous about her new perspective, she stops to contemplate the potential rhetorical effects of her writing. The worry this writer has is that her character (her perceived identity) will be judged based on her writing. In part, she's right. For the young, apprentice memoir writer who cannot separate the writing from the writer, the concern is not that the writer feels an attachment to the piece, but rather that the writer fears others will know her only by one representation. One reason for the entanglement of person and persona may have to do with the process of writing personal narrative: through the writing process students come to realize that the writing of the story shapes the story, and thus also shapes or reshapes themselves as persons. As the author of "Challenged" expresses, the writing itself altered the story which may have caused the writer to imagine an even tighter bond between the person and persona because of the experience of self-discovery during the writing.

As the memoir project progressed, the students became more willing to be vulnerable storytellers, which in turn increased their ability to empathize with one another. Students became more open and seemingly comfortable discussing their personal stories in the public space of our classroom. That vulnerability and affirmation were at work together in the same space produced a sense of trust among the students—-first, that they would not be ridiculed for their stories, and second, that their stories (and therefore, as they perceived, the students themselves) would be received with caring and empathetic gestures.

The interplay between vulnerability and affirmation became evident to me as I observed the students reinforcing the positive as a form of critique during workshop sessions. Positive feedback among peers is a common experience, particularly when novice writers often do not know how to provide constructive criticism. What seemed different in this seminar compared to 
the peer-review sessions in other writing courses was a noticeable presence of empathy as the students understood from their own writing experience the vulnerability they shared with one another. Leslie Jamison, author of The Empathy Exams, observes that "empathy is a choice we make: to pay attention, to extend ourselves," and that this social confidence "gives a person the courage to enter the interpersonal world and practice empathetic skills" (22). My students' choice to extend themselves, as Jamison asserts, created a space for extending potential empathy. Equally, as the students shared personal narratives with empathetic peers, they became even more open with one another. In this seminar, empathy became a contagious affect.

In general, students approached the memoir assignment with the expectation that writing about ones' own life experiences would be "freeing." To their surprise, the emotional toil of writing personal stories for others to hear and to critically handle made the experience quite challenging due to the deep level of discernment required. The author of "Challenged" admits to the unexpected difficulty of this assignment: "my emotions ... had never been given a true voice before. I had to dig deep into the things I really felt while incorporating the things I feel now about the situation I described." Lynn Worsham asserts that discernment is as much a part of emotion as any sentiment. Worsham describes emotion as that "tight braid of affect and judgment, socially and historically constructed and bodily lived, through which the symbolic takes hold of and binds individuals, in complex and contradictory ways, to the social order and its structure of meanings" 82 (1002). As students anticipated the way their writing may sound

\footnotetext{
${ }^{82}$ Worsham's work on emotion in rhetoric and composition follows a line of scholars who have paved the way for a wider acceptance and respect of affect theory across academics, and particularly in composition studies as demonstrated in the work of Alice Brand and Mike Rose among others. Melissa Gregg and Gregory Seigworth provide this description of affect in the opening chapter of in their edited book, The Affect Theory Reader: "Affect arises in the midst of the inbetween-ness: in the capacities to act and be acted upon...Affect... is the name we give to those forces - visceral forces beneath, alongside, or generally other than conscious knowing, vital forces insisting beyond emotion - that can serve to drive us toward movement..." (2). The affective turn in composition as well as debates over the role of personal writing have become tiresome. Critics and theorists who write on the affective turn include: Gilles Deleuze and Felix Guattari, Baruch Spinoza and Henri Bergson. Brian Massumi, Patricia T. Clough
} 
when they read it to their classmates, they in turn wrestled with their own sense of discernment for their stories to have meaning. For many this was an emotional labor.

Students' sense of discernment manifested itself in the ways they approached revision. The centrality of revision and the effect of audience on writing choices are not separate rhetorical functions in memoir writing processes. In fact, the interplay is quite striking. One student explains her effort:

Write what I remember and make it interesting. But there was something missing. My own reflection on these events is what makes the memoir a memoir. This was the tricky part. I had to be honest. Sometimes being honest comes across as harsh, or rude, but that is how I was going to relate to my readers...Being concerned with the reaction of others was always a concern of mine while writing this memoir. I told myself that everyone who has written memoirs acknowledges that people will judge, insult, or degrade your work. If one does not accept that, then their work would be kept private. ("Tic Tac Twitch")

This student writer is reflecting on a piece about being diagnosed with Tourette's syndrome as a young child. The social stigma of the disorder is far worse that the constant battle of medications, the side effects, the toll on the body, and the extensive emotional damage. This writer struggled to communicate something she knows intimately as a way of life to those who have no idea how to relate to a person with tics. She admits being perplexed about how to reach her audience in a meaningful way.

-to name a few. Nevertheless, students" "emotional investments" in the success of personal writing when what is at stake is their own sense of identity as it is tied up in the reactions of others is an ever present issue in many writing workshop environments. Like Didion, Barrington, King and others, students desire for their stories to have meaning. 
I wasn't sure how to even approach this type of writing, so I went to my teacher for advice... She helped me understand the form of the memoir, but I was still somewhat confused after I left. Neither of us knew what to do next. I took it home, and instead of turning on my computer, opening Word, and starting to type, I sat alone in my room just pondering the parts of my childhood that really stood out...I tried to find a connection between the memories I was remembering. Was there a link that tied them together? What was the underlying problem or feeling that was being portrayed in those memories. Then it hit me. Everything stems back to change and attention. That had to be the theme I would work around in my memoir. ("Tic Tac Twitch")

The student's articulation of the composing process in this reflective piece reveals the interplay between the effect of audience and the act of revising. At an early point, the author of "Tic Tac Twitch" wrote a draft that functioned much like one that might be composed in a composition course in response to a prompt that asks for a description of a childhood memory. Her draft described a child with Tourette's syndrome without complicating the subject. The student revised the earlier drafts, and in the end, she was so proud of her work that she brought to class the final version in a book form to read to the class. Parts of the essay revealed a raw honesty about the emotional pain of the disorder that she has lived with because of the disruption her tics cause in public spaces. This is the kind of honesty that is often perceived by readers as "authentic" and, as I have argued, is often recognized as an element of "bravery." Interestingly, she was asked whether she planned to share her writing with her family, who became subcharacters in the story and implicated in ways that were not always flattering. The student smiled without answering. 
Repeatedly, it is through the process of writing that students (and many professional writers for that matter) indeed discover what it is that they want to say. In so doing, many writers, particularly students, may experience a sense of self-empathy because of their discoveries. What I observed through the memoir project was a pedagogy in which the emotional stakes were central to the writing and must be recognized by student writers and teachers as essential to the processes. As Megan Brown acknowledges, "the autobiography course can be a provocative way to improve writing, reading, and critical thinking abilities, in part precisely because such a class allows students and instructors to explore contemporary American culture's problematic, complex fascination with individuality and self-expression." ("Memoir as Provocation" 123).

During the semester teaching the seminar, I caught myself comparing my experience teaching the memoir with my many years of teaching first-year composition. The disciplinary tensions that I felt as a teacher in this seminar were not something my students seemed to share. As the course proceeded, the students' commitment to their memoir projects revealed to me the significance of the affective aspects of memoir practice. I believe that students' failure to detach themselves as persons from the writing did not limit students from engaging in meaningful writing experiences. The turn to the personal as I came to realize exposed the elements of vulnerability and the complexities of authenticity in ways that affected the students' empathetic interactions with one another. Within the emergence of an appreciative rhetoric - where students compliment and find the value or meaning in one another's stories—a viable space for empathy opened up. As students expressed their own anxieties to one another about sharing their stories, this admission, in turn, prompted others to become open-hearted and act to care for the 
vulnerable one. The kind of rhetorical care that emerged, I believe, connotes elements of the rhetoric of bravery as it operates in larger cultural discourses.

Most compelling about teaching the memoir was the effect of audience on students' writing choices and the centrality that revision took in their writing processes. One student reflects: "the journey to write the memoir is just as important as the memoir itself...I realized after I wrote the second draft that I still had a lot of work to do. I think it is easy to get the memories down on paper but hard to write it in a way that makes it easy to read" ("The Monster that Lives Inside Me"). A favorite comment: "After five drafts, I have to say that I tried my best" ("Challenged"), addresses the exasperating experience of revision when the writer realizes that the writing must come to an end even though the product could always continue to be revised. ${ }^{83} \mathrm{I}$ imagine my composition students' reaction if I began an assignment with these instructions: "You will write five drafts of this essay." That would not go over well. What is striking about the role of revision in student memoirs is that the choice to revise is intrinsically motivated from within the writer because of the emotional investment in the story and the accountability they inherit as participants in the affect world they have constructed.

Jane Danielewicz states, "writing autobiography (or other similar genres) encourages the development of public voice... that quality of writing that represents a writer's persona, that conveys the writer's authority" (420). By re-visioning the public space of the classroom as an intimate space, students confront the onset of fear that accompanies vulnerability and exposure with a determination to present oneself as an authentic, truth-telling narrator. Students may even experience a paradigm shift together as a group. For this group, students clearly shifted from thinking that life writing is a somewhat easy task to owning-up to the challenges of memoir

\footnotetext{
${ }^{83}$ As I make my final revisions to this dissertation and realize the writing must come to an end, I must say I have absolute empathy with this student!
} 
authorship. The collective experience of knowing first-hand the challenges of memoir writing seemed to generate a consensual bond among students and a respect for one another as authors. Even their speech marked the significance of their experience as they often referred to the project not as a "memoir essay" or a "life writing assignment" but, with simple grace and ownership, as their "memoir" (period).

\section{Conclusion: Memoir Bravery as a Rhetoric of Empathy?}

This interdisciplinary classroom served as a sort of laboratory for testing a "theory of bravery rhetoric" as I have analyzed in prior chapters. Students were not apt to call one another "brave" literally. However, the "spirit of the rhetoric of bravery" was present in the classroom. By "spirit" I refer to characteristics that I observed and that students reported in their reflective writings that indicated specific qualities of the rhetoric of bravery but without necessarily using the word "bravery." These qualities included the acknowledgment of personal risk, the fear of failure and potential for shame, the desire for their stories to be well-received, the push to present themselves as authentically as possible, and the empathetic awareness of others' vulnerabilities.

The kind of rhetoric that students displayed during writing workshops and in their own reflective texts disclosed cultural overtones of memoir bravery. Students' anxieties about sharing their personal writing in class revealed their anxieties about the ways in which their stories may be heard and judged by their classmates. Commonly, students' reflective essays were about their own fears of exposure and the relief they felt when their stories resonated with their classmates. Lopate writes, "I am inclined to think that what stands in the way of most personal essays is not technique but psychology. The emotional preparedness, if you will, to be honest and open to exposure" (70). My students were experimenting with both technique and psychology, which to me represented the "raw materials" for memoir bravery. The rhetoric of bravery that 
surrounds the memoir genre in our contemporary culture, I believe, plays a role in the ways in which students engage with one another in the classroom and the ways they garner hope for their stories to have meaning in light of sociocultural and rhetorical realities.

In this dissertation, I have argued that culture influences the production, circulation, and consumption of the memoir genre, and to a sizeable degree, the rhetorical choices of writers. In turn, memoirs do cultural work, and possibly affective work, as the rhetoric of bravery attests. The rhetoric that names and assesses certain memoirs as "brave" reflects, largely, a cultural ideology that places value on duties performed beyond expectation and commonly, but not always, for the sake of others. It is rhetoric that boasts of what attributes are valued, and consequently, represses those not valued. The rhetoric of bravery that surrounds the contemporary memoir is an appreciative rhetoric that encourages the production of more brave stories, and in so doing, reinforces the trace of a society mirrored and mired in the heroic language as re-inscribed in each new memoir that we call brave.

I have also made the claim that the rhetoric of bravery can indeed function as a linguistic effect of readers' empathy. This claim is significant in the way it engages Suzanne Keen's critique of empathy and the novel and suggests ways in which empathy and the memoir may be conceived differently. As I reviewed in prior chapters, Keen critiques scholars who make "large claims" about empathy and the novel, arguing against theories that single out the novel as a "technology most adept at invoking empathy and shaping behavior" (35). Keen surveys scholarship in empathy studies and exposes the gaps in evidence for claims that empathy is a viable readers' response to fiction. Even though the large claims made on behalf of the novel "endorses what many people believe about the transformative power of reading and of reading fiction in particular," Keen believes psychologists have not been able to discover the kind of 
evidence about empathy that would warrant these claims (35). Using Keen's work as a springboard, I theorized the rhetoric of bravery and its empathetic connotations as a possible form of readers' response to certain kinds of memoirs, particularly memoirs of trauma, as I analyzed in Chapter 4. The perspective of memoir as a genre with the potential to affect empathy in readers, I realize, may rest on large claims made about the cultural work of memoir that are similar to the large claims made about the novel which Suzanne Keen critiques. This is an exciting area for further research.

As my dissertation title, "Braving Shame" playfully depicts, one effect of the rhetoric of memoir bravery is the work it does to cater the personal stories we tell for public consumption. The "braving" work of the rhetoric implies, as I have argued, a preferred way of hearing certain kinds of stories. In light of Amy Shuman's commentary on entitlement and tellability, I have argued that bravery rhetoric functions as a way of re-telling a story, and this may reflect an unspoken collective agreement where we entitle ourselves permission to identify the heroic. By default, the rhetoric of bravery is inclusive and exclusive, sometimes redirecting what may be considered shameful and other times shaming what may be considered unacceptable.

In this final chapter, I have suggested that the manufacturing of memoir bravery requires a degree of exposure and vulnerability on the part of the writer coupled with the distinct feature of perceived authenticity — the hallmark of the genre. The rhetoric of bravery names, assesses, and values certain stories as brave, which in effect, rejects the potential of shame or shaming that can accompany exposure of such stories. In lieu of gawking at the raw and explicit details of personal stories, it is a rhetoric that salutes potential heroism. Memoir bravery is a rhetoric of inclusions and exclusions, of productions and reflections, of births and deaths, of longings and losses, of duties expected and duties performed above expectation, of potential shame and 
potential pride. To what end? I believe it is a rhetoric with connotations of care and empathy that reflects, reinforces, and redirects potential shame while at the same time underscores a sense of belonging as accessed through common and shared experiences of productions and losses. While authenticity is a necessary ethical element in memoir authorship, the vulnerability of the narrator presents a gesture towards trust on a deeper level because of the potential risk-factor.

Authenticity is a genre expectation; vulnerability is a genre opportunity. What they have in common is their nod toward bravery as a potential rhetoric of empathetic awareness. 


\section{WORKS CITED}

AAC\&U. Association of American Colleges \& Universities. AAC\&U, n.d. Web. 2 Aug. 2016.

“About." COURAGEworks: Braver Living and Loving with Brené Brown. N.p., 2015. Web. 09 Nov. 2016.

American Psychological Association. Diagnostic and Statistical Manual of Mental Disorders. 3rd Ed. Washington, D.C.: American Psychological Association, 1987.

Andreeva, Nellie. "Reese Witherspoon \& Laura Dern To Produce Drama Project for HBO Based on Book by 'Wild' Author Cheryl Strayed.” Deadline. Hollywood: Penske Business Media, LLC. 26 Oct. 2015. Web. 10 Nov. 2015.

Aron, Lewis and Karen Star. A Psychotherapy for the People: Toward a Progressive Psychoanalysis. New York: Routledge/Taylor \& Francis Group, 2013.

Austin, J.L. How to Do Things with Words. Cambridge: Harvard UP, 1975.

Bakhtin, Mikhail M. "Discourse in the Novel." The Dialogic Imagination: Four Essays. Trans. Caryl Emerson and Michael Holquist. Ed. Michael Holquist. Austin: University of Texas Press, 1981. 259-422.

Barrington, Judith. Writing the Memoir: From Truth to Art, 2nd ed. Portland, OR: The Eighth Mountain Press, 2002.

Bartholomae, David. Writing on the Margins: Essays on Composition and Teaching. Boston: Bedford/St. Martins, 2005.

---. "Writing with Teachers: A Conversation with Peter Elbow." College Composition and Communication 46.1 (1995): 62-71. Web. 31 Oct. 2016.

Barton, Ellen. "Further Contributions from the Ethical Turn in Composition/Rhetoric: Analyzing Ethics in Interaction." College Composition and Communication 59.4 (2008): 596-632. Web. 31 Oct. 2016.

Beasley, Chris, and Carol Bacchi. "The Political Limits of 'Care' In Re-Imagining Interconnection/Community and An Ethical Future." Australian Feminist Studies 20.46 (2005): 49-64. Web. 31 Oct. 2016.

Bechdel, Alison. Fun Home: A Family Tragicomic. Boston: Houghton Mifflin, 2006.

Benedict, Ruth. The Chrysanthemum and the Sword: Patterns of Japanese Culture. Boston: Houghton Mifflin, 2005. 
Benjamin, Walter. "The Work of Art in the Age of Mechanical Reproduction." Film Theory and Criticism: Introductory Readings. Eds. Leo Braudy and Marshall Cohen. New York: Oxford UP, 1999. 731-751.

Berger, Ronald J. "Disability and the Dedicated Wheelchair Athlete: Beyond the 'Supercrip' Critique." Journal of Contemporary Ethnography. 37:6 (2008): 647-678. Web. Oct. 31 2016.

Berlant, Lauren Gail. Desire|Love. New York: Punctum Books, 2012.

---. The Female Complaint: The Unfinished Business of Sentimentality in American Culture. Durham: Duke UP, 2008.

Berlant, Lauren, and Jay Prosser. "Life Writing and Intimate Publics: A Conversation with Lauren Berlant." Biography 1 (2011): 180. Web. 31 Oct. 2016.

Bobker, Danielle. "Intimate Points: The Dash in The Autobiography of Benjamin Franklin." Papers on Language \& Literature 49.4 (2013): 415-443. Web. 31 Oct. 2016.

Booth, Wayne C. The Rhetoric of Fiction. Chicago: University of Chicago Press, 1961.

Bordo, Susan. Unbearable Weight: Feminism, Western Culture, and the Body. Oakland: University of California Press, 2004.

Bourke, Joana. Rape: A History from 1860 to the Present. London: Virago Press, 2008.

Bouson, J. Brooks. Embodied Shame: Uncovering Female Shame in Contemporary Women's Writings. New York: SUNY Press, 2009.

Bracher, Mark. "Healing Trauma, Preventing Violence: A Radical Agenda for Literary Study." JAC 24.3 (2004): 515-561. Web. 22 Mar. 2012.

Brison, Susan J. Aftermath: Violence and the Remaking of a Self. Princeton, NJ: Princeton UP, 2002.

Brown, Brene. "Brene Brown: The Power of Vulnerability | Video on TED.com." TED: Ideas Worth Spreading. TED CONFERENCES, Dec. 2010. Web. 9 Nov. 2016.

Brown, Megan C. "Learning to Live Again: Contemporary US Memoir as Biopolitical Self-Care Guide." Biography: An Interdisciplinary Quarterly 36.2 (2013): 359-375. Web. 31 Oct. 2016.

---. "The Memoir as Provocation: A Case For "Me Studies" In Undergraduate Classes." College Literature 37.3 (2010): 121-142. Web. 31 Oct. 2016. 
Bryant, Nick. "US Set for Year of Fear.” BBC News. US \& Canada. 4 Jan. 2016. Web. 6 Nov. 2016.

Burrus, Virginia. Saving Shame: Martyrs, Saints, and Other Abject Subjects. Philadelphia: University of Pennsylvania Press, 2008.

Butler, Judith. Precarious Life: The Powers of Mourning and Violence. New York: Verso Books, 2004.

Cahill, Ann J. Rethinking Rape. Ithaca and London: Cornell UP, 2001.

Caruth, Cathy. Trauma: Explorations in Memory. Baltimore: Johns Hopkins UP, 1995.

“Challenged by Life Writing.” May 2014. TS.

Charon, Rita and Martha M. Montello. Stories Matter: The Role of Narrative in Medical Ethics. New York Routledge, 2002.

“Courage.” Online Etymology Dictionary. Web. 10 June 2016.

Couser, G. Thomas. Memoir: An Introduction. Oxford: Oxford UP, 2011.

---. Vulnerable Subjects: Ethics and Life writing. Ithaca: Cornell UP, 2004.

Derrida, Jacques. Archive Fever: A Freudian Impression. Chicago: University of Chicago Press, 1995.

DeVolder, Beth. "Overcoming the Overcoming Story: A Case Of "Compulsory Heroism." Feminist Media Studies 13.4 (2013): 746-754. Web. 31 Oct. 2016.

Didion, Joan. The Year of Magical Thinking. New York: Alfred A. Knopf, 2005.

---. The White Album. New York: Simon and Schuster, 1979.

Dodds, Eric R. The Greeks and the Irrational. Oakland: University of California Press, 1951.

Douglas, Kate. Contesting Childhood: Autobiography, Trauma, and Memory. New Brunswick, NJ: Rutgers UP, 2010.

Duval, Shelley, and Robert A. Wicklund. A Theory of Objective Self Awareness. New York: Academic Press, 1972.

Eakin, Paul John, ed. The Ethics of Life Writing. Ithaca, NY: Cornell UP, 2004.

---. Living Autobiographically: How We Create Identity in Narrative. Ithaca, NY: Cornell UP, 2008. 
Elbow, Peter. "Being a Writer vs. Being an Academic: A Conflict in Goals." College Composition and Communication 46:1 (1995): 72-83. Web. 31 Oct. 2016.

Fassin, Didier and Richard Rechtman. The Empire of Trauma: An Inquiry into the Condition of Victimhood. Trans. Rachel Gomme. Princeton and Oxford: Princeton UP 2009.

Featherstone, Mike. Consumer Culture \& Postmodernism. London: Sage, 1991.

Feldman, Simon. Against Authenticity: Why You Shouldn't be Yourself. London: Lexington Books, 2015.

Felman, Shoshana, and Dori Laub, M.D. Testimony: Crises of Witnessing in Literature, Psychoanalysis, and History. New York: Routledge, 1992.

Ferrera, Alessandro. Modernity and Authenticity: A Study in the Social and Ethical Thought of Jean-Jacques Rousseau. Albany: SUNY Press, 1993.

Fishman, Stephen M., and Lucille Parkinson McCarthy. "Is Expressivism Dead? Reconsidering Its Romantic Roots and Its Relation to Social Constructionism.” College English 54.6 (1992): 647-61.

Foucault, Michel. The Archaeology of Knowledge. New York: Vintage, 1982.

---. The Order of Things: An Archaeology of the Human Sciences. New York: Vintage, 1994.

---. "Technologies of the Self." Ed. Paul Rabinow. Trans. Robert Hurley and others. Ethics: Subjectivity and Truth, Vol. 1 of The Essential Works of Michel Foucault, 1954-1984. New York: New Press, 1997. 223-251.

Francisco, Patricia Weaver. Telling: A Memoir of Rape and Recovery. New York: HarperCollins Publishers, 2000.

Freadman, Richard. Threads of Life: Autobiography and the Will. Chicago: University of Chicago, 2001.

Frey, James. A Million Little Pieces. New York: N.A. Talese/Doubleday, 2003.

Fuchs, Miriam, and Craig Howes. Teaching Life Writing Texts. New York: Modern Language Association of America, 2008.

Gadoua, Renee K. "1 in 4 Women Will Be Raped Before Graduating College.” Syracuse NewTimes. 16 Apr. 2014. Web. 3 Nov. 2016.

Ganteau Jean-Michael. The Ethics and Aesthetics of Vulnerability in Contemporary British Fiction. New York and London: Routledge/Taylor \& Francis Group, 2015. 
Garber, Marjorie B., Beatrice Hanssen, and Rebecca L. Walkowitz, eds. The Turn to Ethics. New York: Routledge, 2000.

Gavey, Nicole. Just Sex: The Cultural Scaffolding of Rape. New York: Routledge, 2005.

Genette, Gerard. Paratexts: Thresholds of Interpretation. Cambridge: Cambridge UP, 1997.

Gere, Anne Ruggles. "Revealing Silence: Rethinking Personal Writing." CCC 53.2 (2001): 203223. Web. 31 Oct. 2916.

Gerstein, Josh. “Terror Attacks Spark Cowardly Debate.” ABC News. Washington. 26 Sept. Web. 6 Feb. 2016.

Gilligan, Carol. In A Different Voice: Psychological Theory and Women's Development. Cambridge: Harvard UP, 1993.

Gilmore, Leigh. "Covering Pain: Pain Memoirs and Sequential Reading as an Ethical Practice." Biography: An Interdisciplinary Quarterly 38.1 (Winter 2015): 104-117. Web. 31 Oct. 2016.

---. The Limits of Autobiography: Trauma and Testimony. Ithaca: Cornell University Press, 2001.

--. "Limit-Cases: Trauma, Self-Representation, and the Jurisdictions of Identity." Biography 24.1: (2001): 128-38. Web. 31 Oct. 2016.

--. "Wild: From Lost to Found on the Pacific Crest Trail." Fourth Genre: Explorations in Nonfiction 14.1 (2012): 187-190. Web. 31 Oct. 2016.

Glenn, Cheryl. Unspoken: A Rhetoric of Silence. Carbondale: Southern Illinois UP, 2004.

Golomb, Jacob. In Search of Authenticity: from Kierkegaard to Camus. London and New York: Routledge, 1995.

Gornick, Vivian. The Situation and the Story. New York: Farrar, Straus and Giroux, 2001.

Gray-Rosendale, Laura. College Girl: A Memoir: Albany, N.Y.: Excelsior Editions/State University of New York Press, 2013.

Grealy, Lucy. Autobiography of a Face. Boston and New York: Houghton Mifflin Company, 1994.

Greenwood, Elizabeth. "Eat, Pray, Love Like a Badass: Cheryl Strayed, the Oprah Author 2.0." Atlantic: Web Edition Articles (USA) 08 Oct. 2012. Web. 31 Oct. 2016. 
Gregg, Melissa, and Gregory J. Seigworth. The Affect Theory Reader. Durham, NC: Duke UP, 2010.

Guignon, Charles. On Being Authentic. New York: Routledge, 2004.

Hanna, Ralph. "Pause and Effect - An Introduction to The History of Punctuation in The West by M.B. Parkes" Huntington Library Quarterly 57.4 (1994): 377-382. Web. 31 Oct. 2016.

Hanstedt, Paul. General Education Essentials: A Guide for College Faculty. San Francisco: Jossey-Bass, 2012.

Harris, Judith. "Re-Writing the Subject: Psychoanalytic Approaches to Creative Writing and Composition Pedagogy." College English 64.2 (2001): 175-204.

Harrison, Kathryn. The Kiss. New York: Random House, 1997.

Hatch. Evelyn. Discourse and Language Education. Cambridge [England]: Cambridge UP, 1992.

Heberle, Renee and Victoria Grace, eds. Theorizing Sexual Violence. New York: Routledge/Taylor \& Francis, 2009.

Heidegger, Martin. Being and Time: A Translation of Sein and Zeit. Trans. Joan Stambaugh. Albany: State University of New York Press, 1996.

Held, Virginia. The Ethics of Care: Personal, Political, and Global. NY: Oxford University Press, 2006.

Herman, Judith Lewis. Trauma and Recovery. New York: BasicBooks, 1997.

Hesse, Douglas. "The Place of Creative Writing in Composition Studies." CCC 62.1 (2010): 3152.

Hindman, Jane E. “Special Edition: Personal Writing." College English 64.1 (2001): 34-40.

Hobbs, Catherine. "The Red and the Black: Life Narrative and Ethics." JAC 25.2 (2005): 407418. Web. 2 Nov. 2016.

Hoffman, Martin. Empathy and Moral Development: Implications for Caring and Justice. New Cambridge: Cambridge UP, 2000.

Holdstein, Deborah H. and David Bleich. Personal Effects: The Social Character of Scholarly Writing. Logan: Utah State UP, 2001. 
Hughes-Hallett, Lucy. Heroes: A History of Hero Worship. New York: Alfred A. Knopf, 2004.

Hutton, Patrick H. History as an Art of Memory. Hanover: UP of New England, 1993.

Huyssen, Andreas. Twilight Memories: Marking Time in a Culture of Amnesia. New York: Psychology Press, 1995.

Hyde, Michael. "The Rhetor as Hero and the Persuit of Truth: The Case of 9/11." Rhetoric \& Public Affairs 8:1 (2005): 1-30. Web. 31 Oct. 2016.

Jamison, Leslie. The Empathy Exams: Essays. Minneapolis: Graywolf Press, 2014.

Kaltenbock, G, B Heine, and T. Kuteva. "On Thetical Grammar." Studies in Language 35.4 (2011): 852-897. Web. 31 Oct. 2016.

Karen, Robert. "The Psychology of Shame: Theory and Treatment of Shame-based Syndromes." The Atlantic Monthly: 269:2 (1992): 40-66. Web. 2 Nov. 2016.

Karr, Mary. The Liars' Club. New York: Viking, 1995.

---. Slate Magazine. “The Liars' Club.” 27 March 2007.

Kaufman, Gershen. Shame, The Power of Caring: Cambridge, MA.: Schenkman Publishing Company, 1980.

Keen, Suzanne. Empathy and the Novel. New York: Oxford UP, 2007.

---. Narrative Form: Revised and Expanded Second Edition. London: Pelgrave MacMillan, 2015.

King, Stephen. On Writing: A Memoir of the Craft. London: Hodder and Stoughton, 2000.

Klaiber, Isabell. "Multiple Implied Authors: How Many Can a Single Text Have?" Style 45.1 (2011): 138-152.

LaCapra, Dominick. Writing History, Writing Trauma. Baltimore: Johns Hopkins UP, 2014.

Larson, Thomas. The Memoir and the Memoirist Reading and Writing Personal Narrative. Athens, Ohio: Swallow/Ohio UP, 2007.

Lamott, Anne. Bird by Bird: Some Instructions on Writing and Life. Random House Publishers, 1994.

Laub, Dori. "An Event Without a Witness: Truth, Testimony, and Survival." Testimony: Crisis of Witnessing in Literature, Psychoanalysis, and History. Eds. Shoshana Felman and Dori Laub, MD. New York: Routledge/Taylor \& Francis, 1992. 75-92. 
Lejeune, Philippe, and Paul John Eakin. On Autobiography. Minneapolis: University of Minnesota, 1989.

Lennard, John. But I Digress: The Exploitation of Parentheses in English Printed Verse. United Kingdom: Clarendon Press, 1991.

Lewis, Helen Block. "Shame and the Narcissistic Personality." Ed., Donald Nathanson. The Many Faces of Shame. New York: Guilford Press, 1987. 93-132.

Lewis, Michael. Shame: The Exposed Self. New York: The Free Press, 1995.

Leys, Ruth. From Guilt to Shame: Auschwitz and After. Princeton: Princeton UP, 2007.

Lionnet, Françoise. Autobiographical Voices: Race, Gender, Self-portraiture. Ithaca: Cornell UP, 1989.

Lopate, Phillip. To Show and to Tell: The Craft of Literary Nonfiction. New York: Free, 2013.

---. The Art of the Personal Essay: An Anthology from the Classical Era to the Present. New York: Anchor, 1994.

MacCannell, Dean. The Ethics of Sightseeing. Oakland: University of California Press, 2011.

---. The Tourist: A New Theory of the Leisure Class. Oakland: University of California Press, 1999.

MacIntyre, Alasdair C. After Virtue. 2nd ed. Notre Dame: University of Notre Dame Press, 1984.

Manning, Rita C. "A Care Approach." Eds., Helga Kuhse and Peter Singer. A Companion to Bioethics (Second Edition). Malden: Wiley-Blackwell, 2009. E-book.

---. Speaking from the Heart: A Feminist Perspective on Ethics. Lanham, Md.: Rowman \& Littlefield, 1992.

McCourt, Frank. Angela's Ashes: A Memoir. New York: Scribner, 1996.

Micciche, Laura R. Doing Emotion: Rhetoric, Writing, Teaching. Portsmouth, NH: Boynton/Cook-Heinemann, 2007.

Miller, Nancy K. "The Ethics of Betrayal: Diary of A Memoirist." The Ethics of Life Writing. Ed. Paul JohnlEakin. Ithaca, NY: Cornell UP, 2004. 147-160.

---. But Enough About Me. New York: Columbia UP, 2002.

Miller, William Ian. The Mystery of Courage. Cambridge: Harvard UP, 2000. 
Montello, Martha. "Confessions and Transgressions: Ethics and Life Writing." The Hastings Center Report. 36:2 (Mar-Apr 2006): 46-47.

Mortensen, Peter and Gesa E. Kirsch, eds. Ethics and Representation in Qualitative Studies Of Literacy. Urbana, IL.: National Council of Teachers of English, 1996.

Mulcaster, Richard, and Ernest Trafford Campagnac. "Mulcaster's Elementarie." (1925): HathiTrust. Web. 7 Apr. 2014.

Murphy, Anne. "Rethinking the Ethics of Vulnerability." Eds., Heberle, Renee and Victoria Grace. Theorizing Sexual Violence. New York: Routledge/Taylor \& Francis, 2009. 55-71.

Murray, Joddy. Non-Discursive Rhetoric: Image and Affect in Multimodal Composition. Albany, NY: State U of New York P, 2009.

Murray, Michael D. "The Promise of Parentheticals: An Empirical Study of The Use of Parentheticals in Federal Appellate Briefs." Journal of the Association of Legal Writing Directors 10 (2013): 229-264. Web. 2 Nov. 2016.

Mython, Gabe. "Cultural Victimology: Are We All Victims Now?” Ed. Sandra Walklate. Handbook of Victims and Victimology. Portland, OR.: Willan Publishing, (2007): 464483.

Nathanson, Donald, ed. Knowing Feeling: Affect, Script, and Psychotherapy. New York: Norton, 1996.

--. Ed. The Many Faces of Shame. New York: Guilford Press, 1987.

Nelson, Katherine. "The Psychological and Social Origins of Autobiographical Memory." Psychological Science (Wiley-Blackwell) 4.1 (1993): 7-14. Web. 31 Oct. 2016.

Nelson, Katherine, and Robyn Fivush. "The Emergence of Autobiographical Memory: A Social Cultural Developmental Theory." Psychological Review 111.2 (2004): 486-511. Web. 31 Oct. 2016.

Newton, Adam Zachary. Narrative Ethics. Cambridge: Harvard UP, 1995.

Nissim-Sabat, Marilyn. Neither Victim nor Survivor: Thinking Toward a New Humanity. Lanham, MD: Rowman and Littlefield Publishers, Inc., 2009.

Noddings, Nel. Caring: A Feminine Approach to Ethics and Moral Education. Oakland: University of California Press, 1984.

Nodelman, Perry. The Hidden Adult: Defining Children's Literature. Baltimore: The Johns Hopkins UP, 2008. 
Nora, Pierre. "Between Memory and History: Les Lieux de Mémoire." Representations. 26 (Spring 1989): 7-25. Web. 31 Oct. 2016.

Nussbaum, Martha. Cultivating Humanity: A Classical Defense Reform in Literal Education. Cambridge: Harvard UP, 1997.

---. Hiding from Humanity: Disgust, Shame, and the Law. Princeton and Oxford: Princeton UP, 2004.

---. Upheavals of Thought: The Intelligence of Emotions. Cambridge and New York: Cambridge UP, 2001.

Obama, Barack. "State of the Union." The White House. 12 Jan. 2016. <https://www.whitehouse.gov/sotu>. Web. 6 Nov. 2016.

"Oprah Talks to Cheryl Strayed About Walking Her Way to Peace and Forgiveness." $O$ Magazine. (July 2012). Web. 6 Nov. 2016.

Parkes, Malcolm B. Pause and Effect: An Introduction to The History of Punctuation in The West. Oakland: University of Calif. Press, 1993.

Peck, Janice. The Age of Oprah: Cultural Icon for the Neoliberal Era. Boulder, CO: Paradigm, 2008.

Pelzer, David J. A Child Called "It": One Child's Courage to Survive. Deerfield Beach, Fla.: Health Communications, 1995.

Peterson, Tiamoyo, Suzanne O. Kaasa and Elizabeth F. Loftus. "Me Too!: Social Modelling Influences on Early Autobiographical Memories." Applied Cognitive Psychology 23.2 (2008): 267-77. Web. 21 July 2016.

Phelan, James. "The Implied Author, Deficient Narration, and Nonfiction Narrative: Or, What's Off-Kilter in The Year of Magical Thinking and The Diving Bell and The Butterfly?" Style 45.1 (2011): 119-137. Web. 2 Nov. 2016.

--. Living to Tell About It: A Rhetoric and Ethics of Character Narration. Ithaca, N.Y.: Cornell UP, 2005.

Pierce, Andrew. "Authentic Identities." Theory and Practice: An International and Interdisciplinary Journal of Social Philosophy 41.3 (July 2015): 435-457. Web. 2 Nov. 2016.

Pine, Joseph and James Gilmore. Authenticity: What Consumers Really Want. Boston: Harvard Business School Press Books, 2007. 
Probyn, Elspeth. "Writing Shame.” The Affect Theory Reader. Eds. Melissa Gregg \& Gregory J. Seigworth. Durham: Duke UP, 2010. 71-91.

Pullman, George. Persuasion: History, Theory, Practice. Indianapolis: Hackett Publishing, 2013.

Radstone, Susannah and Bill Schwarz, eds. Memory: Histories, Theories, Debates. New York: Fordham UP, 2010.

Raine, Nancy. After Silence: Rape and My Journey Back. New York: Three Rivers Press, 1998.

Rak, Julie. Boom! Manufacturing Memoir for the Popular Market. Canada: WLU Press, 2013.

Ranney, Francis. "Mining the Collective Unconscious.” Rhetorica in Motion: Feminist Rhetorical Methods \& Methodologies. Eds. Ellen Schell and K.J. Rawson. Pittsburgh, Pa.: U of Pittsburgh, 2010. 118-135.

Raulff, Ulrich. "Grand Hotel Abyss: Towards A Theory of The Modern Literary Archive." Comparative Critical Studies 8.2-3 (Oct. 2011): 157-168. Web. 2 Nov. 2016.

Repko, Allen F. Interdisciplinary Research: Process and Theory. Los Angeles: Sage, 2008.

Reynolds, John Frederick, ed. Rhetorical Memory and Delivery: Classical Concepts For Contemporary Composition and Communication. Hillsdale, NJ: L. Erlbaum Associates, 1993.

Rich, Adrienne. "When We Dead Awaken: Writing as Re-Vision." College English 34.1 (1972): 18-30. Web. 20 Apr. 2016.

Rizzuto, Rahna Reiko. Hiroshima in the Morning. New York: Feminist Press, 2010.

Robson, Kathryn. Writing Wounds: The Inscription of Trauma in Post-1968 French Women's Life-writing. New York: Rodopi, 2004.

Royster, Jacqueline Jones and Gesa E. Kirsch. Feminist Rhetorical Practices: New Horizons for Rhetoric, Composition, and Literacy Studies. Carbondale: Southern Illinois UP, 2012.

Ruddick, Sara. "Rationality of Care." In Women, Militarism, \& War: Essays in History, Politics, and Social Theory, eds. Jean Bethke Elshtain and Sheila Tobias. New York: Rowman \& Littlefield, 1990.

Saunders, Rebecca. Lamentation and Modernity in Literature, Philosophy, and Culture. New York: Palgrave Macmillan, 2007.

Schell, Eileen E. Rhetorica in Motion: Feminist Rhetorical Methods \& Methodologies. Pittsburgh, Pa.: U of Pittsburgh, 2010. 
---. Gypsy Academics and Mother-Teachers: Gender, Contingent labor, and Writing Instruction. Portsmouth, NH: Boynton/Cook Publishers, 1998.

Schneider, Carl. Shame, Exposure, Privacy. Boston: Beacon Press, 1977.

Schott, Robin May. "Review Essay On 'Neither Victim nor Survivor: Thinking Toward A New Humanity' By Marilyn Nissim-Sabat; 'Theorizing Sexual Violence' Edited by Renée J. Heberle And Victoria Grace." Hypatia: A Journal of Feminist Philosophy 27.4 (2012): 929-935. Web. 13 Nov. 2016.

Sebold, Alice. Lucky: A Memoir. Boston: Back Bay Books, 1999

Sedgwick, Eve Kosofsky, Irving E. Alexander, and Adam Frank. Shame and Its Sisters: A Silvan Tomkins Reader. Durham: Duke UP, 1995.

Seidler, Gunter H. In Others' Eyes. An Analysis of Shame. Madison: International Universities Press, 2000.

Shame. Oxford English Dictionary. Web. 31 Oct. 2016.

Shen, Dan. "What Is the Implied Author?" Style 45.1 (2011): 80-98. Web. 2 Nov. 2016.

Shepherd, Elizabeth. "Culture and Evidence: Or What Good Are the Archives? Archives and Archivists in Twentieth Century England." Archival Science 9.3/4 (2009): 173-185. Web. 31 Oct. 2016.

Sheringham, Michael. "Memory and The Archive in Contemporary Life-Writing." French Studies 59.1 (2005): 47. Web. 31 Oct. 2016.

Shuman, Amy. Other People's Stories: Entitlement Claims and the Critique of Empathy. Urbana and Chicago: University of Illinois Press, 2005.

Shumway, David R. "Authenticity: Modernity, Stardom, And Rock \& Roll." Modernism/Modernity 14.3 (2007): 527-533. Web. 13 Nov. 2016.

Silvarole, Georgie. "SU Alumni and Author Discusses 'College Girl' Memoir, Off-Campus Sexual Assault.” NewHouse. 14 Oct. 2014. Web. 31 Oct. 2016.

Smith, Sidonie and Julia Watson. Reading Autobiography: A Guide for Interpreting Life Narratives Minneapolis: University of Minnesota Press, 2010.

---. "Witness or False Witness? Metrics of Authenticity, Collective I-formations, and the Ethic of Verificaiton in First-person Testimony." Biography 35.4 (2012): 590-626. Web. 31 Oct. 2016. 
Spiegel, Maura and Rita Charon. "Editors' Preface: Narrative, Empathy, Proximity." Literature and Medicine. Baltimore: Johns Hopkins UP, 23.2 (Fall 2004): vii-x. Web. 9 Nov. 2016.

Starhawk. Truth or Dare: Encounters with Power, Authority, and Mystery. New York: Harper \& Row Publishers, 1987.

Stenberg, Shari. "Teaching and (Re)Learning the Rhetoric of Emotion." Pedagogy 11.2 (2011): 349-69.

“Stereotypical.” May 2014. TS.

Stern, Jessica. Denial: A Memoir of Terror. New York: Ecco, 2010.

Strayed, Cheryl. Brave Enough. New York: Alfred A. Knopf, 2015.

---. Tiny Beautiful Things: Advice on Love and Life from Dear Sugar. New York: Random House, 2012.

---. Wild: From Lost to Found on the Pacific Crest Trail. New York: Alfred A. Knopf, 2012.

Sullivan, Patricia A. "Composing Culture: A Place for the Personal." College English 66.1 (2003): 41-54.

Summey, George. American Punctuation. New York: Ronald Press Co., 1949.

SUNY Press. College Girl: A Memoir. Web. 6 Nov. 2016.

Sutherland, Olga, Andrea V. Breen, and Stephen P. Lewis. "Discursive Narrative Analysis: A Study of Online Autobiographical Accounts of Self-Injury." Qualitative Report 18.48 (2013): 1-17. Web. 31 Oct. 2016.

Sutton, Matthew. "Amplifying the Text: Paratext In Popular Musicians' Autobiographies." Popular Music \& Society 38.2 (2015): 208-223. Web. 2 Nov. 2016.

Symposium Collective. "The Politics of the Personal: Storying Our Lives against the Grain." College English 64.1: 41-62. Web. 31 Oct. 2016.

Tangney, June Price, and Ronda L. Dearing. Shame and Guilt. New York: Guilford Press, 2002.

Tangney, June Price, Jeffrey Stuewig, and Andres G. Martinez. "Two Faces of Shame the Roles of Shame and Guilt in Predicting Recidivism." Psychological Science 25.3 (Mar. 2014) 799-805. Web. 2 Nov. 2016.

Tardif, Jenn. "Cheryl Strayed: On 'Binge Writing.' Doling Out Advice and Finding Clarity." 99U: Insights on Making Ideas Happen. Web. 10 Nov. 2015. 
Tartakovsky, Roi. "E. E. Cummings's Parentheses: Punctuation as Poetic Device." Style: A Quarterly Journal of Aesthetics, Poetics, Stylistics, And Literary Criticism 43.2 (2009): 215-247. Web. 31 Oct. 2016.

Taylor, Charles. The Ethics of Authenticity. Cambridge, MA. and London: Harvard UP, 1992.

“The Monster That Lives Inside Me.” May 2014. TS.

Thompson, Curt. The Soul of Shame: Retelling the Stories We Believe About Ourselves. Downers Grove, IL.: InterVarsity Press, 2015.

“Tic Tac Twitch.” May 2014. TS.

Tomkins, S.S. Affect Imagery Consciousness. Vol. 2: The Negative Affects. New York: Springer, 1963.

Tronto, Joan C. Caring Democracy: Markets, Equality, and Justice. New York: New York UP, 2013.

Tuhus-Dubrow, Rebecca. "I Change, You Change." New York Times Sunday Book Review. 18 Jan. 2013. Web. 6 Feb. 2015.

Varga, Somogy and Charles Guignon. "Authenticity." The Stanford Encyclopedia of Philosophy. Ed. Edward N. Zalta, Fall 2014.

Voigt, Eric P. "Explanatory Parentheticals Can Pack a Persuasive Punch." McGeorge Law Review 45 (2013): 269-304. Web. 2 Nov. 2016.

Walsh, Chris. Cowardice: A Brief History. Princeton: Princeton UP, 2014.

Whitlock, Gillian. "Disciplining the Child: Recent Academic Memoir." A/B: Auto/Biography Studies 19.1-2 (2004): 46-58. Web. 31 Oct. 2016.

Wilkomirski, Binjamin. Fragments: Memories of A Wartime Childhood. Trans. Carol Brown Janeway. New York: Schocken Books, 1997.

Worsham, Lynn. "Going Postal: Pedagogic Violence and the Schooling of Emotion." JAC 18.2 (1998): 213-245. Web. 2 Nov. 2016.

Wurmser, Leon. The Mask of Shame. Baltimore: Johns Hopkins UP, 1981.

Yagoda, Ben. Memoir: A History. New York, NY: Riverhead, 2009.

Zahavi, Dan. Self \& Other: Exploring Subjectivity, Empathy, and Shame: Exploring Subjectivity, Empathy, and Shame. Oxford: Oxford UP, 2014. 


\section{APPENDIX A}

\section{MEMOIR BLURBS OF BRAVERY AND COURAGE: A SAMPLING}

\begin{tabular}{|c|c|}
\hline Memoirs & Blurbs \\
\hline $\begin{array}{l}\text { Bechdel, Alison. } \\
\text { Fun Home: A Family } \\
\text { Tragicomic, } 2007 .\end{array}$ & $\begin{array}{l}\text { "Alison Bechdel's uncommon courage as a storyteller and truth-seeker equals her } \\
\text { skills as a writer and illustrator." } \\
\text {-Atlanta Journal-Constitution } \\
\text { "Brave and forthright and insightful—exactly what Alison Bechdel does best." } \\
\text {-Dorothy Allison, author of Bastard Out of Carolina }\end{array}$ \\
\hline $\begin{array}{l}\text { Deraniyagala, Sonali. } \\
\text { Wave, } 2013 .\end{array}$ & $\begin{array}{l}\text { "Immeasurably potent...This massively courageous, tenaciously unsentimental } \\
\text { chronicle of unthinkable loss and incremental recovery explodes-and then expands- } \\
\text { our notion of what love really means." } \\
\text {-More magazine }\end{array}$ \\
\hline $\begin{array}{l}\text { Didion, Joan. } \\
\text { The Year of Magical } \\
\text { Thinking, } 2005 .\end{array}$ & $\begin{array}{l}\text { "An act of consummate literary bravery, a writer known for her clarity allows us to } \\
\text { watch her mind as it becomes clouded with grief." }\end{array}$ \\
\hline $\begin{array}{l}\text { Gordon, Mary. } \\
\text { The Shadow Man: A } \\
\text { Daughter's Search for her } \\
\text { Father, } 1997 .\end{array}$ & "Fiercely passionate ... powerful...a courageous work." $\quad$ _Cleveland Plain Dealer \\
\hline $\begin{array}{l}\text { Gray-Rosendale, Laura. } \\
\text { College Girl: a Memoir, } \\
\text { 2013. }\end{array}$ & $\begin{array}{l}\text { "College Girl is an exceptionally well-written, gripping rarity. Though the book tells } \\
\text { the story of a horrific rape, it is I fact, about the attack's aftermath-for its } \\
\text { perpetrator, its victim, each of their families, and beyond. It is about the dividing line } \\
\text { between bravery and cowardice. It is about human beings behaving extraordinarily, } \\
\text { under almost unthinkable circumstances. } \\
\text { —Evan Handler, author of Time on Fire: My Comedy of Terrors } \\
\text { "Words like "brave" and "honest" usually used to describe a memoir of trauma and } \\
\text { recovery don't even come close to capturing this searingly painful, unflinchingly } \\
\text { self-reflective, and painstakingly subtle memoir." } \\
\text {-Michael Kimmel, author of Guyland: The Perilous World Where Boys Become } \\
\text { Men }\end{array}$ \\
\hline $\begin{array}{l}\text { Gregory, Julie. } \\
\text { Sickened: The True Story of a } \\
\text { Lost Childhood, } 2003 .\end{array}$ & $\begin{array}{l}\text { "The tale of courage, endurance, and real horror." } \\
\text { "A bon Diego Union-Tribune } \\
\text { surreal form of cruelty, in which the ultimate weapon is the scalpel, with originality, } \\
\text { gusto, and heart-stopping courage" } \\
\text { - Sylvia Fraser, author of My Father's House: A Memoir of Incest and of Healing } \\
\text { "This story of unfathomable child abuse is told with remarkable wit, compassion, } \\
\text { and courage." }\end{array}$ \\
\hline $\begin{array}{l}\text { Harrison, Kathryn. } \\
\text { The Kiss: a Memoir, } 1997 .\end{array}$ & $\begin{array}{l}\text { "I am in awe-no other word will do- of the courage it took to write this book, and } \\
\text { the art. Especially the art...I will never forget this book." } \\
\text {-Tobias Wolf, author of This Boy's Life } \\
\text { "A father who seduces a beautiful daughter enacts a monstrous betrayal. Until } \\
\text { Kathryn Harrison, no one I've read has broken open the psychological soul of such a } \\
\text { betrayal. The bravery in Harrison's raw, clear voice will stay with me a long time." } \\
\text {-Mary Karr, author of The Liars' Club }\end{array}$ \\
\hline
\end{tabular}




\begin{tabular}{|c|c|}
\hline $\begin{array}{l}\text { Homes A.M. } \\
\text { The Mistress's Daughter: a } \\
\text { Memoir, } 2007 .\end{array}$ & $\begin{array}{l}\text { "A brave book, one that will be devoured by other adoptees and their families, not } \\
\text { to mention memoir-guzzlers." } \\
\text {-The New York Observer }\end{array}$ \\
\hline $\begin{array}{l}\text { Hornbacher, Marya. } \\
\text { Wasted: } \text { a Memoir of } \\
\text { Anorexia and Bulimia, } \\
1988 .\end{array}$ & $\begin{array}{l}\text { Hornbacher's courage may help solve the riddle of why young women punish } \\
\text { themselves for being female. A powerfully personal, complex book about a baffling } \\
\text { disorder." } \\
\text { "[It] was Hornbacher's courage that won me over. She has written a real story." } \\
\text {-Raleigh News \& Observer }\end{array}$ \\
\hline $\begin{array}{l}\text { Meck, Su. } \\
\text { I Forgot to Remember: A } \\
\text { Memoir of Amnesia, } \\
2014 .\end{array}$ & $\begin{array}{c}\text { "A fascinating memoir about resilience, courage, and hope, I Forgot To Remember } \\
\text { is not just a survivor's story. This is a hero's story." } \\
\text {-Lisa Geova, author of Love Anthony } \\
\text { "Brave and raw...Su Mech's spellbinding tale reminds us all of the importance of } \\
\text { living in the moment and the need to cherish the memories we own." } \\
\text {-Lee Woodruff, coauthor of In an Instant }\end{array}$ \\
\hline $\begin{array}{l}\text { Miller, Kimberly Rae. } \\
\text { Coming Clean: a Memoir, } \\
2013 .\end{array}$ & $\begin{array}{l}\text { "Kimberly Rae Miller is a brave and gifted writer, and her insightful examination } \\
\text { of her troubled relationship with her parents will speak to anyone who has ever } \\
\text { struggled to hide a family secret." } \\
\qquad \text {-Kjerstin Gruys, author of Mirror, Mirror Off the Wall }\end{array}$ \\
\hline $\begin{array}{l}\text { Rizzuto, Raha Reiko. } \\
\text { Hiroshima in the Morning, } \\
2010 .\end{array}$ & $\begin{array}{l}\text { "A brave, compassionate, and heart-wrenching memoir of one woman's quest to } \\
\text { redeem the past while learning to live fully in the present." } \\
\text {-Kate Moses, author of Cakewalk, A Memoir }\end{array}$ \\
\hline $\begin{array}{l}\text { Sebold, Alice. } \\
\text { Lucky, } 1999 .\end{array}$ & $\begin{array}{l}\text { "Sebold's commanding skill as a narrator (at her best, Joan Didion) forces you to } \\
\text { relive her terror... This is a brave and modest work of demystification... A rueful, } \\
\text { razor-sharp memoir." } \\
\text {-Sarah Kerr, Vogue } \\
\text { "Lucky - which reads like a John Grisham page-turner — can't help but haunt } \\
\text { you... Sebold's is a story about having the courage to speak about the unspeakable." } \\
\text {-Sheryl Altman, Biography }\end{array}$ \\
\hline $\begin{array}{l}\text { Shapiro, Dani. } \\
\text { Slow Motion: a Memoir of a } \\
\text { Life Rescued by Tragedy, } \\
1988 .\end{array}$ & $\begin{array}{l}\text { "Riveting...A combination of breathtaking candor and bravado...Slow Motion is a } \\
\text { smart, well-written take on the form." } \\
\text {-San Francisco Chronicle }\end{array}$ \\
\hline $\begin{array}{l}\text { Smith, Claire Bidwell. } \\
\text { The Rules of Inheritance: a } \\
\text { Memoir, } 2012 .\end{array}$ & $\begin{array}{l}\text { "In The Rules of Inheritance Claire takes us on a heartbreaking journey into grief's } \\
\text { deepest waters and then shows us how she found her way back to hope's shores. } \\
\text { With courageous vulnerability and uncompromising authenticity, Smith transforms } \\
\text { tragic misfortune into a rite of passage." } \\
\text { "Forget everything you think you know about grief. Smith's memoir is the most } \\
\text { honest book I've ever read about how loss unmoors, challenges, and changes you, } \\
\text { written in prose so exquisite, it could be poetry. Dazzlingly brave and absolutely } \\
\text { true. } \\
\text { - Caroline Leavitt, author of Pictures of You }\end{array}$ \\
\hline $\begin{array}{l}\text { Sontag, Rachel. } \\
\text { House Rules: A Memoir, } \\
2008 .\end{array}$ & $\begin{array}{l}\text { "Sontag's is a brave account not only of what it's like to take the brunt of an } \\
\text { abusive parent's wrath but of what it means to have the courage to leave." } \\
\text {-Publishers Weekly } \\
\text { "In this brave, hard-won, and gorgeously written memoir, Rachel Sontag lays out } \\
\text { the story of her family I prose as tautly strung and delicate as a high-wire." } \\
\text {-Dani Shapiro, author of Black \& White }\end{array}$ \\
\hline
\end{tabular}




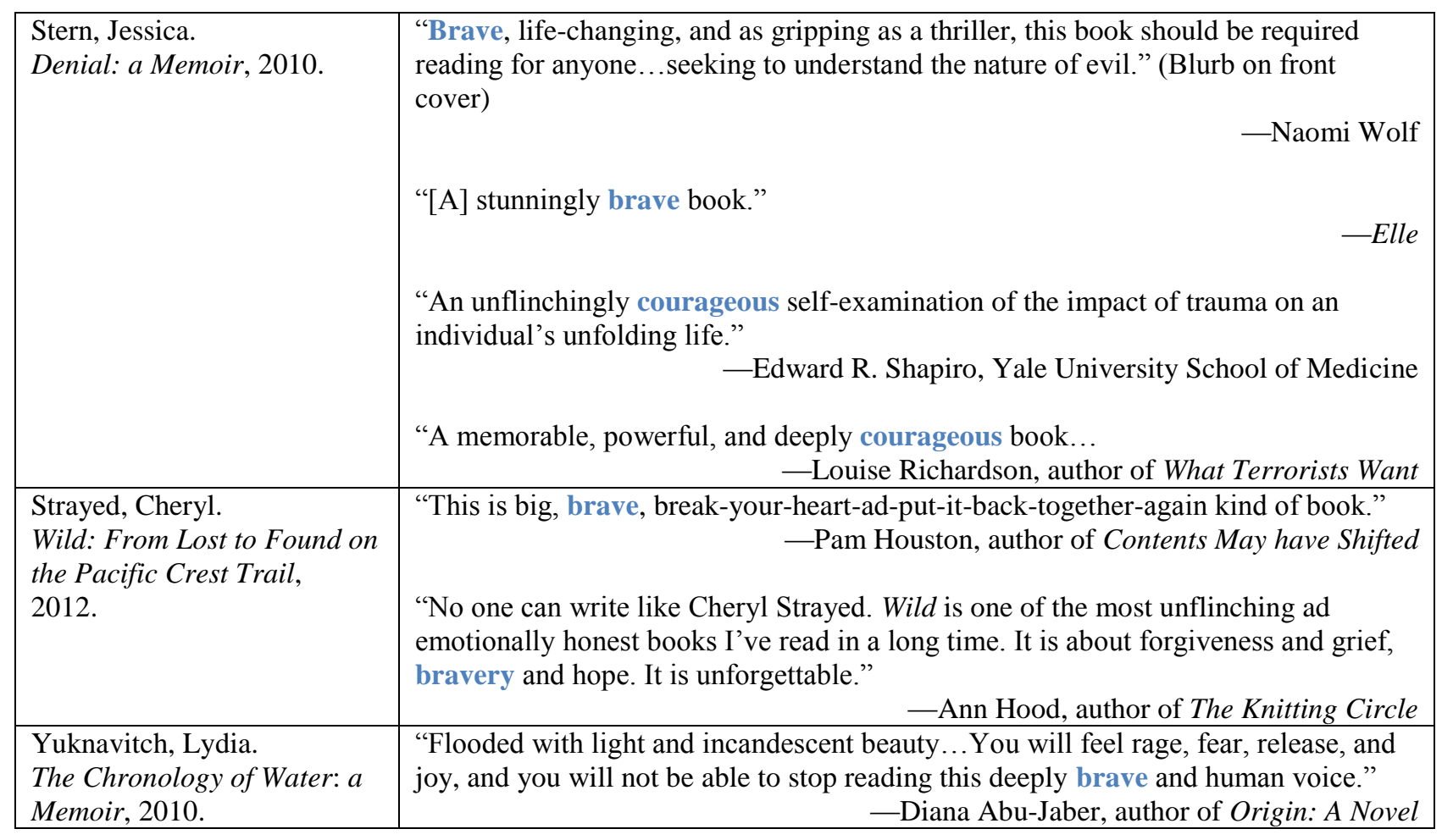




\section{APPENDIX B}

\section{PARENTHETICAL CONSTRUCTIONS CONTENT DATA}

\section{IN THE LIARS' CLUB BY MARY KARR}

Chapter 1

\begin{tabular}{|l|l|}
\hline \multicolumn{1}{|c|}{ Page } & \multicolumn{1}{c|}{ Parenthetical content } \\
\hline 4 & (pronounced, she would have me tell you, "Lisa"). \\
\hline 6 & (in translation, of course-I was a lazy student). \\
\hline 6 & (or Ovid or Virgil) \\
\hline 8 & (Our house was perceived as Dangerous, a consequence of Mother's being Nervous). \\
\hline 10 & (unlikely, given the lack of traffic). \\
\hline 11 & $\begin{array}{l}\text { (Paolo's mother lived in Seattle, and they'd traveled there from New York, then down to Texas, where } \\
\text { divorce laws permitted Mother to quickly get rid of husband number three before signing up with } \\
\text { number four) }\end{array}$ \\
\hline 11 & $\begin{array}{l}\text { (she had on a beige silk suit) } \\
\text { (In fact, there wasn't ever much fighting to it, at least that I ever saw. Daddy hit people, and then they } \\
\text { fell down. End of fight.) }\end{array}$ \\
\hline 13 & $\begin{array}{l}\text { (Its lid, held in place by a wooden peg at one end, gives a fagged gobble when you slide it back and } \\
\text { forth across the chalked edges of the box.) }\end{array}$ \\
\hline 20 & (who also received no name, only initials-J.P.), (Pug) (A.D.). \\
\hline 21 & (his term) \\
\hline 21 & (I think it was during the Kennedy-Nixon debate) \\
\hline
\end{tabular}

Chapter 2

\begin{tabular}{|l|l|}
\hline Page & \multicolumn{1}{|c|}{ Parenthetical content } \\
\hline 25 & $\begin{array}{l}\text { (Even then, my sister had a sense of propriety I lacked: if I wet my underpants playing, back then, I just } \\
\text { stepped out of them and kept running.) }\end{array}$ \\
\hline 26 & (Lecia went on to make an adult fortune selling whole-life insurance in Houston.) \\
\hline 28 & (I had been a difficult birth, feet first, like Caesar, Mother liked to say.) \\
\hline 29 & $\begin{array}{l}\text { (Tatting is an insane activity that involves an eensy shuttle, thin silk thread, and maniacal patience. } \\
\text { Belgian nuns are famous for tatting, it turns out.) }\end{array}$ \\
\hline 32 & (and grotesquely inaccurate)...(where the mean troll forced the lady to spin straw into gold herself) \\
\hline 38 & $\begin{array}{l}\text { (To this day I have some chute in my head from which "kiss my ass" tumbles. It's truly amazing the } \\
\text { number of times it seems applicable.) }\end{array}$ \\
\hline 42 & (mint-green vinyl with square black arms) \\
\hline 42 & (Never.) \\
\hline 42 & $\begin{array}{l}\text { (Lecia had managed to come out blond like her people, but Grandma never got over my looking } \\
\text { vaguely Indian like Daddy.) }\end{array}$ \\
\hline 42 & $\begin{array}{l}\text { (Marvalene Seesacque once described her incentive for crawdadding all day: "You don't catch, you } \\
\text { don't eat.") }\end{array}$ \\
\hline 42 & (I remember sucking the cuminy tomato sauce off the paper each one was wrapped in) \\
\hline 42 & (Hence, our tendency to say, It ain't the heat, it's the stupidity.) \\
\hline 43 & (It had supposedly accumulated quite a crust.) \\
\hline 43 & (I could sustain a full-lotus position at five.) \\
\hline 45 & (I called her Helmet-head.) \\
\hline
\end{tabular}




\begin{tabular}{|c|c|}
\hline Page & Parenthetical content \\
\hline 47 & $\begin{array}{l}\text { (If I gave my big sister a paragraph here, she would correct my memory. To this day, she claims that } \\
\text { she genuinely mourned for the old lady, who was a kindly soul and that I was too little and mean- } \\
\text { spirited then to remember things right. I contend that her happy memories are shaped more by } \\
\text { convenience than reality: she also recalls tatting as fun, and Ronald Reagan, for whom she voted twice, } \\
\text { as a good guy.) }\end{array}$ \\
\hline 48 & (which is now the Houston Medical Center) \\
\hline 52 & $\begin{array}{l}\text { (Here time telescopes and gets slow, for some reason. I almost have to hold my head very still to keep } \\
\text { from backing away.) }\end{array}$ \\
\hline 53 & (Maybe, like the Greeks used to say, her ate(italicize at) suddenly filled her.) \\
\hline 56 & (Children can be a lot like cats or dogs, sometimes, in how physical comfort soothes them.) \\
\hline 58 & (Lecia says that I would eat them only in pairs, so none would feel lonely in my stomach.) \\
\hline 58 & (Even at seven I had a taste for liquor.) \\
\hline 61 & (and was, since her surgery, consuming about a case of beer every day). \\
\hline 62 & $\begin{array}{l}\text { (Lecia and I had impressed Uncle Frank by both learning to read pretty much without instruction before } \\
\text { we were three. Mother took us each down to his office inturn, and we each dutifully read the front page } \\
\text { of the day's paper out loud to him, so he could be sure it wasn't just some story we'd memorized.) }\end{array}$ \\
\hline 63 & $\begin{array}{l}\text { (To this day, I don't know whether to measure this as courage or cowardice, but it stuck. After I grew } \\
\text { up, the only man ever to punch me found himself awakened two nights later from a dead sleep by a } \\
\text { solid right to the jaw, after which I informed him that, should he ever wish to sleep again, he shouldn't } \\
\text { hit me. My sister grew up with an almost insane physical bravery: once in a parking lot outside her } \\
\text { insurance office, she brushed aside the } .22 \text { pistol of a gunman demanding her jewelry. "Fuck you," she } \\
\text { said and opened her Mercedes while the guy ran off. The police investigator made a point of asking her } \\
\text { what her husband did, and when she said she didn't have one, the cop said, "I bet I know why.") }\end{array}$ \\
\hline 63 & ("Oil Chemical and Atomic Workers, Local 1242" was how they answered the phone on Daddy's unit.) \\
\hline 63 & (Our family had been considered rich because of Mother's part-time newspaper work.) \\
\hline 64 & (She'd attended both Texas Tech and art school.) \\
\hline 66 & $\begin{array}{l}\text { (I picture him now reading this, and long to reach out of the page and grab ahold of his shirt front that } \\
\text { we might together reminisce some. Hey, bucko. Probably you don't read, but you must have somebody } \\
\text { who reads for you--your pretty wife or some old neighbor boy you still go fishing with. Where will you } \\
\text { be when the news of this paragraph floats back to you? For some reason, I picture you changing your } \\
\text { wife's tire. She'll mention that in some book I wrote, somebody from the neighborhood is accused of } \\
\text { diddling me at seven. Maybe you'll see your face's image spread across the silver hubcap as though it's } \\
\text { been flattened by a ball-peen hammer. Probably you thought I forgot what you did, or you figured it } \\
\text { was no big deal. I say this now across decades and thousands of miles solely to remind you of the long } \\
\text { memory my daddy always said I had.) }\end{array}$ \\
\hline
\end{tabular}

Chapter 4

\begin{tabular}{|l|l|}
\hline \multicolumn{1}{|c|}{ Page } & \multicolumn{1}{c|}{ Parenthetical content } \\
\hline 71 & (We were imitating a floor wax commercial.) \\
\hline 71 & $\begin{array}{l}\text { (My spankings were a kind of family sporting event complete with rounds and what my sister still } \\
\text { claims was a system of scoring more subtle and intricate than the mating signals of certain spiders.) }\end{array}$ \\
\hline 71 & $\begin{array}{l}\text { (Being spanked is never near as bad as being laughed at during the spanking. Trust me. The opresence } \\
\text { of another kid ups the humiliation quotient exponentially.) }\end{array}$ \\
\hline 74 & $\begin{array}{l}\text { (She became a terrible baby-aspirin junkie at this time, ate them like peanuts from an economy-size jar } \\
\text { with a depressing label on which two pink-cheeked Swedish-looking trudged off to a red schoolhouse } \\
\text { hand in hand.) }\end{array}$ \\
\hline 75 & $\begin{array}{l}\text { (Shrimp remoulade, I might add here, was my grandma's moral antidote to all those little split-up } \\
\text { squirrel carcasses dismantled and frying in fat.) }\end{array}$ \\
\hline 76 & (There's something overdressed about a shoe on a plastic foot, like it's beside the point.) \\
\hline
\end{tabular}


Chapter 4 continued

\begin{tabular}{|c|c|}
\hline Page & Parenthetical content \\
\hline 76 & $\begin{array}{l}\text { (I knew a drug dealer once who collected them in glass tanks all over his trailer. He had a harelip that } \\
\text { somehow protected him from the stink, but the rest of us became, when dickering over pharmaceuticals } \\
\text { with him, the noisiest and most adenoidal mouth breathers. We all sounded like Elmer Fudd, so a coke } \\
\text { deal took on a cartoonlike quality: "You weally tink dis is uncut?" It was particularly hard to talk this } \\
\text { way when you were tripping your brains out on LSD and had gone there only as a last resort to buy } \\
\text { something to help you come down.) }\end{array}$ \\
\hline 79 & $\begin{array}{l}\text { (The closest I had ever come to that smell before Grandma's room was the closest I'd come to a } \\
\text { snakebite. One evening when Daddy had rowed our rented boat into a patch of morning glories, he all } \\
\text { of a sudden lifted the dripping oar from the bayou and took a swipe about three inches above my head, } \\
\text { so the water from the oar fanned down over my face and bare arms. There was a quick plop in the } \\
\text { water next to the boat. The cottonmouth had been draped off a branch right over me, he said. We } \\
\text { watched it drag its S-shaped body through the brown water. I started shaking, not from cold.) }\end{array}$ \\
\hline 79 & $\begin{array}{l}\text { (I later learned that she'd been shown the same pictures by Grandma. She had also promptly forgotten } \\
\text { them. I this way, we entered amnesia together.) }\end{array}$ \\
\hline 80 & $\begin{array}{l}\text { (An often-divorced friend of mine once declared that when you're saying "I so" for the third or fourth } \\
\text { time, you have to admit to yourself that they can't be entirely at fault.) }\end{array}$ \\
\hline 81 & $\begin{array}{l}\text { (which invariably blew at the east Texas coast either northwest from the Caribbean or northwest across } \\
\text { the Florida Keys). }\end{array}$ \\
\hline 82 & (I favored purples and lavenders and royal blues. Lecia stuck with the more fashionable pinks.) \\
\hline 84 & (Which I don’t remember his answering.) \\
\hline 85 & $\begin{array}{l}\text { (Despite my breathtaking gullibility, I was able to spew out such random hunks of elementary logic } \\
\text { sometimes.) }\end{array}$ \\
\hline 87 & $\begin{array}{l}\text { (Lecia was nothing if not cool in a crisis. She learned to drive at twelve, at which age I once saw her } \\
\text { convince a state trooper that she'd just left her license at home because she was running out to get her } \\
\text { baby milk while he was still sleeping.) }\end{array}$ \\
\hline 88 & $\begin{array}{l}\text { (I once made the trip dead drunk on a summer morning in a souped-up Mustang in forty-five minutes, } \\
\text { and I never got under eighty, slowed for a curve, or stopped for a light.) }\end{array}$ \\
\hline 90 & $\begin{array}{l}\text { (Were Lecia writing this memoir, I would appear in one of the only three guises: sobbing hysterically, } \\
\text { wetting my pants in a deliberately inconvenient way, or biting somebody, usually her, with no } \\
\text { provocation.) }\end{array}$ \\
\hline 91 & (or, conversely, Daddy to speed up) \\
\hline 92 & $\begin{array}{l}\text { (People never walked over, of course, but workers hung platforms off it for painting and repairs.) } \\
\text { (Typo) }\end{array}$ \\
\hline 92 & (We both have hands perfect only for fieldwork and volleyball.) \\
\hline 93 & (pronounced Ain'tee) \\
\hline 94 & (I would give her my dime for this service.) \\
\hline 95 & (I'd felt bad they were locked up), \\
\hline
\end{tabular}

\section{Chapter 5}

\begin{tabular}{|l|l|}
\hline Page & \multicolumn{1}{c|}{ Parenthetical content } \\
\hline 99 & $\begin{array}{l}\text { (I had the smug pleasure once of using this term up north and having a puzzled young banker-to-be } \\
\text { then ask me if these worm farmers in Texas sold worms for fishing, or what.) }\end{array}$ \\
\hline 100 & (in junior year, she would run anchor on the four-forty relay), \\
\hline 100 & (which I'd built up by being a smart mouth and getting my ass whipped a lot). \\
\hline 101 & $\begin{array}{l}\text { (It is a sad commentary on the women of my family that we can recite whole wardrobe assemblages } \\
\text { from the most minor event in detail, but forget almost everything else. In fact, the more important the } \\
\text { occasion - funeral, wedding, divorce court - the more detailed the wardrobe memory and the dimmer } \\
\text { the hope of dredging up anything that happened.) }\end{array}$ \\
\hline 105 & (a phrase I'd picked up from one of Mother's less-than-Christian tirades) \\
\hline
\end{tabular}


Chapter 5 continued

\begin{tabular}{|l|l|}
\hline Page & \multicolumn{1}{c|}{ Parenthetical content } \\
\hline 107 & $\begin{array}{l}\text { (Lecia became an adult devotee of such heels. Once at a party in Boston, a loafer-wearing debutante } \\
\text { suggested jokingly to her that if God had wanted women to wear heals, He wouldn't have designed our } \\
\text { feet as He did. Lecia replied that if God hadn't intended us to wear heels, She wouldn't have made our } \\
\text { legs look so great in them.) }\end{array}$ \\
\hline 108 & $\begin{array}{l}\text { (Silence can make somebody bigger, I've come to believe. Grief can, too. A big sad silence emanating } \\
\text { from someone can cause you to invest that person with all manner of gravitas.) }\end{array}$ \\
\hline 111 & (These cans get chucked into the surf when empty, of course, with no mea culpa to the environment.) \\
\hline 111 & (Bucky presumably) \\
\hline 111 & (who was wearing pink rubber gloves of the type grandmas use to wash dishes) \\
\hline 113 & (The terrible thing about children-I'd like to mention here-is that they're so childish.) \\
\hline
\end{tabular}

\section{Chapter 6}

\begin{tabular}{|c|c|}
\hline Page & Parenthetical content \\
\hline 126 & (a combination she likened to sparkling burgundy), \\
\hline 127 & (seven-year-olds don't yet have any phone life to speak of), \\
\hline 127 & $\begin{array}{l}\text { (When she got older and studied calculus, she even worked out a formula that factored into account the } \\
\text { percentage of alcohol in various liquors-wine's only about fourteen percent alcohol, for example-as } \\
\text { well as how much time had elapsed from the first drink, whether Mother had eaten, and much she } \\
\text { weighed. She'd then compare the outcome to that from another drinking bout in a way that sounded } \\
\text { like this: "At Thanksgiving she was doing at least four ounces of eighty-six-proof alcohol per hour for } \\
\text { four hours, and she weighed ten pounds less but was nowhere near this wild. Of course she'd eaten a } \\
\text { lot. ...") }\end{array}$ \\
\hline 128 & $\begin{array}{l}\text { (When I read about Napoleon defeated and shipped off to that squatty volcanic island, how he lay } \\
\text { pouting for days in his bath about his lost empire, it put me in mind of Mother in Leechfield conjuring } \\
\text { New York.) }\end{array}$ \\
\hline 129 & (a plantain tree, really), \\
\hline 130 & $\begin{array}{l}\text { (If Daddy had been present, he would have reminded us at length at this point that Dietrich had kissed } \\
\text { him full on the mouth during a USO show. Hence my middle name: Marlene.) }\end{array}$ \\
\hline 131 & $\begin{array}{l}\text { (In fights Lecia and I have as grown-ups, she'll scream at me, "You were always so fucking cute!" And } \\
\text { I'll scream back, "You were always so fucking competent! Which sums up our respective jobs in the } \\
\text { family.) }\end{array}$ \\
\hline 131 & (I am Marline Dietrich. I am the cathedral wall on which the painter Giotto outlines an angel.) \\
\hline 131 & (where she'd done some mechanical drawing in the war years-a detail it took us years to unearth). \\
\hline 132 & $\begin{array}{l}\text { (The pictures themselves were being seared into my head with all the intensity of childhood. When I } \\
\text { stumbled on the actual paintings years later in museums, I often lapsed into that feeling you get when } \\
\text { stepping inside your old grade school, of being tiny again in a huge and uncontrollable world-and yet } \\
\text { the low-slung water fountains tell you that you're a giant now. Van Gogh's Bedroom at Arles, when I } \\
\text { stood before it at eighteen, seemed ridiculously small, yet intensely familiar.) }\end{array}$ \\
\hline 132 & (in Italian, of course) \\
\hline 134 & $\begin{array}{l}\text { (Mercury's helmet always put me in mind of that hard hat, for some reason-minus the wings of } \\
\text { course.) }\end{array}$ \\
\hline 134 & $\begin{array}{l}\text { (Finding that dress, infact, was about the first event other than an occasional meal that she'd gotten up } \\
\text { for since coming back from the funeral.) }\end{array}$ \\
\hline
\end{tabular}




\begin{tabular}{|c|c|}
\hline Page & Parenthetical content \\
\hline 142 & (Anna Karenina was her favorite book) \\
\hline 143 & (we called them undersancies) \\
\hline 143 & $\begin{array}{l}\text { (That was the last time my school formally invited her anywhere; after that she occasionally gate- } \\
\text { crashed the Christmas play, but otherwise was a vapor trail at school functions.) }\end{array}$ \\
\hline 143 & $\begin{array}{l}\text { (We saved the art books for kids who could cough up as much as a quarter for a long stare at a Bosch } \\
\text { painting with lots of skinny demons and some large-breasted matron being poked with sticks.) }\end{array}$ \\
\hline 145 & $\begin{array}{l}\text { (The figure also varies with Mother's telling, from "only } \$ 100,000 \text { " to "over half a million" depending } \\
\text { on the point she's trying to make with the story. To this day, if pressed to give us the exact number, she } \\
\text { presents a kind of walleyed expression with a loose-shouldered shrug that suggests such sums of } \\
\text { money must be taken in stride, give or take a hundred thousand.) }\end{array}$ \\
\hline 146 & $\begin{array}{l}\text { (To my knowledge we still hold drilling rights on that land, through every inch of it has long since been } \\
\text { proven bone-dry to the earth's core.) }\end{array}$ \\
\hline 148 & $\begin{array}{l}\text { (Later on, I'd find a brown scorch spot on the vaulted ceiling. I also later figured that she was feeding } \\
\text { the stove with all the mail that had come addressed to Grandma since her death-bank statements and } \\
\text { seed catalogues and get-well cards from the Lubbock Methodist Church Ladies' Auxiliary.) }\end{array}$ \\
\hline 152 & $\begin{array}{l}\text { (Epictetus has a great line about the division between body and soul- "Thou art a little spirit bearing } \\
\text { up a corpse." When I read that line years later, I automatically pictured those dresses emptied of their } \\
\text { occupants and sailing into the fire in graceful arcs.) }\end{array}$ \\
\hline 153 & $\begin{array}{l}\text { (The thought that burdens me most today is that somebody did call Daddy to let him know, and } \\
\text { Daddy - gripped by the same grinding machine that gripped us-just stayed in the slot that fate had } \\
\text { carved for him and said he planned to come on home directly. Or he said kiss my rosy red ass, for } \\
\text { Daddy could turn the volume on any portion of the world up or down when he had a mind to. I can } \\
\text { very well picture his big hand setting the phone back in its black cradle. The men on his unit might } \\
\text { have been frying up some catfish they'd caught. From high in his tower, he could have looked out that } \\
\text { curved window across fields of industrial pipes and oil-storage talks, past the train yards to the grid of } \\
\text { identical houses - in the yard of one of which Mother was setting first to our lives-and maybe Daddy } \\
\text { just decided to change the channel away from that fire to the sizzle of cornbread-dipped catfish floating } \\
\text { in hot lard. Boy that fish smells good, I can imagine him saying.) }\end{array}$ \\
\hline
\end{tabular}

\section{Chapter 8}

\begin{tabular}{|c|l|}
\hline Page & \\
\hline 159 & (or lack thereof) \\
\hline 159 & (the alleged target, we later heard) \\
\hline 160 & (i.e., in the above case, the Ambusher's daddy) \\
\hline 169 & $\begin{array}{l}\text { (Lecia was sleeping over at a friend's that morning, having outgrown Daddy somehow, having also } \\
\text { gotten agile at worming her way into families quieter than ours.) }\end{array}$ \\
\hline
\end{tabular}

\section{Part II}

Chapter 9

\begin{tabular}{|c|l|}
\hline Page & \multicolumn{1}{|c|}{ Parenthetical content } \\
\hline 179 & $\begin{array}{l}\text { (Maybe that coat—a torture to wear in our tropical climate-proved Mother never intended to come } \\
\text { back to Texas from that trip, though she denied any such plan.) }\end{array}$ \\
\hline 182 & (as Mother, in face, did) \\
\hline 183 & (I had to climb a few boards up on the stall side to accomplish this) \\
\hline 184 & $\begin{array}{l}\text { (Lecia took sixth in the Washington pole bendings, though she would have me point out here that the } \\
\text { competition in her category was far stiffer than in mine, which was only little kids.) }\end{array}$ \\
\hline 187 & (she can still pluck a dove from a tree) \\
\hline 190 & (Comfort makes fools of us that way, and a kid gets faith back quick.) \\
\hline 194 & (though we'd rather have chewed linoleum than gone to Sunday school.) \\
\hline 196 & (In Leechfield parlance, he couldn't trap a hog in a ditch.) \\
\hline 197 & (we'd been staying with the stable master's family for pay) \\
\hline
\end{tabular}




\begin{tabular}{|c|l|}
\hline \multicolumn{1}{|c|}{ Page } & \multicolumn{1}{|c|}{ Parenthetical content } \\
\hline 198 & (that's how we heard the phrase "tied one on") \\
\hline 200 & (That'll be a cold day in hell," I'd said.) \\
\hline 206 & (or tie back, or ebony domino set) \\
\hline 207 & (meaning me) \\
\hline
\end{tabular}

Chapter 11

\begin{tabular}{|l|l|}
\hline \multicolumn{1}{|c|}{ Page } & \multicolumn{1}{c|}{ Parenthetical content } \\
\hline 213 & (This I postponed actually trying till there were more members to wow with it.) \\
\hline 213 & (Vlkoslak was the one, I think, that meant vampire.) \\
\hline 214 & (plural) \\
\hline 215 & (who'd gone to jail, if I remember right, for embezzlement). \\
\hline 224 & (Something about the small betrayal of moving away from her still gives me a stab of guilt.) \\
\hline 225 & (which Mother had also asked his doctor to prescribe for her) \\
\hline 227 & (I was not given to restraint) \\
\hline
\end{tabular}

\section{Chapter 12}

\begin{tabular}{|l|l|}
\hline \multicolumn{1}{|c|}{ Page } & \multicolumn{1}{|c|}{ Parenthetical content } \\
\hline 236 & (whiskey for him, vodka or scotch for her, single malt when she could afford it). \\
\hline 241 & $\begin{array}{l}\text { (Later, I'll learn that's the structure of an elegy: lament, consolation; bad news, followed by good } \\
\text { news.) }\end{array}$ \\
\hline
\end{tabular}

Chapter 13

\begin{tabular}{|l|l|}
\hline Page & \multicolumn{1}{|c|}{ Parenthetical content } \\
\hline 260 & $\begin{array}{l}\text { (When mystics talk about states of grace, surely that's the feeling they mean-hope rising out of some } \\
\text { Dust Bowl farmer's heart when he's surveying the field of chewed stems that locusts left.) }\end{array}$ \\
\hline 261 & $\begin{array}{l}\text { (Sure the world breeds monsters, but kindness grows just as wild, elsewise every raped baby would } \\
\text { grow up to rape.) }\end{array}$ \\
\hline
\end{tabular}

\section{Chapter 14}

\begin{tabular}{|c|l|}
\hline Page & \multicolumn{1}{c|}{ Parenthetical content } \\
\hline 277 & (before I managed to snag a job in a T-shirt factory) \\
\hline 278 & $\begin{array}{l}\text { (Mother actually put the idea in my head, afterwards tacking on this heart-breaking sentence, "All that } \\
\text { was over between me and your daddy was back.") }\end{array}$ \\
\hline 283 & (his ex-wife had done crewelwork) \\
\hline 284 & (translate: sit alone in the dark garage sneaking pulls off a bourbon bottle), \\
\hline 285 & (crawfish die when they dry off, it turns out), \\
\hline 288 & (I shit you not, the cat would only come in or out once these words were spoken), \\
\hline 289 & (six feet even, one hundred and sixty-five pounds), \\
\hline 293 & (It's still right up there with Bhopal and Chernobyl.) \\
\hline
\end{tabular}

\section{Chapter 15}

\begin{tabular}{|l|l|}
\hline \multicolumn{1}{|c|}{ Page } & \multicolumn{1}{|c|}{ Parenthetical content } \\
\hline 299 & (Etymology: sarkazein, to tear flesh.) \\
\hline 299 & (as the Buddha says), \\
\hline 310 & $\begin{array}{l}\text { (The only metaphor I can find for such a change is musical: where one note had been playing, it } \\
\text { suddenly grew into a chord involving lots of black keys.) }\end{array}$ \\
\hline 311 & $\begin{array}{l}\text { (She worked her butt off all day and had a full-time, live-in cleaning lady, but spent hours every night } \\
\text { in rubber gloves. Her house was as gleamingly sterile as most operating theaters.) }\end{array}$ \\
\hline
\end{tabular}




\title{
APPENDIX C
}

\section{INFORMED CONSENT LETTER FOR MEMOIR PEDAGOGY STUDY}

\section{INFORMED CONSENT FOR}

\author{
"Using Rhetorical Theory to Understand Childhood Memory in Life Writing"
}

\section{Dear Potential Participant,}

Debra Parker, your instructor for IDS 301 Interdisciplinary Seminar: Memory, Truth, and Childhood is conducting a research project to aid in writing her dissertation. The purpose of this research is to better understand participants' representations of childhood, to identify how participants have been socialized to discuss childhood as it relates to memory, and to develop a pedagogy for investigating the connections between childhood, memory, and life writing.

You are being asked to participate in this research during the time you are enrolled in IDS 301 (Spring 2014), and participation is completely voluntary. The data gathered during this research will come from the work that is required for this course, which is primarily written assignments (reading responses, and two projects). Professor Parker will also observe and take notes on class discussions. All students in this course will do the same assignments and work regardless of participation in the study. However, those who agree to participate will be invited to have a short, informal interview with your instructor after the course is completed and after grades have been submitted. Signing the consent form does not obligate you to the outgoing interview.

Risks and Confidentiality: We anticipate few risks to you as a participant in this research, and those risks include social risks such as feeling pressure from your instructor or peers to participate and potential embarrassment if any work is identified as yours in any public space. Professor Parker will take precautions to protect participants from this risk, including taking steps to keep all work confidential; neither your name nor any identifying characteristics will be used in any resulting publication.

To address risks of pressure to participate, your choice to participate will be kept confidential and will not influence your standing or grade in the course. Professor Parker will not learn the names of the participants until after grades are turned in at the end of the semester. Consent forms will be kept in a locked file cabinet in the office of Dean Joanna Beth Tweedy (not the instructor) to ensure that no students receive preferential treatment based on their decision to participate or not participate.

Benefits: You may benefit from participating in this research project by learning the ways in which society constructs childhood that is based on particular ideologies. You may also learn how an interdisciplinary approach is useful in understanding complex issues related to memory and life writing about childhood. Professor Parker may benefit from this research by gathering data to be used in her dissertation in order to earn her doctorate degree. Any resulting publications that utilize this research are likely to further her professional career.

Participation: Your participation in this research project is entirely voluntary. As an adult member of this class you are invited to participate but you are in no way obligated to do so. Your refusal to participate involves no penalty or loss of benefits. If you agree to participate and wish to discontinue at any time, you may do so without penalty or loss of benefits from the course. 


\section{Contacts}

If you have any questions or concerns about this research at any time, please contact Debra Parker, the instructor of this course and Co-Principal Investigator of this study, at dparker@ben.edu. For any further questions, please contact Dr. Amy E. Robillard, the Principal Investigator of this study, at aerobil@ilstu.edu or 309-438-7970.

If you have any questions about your rights as a subject/participant in this research, or if you feel you have been placed at risk, please contact the Research Ethics \& Compliance Office at

Illinois State University

Phone: (309) 438-2529

Mailing address:

Research Ethics and Compliance Office

C/o Office of Research and Sponsored Programs

Hovey Hall 310

Campus Box 3040

Normal, IL 61790-3040

Please check one of the following lines:

I choose to participate in this research project

I choose not to participate in this research project

By signing below, I affirm that I am at least 18 years of age, and I understand that refusal to participate involves no penalty or loss of benefits of any kind and that no there is no penalty to me for withdrawing from this study at any time.

Name (please print) Date

Signature

Please keep a second copy of this form for your records and thank you for considering this request to participate in this research project. 